\title{
IntechOpen
}

\section{Methods for Film Synthesis and Coating Procedures}

Edited by László Nánai, Aneeya Samantara, László Fábián and Satyajit Ratha

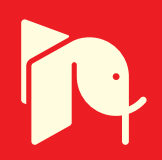





\section{Methods for Film Synthesis and Coating Procedures}

Edited by László Nánai, Aneeya Samantara, László Fábián and Satyajit Ratha 

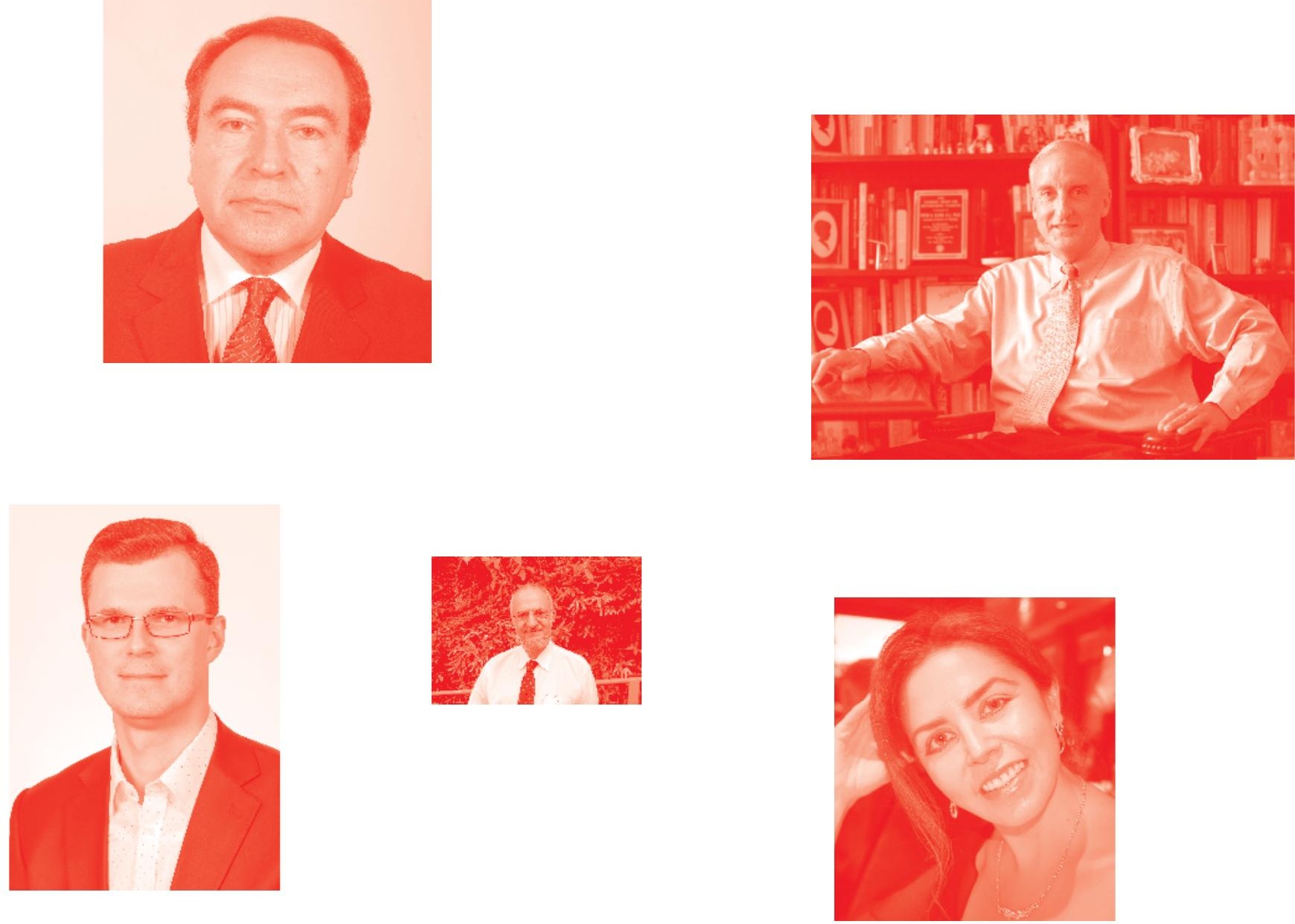

Supporting open minds since 2005
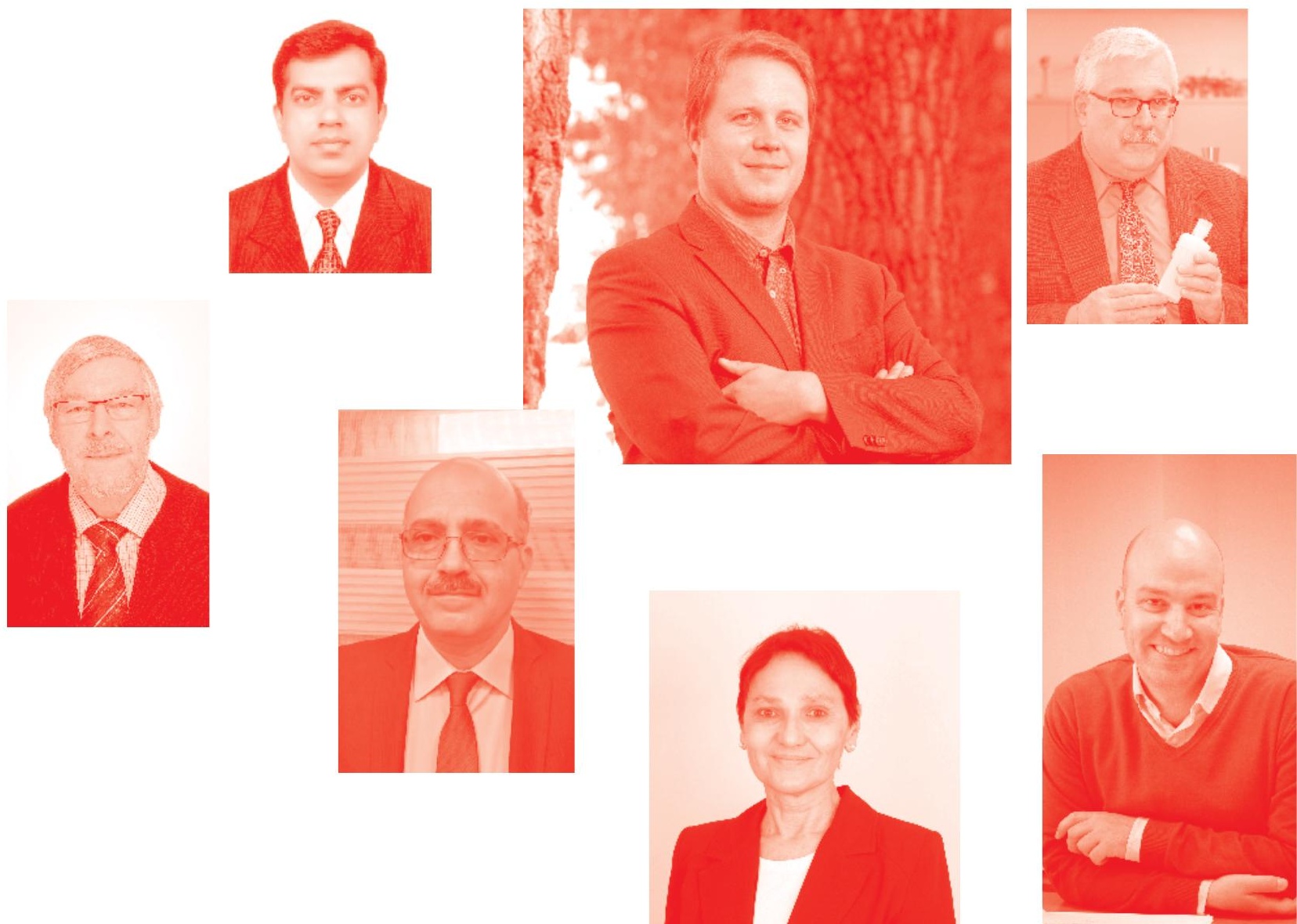
Methods for Film Synthesis and Coating Procedures

http : //dx. doi . org/10.5772/intechopen . 73994

Edited by László Nánai, Aneeya Samantara, László Fábián and Satyajit Ratha

Contributors

Ana Piedade, Paula Morais, Romeu Francisco, Rita Branco, Mitsunobu Sato, Chihiro Mochizuki, Tohru Hayakawa, Chih Wei Luo, Phuoc Huu Le, Sergey Dvoretsky, Laszlo Nanai, Zhaoliang Qu, Rujie He, Daining Fang, David Everett Weidner, Gultekin Goller, Mustafa Guven Gok, Hitesh Vasudev, Lalit Thakur, Amit Bansal, Aneeya Kumar Samantara

(-) The Editor(s) and the Author(s) 2020

The rights of the editor(s) and the author(s) have been asserted in accordance with the Copyright, Designs and Patents Act 1988. All rights to the book as a whole are reserved by INTECHOPEN LIMITED . The book as a whole (compilation) cannot be reproduced, distributed or used for commercial or non-commercial purposes without INTECHOPEN LIMITED's written permission. Enquiries concerning the use of the book should be directed to INTECHOPEN LIMITED rights and permissions department (permissions@intechopen.com).

Violations are liable to prosecution under the governing Copyright Law .

\section{(cc) BY}

Individual chapters of this publication are distributed under the terms of the Creative Commons Attribution 3.0 Unported License which permits commercial use, distribution and reproduction of the individual chapters, provided the original author(s) and source publication are appropriately acknowledged. If so indicated, certain images may not be included under the Creative Commons license. In such cases users will need to obtain permission from the license holder to reproduce the material. More details and guidelines concerning content reuse and adaptation can be found at http : //www . intechopen . com/copyright-policy . html.

\section{Notice}

Statements and opinions expressed in the chapters are these of the individual contributors and not necessarily those of the editors or publisher. No responsibility is accepted for the accuracy of information contained in the published chapters. The publisher assumes no responsibility for any damage or injury to persons or property arising out of the use of any materials, instructions, methods or ideas contained in the book.

First published in London, United Kingdom, 2020 by IntechOpen

IntechOpen is the global imprint of INTECHOPEN LIMITED, registered in England and Wales,

registration number: 11086078, 7th floor, 10 Lower Thames Street, London,

EC3R 6AF, United Kingdom

Printed in Croatia

British Library Cataloguing-in-Publication Data

A catalogue record for this book is available from the British Library

Additional hard and PDF copies can be obtained from orders@intechopen.com

Methods for Film Synthesis and Coating Procedures

Edited by László Nánai, Aneeya Samantara, László Fábián and Satyajit Ratha

p. cm.

Print ISBN 978-1-78985-566-1

Online ISBN 978-1-78985-860-

eBook (PDF) ISBN 978-1-78985-863-1 


\section{We are IntechOpen, \\ the world's leading publisher of Open Access books}

Built by scientists, for scientists

\section{$4,700+$}

Open access books available

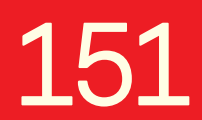

Countries delivered to

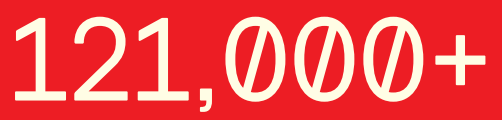

International authors and editors

Our authors are among the

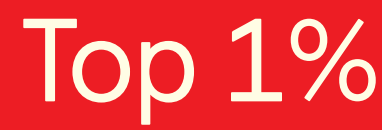

most cited scientists

Contributors from top 500 universities
40010

Downloads

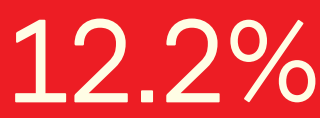

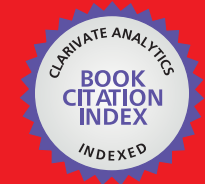

WEB OF SCIENCE ${ }^{\text {MM }}$

Selection of our books indexed in the Book Citation Index in Web of Science ${ }^{\mathrm{TM}}$ Core Collection (BKCI)

Interested in publishing with us?

Contact book.department@intechopen.com

Numbers displayed above are based on latest data collected.

For more information visit www.intechopen.com

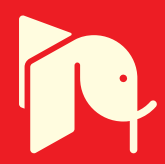





\section{Meet the editors}

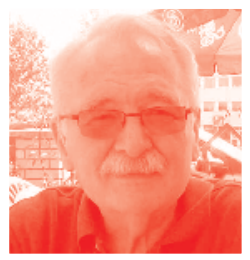

Prof. Nánai was born on April 19, 1948, in Csopak (Hungary). He studied physics (MSc) at Saint Petersburg State University (RU), and his PhD degree and habilitation in the field of quantum electronics were obtained at Lebedev Physical Institute, Moscow (RU), and Szeged University (Hungary). He is a specialist in the fields of solid-state physics, laser-matter interaction fabrication, and characterization of nanostructures. He has written over 170 scientific publications including about 10 books and chapters in books and conference proceedings.

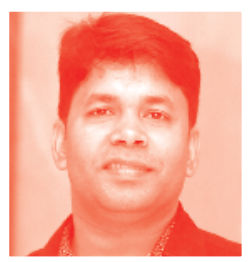

Dr Aneeya Kumar Samantara is presently working as a post-doctorate fellow at the School of Chemical Sciences, National Institute of Science Education and Research, Khordha, Odisha, India. He has pursued his PhD. at the CSIR-Institute of Minerals and Materials Technology, Bhubaneswar, Odisha, India. Before his $\mathrm{PhD}$. he completed his Master of philosophy (M.Phil.) in chemistry from Utkal University and Master in Science in Advanced Organic Chemistry at Ravenshaw University, Cuttack. He has authored articles in twenty-four peer-reviewed international journals, nine books, and four book chapters for international publishing houses of repute. Three books and four research articles are in press and will be published soon. Dr Samantara has received many national and international awards for his breakthrough research in the field of electrochemistry.

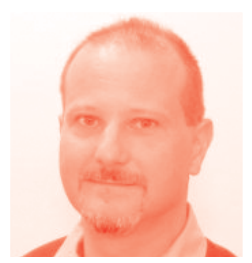

Dr Fábián was born on September 27, 1975 in Dombóvár, Hungary. He graduated as a physicist (MSc) at the University of Szeged (Szeged, Hungary). He obtained his PhD degree in the field of integrated optics. Currently, he is working as a researcher at the Biological Research Centre of the Hungarian Academy of Sciences and he also teaches "Bioelectronics" and "Solid State Physics" at the University of Szeged. His research interests include numerical simulations of photonic structures, biosensors, and spectroscopy of light-sensitive proteins.

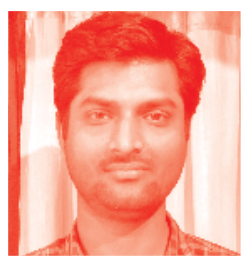

Mr Satyajit Ratha has pursued his PhD. at the School of Basic Sciences, Indian Institute of Technology Bhubaneswar, India. Prior to joining IIT Bhubaneswar, he received his Bachelor of Science, First Class Honors from Utkal University in 2008 and his Master of Science from Ravenshaw University in 2010. Satyajit's research interests include two-dimensional semiconductors, nanostructure synthesis, applications, energy storage devices, and supercapacitors. He has authored and co-authored about 20 peer-reviewed articles in international journals and seven books from reputed international publishing houses. 



\section{Contents}

Preface

Section 1

Different Methods of Coating Technologies - Fabrication, Characterization and Future Perspectives

Chapter 1

Prologue: Coating Technology

by Aneeya Kumar Samantara and Satyajit Ratha

Chapter 2

Fabrication of Apatite Films on Ti Substrates of Simple and Complicated Shapes by Using Stable Solutions of Ca Complex

by Chihiro Mochizuki, Mitsunobu Sato and Tohru Hayakawa

Chapter 3

State of the Art of Gadolinium Zirconate Based Thermal Barrier Coatings: Design, Processing and Characterization

by Mustafa Guven Gok and Gultekin Goller

Chapter 4

The Growth of CdTe Layer on GaAs Substrate by MBE

by S.A. Dvoretsky, N.N. Mikhailov, D.G. Ikusov, V.A. Kartashev,

A.V. Kolesnikov, I.V. Sabinina, Yu. G. Sidorov and V.A. Shvets

Chapter 5

High Temperature Oxidation and Wear Resistant Bi-Layer Coating for Turbocharger Housing

by Hitesh Vasudev, Lalit Thakur and Amit Bansal

\section{Section 2}

Physico-Chemical Methods of Thin-Film and Nanostructure Formation for Medical and Biological Applications

Chapter 6

Prologue: Thin-Film Synthesis and Application for Medical

and Biological Use

by László Fábián and László Nánai 
Chapter 7

Numerical Simulation of the Spin Coating of the Interior of Metal

Beverage Cans

by David E. Weidner

Chapter 8

Thin Films for Medical and Environmental Applications

by Ana P. Piedade, Francisco Romeu, Rita Branco and Paula V. Morais

Chapter 9

121

Nanostructuring Indium-Tin-Oxide Thin Films by Femtosecond

Laser Processing

by Phuoc Huu Le and Chih-Wei Luo

Chapter 10

137

Stress among the APS-Prepared TBCs: Testing and Analysis

by Zhaoliang Qu, Rujie He and Daining Fang 


\section{Preface}

With the advent of new surface and thin layer technologies, including different coating methods, it is now possible to make new materials with extreme physicochemical properties.

The new materials (films, mono- and multi-layers, nanostructures, composites etc) produced using the new methods have been used in many places in various fields of engineering technology and life science.

In this book, studies written by renowned researchers draw the reader's attention to different technologies of film fabrication eg, deposition, from liquid and solid phases, sputtering, and nanoscale layer fabrications. Some measuring methods by which the extreme material and life science parameters of the layers produced can be determined are also presented.

The reader will find many examples of medical-biological applications, highlighting the compatibility problems of tissues with the materials deposited (coating behavior in living environments).

We hope that the book will serve as an interesting scientific and practical base for people interested in applications of coatings for medical-biological use.

László Nánai

Department of Physics, University of Szeged JGYPK, Szeged, Hungary

Aneeya Samantara School of Chemical Sciences, National Institute of Science Education and Research, Bhubaneswar, Odisha, India

László Fábián University of Szeged JGYPK, Szeged, Hungary

Satyajit Ratha School of Basic Sciences, Indian Institute of Technology, Bhubaneswar, Odisha, India 



\section{Dedication}

Dr. Aneeya K. Samantara would like to dedicate this work to,

His parents, Mr. Braja Bandhu Dash, Mrs. Swarna Chandrika Dash and his beloved wife Elina.

Dr. Satyajit Ratha would like to dedicate this work to,

His parents, Mrs. Prabhati Ratha and Mr. Sanjaya Kumar Ratha. 

Section 1

Different Methods

of Coating

Technologies-Fabrication,

Characterization and

Future Perspectives 



\title{
Prologue: Coating Technology
}

\author{
Aneeya Kumar Samantara and Satyajit Ratha
}

\section{Introduction}

The advanced technological application demands value-added materials of requisite surface properties. In most of the cases, the metallic materials are employed as prime part of the instrument/device. But after certain period of repeated use, passivation/inactiveness of the surface has been realized. This is mainly due to the corrosion of the metallic surface. Corrosion is nothing but the physicochemical interaction of a metal surface with the surrounding environment leading to change the original properties of that metal. Further it impairs the function of the metal as well as the environment and the technical equipment of which these form a part. Therefore methods/technologies are strictly indispensable to protect the metal surface from the detrimental effect of the environment as well as to preserve its integrity. Although many technological prospects have been formulated, still now focus is given on the development of methods for surface modification/functionalization of materials. The definition of surface modification/functionalization directs the employment of a procedure to introduce new properties to an existing material to fulfil the requirement for a particular application. These techniques have been used from the ancient times aiming for an improved response of a material when it interacts with the environment.

After the evolution of nanoscale materials and nanotechnology, this functionalization is performed in either by manipulating the material composition in molecular level or by making an optimized coating onto the material surface. Basically the surface modification is performed by applying advanced coatings onto the material surface. These coatings offer an efficient physical barrier clogging the approach of corrosive species to the metal surface, thereby lengthening the lifetime of the equipment. Additionally these coatings are capable to suppress the corrosion process, if the protective barrier is disrupted by any means. Hence these corrosion protective materials require the use of anticorrosion pigments or corrosion inhibitors which will protect the underlying metallic surface. Further the thickness of coating and optimization of the number of layers strictly depends on the application for which it is intended. Generally the thickness varies from micro to millimetres, and the number of layers varies according to the targeted application. Each of the layers is designed to aim specific functionalities like as adhesive to the metal surface or in between the metal and other coating layers, corrosion inhibitor, water-repellent, antifouling/wear resistive agent, etc.

From the heritage of mankind, animal fat, gelatins, beeswax, clay minerals, and different vegetable oils have been employed as the coating material to protect the surface of metallic articles from corrosion, to retain brightness, for lubrication, etc. [1]. Later on with the passage of time, the boost on nanomaterials and nanotechnology developed many advanced routes for surface coating, but still now some of the ancient coating materials are in use. Afterwards the chromate-based surface treatments are developed and show efficient corrosion protective properties; however the use of hexavalent chromium is imposed legislatively (because of its carcinogenic properties) in most of the areas excluding the aerospace industries. Therefore more focus has been paid to design advanced, nontoxic (low-volatility, 
organic, hexavalent chromium- and isocyanate-free compounds), and low-cost coatings for corrosion protection. In this regard, many of the nanomaterial-based coatings (organic, inorganic, or composites) have been formulated and demonstrated successfully.

\section{Materials and processes}

These coating materials are applied in various sectors to prevent corrosion and to retain the integrity of the metal performance. Generally two main strategies have been considered to achieve the required functionalities into coatings: (a) encapsulation or loading of the active species in host carriers and (b) manipulation in composition of the coating matrix to include bulk or surface functional groups. The former one involves the intermixing of carriers of active agents (polymeric capsules, nanotubes, mesoporous inorganic particles, clays, etc.) along with the functional species (cerium ions, benzotriazole, nitrates, silyl esters, etc.) with the coating matrix. These carriers act as the reservoirs that store the active material and release at the time of requirement. It is necessary to maintain the compatibility and to check the long-term stability of the carrier material with the coating matrix. A number of carriers, functional species, and coating matrix have been summarized in Table 1.

In addition to the above-discussed processes, an alternative route is also explored and demonstrated successfully for corrosion protection. It constitutes the functionalization of the coating surface or bulk matrix by manipulating its molecular structure and composition [11-16]. Out of others, the process involving the manipulation of cross linking/molecular structure of the polymeric matrixes by integrating different additives (like cyclic carbonates, amines, and siloxanes) is considered as the greener route to surface functionalization. As a result a thin and dense cost-effective coating is formed showing improved protective action with better durability. Some examples on the coating materials based on surface modification is presented in Table 2.

\begin{tabular}{|c|c|c|c|c|}
\hline Substrate & Coating Matrix & Active agent & Carrier & Reference \\
\hline Steel & Epoxy polymer & Polysiloxanes & $\begin{array}{l}\text { Urea-formaldehyde } \\
\text { microcapsules }\end{array}$ & [2] \\
\hline Aluminium & Sol-gel & $\begin{array}{l}\text { Cerium (III), Lanthanum } \\
\text { (III), Salicylaldoxime, } \\
\text { 8-hydroxyquinoline }\end{array}$ & $\begin{array}{l}\text { Hydroxyapatite } \\
\text { particles }\end{array}$ & [3] \\
\hline Steel & Primer & Silver & Silica & {$[4]$} \\
\hline $\begin{array}{l}\text { Galvanised } \\
\text { steel }\end{array}$ & Silane & Cerium ions & $\mathrm{CeO}_{2}$ nanoparticles & {$[5]$} \\
\hline Glass & Silane & Sodium montmorillonite & $\begin{array}{l}\text { Sodium } \\
\text { montmorillonite }\end{array}$ & {$[6]$} \\
\hline Steel & Polyester coating & Benzalkonium chloride & Mesoporous silica & {$[7]$} \\
\hline $\begin{array}{l}\text { Aluminium } \\
\text { and } \\
\text { Galvanneal }\end{array}$ & Epoxy & Mercaptobenzothiazole & $\begin{array}{l}\text { Polyelectrolyte } \\
\text { nanocapsules }\end{array}$ & {$[8]$} \\
\hline Steel & Acrylic paint & Silver & $\begin{array}{l}\text { Polymer } \\
\text { microparticles }\end{array}$ & [9] \\
\hline $\mathrm{Al}$ alloys & Epoxy & Silyl ester & Polymeric capsules & {$[10]$} \\
\hline
\end{tabular}

Table 1.

Examples of different active agents, carriers, and coating matrixes used for coatings to protect the metallic surface from corrosion. 


\begin{tabular}{llll}
\hline Substrate & Coating matrix & Active agent & References \\
\hline Al alloys & Polyester & Various silane & {$[17]$} \\
\hline AZ31 & Epoxy & Various silanes aminosilanes & {$[14]$} \\
\hline Steel & Acrylics & Inorganic fillers & {$[18]$} \\
\hline Zinc and & Polyvynilbutyral & PANI-emeraldine salt of paratoluene & {$[19]$} \\
AA2024 & & sulphonic acid & \\
\hline AA2024 & Epoxy & PANI-lignosulfonate & {$[20]$} \\
\hline Steel panels & Commercial resins & Glycidyl carbamate & {$[21]$} \\
\hline Steel & Silicone rubber & Inorganic nanoparticles & {$[22]$} \\
\hline Tin & Poly(methyl & Mixture of silanes & {$[16]$} \\
& methacrylate $)$ & & {$[23]$} \\
\hline Steel & Epoxy-ester & dodecylbenzenesulfonic acid polyaniline & \\
\hline
\end{tabular}

Table 2.

Examples of different active agents used in manipulation of the coating matrix to make effective coatings for corrosion protection.

\section{Conclusion}

The encapsulation of coating matrixes with active agents provides an advanced route to maintain the properties of metallic materials used in different technological applications. Also the functionalization of surface with active materials by manipulating the molecular composition adds another route to prevent corrosion. Further the coating thickness and number of layer optimization is strictly needed to achieve an efficient coating. Therefore not only on the material development but also focus should be given to manage the compatibility among the coating layers and efficiencies of carrier material to hold active agents for targeted applications. This book aims to present detailed information and current advancements in the coatings technology applied to prevent the metallic substrates from corrosion maintaining its integrity.

\section{Author details}

Aneeya Kumar Samantara ${ }^{1 *}$ and Satyajit Ratha ${ }^{2}$

1 School of Chemical Sciences, National Institute of Science Education and Research, Bhubaneswar, Odisha, India

2 School of Basic Sciences, Indian Institute of Technology, Bhubaneswar, Odisha, India

*Address all correspondence to: cmrjitu@gmail.com; aneeya1986@gmail.com

\section{IntechOpen}

(C) 2020 The Author(s). Licensee IntechOpen. This chapter is distributed under the terms of the Creative Commons Attribution License (http://creativecommons.org/licenses/ by/3.0), which permits unrestricted use, distribution, and reproduction in any medium, provided the original work is properly cited. (cc) BY 


\section{References}

[1] Montemor MF. Functional and smart coatings for corrosion protection: A review of recent advances. Surface and Coating Technology. 2014;258:17-37. DOI: 10.1016/j.surfcoat.2014.06.031

[2] Cho SH, White SR, Braun PV. Selfhealing polymer coatings. Advanced Materials. 2009;21:645-649. DOI: 10.1002/adma.200802008

[3] Snihirova D, Lamaka SV, Taryba M, Salak AN, Kallip S, Zheludkevich ML, et al. Hydroxyapatite microparticles as feedback-active reservoirs of corrosion inhibitors. ACS Applied Materials \& Interfaces. 2010;2:3011-3022. DOI: 10.1021/am1005942

[4] Le Y, Hou P, Wang J, Chen JF. Controlled release active antimicrobial corrosion coatings with $\mathrm{Ag} / \mathrm{SiO}_{2}$ coreshell nanoparticles. Materials Chemistry and Physics. 2010;120:351-355. DOI: 10.1016/j.matchemphys.2009.11.020

[5] Montemor MF, Ferreira MGS. Analytical characterization of silane films modified with cerium activated nanoparticles and its relation with the corrosion protection of galvanised steel substrates. Progress in Organic Coating. 2008;63:330-337. DOI: 10.1016/j.porgcoat.2007.11.008

[6] Miccichè F, Fischer H, Varley R, van der Zwaag S. Moisture induced crack filling in barrier coatings containing montmorillonite as an expandable phase. Surface and Coating Technology. 2008;202:3346-3353. DOI: 10.1016/j. surfcoat.2007.12.003

[7] Zheng Z, Huang X, Schenderlein M, Borisova D, Cao R, Möhwald H, et al. Self-healing and antifouling multifunctional coatings based on $\mathrm{pH}$ and sulfide ion sensitive nanocontainers. Advanced Functional Materials. 2013;23:3307-3314. DOI: 10.1002/adfm.201203180
[8] Plawecka M, Snihirova D, Martins B, Szczepanowicz K, Warszynski P, Montemor MF. Self healing ability of inhibitor-containing nanocapsules loaded in epoxy coatings applied on aluminium 5083 and galvanneal substrates. Electrochimica Acta. 2014;140:282-293. DOI: 10.1016/j. electacta.2014.04.035

[9] Szabó T, Mihály J, Sajó I, Telegdi J, Nyikos L. One-pot synthesis of gelatin-based, slow-release polymer microparticles containing silver nanoparticles and their application in anti-fouling paint. Progress in Organic Coating. 2014;77:1226-1232. DOI: 10.1016/j.porgcoat.2014.02.007

[10] García SJ, Fischer HR, White PA, Mardel J, González-García Y, Mol JMC, et al. Self-healing anticorrosive organic coating based on an encapsulated water reactive silyl ester: Synthesis and proof of concept. Progress in Organic Coating. 2011;70:142-149. DOI: 10.1016/j. porgcoat.2010.11.021

[11] Twite RL, Bierwagen GP. Review of alternatives to chromate for corrosion protection of aluminum aerospace alloys. Progress in Organic Coating. 1998;33:91-100. DOI: 10.1016/ S0300-9440(98)00015-0

[12] Chattopadhyay DK, Raju KVSN. Structural engineering of polyurethane coatings for high performance applications. Progress in Polymer Science. 2007;32:352-418. DOI: 10.1016/j.progpolymsci.2006.05.003

[13] Mathiazhagan A, Joseph R.

Nanotechnology-A new prospective in organic coating-Review. International Journal of Chemical Engineering and Applications. 2013;2: 225-237. DOI: 10.7763/ijcea.2011.v2.108

[14] Brusciotti F, Snihirova DV, Xue H, Montemor MF, Lamaka SV, 
Ferreira MGS. Hybrid epoxy-silane coatings for improved corrosion protection of $\mathrm{Mg}$ alloy. Corrosion Science. 2013;67:82-90. DOI: 10.1016/j. corsci.2012.10.013

[15] Qian M, Mcintosh Soutar A, Tan XH, Zeng XT, Wijesinghe SL. Twopart epoxy-siloxane hybrid corrosion protection coatings for carbon steel. Thin Solid Films. 2009;517:5237-5242. DOI: $10.1016 /$ j.tsf.2009.03.114

[16] Kunst SR, Cardoso HRP, Oliveira CT, Santana JA, Sarmento VHV, Muller IL, et al. Corrosion resistance of siloxane-poly (methyl methacrylate) hybrid films modified with acetic acid on tin plate substrates: Influence of tetraethoxysilane addition. Applied Surface Science. 2014;298:1-11. DOI: 10.1016/j.apsusc.2013.09.182

[17] Pathak SS, Khanna AS. Investigation of anti-corrosion behavior of waterborne organosilane-polyester coatings for AA6011 aluminum alloy. Progress in Organic Coating. 2009;65:288-294. DOI: 10.1016/j. porgcoat.2008.12.006

[18] Achar S, Procopio LJ. Developments in waterborne thermal insulation coatings. Journal of Protective Coatings Linings. 2013;30:48-59. Available from: https://search. proquest.com/openview/aa4d92 247d81dd5738dca7d30118465b/1 ?pq-origsite $=$ gscholar $\& \mathrm{cbl}=36623$

[19] Williams G, Gabriel A, Cook A, McMurray HN. Dopant effects in polyaniline inhibition of corrosion-driven organic coating cathodic delamination on iron. Journal of the Electrochemical Society. 2006;153:B425-B433. DOI: 10.1149/1.2229280

[20] Gupta G, Birbilis N, Cook AB, Khanna AS. Polyaniline-lignosulfonate/ epoxy coating for corrosion protection of AA2024-T3. Corrosion Science.
2013;67:256-267. DOI: 10.1016/j. corsci.2012.10.022

[21] Upadhyay V, Harkal UD, Webster DC, Bierwagen GP. Preliminary investigation of the impact of polymer composition on electrochemical properties of coatings as determined by electrochemical impedance spectroscopy. Journal of Coating Technology and Research. 2013;10:865878. DOI: $10.1007 / s 11998-013-9497-z$

[22] Arianpour F, Farzaneh M, Kulinich SA. Hydrophobic and iceretarding properties of doped silicone rubber coatings. Applied Surface Science. 2013;265:546-552. DOI: 10.1016/j.apsusc.2012.11.042

[23] Arefinia R, Shojaei A, Shariatpanahi H, NeshatiJ. Anticorrosion properties of smart coating based on polyaniline nanoparticles/epoxy-ester system. Progress in Organic Coating. 2012;75:502-508. DOI: 10.1016/j. porgcoat.2012.06.003 



\title{
Fabrication of Apatite Films on Ti Substrates of Simple and Complicated Shapes by Using Stable Solutions of Ca Complex
}

\author{
Chihiro Mochizuki, Mitsunobu Sato and \\ Tohru Hayakawa
}

\begin{abstract}
Titanium ( $\mathrm{Ti}$ ) is known as the most popular implant materials. In addition, the coating technology of hydroxyapatite (HA) or carbonate-containing apatite (CA) on Ti substrates having various shapes has been interested from the viewpoint for improvement of implant's osteoconductivity. The fabrication of apatite coatings on metallic substrates has been investigated by several techniques. We developed novel wet processes using some stable solutions in which Ca complexes and phosphate ion dissolve simultaneously. The CA film can be deposited homogeneously on substrates, Ti plate and Ti fiber mesh, using a stable precursor solution involving a $\mathrm{Ca}^{2+}$ complex of ethylenediaminetetraacetic acid (EDTA). Another stable aqueous solution was prepared by the addition of phosphoric acid to a calcium hydrogen carbonate solution. The solution is adequate to be sprayed facilely onto a Ti plate by using an airbrush. It is important that the fabricated apatite films by the spray process have the characteristic network structures. The materials with these CA films are nontoxic and have the excellent bonding ability to bone tissues.
\end{abstract}

Keywords: apatite film, implant, Ca complex, chemical process

\section{Introduction}

Titanium (Ti) and its alloys are the most commonly used metal for the manufacture of orthopedic implants, while hydroxyapatite (HA), which is a calcium phosphate ceramic, is bioactive and biocompatible when used as a bone substitute. To improve the biocompatibility and mechanical properties of prostheses, calcium phosphate coatings on titanium surfaces are often investigated in order to combine the benefits of both the materials $[1,2]$. In addition to HA, the deposition of other carbonate-containing apatite (CA) films on titanium substrates is interesting because of the resulting chemical resemblance to bone mineral [3]. For the coating method, physical vapor deposition (PVD) techniques such as ion plating [4], magnetron sputtering [5], and ion beam dynamic mixing [6] have been introduced to deposit thin calcium phosphate coatings on medical or oral implants. A plasma spray technique, which is a physical process, is currently the most widely used method for the deposition of calcium phosphate 
coatings on Ti substrates [7-10]. However, plasma-sprayed calcium phosphate coatings have some shortcomings such as faster degradation and fatigue of the coating; moreover, their long-term clinical safety has been questioned [11-13]. On the other hand, Liu et al. [14] deposited a thin hydroxyapatite film on stainless steel using a waterbased sol-gel technique. A dense and adhesive apatite coating can be produced through water-based sol-gel technology after short-term annealing at around $400^{\circ} \mathrm{C}$ in air. Kim et al. [15] used a sol-gel method to coat a fluoro-hydroxyapatite film on a zirconia substrate. The use of the sol-gel technique has the potential for applying uniform coatings to porous substrates. However, in the conventional sol-gel process, alkoxides are employed, and the rigorous exclusion of water from the system is essential for the synthesis and conservation of the precursor alkoxides and their solutions since the process is based on partial or complete hydrolysis of such metal alkoxides [16]. Furthermore, Leeuwenburgh et al. $[17,18]$ and Siebers et al. $[19,20]$ reported a CA coating produced using electrostatic spray deposition (ESD) that was originally developed to fabricate thick ceramic films for solid electrolytes [21]. Amorphous films deposited by ESD on a substrate heated to $470^{\circ} \mathrm{C}$ converted to crystalline CA films after heat treatment at temperatures above $700^{\circ} \mathrm{C}$ for $15 \mathrm{~s}$ in air. Additionally, Siebers et al. [22] assayed the cell proliferation, alkaline phosphatase activity, and osteocalcin concentration of the osteoblast-like cells of the CA coatings deposited by ESD.

This chapter focuses on the fabrication of apatite film on Ti substrate by chemical process used in the metal complexes. We prepared two coating solutions with sufficient concentrations of $\mathrm{Ca}^{2+}$ complex and $\mathrm{PO}_{4}{ }^{3-}$ ion. CA film on Ti substrates fabricated by the solvent of one solution is ethanol, and another one is aqueous solution. Resultant films evaluated the characteristic and animal experimental.

\section{Molecular precursor method for apatite coating on titanium substrates}

\subsection{Preparation of stable coating solution by molecular precursor method}

The molecular precursor method (MPM) that was developed in our study is one of chemical processes for fabricating metal oxide and phosphate thin films [23-28]. This method is based on the design of metal complexes in coating solutions with excellent stability, homogeneity, miscibility, coatability, etc., which have many practical advantages. This is because metal complex anions with high stability can be generally dissolved in volatile solvents adequate to spin-coating, etc., by combining them with appropriate alkylamines via acid-base reaction. Furthermore, the resultant solutions can form excellent precursor films through various coating procedures. The precursor films involving metal complexes should be amorphous in order to obtain homogeneous films without crack and pinhole. Heat-treatment is usually employed to fabricate the desired metal oxide or phosphate films by eliminating the ligand in the metal complex and alkylamine in the precursor films. It is important that densification of the films during heat treatment occurs only in the vertical direction on the substrate.

The molecular precursor solution for the CA coating was obtained as an ethanol solution by adding diphosphate salt to a butylammonium salt of Ca complex with EDTA, which was isolated by the reaction of ethylenediamine- $N, N, N^{\prime}, N^{\prime}$ tetraacetic acid (EDTA) and $\mathrm{Ca}\left(\mathrm{CH}_{3} \mathrm{COO}\right)_{2} \cdot 2 \mathrm{H}_{2} \mathrm{O}$ from the hot aqueous solution. The obtained solution was clear and stable.

The general procedure for preparing the molecular precursor solution is shown in Figure 1 [29].

The abovementioned Ca complex was isolated as a white powder and characterized by elemental analysis, Fourier transform infrared (FT-IR), and thermogravimetry-differential thermal analysis (TG-DTA). Figure 2 shows the FT-IR spectra of 
Fabrication of Apatite Films on Ti Substrates of Simple and Complicated Shapes by Using Stable... DOI: http://dx.doi.org/10.5772/intechopen.80409

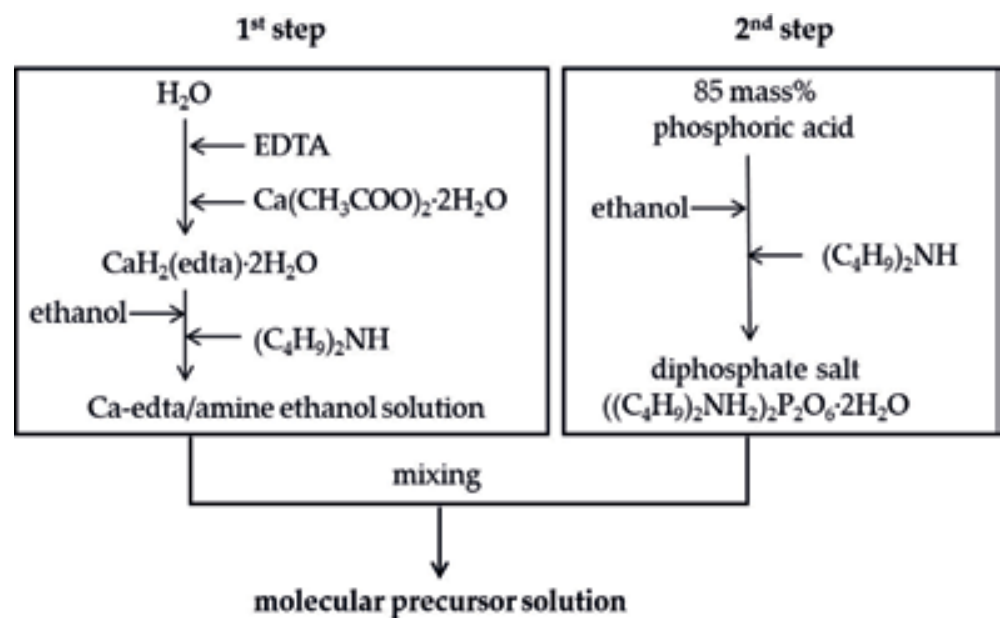

Figure 1.

Schematic of preparation of precursor solution.

the white compound. The characteristic peak assignable to carboxyl group can be observed at $1620 \mathrm{~cm}^{-1}$. The peaks at 1200,2980 , and $3360 \mathrm{~cm}^{-1}$ can be assigned to $\mathrm{H}_{5} \mathrm{O}_{2}{ }^{+}$ion. Figure 3 shows TG-DTA curves of the obtained white compound. The endothermic peak with the mass loss at $235^{\circ} \mathrm{C}$ can be assigned to the elimination of the coordinated water molecules. It was clarified by these results that the number of coordinated water is 2 . The exothermic peak with the mass loss from 324 to $464^{\circ} \mathrm{C}$ corresponds to the combustion of EDTA. As a result, the chemical component of the isolated white powder was confirmed as $(\mathrm{H})\left(\mathrm{H}_{5} \mathrm{O}_{2}\right)[\mathrm{Ca}($ edta $)]$ and consistent to the elemental analysis.

The isolated Ca complex of EDTA is not soluble to ethanol, producing a suspended solution when the compound is added into the solvent. However, by the addition of dibutylamine to the suspended solution, a clear solution can be facilely obtained. In addition, the dibutylammonium salt of the Ca complex with EDTA produces an amorphous film on the Ti substrate by spin-coating before firing, under the presence of phosphate ion.

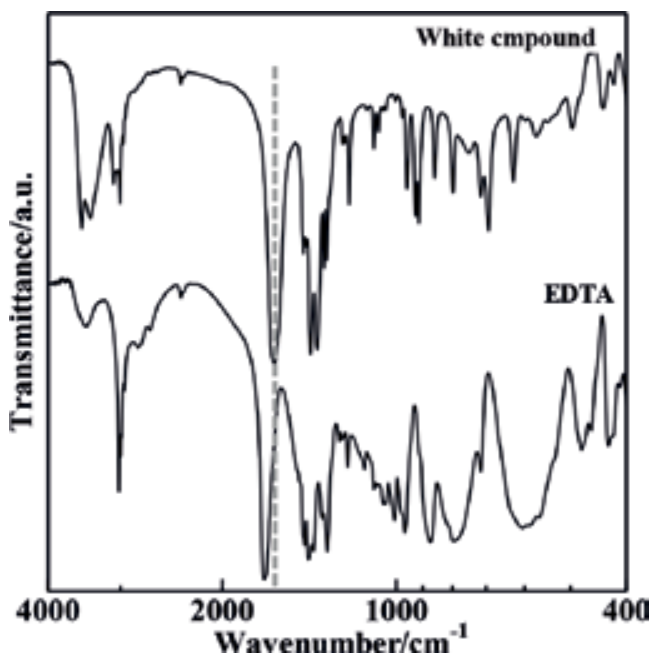

Figure 2.

FT-IR spectra of EDTA and white compound. 


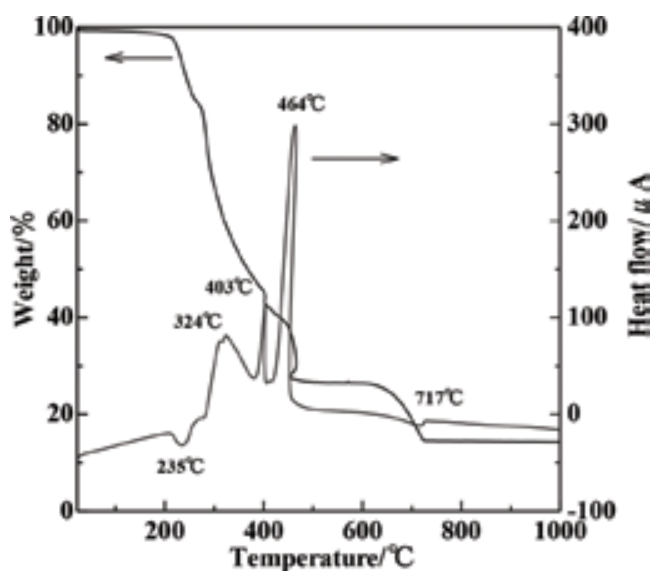

Figure 3.

TG-DTA curves of white compound.

When an aqueous solution of 85 mass\% phosphoric acid was directly added to the dibutylammonium salt of the Ca complex with EDTA in ethanol instead of the dibutylammonium diphosphate, the gelation of the mixed solution was observed after several days at ambient temperature. This may be caused by the hydrolysis involving $\mathrm{Ca}^{2+}$ and $\mathrm{PO}_{4}{ }^{3-}$ species due to the copresence of the large amount of water molecules derived from the aqueous solution of phosphoric acid. It is important to note that the present molecular precursor solution does not occur in such a hydrolysis for several months, due to the negligible amount of water in the solution.

\subsection{Fabrication of the apatite films}

Machined commercially pure wrought Ti disks were used as a substrate material. The molecular precursor solution was dropped onto the Ti surface to cover the entire area of the disk. The precursor films formed on the disks were dried at $60^{\circ} \mathrm{C}$ for $20 \mathrm{~min}$ and then fired at $300,400,500,600$, and $700^{\circ} \mathrm{C}$ for $2 \mathrm{~h}$ using a furnace in air.

Figure 4 shows the XRD patterns of the coating films on the substrate at different firing temperatures. No peak could be observed when the precursor films were fired at 300 and $400^{\circ} \mathrm{C}$, in the exception of the peaks assignable to Ti. Thus, the heat treatment below $400^{\circ} \mathrm{C}$ did not produce calcium phosphate crystals on the Ti substrate. Thermal analysis of the molecular precursor gel demonstrated that the decomposition of organic materials occurred at around $360^{\circ} \mathrm{C}$ and that complete decomposition of organic materials can be achieved at a firing temperature higher than $400^{\circ} \mathrm{C}$. By the heat treatment at $500^{\circ} \mathrm{C}$, the thickness of the coated film decreased more than that at $300^{\circ} \mathrm{C}$. Also, in the XRD patterns of the heat-treated films at $500^{\circ} \mathrm{C}$, the peak intensities assignable to Ti substrate increased in comparison with those obtained at 300 and $400^{\circ} \mathrm{C}$. These changes in film thicknesses and detection of the Ti substrate are due to the combustion and removal of organic material in the precursor film. The organic materials in the precursor film on the Ti disk disappeared completely at the temperatures in the range $600-700^{\circ} \mathrm{C}$.

The CA film formed at a firing temperature at $500^{\circ} \mathrm{C}$ was almost amorphous, but the films formed at firing temperatures of 600 and $700^{\circ} \mathrm{C}$ showed a crystalline structure. The greater intensities of the rutile and anatase peaks resulted from heat treatment of the Ti substrate. It is thus suggested that a firing temperature at $600^{\circ} \mathrm{C}$ is suitable for the production of a thin CA film on the Ti substrate.

The surface of the coating film is quite smooth with no crack nor pinhole. 
Fabrication of Apatite Films on Ti Substrates of Simple and Complicated Shapes by Using Stable... DOI: http://dx.doi.org/10.5772/intechopen.80409

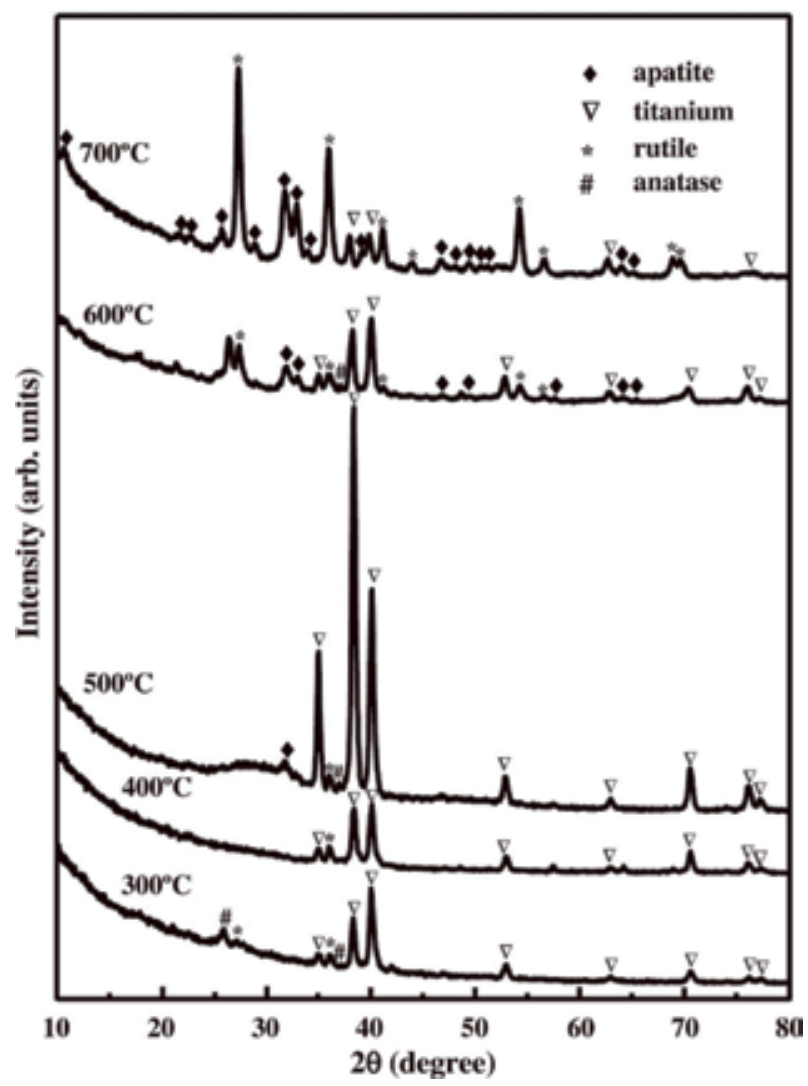

Figure 4.

XRD patterns of CA film firing at several temperatures.

\subsection{Characterizations of the fabricated film}

Table 1 lists the changes of film thickness and $\mathrm{Ca} / \mathrm{P}$ ratio, which was measured by electron probe microanalysis (EPMA), of the coating films fired at $600^{\circ} \mathrm{C}$ on titanium disk by immersing them in phosphate-buffered saline ( $\mathrm{PBS}, \mathrm{pH}=7.4)$. It was thus shown that this crystalline apatite film on the Ti substrate is robust to the immersion in PBS. Only a slight crack could be observed after immersion for 7 and 28 days, respectively. No distinct degradation of the deposited coatings was detected. However, the gradual decreases of the $\mathrm{Ca} / \mathrm{P}$ ratio of the coating film were observed after immersion in PBS. It is suggested that ion exchange reaction between the coating film and PBS occurred gradually via the dissolution/precipitation process.

The tensile bond strength of the coated film onto the Ti substrate was measured to evaluate the degree of adherence. Table 2 lists the tensile bond strength of CA film on the Ti substrate. The tensile bond strengths of several coating films onto Ti have been reported as follows: $31.9 \mathrm{MPa}$ by the plasma spraying method

\begin{tabular}{lcccc}
\hline Immersion period (day) & $\mathbf{0}$ & $\mathbf{1}$ & $\mathbf{7}$ & $\mathbf{2 8}$ \\
\hline Coating thickness $(\mu \mathrm{m})$ & $0.44(0.01)$ & $0.45(0.01)$ & $0.43(0.01)$ & $0.45(0.04)$ \\
\hline Ca/P ratio & $1.56(0.04)$ & $1.40(0.05)$ & $1.41(0.04)$ & $1.31(0.05)$ \\
\hline
\end{tabular}

Table 1.

Change in thickness of CA film after immersion in PBS. 


\begin{tabular}{lc}
\hline Substrate & Tensile bond strength (MPa) \\
\hline Uncoated titanium & $42.1(9.4)$ \\
\hline Coated film before PBS immersion & $40.2(5.6)$ \\
\hline Coated film after PBS immersion & $38.6(6.3)$ \\
\hline
\end{tabular}

Table 2.

Tensile bond strength of CA film on Ti substrate.

[30], 8.02-45.82 MPa by ion beam sputtering deposition [31], 59.0 MPa by ion beam dynamic mixing [6], and 32.50 MPa by plasma spraying coating to titanium plasma-sprayed titanium [32], respectively. The bond strength obtained in the present study, $40 \mathrm{MPa}$, was compatible with these reported values, although it was impossible to obtain the real interfacial bond strength by this method owing to the cohesive failure of the epoxy glue used to fix the samples (Table 2).

\subsection{Animal experimental and histological evaluation}

The CA films on a Ti screw cylinder for animal experiments were coated by using the abovementioned ethanol solution as follows. The Ti screw cylinders were immersed in the molecular precursor solution for $5 \mathrm{~min}$ and taken out from the solution slowly. Subsequently, the precursor films that formed on the Ti screw cylinder were dried at $60^{\circ} \mathrm{C}$ for $20 \mathrm{~min}$ and then heat treated at $600^{\circ} \mathrm{C}$ for $2 \mathrm{~h}$ in air using a furnace. The film thickness was approximately $0.16 \mu \mathrm{m}$, and the $\mathrm{Ca} / \mathrm{P}$ ratio was $1.49 \pm 0.20$. All implants, CA-coated Ti screw cylinder and uncoated Ti screw cylinder, were sterilized in an autoclave before surgery; the implants were inserted into the trabecular bone of rabbits according to a previously used technique [33,34]. After the implantation for 2, 4, 8, and 12 weeks, no clinical signs of inflammation or adverse tissue reactions were observed at sacrifice. All implants were still in situ at sacrifice. After implantation for 2 weeks, as has been shown in Figure 5, the overall trabecular bone response to the two different implant surfaces was almost identical [35]. With progress of implantation time, as for both implants, new bone and remodeling were observed, and no clear differences in bone responses to the two different implants could be seen (as shown in Figure 6). Then, besides a descriptive evaluation, the percentage of bone contact was determined for the 4-, 8-, and 12-week specimens. Table 3 shows the results of the measured percentage of bone-implant contact. At 4 and 8 weeks, no significant difference existed in bone contact between uncoated and CA-coated implants $(\mathrm{P}>0.05)$. However, after 12 weeks, statistical analysis revealed that the amount of bone contact to the CA-coated implants was significantly higher than the uncoated titanium implant $(\mathrm{P}<0.05)$.
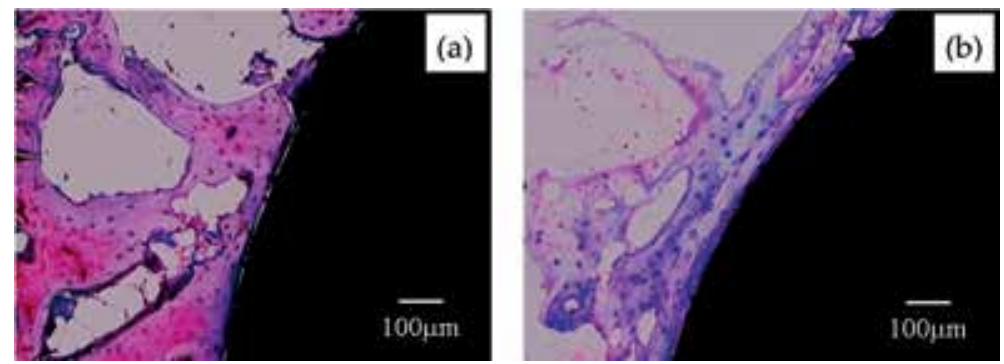

Figure 5.

Histological appearances of (a) uncoated Ti screw cylinder and (b) CA-coated Ti screw cylinder 2 weeks after implantation. 

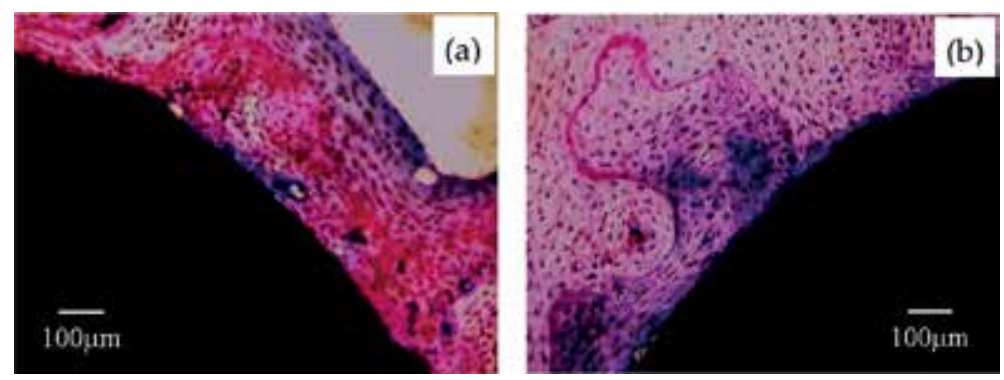

Figure 6.

Histological appearances of (a) uncoated Ti screw cylinder and (b) CA-coated Ti screw cylinder 12 weeks after implantation.

\begin{tabular}{cccc}
\hline & \multicolumn{3}{c}{ Implantation periods } \\
\cline { 2 - 4 } & $\mathbf{4}$ weeks & $\mathbf{8}$ weeks & $\mathbf{1 2}$ weeks \\
\hline Uncoated & $46.4(16.6)$ & $58.2(12.4)$ & $71.3(6.9)$ \\
\hline CA coated & $47.7(14.9)$ & $61.8(10.8)$ & $80.7(5.6)$ \\
\hline
\end{tabular}

Means connected with vertical lines are not significantly different at $P>0.05$.

Table 3.

Percentage of the measured bone-implant contact.

Wolke and coworkers suggested that 1 - $\mu$ m-thick heat-treated $\mathrm{Ca} / \mathrm{P}$ sputter coatings on roughened $\mathrm{Ti}$ implants appear to be of sufficient thickness to show bioactive properties under in vivo conditions [36]. Our study demonstrated that a CA coating with a thickness of approximately $0.16 \mu \mathrm{m}$, which was also inserted into the trabecular bone of the rabbit, has a beneficial effect on the bone response during the healing phase.

From these results, it was suggested that the MPM is promising as the apatite film formation method. Furthermore, this method is useful to fabricate the apatite films homogeneously on various and complicated shapes, e.g., Ti mesh [37].

\section{Aqueous spray method for apatite coating on titanium substrate}

\subsection{Preparation of aqueous spray solution}

We first prepared a clear solution by blowing $\mathrm{CO}_{2}$ gas into an aqueous solution of calcium hydroxide [38]. Into the solution, an aqueous solution involving phosphoric acid was then added slowly, and a clear solution could be prepared. Generally, $\mathrm{Ca}^{2+}$ ion reacts immediately with $\mathrm{PO}_{4}{ }^{3-}$ ion in aqueous solution, and calcium phosphate compounds precipitate. However, the finally obtained solution is stable if enough concentration of $\mathrm{CO}_{2}$ is maintained in the solution. In fact, many crystals of brushite $\left(\mathrm{CaHPO}_{4} \cdot 2 \mathrm{H}_{2} \mathrm{O}\right)$ deposited when $\mathrm{CO}_{2}$ in the solution decreased. Therefore, the periodical blowing of $\mathrm{CO}_{2}$ into the solution can prevent from precipitating such calcium phosphate compounds.

\subsection{Fabrication of the apatite films}

The CA film on a Ti plate was fabricated by the aqueous spray method and characterized precisely [38]. In the spraying process with a pressure of $0.2 \mathrm{MPa}$ supplied by an air compressor, the mist of the aqueous solution emitted from the nozzle 
of an airbrush was vertically collided on a preheated Ti substrate. The thickness of the sprayed film measured by a profilometer and those of the films obtained by heat treatment of the sprayed film at $400-700^{\circ} \mathrm{C}$ under an Ar gas flow were in the range 1.21-1.40 $\mu \mathrm{m}$. The well-developed network structure with many round particle was observed on the surface of the sprayed CA film, as has been shown in Figure 8. The characteristic network structure of the films fabricated in this present work can be also observed for those formed by the ESD method [17-20]. The size of the network structure found on the surface of the present films $(10-15 \mu \mathrm{m})$ was twice as large as those of the films formed by ESD method $(5-7 \mu \mathrm{m})$ [39]. The round bulged wall may be formed by spreading of the mist reached on the surface. The round particles (Figure 7), which were not observed for the films formed by the ESD method, may be formed by particle growth of the crystal nuclei generated in the sprayed mist during the approach to the substrate and appeared on the film surface. This difference in morphology may be due to the size of the fine drops in the mist and the boiling point of the solvent.

The apatite deposition on the preheated substrate occurs through at least the following four steps. Firstly, spraying of the aqueous solution with compressed air from the nozzle forms fog-like drops of the solution. Secondly, the fog-like drops gradually evaporate due to heat near the substrate, and a continuous increase in ion concentration in the drops occurs during the approach and before contact with the substrate. This step includes the partial removal of $\mathrm{CO}_{2}$ gas. In the next step, the concentrated sprayed drops in the mist collide with and spread on the substrate. In the fourth and final step, the spread apatite immediately deposited on the substrate by evaporation of the water molecules in the hydrated ions, and the apatite accumulates by continuous collision of the concentrated sprayed mist.

From the XRD measurement of the sprayed film, it is clear that the apatite structure is easily formed using this method. In addition, the surface morphology of the sprayed film did not change by heat treatment at $400-700^{\circ} \mathrm{C}$ under an Ar gas flow.

On the other hand, the amount change of the spray solution caused the drastic change of the surface morphologies. Figure 8 shows the tilt-viewed surface morphologies for A whose spray amount and film thickness were $25 \mathrm{~mL}$ and $1.3 \mu \mathrm{m}$ and $\mathbf{B}$ whose spray amount and film thickness were $5 \mathrm{~mL}$ and $0.11 \mu \mathrm{m}$, respectively [40]. The image of the thinner-film $\mathbf{B}$ indicated that the formation of the network structures with round particles occurred as found on the thicker-film $\mathbf{A}$, even if the amount of the sprayed solution decreased.

On the basis of these SEM images, Table 4 also lists the averaged border heights of 10 arbitrarily selected networks. The other two films, $\mathbf{A}^{\prime}$. and B', were prepared by heat treating $\mathbf{A}$ and $\mathbf{B}$, respectively, at $600^{\circ} \mathrm{C}$ for $10 \mathrm{~min}$ under Ar gas flow of
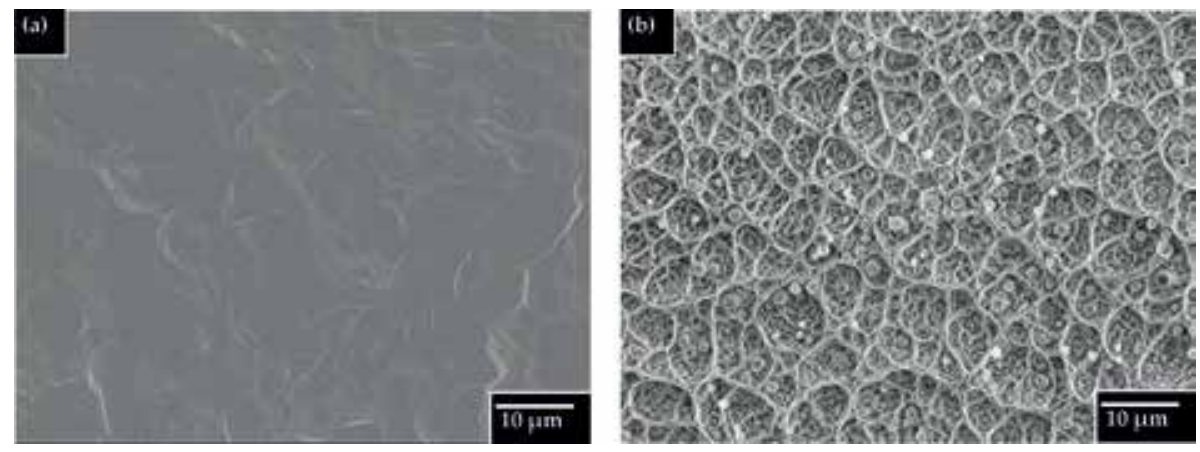

Figure 7.

Surface morphologies of the (a) Ti substrate and (b) sprayed film (the amount of spray solution is $25 \mathrm{~mL}$ ). 

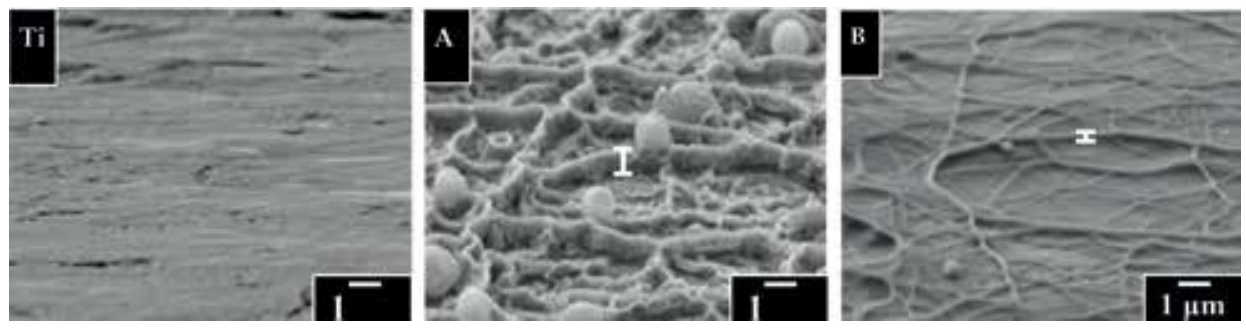

Figure 8.

Tilte-viewed SEM images of Ti substrate (Ti), spray amount of $25 \mathrm{~mL}$ on Ti (A) and spray amount of $5 \mathrm{~mL}$ (B). The tilte angle was $85^{\circ}$.

$0.5 \mathrm{~L} \mathrm{~min}^{-1}$. The ratios of border height to thickness of $\mathbf{A}, \mathbf{A}^{\prime} \cdot \mathbf{B}$, and $\mathbf{B}^{\prime} \cdot$ were 0.6 , $0.8,2.4$, and 2.8 , respectively. Thus, the degree of film shrinkage in the vertical direction by thermal densification was larger than that of border height reduction when the films $\mathbf{A}$ and $\mathbf{B}$ were heat treated in the abovementioned conditions.

\subsection{Characterizations of the fabricated film}

The results of elemental and Fourier transform infrared (FT-IR) analyses of the powder mechanically collected from the surface of the sprayed film agreed well with those of $\mathrm{Ca}_{10}\left(\mathrm{PO}_{4}\right)_{6}\left(\mathrm{CO}_{3}\right) \cdot 2 \mathrm{CO}_{2} \cdot 3 \mathrm{H}_{2} \mathrm{O}$.

Figure 9 shows the FT-IR spectra of the powders collected from the sprayed film before heat treatment and those heat treated at different temperatures. The bands around 1639 and $3435 \mathrm{~cm}^{-1}$ are likely due to water molecules, but not the hydroxy group. The peak at $2343 \mathrm{~cm}^{-1}$, which was observed for both the sprayed film before heat treatment and those heat treated at $400^{\circ} \mathrm{C}$ and $500^{\circ} \mathrm{C}$, can be assigned to the asymmetric stretching mode of the $\mathrm{CO}_{2}$ molecule [41]; the corresponding peaks for the two films heat treated above $600^{\circ} \mathrm{C}$ were extremely small. This unexpected behavior of the films heat treated above $600^{\circ} \mathrm{C}$ may be due to crystallite decay that occurs by elimination of $\mathrm{CO}_{2}$ molecules that were initially inserted in the apatite skeleton, as shown in the FT-IR spectra.

The shear stresses developed in the sprayed film before heat treatment and the sprayed films heat treated at different temperatures were measured. For the film heat treated at $700^{\circ} \mathrm{C}$, the shear stress exceeded the measurable limit, indicating more than $133 \mathrm{MPa}$ based on the maximum load of this instrument $(0.50 \mathrm{~kg})$. The shear stress of the sprayed film $(21 \mathrm{MPa})$ is notably larger than the value reported (13 $\mathrm{MPa})$ for an HA film formed on a Ti substrate via plasma spray deposition [42]. The spray solution contains various ions, such as hydroxide, carbonate, and phosphate ions, that may act as bridging ions and can readily form strong chemical bonds at the interface of the Ti substrate and the film. The remarkable decrease in wthe shear

\begin{tabular}{ccc}
\hline Notation & Average film thickness & Average border height \\
\hline A & $\boldsymbol{\mu m}$ & $\boldsymbol{\mu m}$ \\
\hline A $^{\prime}$ & $1.31(9)$ & $0.84(7)$ \\
\hline B & $1.21(4)$ & $0.98(9)$ \\
\hline B' & $0.12(2)$ & $0.29(3)$ \\
\hline
\end{tabular}

Table 4.

Average thicknesses and average border height of network of A, A', B, and B'. 


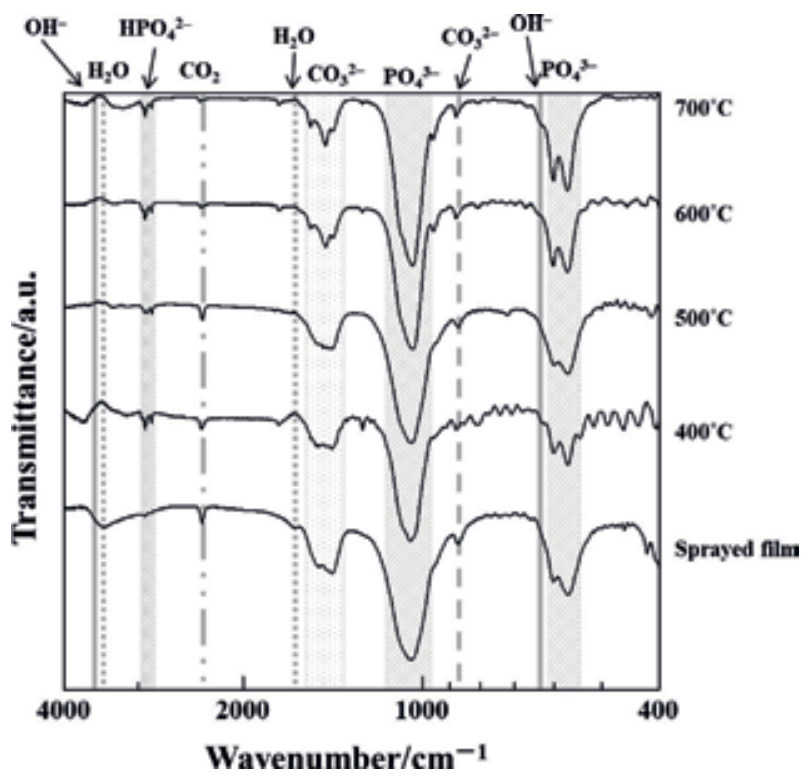

Figure 9.

FT-IR spectra of the powders obtained from the sprayed film and heat-treated films.

stresses observed for the films heat treated at 400 and $500^{\circ} \mathrm{C}$ can also be explained by the following assumption; at these low temperatures, a large amount of $\mathrm{CO}_{2}$ may be eliminated from the films, because the TG curve shows that $\mathrm{CO}_{2}$ moieties were removed below $600^{\circ} \mathrm{C}$. As a result, the densities of these films formed at low temperatures are relatively low as compared to those obtained at higher temperatures which cause sufficient film densification.

\subsection{Animal experimental and histological evaluation}

Bone responses of Ti implant and CA sprayed on Ti implants, A' and B', were evaluated after implantation into a femoral bone defect in rats [43]. After implantation at 2 weeks, differences in the histopathological appearances of cortical bone formation around the implants revealed new bone formation in all implants (Figure 10).

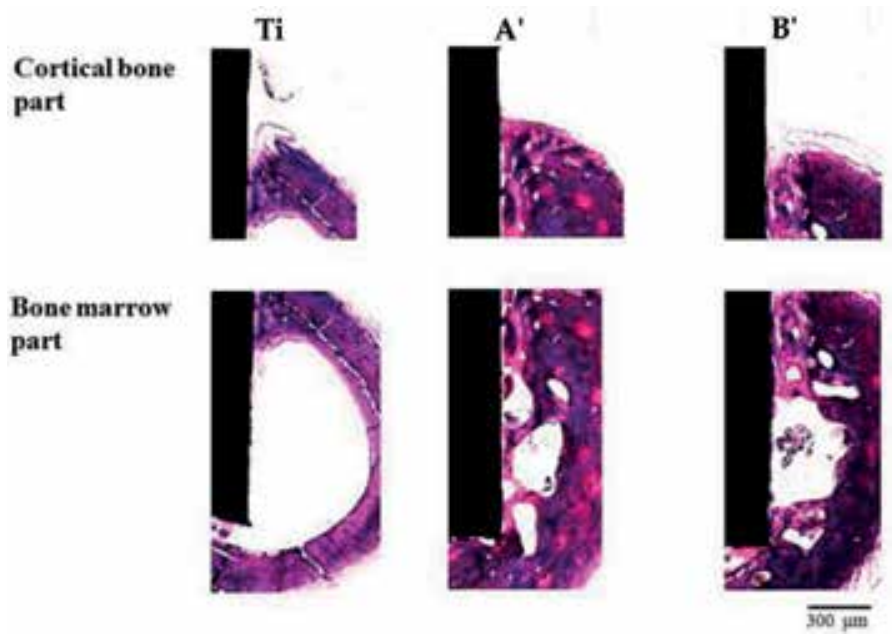

Figure 10.

Histological appearances of Ti, A' and B', 2 weeks after implantation. 
Fabrication of Apatite Films on Ti Substrates of Simple and Complicated Shapes by Using Stable... DOI: http://dx.doi.org/10.5772/intechopen.80409

\begin{tabular}{ccccc}
\hline \multirow{2}{*}{ Notation } & Cortical bone part & \multicolumn{3}{c}{ Bone marrow part } \\
\cline { 2 - 5 } & 2 weeks & 4 weeks & 2 weeks & 4 weeks \\
\hline $\mathrm{Ti}$ & $29.7(14.8)$ & $46.1(7.6)$ & $22.6(6.9)$ & $27.6(14.8)$ \\
\hline A $^{\prime}$ & $46.1(10.0)$ & $64.1(8.2)$ & $46.5(9.4)$ & $63.8(10.2)$ \\
\hline B' & $41.4(11.7)$ & $78.7(4.8)$ & $34.9(12.3)$ & $72.3(18.6)$ \\
\hline
\end{tabular}

Table 5 .

Measured BIC in cortical bone and bone marrow part of implant specimens.

\begin{tabular}{ll}
\hline Notation & Load/N \\
\hline Ti & $3.3(0.2)$ \\
\hline A' $^{\prime}$ & $20.1(0.7)$ \\
\hline B' $^{\prime}$ & $23.4(5.5)$ \\
\hline
\end{tabular}

Table 6.

Measurement push-in loads of implant.

Haversian canals were observed in A' and B', but not in Ti. The bone marrow demonstrated more distinct differences in new bone formation between $\mathrm{Ti}$ - and CA-coated specimens. Greater amounts of new bone formation were observed for A' and B' than for Ti inside the bone marrow. Newly formed bone in bone marrow was trabecular bone, and a part of new bone was formed close to implant materials, A' and B'.

There were no significant differences in BIC (bone-to-implant contact) in the cortical bone among the three different implants 2 weeks after implantation ( $p>0.05$; Table 5). However, 4 weeks after implantation, A' and B' showed significantly higher $\mathrm{BIC}$ than Ti, and BIC was the highest in $\mathbf{B}^{\prime}(\mathrm{p}<0.05)$. Indeed, BIC was significantly higher for A' and $\mathbf{B}^{\prime}$ at 4 weeks post-implantation than that at 2 weeks $(\mathrm{p}<0.05)$. In the bone marrow, A' showed significantly higher BIC than Ti and B' at 2 weeks after implantation. At 4 weeks after implantation, BIC of A' and B' was significantly higher than Ti $(p<0.05)$. No significant differences existed between $\mathbf{A}^{\prime}$ and $\mathbf{B}^{\prime}(\mathrm{p}>0.05)$. BICs of 4 weeks post-implantation were significantly higher than those of 2 weeks for $A^{\prime}$ and $B^{\prime}(p<0.05)$.

CA-coating specimens A' and B' provided significantly greater amounts of BIC in cortical bone and bone marrow than Ti alone. $\mathbf{B}^{\prime}$ was more effective in increasing BIC than $\mathbf{A}^{\prime}$. It is well known that rougher surfaces provide faster and more bone formation [44]. However, the surface roughness did not contribute to an increase of BIC. Mochizuki et al. [40] previously evaluated the attachment, proliferation, and differentiation of osteoblast-like cells on CA-coated Ti. They found that initial attachments of osteoblast-like cells increased due to CA coating and no difference was observed between A' and B'. On the contrary, cell differentiation was enhanced more on $\mathbf{B}^{\prime}$ than on $\mathbf{A}^{\prime}$. They speculated that reduced border heights in the network structure of B' were preferred for the spreading of the osteoblast-like cells, and as a result, mineralization would be more accelerated with $\mathbf{B}$ '. Therefore, higher BIC in the cortical part was obtained for $\mathbf{B}$ ' in the present animal experiments.

The bonding ability of CA-sprayed implant into the bone was examined by push-in tests. A' and B' showed significantly higher push-in loads than $\mathrm{Ti}$ $(p<0.05)$, and there were no significant differences between $A^{\prime}$ and $\mathbf{B}^{\prime}$ ( $p$ > 0.05 ; Table 6). A push-in test was performed to evaluate the bonding between the implant and surrounding bone. Both CA-coating implants produced tighter bonding to the bone than $\mathrm{Ti}$. Surface roughness did not influence the values in push-in 
tests. Lin et al. [45] also reported that surface modification with hydroxyapatite nanoparticles increased the push-in values 2 weeks after implantation into the femur of rats. In the present study, we only monitored the peaks at the loaddisplacement curve. Studies for the failure mode during the push-in test will be necessary to analyze the bonding of CA films to Ti.

\section{Conclusion}

Using two different Ca complexes, the fabrication of carbonate-apatite films was achieved. The ligands of used complexes play an important role to inhibit the direct reactions of $\mathrm{Ca}^{2+}$ ion with $\mathrm{PO}_{4}{ }^{3-}$ ion in ethanol and aqueous solutions. Furthermore, these ligands of the complexes could be facilely removed by usual heat treatment, producing carbonated apatite. The film fabrication by using the ethanol solution, molecular precursor one, involving a Ca complex of EDTA was convenient to form CA films on a Ti plate and screw-type cylinder. The fabricated CA films on a plate have smooth surface and adhered well even if the substrate has a 3D structure such as screw [37]. In addition, a VOC-free coating of CA on a Ti plate was accomplished using an aqueous spray method. The method can easily regulate the thickness and the morphologies of the obtained CA film by changing the amount of spray solution. It was also suggested that the surface morphology of the fabricated CA film by this method is important for the bone reproduction by the CA-coated implant. The CA coating on Ti substrate by the molecular precursor and aqueous spray methods will be useful to clinical application in the field of dentistry.

\section{Author details}

Chihiro Mochizuki ${ }^{1}$, Mitsunobu Sato ${ }^{2 *}$ and Tohru Hayakawa ${ }^{3}$

1 Center for Promotion of Higher Education, Kogakuin University of Technology and Engineering, Tokyo, Japan

2 School of Advanced Engineering, Kogakuin University of Technology and Engineering, Tokyo, Japan

3 School of Dental Medicine, Tsurumi University, Kanagawa, Japan

*Address all correspondence to: ft10302@ns.kogakuin.ac.jp

IntechOpen

(C) 2018 The Author(s). Licensee IntechOpen. This chapter is distributed under the terms of the Creative Commons Attribution License (http://creativecommons.org/licenses/ by/3.0), which permits unrestricted use, distribution, and reproduction in any medium, provided the original work is properly cited. (cc) BY 
Fabrication of Apatite Films on Ti Substrates of Simple and Complicated Shapes by Using Stable... DOI: http://dx.doi.org/10.5772/intechopen.80409

\section{References}

[1] Yang Y, Bumgardner JD, Cavin C, Carnes DL, Ong JL. Osteoblast precursor cell attachment on heat-treated calcium phosphate coatings. Journal of Dental Research. 2003;82:449-453

[2] Yoshinari M, Ohtsuka Y, Dérand T. Thin hydroxyapatite coating produced by the ion beam dynamic mixing method. Biomaterials. 1994;15:529-535

[3] Neuman WF, Neuman MW. The Chemical Dynamics of Bone Mineral. Chicago: The University of Chicago Press USA; 1958

[4] Yoshinari M, Ozeki K, Sumii T. The Bulletin of Tokyo Dental College. 1991;32:147

[5] Jansen JA, Wolke JGC, Swann S, Waerden JPCM, Groot K. Application of magnetron sputtering for producing ceramic coatings on implant materials. Clinical Oral Implants Research. 1993;4:28-34

[6] Yoshinari M, Klinge B, Dérand T. The biocompatibility (cell culture and histologic study) of hydroxy-apatitecoated implants created by ion beam dynamic mixing. Clinical Oral Implants Research. 1996;7:96-100

[7] Jing W, Yang L, Jiyong C, Chenge Z. Chemical gradient in plasmasprayed HA coatings. Biomaterials. 2000;21:1339-1343

[8] Oktar FN, Yetmez M, Agathopoulos A, Lopez Goerne TM, Goller G, Ipeker I, Ferreira JMF. Bond-coating in plasmasprayed calcium-phosphate coatings. Journal of Materials Science: Materials in Medicine. 2006;17:1161-1171

[9] Xu JL, Khor KA. Chemical analysis of silica doped hydroxyapatite biomaterials consolidated by a spark plasma sintering method. Journal of Inorganic Biochemistry. 2007;101:187-195

[10] Inagaki M, Kameyama T. Journal of Plasma and Fusion Research (in Japanese). 2007;83:595-600

[11] Klein CPAT, Wolke JGC, Blieck-Hogervorst JMA, Groot KA. Calcium phosphate plasma-sprayed coatings and their stability: An in vivo study. Journal of Biomedical Materials Research. 1994;28:909-917

[12] Cheang P, Khor KA. Addressing processing problems associated with plasma spraying of hydroxyapatite coatings. Biomaterials. 1996;17:537-544

[13] Ogiso M, Yamashita Y, Matsumoto T. Microstructural changes in bone of HA-coated implants. Journal of Biomedical Materials Research. 1998;39:23-31

[14] Liu DM, Yang Q, Troczynski T. Sol-gel hydroxyapatite coatings on stainless steel substrates. Biomaterials. 2002;23:691-698

[15] Kim HW, Kong YM, Bae CJ, Noh YJ, Kim HE. Sol-gel derived fluor-hydroxyapatite biocoatings on zirconia substrate. Biomaterials. 2004;25:2919-2969

[16] Bruce DW, O’Hare D. Inorganic Materials. Wet Sussex: John Wiley \& Sons; 1993. 519 p

[17] Leeuwenburgh SCG, Wolke JGC, Schoonman J, Jansen JA. Electrostatic spray deposition (ESD) of calcium phosphate coatings. Journal of Biomedical Materials Research. 2003;66A:330-334

[18] Leeuwenburgh SCG, Wolke JGC, Schoonman J, Jansen JA. Influence of precursor solution parameters on chemical properties of calcium 
phosphate coatings prepared using Electrostatic Spray Deposition (ESD). Biomaterials. 2004;25:641-649

[19] Siebers MC, Walboomers XF, Leeuwenburgh SCG, Wolke JGC, Jansen JA. The influence of the crystallinity of electrostatic spray deposition-derived coatings on osteoblast-like cell behavior, in vitro. Journal of Biomedical Materials Research. 2006;78A:258-267

[20] Siebers MC, Wolke JGC, Walboomers XF, Leeuwenburgh SCG, Jansen JA. In vivo evaluation of the trabecular bone behavior to porous electrostatic spray depositionderived calcium phosphate coatings. Clinical Oral Implants Research. 2007;18:354-361

[21] Zomeren AAV, Kelder EM, Marijnissen JCM, Schoonman J. The production of thin films of $\mathrm{LiMn}_{2} \mathrm{O}_{4}$ by electrospraying. Journal of Aerosol Science. 1994;25:1229-1235

[22] Siebers MC, Walboomers XF, Leeuwenburgh SCG, Wolke JGC, Jansen JA. Electrostatic spray deposition (ESD) of calcium phosphate coatings, an in vitro study with osteoblast-like cells. Biomaterials. 2004;25:2019-2027

[23] Sato M, Hara H, Niside T, Sawada Y. A water-resistant precursor in a wet process for $\mathrm{TiO}_{2}$ thin film formation. Journal of Materials Chemistry. 1996;6:1767-1770

[24] Nishide T, Sato M, Hara H. Crystal structure and optical property of $\mathrm{TiO}_{2}$ gels and films prepared from Ti-edta complexes as titania precursors. Journal of Materials Science. 2000;35:465-469

[25] Sato M, Hara H, Kuritani M, Nishide $\mathrm{T}$. Novel route to $\mathrm{Co}_{3} \mathrm{O}_{4}$ thin films on glass substrates via $\mathrm{N}$-alkyl substituted amine salt of Co(III)-EDTA complex. Solar Energy Materials \& Solar Cells. 1997;45:43-49
[26] Nagai H, Mochizuki C, Hara H, Takano I, Sato M. Enhanced UV-sensitivity of vis-responsive anatase thin films fabricated by using precursor solutions involving Ti complexes. Solar Energy Materials \& Solar Cells. 2008;92:1136-1144

[27] Nagai H, Hasegawa M, Hara H, Mochizuki C, Takano I, Sato M. An important factor controlling the photoreactivity of titania: O-deficiency of anatase thin film. Journal of Materials Science. 2008;43:6902-6911

[28] Nagai H, Sato M. Heat treatment in molecular precursor method for fabricating metal oxide thin films. In: Czerwinski F, editor. Heat TreatmentConventional and Novel Applications. Rijeka: InTech; 2012. pp. 103-124

[29] Takahashi K, Hayakawa T, Yoshinari M, Hara H, Mochizuki C, Sato M, Nemoto K. Molecular precursor method for thin calcium phosphate coating on titanium. Thin Solid Films. 2005;484:1-9

[30] Zablotsky M, Meffert R, Mills O, Burgess A, Lancaster D. The macroscopic, microscopic and spectrometric effects of various chemotherapeutic agents on the plasma-sprayed hydroxyapatite-coated implant surface. Clinical Oral Implants Research. 1992;3:189-198

[31] Ong JL, Lucas LC, Lacefield WR, Rigney ED. Structure, solubility and bond strength of thin calcium phosphate coatings produced by ion beam sputter deposition. Biomaterials. 1992;13:249-254

[32] Yang Y, Ong JL. Bond strength, compositional, and structural properties of hydroxyapatite coating on $\mathrm{Ti}, \mathrm{ZrO}_{2}$-coated $\mathrm{Ti}$, and TPS-coated Ti substrate. Journal of Biomedical Materials Research. 2003;64A:509-516 
[33] Hayakawa T, Yoshinari M, Kiba $\mathrm{H}$, Yamamoto H, Nemoto K, Jansen JA. Trabecular bond response to surface roughened and calcium phosphate (Ca-P) coated titanium implants. Biomaterials. 2002;23:1025-1031

[34] Hayakawa T, Yoshibari M, Nemoto K, Wolke JGC, Jansen JA. Effect of surface roughness and calcium phosphate coating on the implant/ bone response. Clinical Oral Implants Research. 2000;11:296-304

[35] Hayakawa T, Takahashi K, Yoshinari M, Okada H, Yamamoto H, Sato M, Nemoto K. Trabecular bone response to titanium implants with a thin carbonate-coating apatite coating applied using the molecular precursor method. International Journal of Oral \& Maxillofacial Implants. 2006;21:851-858

[36] Wolke JGC, van der Waerden JPCM, Schaeken HG, Jansen JA. In vivo dissolution behavior of various $R F$ magnetron-sputtered Ca-P coatings on roughened titanium implants. Biomaterials. 2003;24:2623-2629

[37] Hayakawa T, Takahashi K, Okada H, Yoshinari M, Hara H, Mochizuk C, Yamamoto H, Sato M. Effect of thin carbonate-containing apatite (CA) coating of titanium fiber mesh on trabecular bone response. Journal of Materials Science: Materials in Medicine. 2008;19:2087-2096

[38] Mochizuki C, Hara H, Takano I, Hayakawa T, Sato M. Application of carbonated apatite coating on a $\mathrm{Ti}$ substrate by aqueous spray method. Materials Science and Engineering: C. 2013;33:951-958

[39] Siebers MC, Matsuzaki K, Walboomers XF, Leeuwenburgh SCG, Wolke JGC, Jansen JA. Osteoblastic resorption of calcium phosphate coatings applied with electrostatic spray deposition (ESD), in vitro. Journal of Biomedical Materials Research. 2005;74:570-580

[40] Mochizuki C, Hara H, Oya K, Aoki S, Hayakawa T, Fujie H, Sato M. Behaviors of MC3T3-E1 cells on carbonated apatite films, with a characteristic network structure, fabricated on a titanium plate by aqueous spray coating. Materials Science and Engineering: C. 2014;39:245-252

[41] Sato K, Ikenoya O, Shimazu Y, Aoba T. Carbonation of enamel apatite crystals: Lattice substitutions and surface adsorption. Journal of Oral Biosciences. 1999;41:61-68

[42] Zheng XB, Huang MH, Ding CX. Bond strength of plasma-sprayed hydroxyapatite/Ti composite coatings. Biomaterials. 2000;21:841-849

[43] Yagi R, Mochizuki C, Sato M, Toyama T, Hirota M, Hayakawa T, Ohkubo C. Characterization and bone response of carbonate-containing apatite-coated titanium implants using an aqueous spray coating. Materials. 2017;10:1416

[44] Wennerberg A, Albrektsson T. Effects of titanium surface topography on bone integration: A systematic review. Clinical Oral Implants Research. 2009;20:172-184

[45] Lin A, Wang CJ, Kelly J, Gubbi P, Nishimura I. The role of titanium implant surface modification with hydroxyapatite nanoparticles in progressive early bone-implant fixation in vivo. The International Journal of Oral \& Maxillofacial Implants. 2009;24:808-816 



\author{
Mustafa Guven Gok and Gultekin Goller
}

\begin{abstract}
The fast consumption of fossil fuel resources and economic competitiveness makes it necessary to increase the efficiency of turbine engines. For this purpose, thermal barrier coating (TBC) has been used on some critical parts of gas turbines. Yttria-stabilized zirconia (YSZ) is widely and commercially used as a ceramic top coat material for TBC in the gas turbine system. On the other hand, the efforts to identify new material having better properties than YSZ have been continued. Gadolinium zirconate (GZ) is a promising alternative TBC material with its lower thermal conductivity, better sintering ability, and higher melting point and phase stability than YSZ. However, recent research studies on the responses of GZ-based TBC materials to the complex demands of modern gas turbine applications should be gathered under a study by comparing them with the results of traditional TBC material. This chapter discusses the GZ based TBC system, specifically addressing issues related to the production process and designing of the coating architecture, in comparison with some of the significant properties with YSZ and the test methodology. Moreover, the chapter also contains information about laser surface modification of the GZ-based TBC.
\end{abstract}

Keywords: thermal barrier coating, gadolinium zirconate, multilayered, functionally graded, thermal conductivity, thermal cycling, thermal shock, hot corrosion, CMAS resistance, laser surface modification

\title{
1. Introduction
}

Temperature acting on hot section of gas turbine goes up to about $1300^{\circ} \mathrm{C}$ during engine operation. However, metallic materials cannot be used at these temperatures due to harsh effect of the high temperature. Therefore, a thermal barrier coating (TBC) system is needed to satisfy effective protection to the metallic components of the gas turbine engines [1-3]. Generally, a conventional TBC system consists of four layers having different functions, as seen in Figure 1.

The first part of a TBC system is metallic substrate. Ni-based superalloys (INCONEL) are the most widely used metallic materials in parts of the turbine blade and combustion chamber due to their resistance to high-temperature conditions [4]. Therefore, the substrate material of the TBC system is generally INCONEL alloys. 


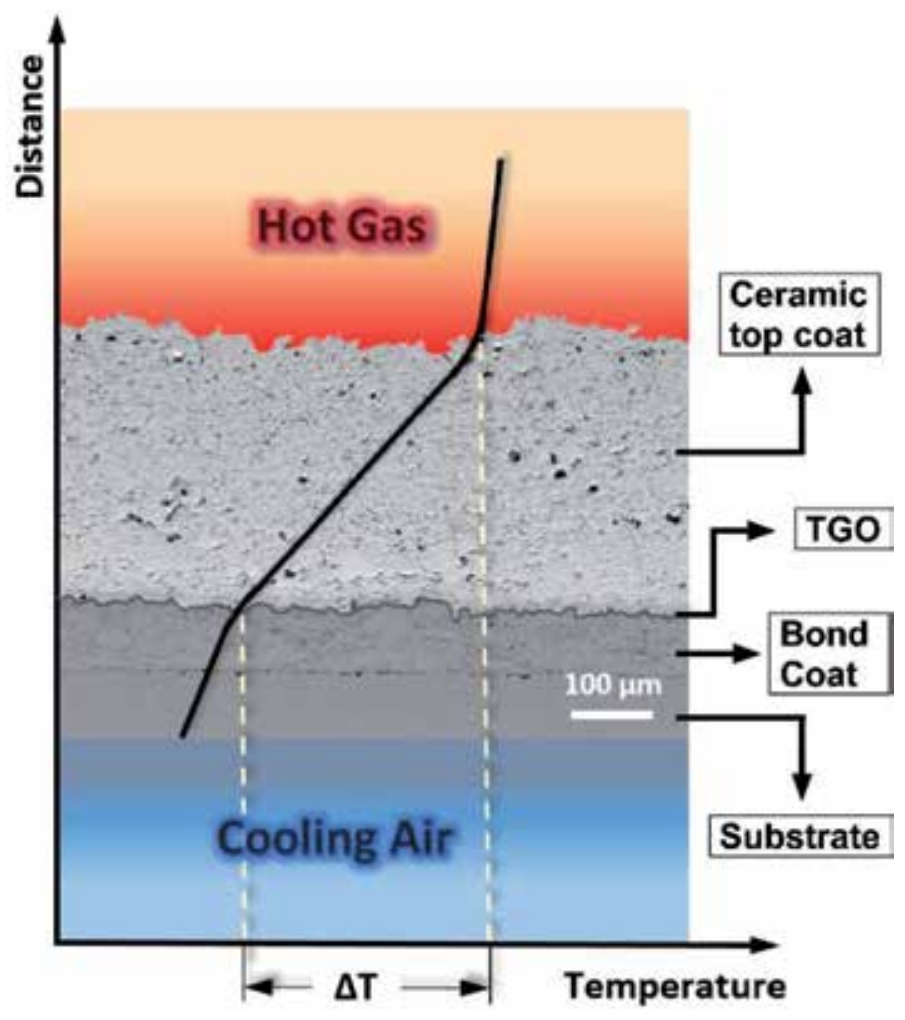

Figure 1.

Thermal barrier coating system.

The bond coat layer is the second part of the TBC system. The MCrAlY $(\mathrm{M}=\mathrm{Ni}$, $\mathrm{Co}$, or both of them alongside $\mathrm{Fe}$ ) bond coating powders are coated with a thickness of 75-150 $\mu \mathrm{m}$ on INCONEL substrate in different techniques such as high-velocity oxy-fuel (HVOF), atmospheric plasma spray (APS), suspension plasma spray (SPS), low-pressure or vacuum plasma spray (LPPS or VPS), and electron beamphysical vapor deposition (EB-PVD). HVOF is the most suitable method to produce the MCrAlY bond coating layer on the substrate due to its cheapness and sufficient characteristic properties [5]. The basic properties expected from the bond coating layer are as follows:

1. The bond coat should provide good oxidation resistance to metallic substrate.

2. The bond coat should provide good adherence between the metallic substrate and ceramic top coat.

3. The bond coat should tolerate the thermal expansion mismatch between the metallic substrate and ceramic top coat.

The third part of the TBC system is a thermally grown oxide (TGO, predominately alpha-alumina) layer between the top coat and bond coat. A very thin TGO layer forms on the bond coat during coating process due to oxidation of the bond coat at the process temperatures, but it grows while the TBC system in gas turbine is operating at high temperatures. This layer has importance because failure of the TBCs mostly happens at the interface between TGO layer and ceramic top coat layer when the thickness of TGO layer reaches a critical value. At elevated temperatures 
$\left(>950^{\circ} \mathrm{C}\right), \mathrm{Al}$ in the bond coat layer diffuses toward the bond coat layer/ceramic top coat layer interface. On the other hand, oxygen penetrates through the ceramic top coat layer and reacted with the Al. As a result, a TGO layer forms between the bond and the ceramic top coat [6-8].

The fourth and most important part of this system is ceramic top coat layer. Its principal role is to reduce the temperature of metallic substrate providing an insulation layer. Thus, efficiency of gas turbine engine is increased thanks to this thermal insulation layer, allowing higher turbine inlet temperatures (in the range of $100-300^{\circ} \mathrm{C}$ ) and reduced cooling requirements. The thickness of the ceramic top coating layer ranges between 100 and $500 \mu \mathrm{m}$ depending on the deposition method. Three different methods are used for the production of the ceramic top coat: (i) EB-PVD, (ii) APS, and (iii) SPS [1, 2, 7-14]. As seen in Figure 2, the main difference among these three methods is in the morphology of their microstructure.

APS coatings have a lamellar microstructure, while EB-PVD and SPS coatings have a columnar microstructure. Thus, ceramic top coating produced by APS technique has lower thermal conductivity due to microporosities between the lamellae. On the other hand, microporosities between the columns provide higher expansion tolerances in the ceramic top coating produced by EB-PVD and SPS techniques. The APS and SPS processes are more suitable for coating large parts and cheaper than EB-PVD process [10]. Static and stationary parts of the gas turbines are coated with a ceramic insulating material using APS process. A ceramic top coating layer suffers from the severe environmental effects of high temperature such as oxidation, hot

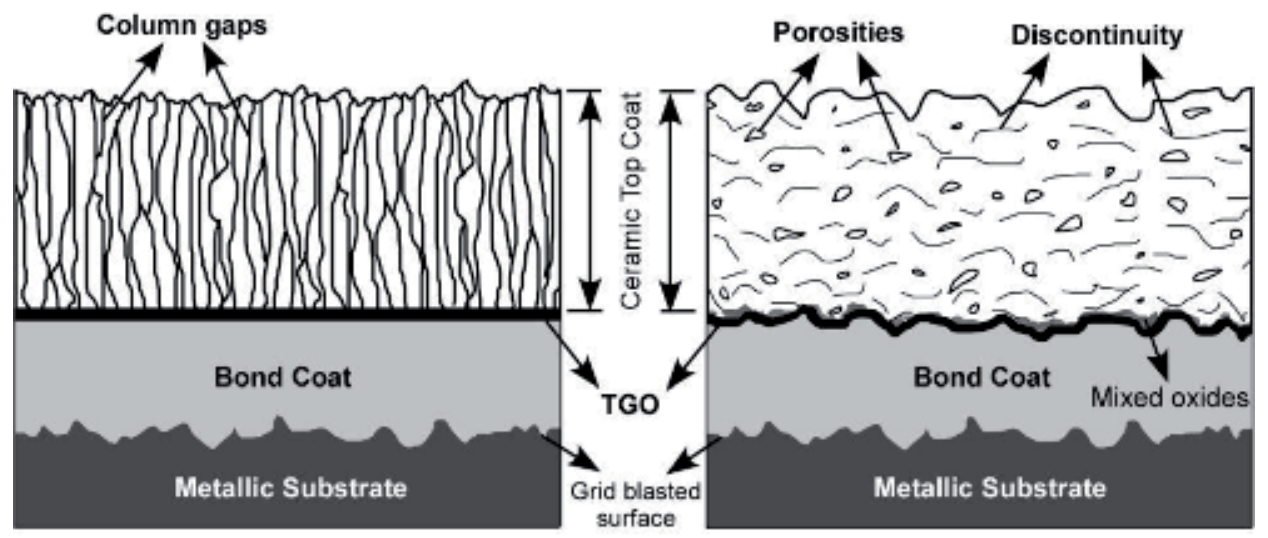

(a)

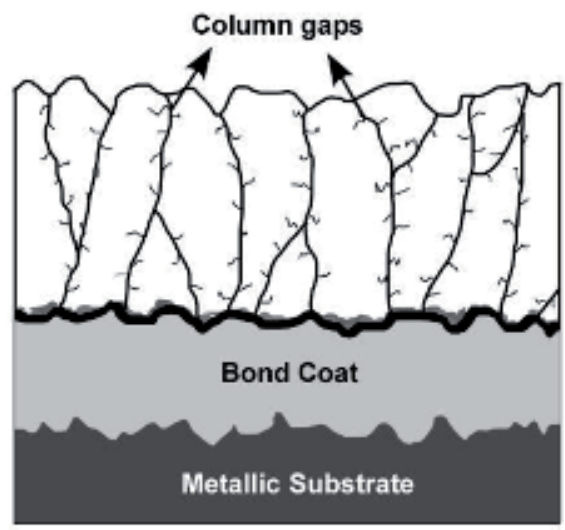

(b)

(c)

Figure 2.

Schematic general structures of TBC produced by (a) EB-PVD method, (b) APS method, and (c) SPS method. 
corrosion, wear, and flying ash damage. Therefore, a ceramic top coating material should have some important characteristic properties [15-17]. The basic properties expected from the ceramic top coating material can be listed as follows:

1. A ceramic top coating material should have high melting temperature to resist to the high temperature of gas plasma.

2. A ceramic top coating material should have low thermal conductivity to provide good insulation to the metallic substrate.

3. A ceramic top coating material should have high thermal expansion coefficient to match with the metallic bond coat and substrate's thermal expansion coefficient.

4. Phase structure of a ceramic top coating material should stay stable from room temperature to operating temperature.

5. A ceramic top coating material should adhere well to the metallic substrate.

6. A ceramic top coating material should have low sintering rate.

7. A ceramic top coating material should have high resistance to erosion, corrosion, and oxidation.

So far, no single coating material has been found which can fully meet all these properties listed above. However, it is believed that the best material that partially meets these properties is 6-8 wt\% yttria-stabilized zirconia (YSZ) for more than 35 years now. Therefore, YSZ is widely and commercially used as a ceramic top coat for TBC in the gas turbine system at the present time. Although an alternative material has not yet been developed for YSZ, studies continue. These studies are important because YSZ has some undesirable properties, limiting working conditions of gas turbine listed below:

1. Above $1200^{\circ} \mathrm{C}$, a diffusionless phase transformation from metastable tetragonal $\left(t^{\prime}\right)$-phase to tetragonal ( $t$ ) and cubic (c) phase occurs above that temperature. This tetragonal phase transforms into monoclinic phase with a high volume change during cooling, and this phenomenon causes severe damages in the coating.

2. The porosity of the coating decreases due to sintering occurring above $1200^{\circ} \mathrm{C}$, and thermally induced stresses come into existence. Failure possibility increases on the YSZ-based TBC due to these stresses.

3. YSZ has a high concentration of oxygen ion vacancies. Above $1200^{\circ} \mathrm{C}$, these ion vacancies promote to oxygen transportation. Hence, a TGO layer forms between the bond coat and the ceramic top coat. When the thickness of this TGO layer reaches a critical value, spallation takes place in the ceramic top coating layer.

4. YSZ can be easily and seriously damaged from the hot corrosion induced by the existence of $\mathrm{Na}_{2} \mathrm{SO}_{4}+\mathrm{V}_{2} \mathrm{O}_{5}$ salts coming from low-quality jet fuel and $\mathrm{Ca}-\mathrm{Mg}$-Al-silicate (CMAS) attack caused by flying ash. Both of them give rise to deterioration and spallation of the coating. 
State of the Art of Gadolinium Zirconate Based Thermal Barrier Coatings: Design, Processing... DOI: http://dx.doi.org/10.5772/intechopen.85451

As a result of these undesirable properties:

1. The maximum use temperature use of YSZ is limited to below $1200^{\circ} \mathrm{C}$.

2. YSZ is vulnerable to the hot corrosion and CMAS attack.

However, the TBC material of advanced next-generation powerful gas turbine engines must be able to operate without any damage both in harsh environments (under hot corrosion and CMAS attack) and at temperatures above $1200^{\circ} \mathrm{C}$. The increase in efficiency in turbine engines is directly proportional to the increase in engine power and turbine inlet temperature. Therefore, an alternative ceramic top coat material having much better thermal properties than YSZ should be developed to be able to produce next-generation turbine engines. However, it is not easy to find a new material that will be an alternative to the YSZ $[8,13,14,18-21]$ because it requires a lot of experimental study, data, and evaluation.

Gadolinium zirconate $\left(\mathrm{Gd}_{2} \mathrm{Zr}_{2} \mathrm{O}_{7}\right.$ or $\left.\mathrm{GZ}\right)$ with pyrochlore or defect fluoritetype structure is a new and promising alternative ceramic top coating material to YSZ. The most important features that make it advantageous are given below:

1. GZ has higher thermal stability at elevated temperatures $\left(>1200^{\circ} \mathrm{C}\right)$ than YSZ. Therefore, it can be used at temperatures above $1200^{\circ} \mathrm{C}$.

2. GZ has lower thermal conductivity $\left(1.3 \mathrm{~W} / \mathrm{mK}^{-1}\right.$ at $\left.1100^{\circ} \mathrm{C}\right)$ than $\mathrm{YSZ}$ $\left(1.8 \mathrm{~W} / \mathrm{mK}^{-1}\right.$ at $\left.1100^{\circ} \mathrm{C}\right)$. Thus, GZ provides better thermal insulation to the metallic substrate than YSZ.

3. GZ has more superior hot corrosion resistance than YSZ. Thanks to this feature, elements emitted due to fuel pollution are less harmful to the GZ-based TBC.

4. GZ has more resistance to the CMAS attack than YSZ. Because the CMAS powders (particles such as dust, volcanic ash, rock, etc.) entering to turbine melt at about $900{ }^{\circ} \mathrm{C}$ and try to penetrate through the coating surface. Porosities of the TBC are filled with CMAS, and thus strain incompatibility of the TBC is limited. This molten CMAS cannot penetrate to GZ-based TBC due to the sealing layer formed on the surface of the GZ-based TBC.

Thanks to these advantageous features, GZ seems to be the most efficient alternative TBC material for advanced next-generation powerful gas turbine engines. However, besides all of these advantages, GZ has two poor properties affecting its thermal cycling (TC) behavior in a negative manner. One of them is its low coefficient of thermal expansion (CTE, $10.4 \times 10^{-6} \mathrm{~K}^{-1}$ and $11 \times 10^{-6} \mathrm{~K}^{-1}$ for GZ and YSZ, respectively), and another one is its high tendency to react with the TGO layer $[8,9,13,14,19,21-32]$. These problems were solved by using multilayered (MLed) and functionally graded (FGed) designs. In these MLed and FGed systems, a second material balances the poor properties (i.e., CTE) of other materials and improves TC performance of TBCs. On the other hand, the reaction between coating layer and TGO which fails the TC performance of rare earth zirconate will be prevented owing to a third layer between GZ and TGO layers $[8,13,14]$.

The purpose of this chapter is to summarize the properties of GZ-based thermal barrier coatings. Their production techniques, coating designs, thermal conductivities, thermal cycling behaviors, mechanical properties, hot corrosion and CMAS resistance, and laser surface modification process were compiled in the following sections to form a meaningful whole. 


\section{Coating process and coating architectures}

\subsection{Production of gadolinium zirconate-based thermal barrier coatings}

The performance and many properties of the TBC mainly depend on the microstructure and hence the production techniques. In literature, gadolinium zirconatebased thermal barrier coatings have been produced by different techniques such as the air plasma spraying (APS) $[8,13,14]$, suspension plasma spraying (SPS) $[25,30]$, and electron beam-physical vapor deposition (EB-PVD) [20,33].

In a study, GZ-based TBC was produced as single layered on metallic bond coat using the APS process [13]. The surface and cross-sectional microstructure of plasma-sprayed GZ-based TBC were shown in Figure 3. The surface roughness $(\mathrm{Ra})$ was $8.3 \mu \mathrm{m}$, and typical surface properties (such as unmelted particles and open porosities) of APSed TBCs could be seen in Figure 3a. The micrographs demonstrate typical characteristic microstructure defects of APSed thermal barrier coatings such as cracks, both parallel (at splats boundaries) and normal to the metal/ceramic interface, and porosities. The interface between ceramic top coat/ bond coats seems continuous and durable.

As seen in Figure 4, XRD patterns of GZ powder having an as-sprayed GZ-based coating proved that there was no decomposition after plasma spraying [8]. Both patterns had a cubic fluorite-type structure of GZ with the space group of $\mathrm{Fm} 3 \mathrm{~m} . \mathrm{Gd}_{2} \mathrm{Zr}_{2} \mathrm{O}_{7}$ phase was maintained its stable position after APS process. Carpio et al. [23] showed that YSZ- and GZ-based TBCs had the same porosity value when

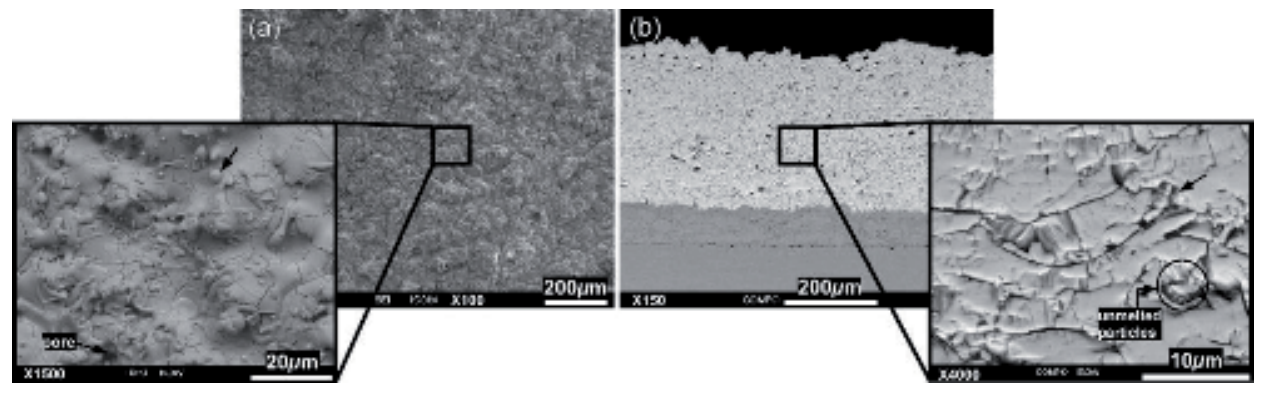

Figure 3.

(a) Surface and (b) cross-sectional SEM images of atmospheric plasma-sprayed GZ coating.

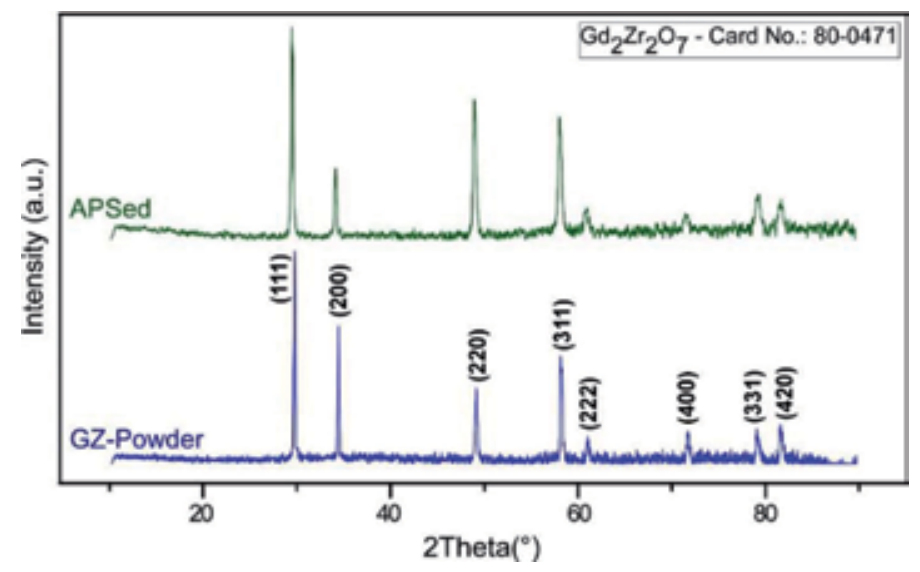

Figure 4.

The XRD patterns of powder and atmospheric plasma-sprayed GZ coating. 
the same APS parameters were used. These results indicate that there is no microstructural problem in producing GZ by APS.

In different studies $[25,30]$, GZ-based TBCs were successfully produced on YSZ by suspension plasma spraying (SPS) process. SPSed GZ-based TBCs had nonporous and crack-free interface between the different top coat layers. In addition, SPSed GZ-based TBCs had a columnar microstructure having orientation perpendicular to the top surface which is a characteristic of the process. On the other hand, it is possible to obtain denser coating morphology by increasing droplet size via changing SPS parameters. Bozbin et al. [33] produced TBCs having GZ-based ceramic top coat by EB-PVD technique. The morphology of TBCs was columnar. This morphology was a characteristic of the coating produced by EB-PVD process. They showed that morphology of the GZ-based TBCs could be controlled by deposition process and temperature. The results of these studies $[8,13,14,20,25,30,33]$ proved that $\mathrm{GZ}$ is a suitable material to be coated with different TBC production processes (such as APS, SPS, and EB-PVD).

\subsection{Design of gadolinium zirconate-based thermal barrier coatings}

Despite all the superior thermophysical properties of the single-layered GZ-based TBC, its thermal cycling lifetime is poor. Multilayered (as seen in Figure 5a-c) and functionally graded (as seen in Figure $5 \mathbf{d}$ and $\mathbf{e}$ ) coating designs with a second TBC material have been used to overcome this problem [16]. In the multilayered (MLed) TBCs, there are two or more coating layers having different functions. On the other hand, a functionally graded (FGed) coating has gradual compositional variation in the layers. In these systems, a second material having higher coefficient of thermal expansion (CTE) balances the CTE of the system and improves TC performance of TBCs. The residual stress on the MLed and FGed coatings is lower than that of single-layered GZ $[8,14,34]$. The reaction between coating layer and TGO has been prevented owing to a second material adjacent to the top of the bond coat $[8,14]$.

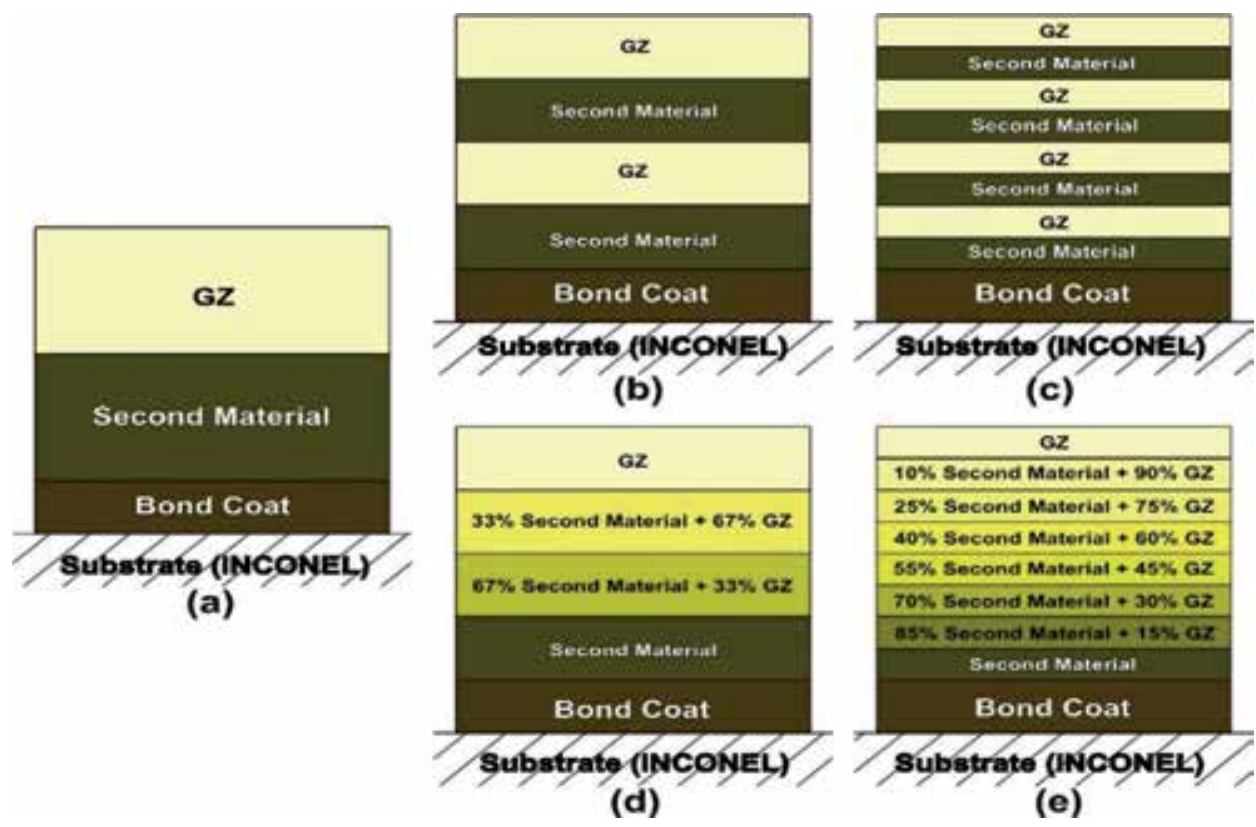

Figure 5.

Schematic view of multilayered $(a-c)$ and functionally graded $(d, e)$ coating designs. 
In a previous study [8], MLed and FGed gadolinium zirconate-based TBCs were produced in 2, 4, 8, and 12 layered by APS process. In this study, CYSZ was used as the second material because its CTE $\left(13 \times 10^{-6} \mathrm{~K}^{-1}\right)$ was better than that of GZ $\left(10.4 \times 10^{-6} \mathrm{~K}^{-1}\right)$. While producing a MLed system, CYSZ or GZ was sprayed to each layer. On the other hand, GZ and CYSZ powders were mixed at different ratios in a turbula-type mixer to obtain different compositions, and these mixtures of powders were sprayed to each layer. The average thickness of the ceramic top coat was $350 \mu \mathrm{m}$. The interfaces between CYSZ and GZ layers were distinguishable, but there were no distinguishable interfaces between the different layers of FGed coatings. The following results were obtained from this study:

1. GZ and CYSZ powders sufficiently melted in the plasma flame.

2. Coating layers had characteristic microstructural defects of APSed TBCs.

3. Good lamination was achieved between GZ and CYSZ layers.

4. Porosity level of the ceramic top coating increased with the increasing number of layers.

The increase in the porosity level was explained by discontinuous coating process of MLed and FGed designs (layer-by-layer spraying).

In a study, double-layered and functionally graded GZ/YSZ coatings having five layers were produced with the thickness of $\sim 200 \mu \mathrm{m}$ by APS process [23]. In the functionally graded GZ/YSZ TBC, ratio of the GZ to YSZ was different in each layer but bottom and top most layer were $100 \%$ YSZ and GZ, respectively. Researchers used two independent feeders to feed GZ and YSZ powders to the plasma flame, separately. Thus, there was no need to mix the powders before the APS process. Thanks to this system, different compositions could be obtained in each layer at the desired grade. It could be understood that it was possible to deposit the GZ and YSZ with functionally graded design by APS.

Mahade et al. $[9,29,30]$ produced a double-layered GZ/YSZ and a triple-layered GZ dense/GZ/YSZ TBC by SPS process. The schematic view of their design was given in Figure 6. The morphology of the coatings was columnar, which was characteristic of the SPS, but dense in the topmost layer of the triple system. They aimed to increase the CMAS resistance of TBC thanks to a dense GZ layer on the topmost layer of triple-layered system. The density of coating layer was adjusted by changing the SPS parameters such as temperature and gas flow. The microstructure
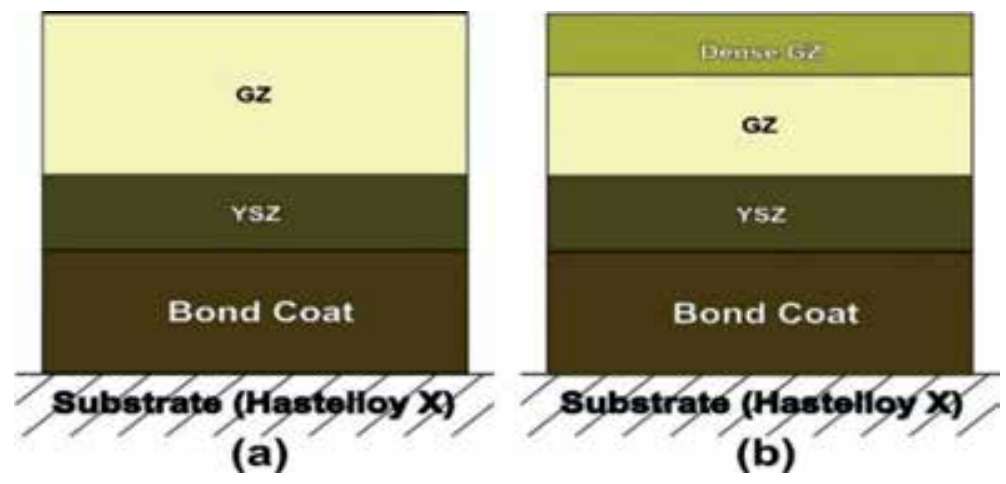

Figure 6.

Schematic view of GZ/YSZ (a) double-layered and (b) triple-layered systems [9, 29, 30]. 
from the top surface of double-layered GZ/YSZ TBC was resembling a cauliflower, but top surface morphology of triple-layered TBC was denser due to dense GZ layer.

Mutilayered GZ/YSZ TBCs having ten layers were deposited by EB-PVD process [35]. In addition, nano-layered GZ/YSZ TBCs having 200 nm layer thickness were produced by the same process. The production of multilayered TBCs was carried out by alternating layers of GZ and YSZ during deposition. As expected, the morphology of the coating was columnar. These results proved that GZ-based TBCs could be deposited with different techniques and designs to improve some of their properties by using a second coating material.

\section{Thermal properties}

\subsection{Thermal conductivity of gadolinium zirconate-based thermal barrier coatings}

It can be said that the thermal conductivity is the most important property of the TBC. Therefore, mechanisms of heat transfer of the TBC material have a great significance. The phonons are primarily responsible for thermal conduction of ceramic materials. So thermal resistivity of the ceramic materials depends on the scattering of phonons. There are a lot of ways to scattering of phonons. One of them is to disturb the lattice vibration with additional scattering centers such as crystallographically changing to a lower symmetry, presence of different atoms inside a unit cell, porosities, grain boundaries, and impurities. As the number of these scattering centers increases, the thermal conductivity decreases [16]. Therefore, $\mathrm{Gd}_{2} \mathrm{Zr}_{2} \mathrm{O}_{7}$ having pyrochlore and disordered fluorite structure has low thermal conductivity due to the oxygen vacancies in the unit cell.

Table 1 summarizes the lowest and highest thermal conductivity values of the GZ- and YSZ-based TBCs at specific temperature ranges produced by different techniques and having different coating designs. In addition, the thermal conductivity data of YSZ-based TBCs were given in Table 1. As understood from the data in the table, the thermal conductivity of the coating was influenced by the production method. This difference is entirely related to the different characteristics of microstructural morphology of the production processes. The lowest thermal conductivity values were obtained in the TBCs produced by APS due to its porous and lamellar morphology containing a lot of defects such as unmelted particles and cracks at splat boundaries. They acted as phonon scattering centers. On the other hand, thermal conductivity values of the TBCs produced by SPS and EB-PVD technique were higher than the TBCs produced by APS. This was because columnar morphology of the TBCs is produced by SPS and EB-PVD. Moreover, it is seen that the GZ-based TBCs had lower thermal than the YSZ-based TBCs produced by the same method and having the same design. This situation could be explained by oxygen vacancies acting as phonon scattering centers in the unit cell of GZ-based TBCs.

MLed and FGed GZ/CYSZ TBCs consisting 2, 4, 8, and 12 layers were produced by APS technique, and their thermal conductivity was analyzed by laser flash method [8]. Thermal conductivity values of the single-layered GZ and MLed and FGed GZ/CYSZ TBCs were lower than single-layered YSZ TBC $\left(0.91-1.79 \mathrm{~W} / \mathrm{mK}^{-1}\right.$ at $25-1105^{\circ} \mathrm{C}$ ). Results showed that the lowest thermal conductivity values at $1105^{\circ} \mathrm{C}$ were achieved for ML12 and FG12 coatings having the highest number of layers. From this point of view, it was concluded that thermal conductivity value decreased by increasing the number of layers. This situation was attributed to the interfaces of the layered periodicity and increasing porosity level by increasing number of layers. Because these porosities and interfaces between GZ and CYSZ phases in the MLed 


\begin{tabular}{|c|c|c|c|c|c|}
\hline Design & Composition & $\begin{array}{l}\text { Production } \\
\text { technique }\end{array}$ & $\begin{array}{c}\text { Thermal } \\
\text { conductivity (W/ } \\
\left.\text { mK }^{-1}\right)\end{array}$ & $\begin{array}{l}\text { Temperature } \\
\left({ }^{\circ} \mathrm{C}\right)\end{array}$ & Reference \\
\hline Single layered & GZ & \multirow[t]{3}{*}{ APS } & $0.81-1.36$ & \multirow[t]{3}{*}{ 25-1105 } & \multirow[t]{3}{*}{ [8] } \\
\hline Multilayered & GZ/CYSZ & & $0.63-1.76$ & & \\
\hline $\begin{array}{l}\text { Functionally } \\
\text { graded }\end{array}$ & & & $0.56-1.55$ & & \\
\hline Single layered & GZ & APS & $0.59-1.50$ & $25-1100$ & [31] \\
\hline Single layered & GZ & \multirow[t]{3}{*}{ SPS } & $0.62-1.07$ & \multirow[t]{3}{*}{$25-1000$} & \multirow[t]{3}{*}{ [29] } \\
\hline Multilayered & GZ/YSZ & & $0.69-1.19$ & & \\
\hline Multilayered & GZ dense/GZ/YSZ & & $0.74-1.42$ & & \\
\hline Multilayered & GZ/YSZ & \multirow[t]{2}{*}{ SPS } & $0.70-0.90$ & \multirow[t]{2}{*}{ 25-1200 } & \multirow[t]{2}{*}[30]{} \\
\hline Multilayered & GZ dense/GZ/YSZ & & $0.82-1.24$ & & \\
\hline Single layered & GZ & \multirow[t]{2}{*}{ EB-PVD } & $1.10-2.10$ & \multirow[t]{2}{*}{$400-1300$} & \multirow[t]{2}{*}[33]{} \\
\hline Multilayered & GZ/YSZ & & $1.60-2.10$ & & \\
\hline Single layered & GZ & \multirow[t]{2}{*}{ EB-PVD } & $1.13-1.42$ & \multirow[t]{2}{*}{ 25-1316 } & \multirow[t]{2}{*}[35]{} \\
\hline Multilayered & $\mathrm{GZ} / \mathrm{YSZ}+\mathrm{Yb}_{2} \mathrm{O}_{3}+\mathrm{Gd}_{2} \mathrm{O}_{3}$ & & $1.10-1.22$ & & \\
\hline Fully dense & GZ & Sintering & $1.47-1.83$ & $25-1400$ & {$[28]$} \\
\hline Fully dense & GZ & Sintering & $1.65-2.05$ & 200-1000 & [3] \\
\hline Fully dense & GZ & Sintering & 1.60 & 700 & {$[17]$} \\
\hline Single layered & YSZ & APS & $0.91-1.79$ & $25-1105$ & {$[8]$} \\
\hline Single layered & YSZ & SPS & $1.57-1.96$ & $25-1000$ & [29] \\
\hline Single layered & YSZ & EB-PVD & $1.38-1.62$ & $400-1300$ & [33] \\
\hline Fully dense & YSZ & Sintering & 2.3 & 700 & [17] \\
\hline
\end{tabular}

Table 1.

Thermal conductivity of GZ-and YSZ-based materials produced via different processes and having different designs.

and FGed designs acted as phonon scattering centers and reduced phonon conduction. Moreover, hemispherical reflection, that is, reduced phonon conduction, was thought to be active in the MLed and FGed designs. A similar phenomenon regarding the increasing hemispherical reflection by increasing the number of layers was reported in other studies [36].

Moskal et al. [31] produced single-layered GZ and YSZ TBCs by APS processes and compared their thermal conductivity at the temperatures between 25 and $1100^{\circ} \mathrm{C}$. According to the results, GZ-based TBC had lower thermal conductivity $\left(0.59-1.50 \mathrm{~W} / \mathrm{mK}^{-1}\right)$ than YSZ-based TBC $\left(0.8-2.25 \mathrm{~W} / \mathrm{mK}^{-1}\right)$. Moreover, differences between the thermal conductivity values of the GZ and YSZ were higher at higher temperatures $\left(900-1100^{\circ} \mathrm{C}\right)$. In different studies [29, 30], Mahade et al. produced single-layered YSZ, double-layered GZ/YSZ, and triple-layered GZ dense/GZ/YSZ TBCs by SPS process. The thickness of the layers was different in the studies. As a result of thermal conductivity measurements, they showed that single-layered YSZ-based TBC had higher thermal conductivity than that of doublelayered and triple-layered GZ-based systems. This situation was attributed to both oxygen vacancies in the crystal structure and larger difference between atomic weights of the cations of the GZ-based TBC. In another study [35], single-layered $\mathrm{GZ}$ and multilayered GZ/YSZ $+\mathrm{Yb}_{2} \mathrm{O}_{3}+\mathrm{Gd}_{2} \mathrm{O}_{3}$ TBCs were produced by EB-PVD process and analyzed their thermal conductivities at temperatures between 25 and 
$1316^{\circ} \mathrm{C}$. They observed slight reduction in the thermal conductivity of the coatings thanks to multilayered design (1.13-1.42 and 1.10-1.22 W/mK ${ }^{-1}$ ) for single and multilayered systems, respectively. This decrease was tried to be explained by increasing porosity and hemispherical reflection of the multilayered design. In the case of sintering (fully dense material), GZ had lower thermal conductivity than YSZ (1.6-2.3 W/mK $\mathrm{m}^{-1}$ at $700^{\circ} \mathrm{C}$ for $\mathrm{GZ}$ and YSZ, respectively) due to the higher concentration of oxygen vacancies of $\mathrm{GZ}$ and atomic weight difference between $\mathrm{Gd}$ and $\mathrm{ZrO}_{2}$ [17]. These oxygen vacancies and atomic weight differences gave rise to an effective phonon scattering.

\subsection{Mechanical properties of gadolinium zirconate-based thermal barrier coatings}

Table 2 shows some of the mechanical properties of YSZ- and GZ-based TBCs produced by APS and sintering techniques. The bonding strength of a coating to a substrate or cohesion strength of the coating has been determined by using adhesion test. This test has been carried out according to the ASTM C-633 standard test method. The bonding strengths of GZ/CYSZ multilayered and functionally graded TBCs that were produced by APS were determined by using ASTM C-633 test method [8]. The bonding strength values of the single-layered GZ and MLed and FGed GZ/CYSZ TBCs having 2, 4, 8, and 12 layers changed between 8.87 and 12.1 $\mathrm{MPa}$. This changing in the bonding strength was attributed to the changing porosity level of the coatings. As the porosity value increased, the adhesion strength of the coating decreased. On the other hand, bonding strength values of the GZ-based TBCs (8.87-12.1 MPa) were comparable to single-layered YSZ-based TBC (10.1 MPa) produced by the same technique [37]. Fracture type of the singlelayered GZ coating was fully adhesive (fracture at the bond coat/ceramic top coat interface), but complex adhesive/cohesive fracture was seen (fracture both bond coat/ceramic top coat interface and within the ceramic top coat layers) in the MLed and FGed coatings. No fracture was observed at the bond coat/substrate interface.

Carpio et al. [23] analyzed the hardness of double-layered and functionally graded GZ/YSZ TBCs produced by APS. The hardness values of the TBCs were 4.0 and 4.1 for double-layered and functionally graded GZ/YSZ, respectively. On the

\begin{tabular}{|c|c|c|c|c|c|c|}
\hline Design & Composition & $\begin{array}{l}\text { Production } \\
\text { technique }\end{array}$ & $\begin{array}{c}\text { Bonding } \\
\text { strength } \\
(\mathrm{MPa})\end{array}$ & $\begin{array}{l}\text { Hardness } \\
\text { (GPa) }\end{array}$ & $\begin{array}{c}\text { Elasticity } \\
\text { modulus } \\
(\mathrm{GPa})\end{array}$ & Reference \\
\hline Single layered & GZ & \multirow[t]{3}{*}{ APS } & 12.10 & - & - & [8] \\
\hline Multilayered & \multirow[t]{2}{*}{ GZ/CYSZ } & & 8.87-10.18 & & & \\
\hline $\begin{array}{l}\text { Functionally } \\
\text { graded }\end{array}$ & & & $9.21-10.68$ & & & \\
\hline Double layered & \multirow[t]{2}{*}{ GZ/YSZ } & \multirow[t]{2}{*}{ APS } & \multirow[t]{2}{*}{-} & 4.0 & \multirow[t]{2}{*}{-} & \multirow[t]{2}{*}{ [23] } \\
\hline $\begin{array}{l}\text { Functionally } \\
\text { graded }\end{array}$ & & & & 4.1 & & \\
\hline Single layered & YSZ & APS & 10.1 & - & - & [37] \\
\hline Fully dense & GZ & Sintering & - & 10.0 & 205 & [17] \\
\hline Fully dense & GZ & Sintering & - & 6.0 & 215 & [3] \\
\hline
\end{tabular}

Table 2.

Mechanical properties of GZ-and YSZ-based materials produced via different processes and having different designs. 
other hand, hardness value of the sintered (fully dense) GZ was changing between 6.0 and $10.0 \mathrm{GPa}[3,17]$. The reason of this increase in the hardness was related with the reduction of porosity and cracks after sintering process. It is suggested to investigate the mechanical properties of the GZ-based TBCs produced by EB-PVD technique in future works.

\subsection{Thermal cycling and thermal shock performance of gadolinium zirconate-based thermal barrier coatings}

Thermal cycling performance test has been generally conducted by heating the TBCs to the exact temperatures in exact time, holding them at that temperature in exact time and cooling them to a certain temperature. Therefore, the failure mechanism in the TBC that is exposed to the thermal cycle test is associated with the stress produced by growth and shrinkage of TGO during heating and cooling. As a result, complex failure morphologies such as cracks propagating within the $\mathrm{TBC}$, at TBC/TGO and TGO/bond coat interface, come into existence. On the other hand, thermal shock test has been carried out by sudden heating and cooling of the TBCs. Thermal shock resistance of the TBC material depends on the its thermal expansion coefficient, elastic module, fracture resistance, and phase transformation phenomenon.

As already mentioned before (introduction part), GZ has very advantageous properties (low thermal conductivity, high phase stability and higher CMAS, and hot corrosion resistance than YSZ) as TBC material, but its thermal cycle and thermal shock performance is poor. Therefore, works on GZ-based TBC are focused on improving its thermal cycling and thermal shock performance. Thermal cycling performance of the MLed and FGed GZ/CYSZ TBCs was tested by using gas burner method (oxy-propane flame) [8]. TBCs were heated to $1250^{\circ} \mathrm{C}$ for $1 \mathrm{~min}$ and cooled below $150^{\circ} \mathrm{C}$ by using air jet. According to the results, single-layered GZ fully spalled after 165 cycles, and there was a small edge spallation in the MLed GZ/ CYSZ TBCs after 300 cycles. However, there was no visible spallation in the FGed GZ/CYSZ TBCs even after 300 cycles. The microstructural characterizations of MLed and FGed GZ/CYSZ TBCs after thermal cycling test revealed that TGO layer played an active role on the spallation of single-layered GZ. In the case of MLed GZ/CYSZ TBCs, horizontal cracks propagating inside the ceramic coating layers were observed. On the other hand, there was no microcrack or spallation in the FGed GZ/CYSZ TBCs. It was concluded that an improvement in the thermal cycling performance of the single-layered GZ TBC took place thanks to MLed and FGed designs. Furthermore, GZ/CYSZ TBCs having FGed design had superior thermal cycling performance than that of MLed design. As a continuation of the previous work, in another study [14], these TBCs (MLed and FGed GZ/CYSZ coatings) were subjected to the thermal shock test. During the test, the TBCs were directly placed to the furnace at $1250^{\circ} \mathrm{C}$ and hold for $5 \mathrm{~min}$. Then they were dropped into the cold water. As seen in Figure 7, single-layered GZ and YSZ (sample codes: GZ1 and YSZ1, respectively) TBCs were subjected to the thermal shock test as reference samples as well as MLed and FGed TBCs, and the number of cycles to failure for each coating was written on the images. The failure or spallation took place on the coating of single-layered GZ1 after only ten cycles. On the other hand, a significant improvement happened in the thermal shock lifetime of the MLed and FGed TBCs.

This improvement in thermal shock lifetime of TBCs having MLed and FGed designs was ascribed to the decreasing high thermal mismatch stress generated due to the sharp differences in the CTE between bonding layer and CYSZ and GZ phases. As mentioned before CYSZ had higher CTE $\left(13 \times 10^{-6} \mathrm{~K}^{-1}\right)$ than GZ $\left(10.4 \times 10^{-6} \mathrm{~K}^{-1}\right)$. Therefore, large thermal expansion mismatch among ceramic 
layers, metallic bond coat, and substrate was balanced thanks to gradual compositional variation of CYSZ layers having in GZ layers. Furthermore, microstructural evaluations were carried out on GZ/CYSZ MLed and FGed TBCs exposed to thermal shock test. Microstructures of the GZ-based TBCs after thermal test showed the evidence of the thermal stress on the ceramic layer. The vertical, horizontal, and propagating cracks were formed on the ceramic top layers. Propagating cracks are located around the vertical cracks. The shape of the vertical cracks was looking like capillary vessels. Other than this, there were penetrating cracks forming in the TGO layer and penetrating into the bond coat. A similar microstructure regarding the shape of the cracks of thermally cycled TBCs was reported in other studies $[23,38]$. As a result, the improvement in thermal shock life of GZ-based TBCs was directly reducing the thermal mismatch among the layers thanks to CYSZ. Furthermore, from the microstructures, it was assumed that energy of thermal fatigue cracks absorbed at the interface between GZ and CYSZ layers or splats causing improvement in thermal shock life.

In a study [22], double-layered GZ/YSZ TBCs were produced by APS technique so as to have different porosity values. Then thermal cycling behavior of the TBCs were tested at $1400^{\circ} \mathrm{C}$ by using a gas flame (for heating) and air jet (for cooling). Results showed that thermal cycling lifetime of the single-layered GZ was significantly improved thanks to a double-layered design. Moreover, GZ/YSZ TBCs having the highest porosity level (\%32) withstood up to 1627 thermal cycles. Carpio et al.
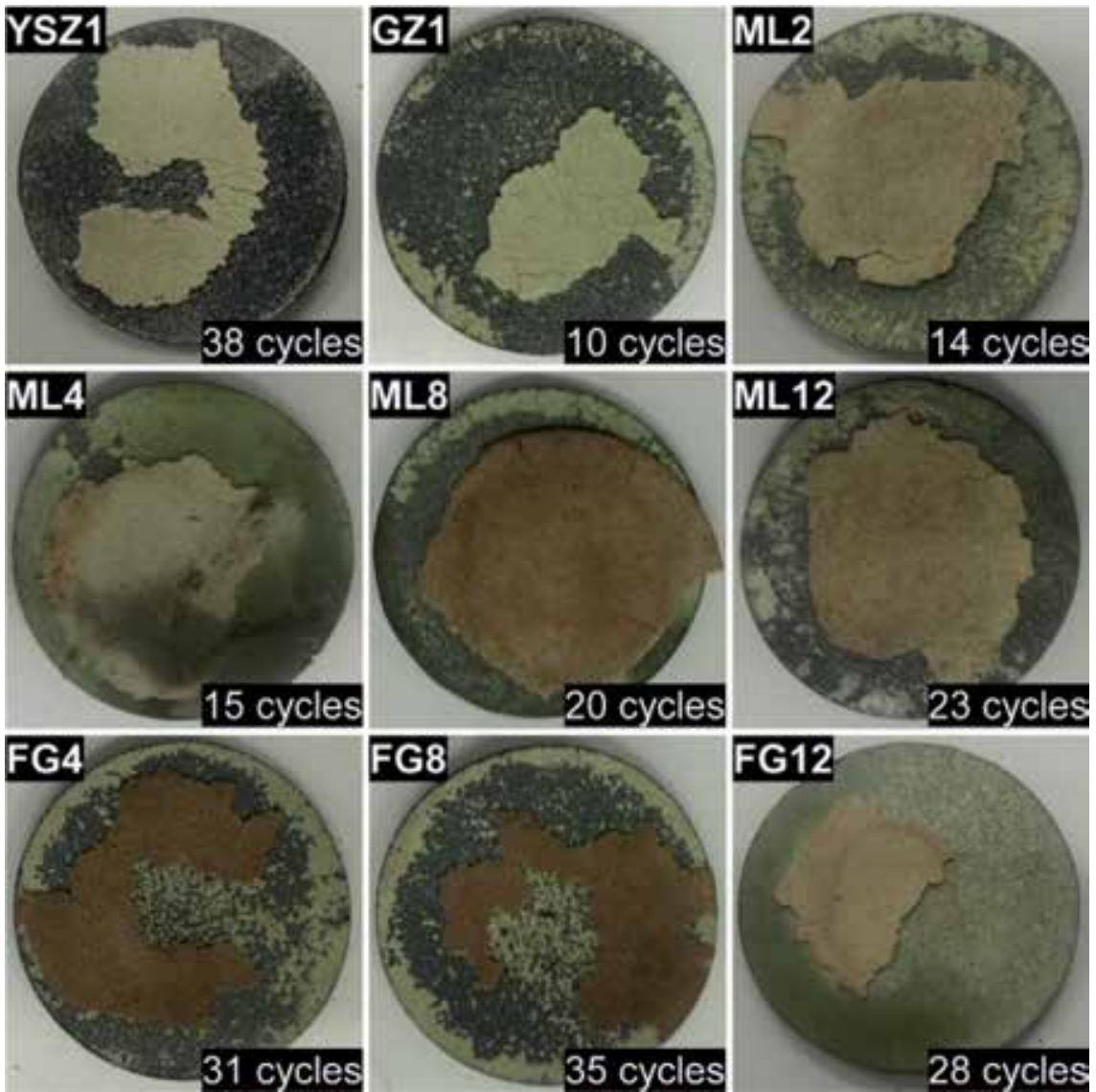

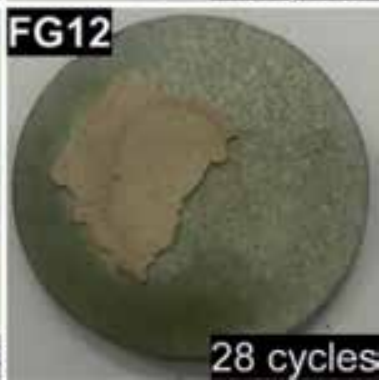

Figure 7.

Macroscopic image showing remaining top coats on the substrate after thermal shock test and number of cycles to failure. 
produced MLed and FGed GZ/YSZ TBCs by APS technique [23]. The GZ/YSZ TBCs having two and five layers were exposed to thermal cycling test in the furnace. The TBCs were heated to $1050^{\circ} \mathrm{C}$ and then cooled by air. The thermal cycling life of the MLed GZ/YSZ TBC was about 1000 cycles. On the other hand, FGed GZ/ YSZ TBC had resistance up to about 2300 cycles. This situation was attributed to the homogenous distribution of thermal stress in the layers of FGed coating. Mahade et al. subjected the specimens of double- and triple-layered (GZ dense/GZ/ YSZ) TBCs that were produced by SPS technique to the thermal cycling test. The thermal cycling tests were carried out in the furnace (heating the specimens up to 1100 and $1200^{\circ} \mathrm{C}$ for 1 hour and cooling to $100^{\circ} \mathrm{C}$ ). Researchers concluded that an improvement in the thermal cycling lifetime took place thanks to GZ dense/GZ/ YSZ triple-layer approach. This was due to the lower porosity content of triple-layer approach. Thanks to dense GZ layer, less oxygen has reached to the bond layer. As a result, the thickness of TGO had remained below the critical value causing failure in the coating. In another study by Zhang et al. [6], double-layered $\mathrm{Yb}_{2} \mathrm{O}_{3}$-doped $\mathrm{GZ}$ (GYbZ)/YSZ TBCs are produced by EB-PVD technique. They produced two sets of (GYbZ)/YSZ TBCs. One of them had normal (sharp) interface between GYbZ and YSZ phases. On the other hand, another set of the TBCs had a uniform interface with a fluent transition (gradient coating) region (nearly $10 \mu \mathrm{m}$ ). Results of thermal cycling test, which was carried out by heating the surface of the TBCs up to $1350^{\circ} \mathrm{C}$ by a flame and cooling by compressed air, showed that TBC having a gradient transition region had higher lifetime (1346 cycles) than that of TBC having sharp interface (942 cycles). This beneficial effect of the gradient transition region was attributed to the gradually compositional change reducing the thermal mismatch at the interface between ceramic layers.

Consequently, it is possible to prolong the thermal cycling and thermal shock lifetime of the GZ by using a second material (such as YSZ and CYSZ) in multilayered and functionally graded designs. The stress generated by thermal mismatch has been reduced and reaction tendency of the GZ with TGO layer prevented thanks to multilayered and functionally graded designs.

\section{Attack of harmful foreign substances}

\subsection{CMAS and hot corrosion resistance of gadolinium zirconate-based thermal barrier coatings}

The jet engine fuel especially used in military aircrafts has low quality, and it contains appreciable levels of impurities such as $\mathrm{Na}_{2} \mathrm{SO}_{4}+\mathrm{V}_{2} \mathrm{O}_{5}$. They cause severe damage on the ceramic top layer at high temperatures $[14,26,39]$. On the other hand, calcium-magnesium-alumino-silicate (CMAS) is known as airborne silicate particles (sand, ash, dust, etc.). The CMAS entering to the turbine melts on the hot TBC surfaces and penetrates into the ceramic top coat. This situation leads to premature failure of the coating $[12,14]$. There are a lot of studies in the literature proving that GZ-based TBCs have excellent CMAS and hot corrosion resistance.

In the studies that were carried out by Habibi et al. [21, 24], YSZ- and GZ-based TBCs were produced by APS technique. To evaluate hot corrosion behavior of the TBCs, hot corrosion powders $\left(\mathrm{Na}_{2} \mathrm{SO}_{4}+\mathrm{V}_{2} \mathrm{O}_{5}\right)$ were applied $\left(20 \mathrm{mg} / \mathrm{cm}^{2}\right)$ on the TBCs, and they were cyclically exposed to the $1050^{\circ} \mathrm{C}$. The failure of the YSZ-based top coat started after 24 hours and spallation occurred. The detailed characterizations revealed that $\mathrm{YVO}_{4}$-type crystals formed as result of the reactions between yttria $\left(\mathrm{Y}_{2} \mathrm{O}_{3}\right)$ and $\mathrm{V}_{2} \mathrm{O}_{5}$ or $\mathrm{NaVO}_{3}$. This formation of the $\mathrm{YVO}_{4}$ caused the transformation of $\mathrm{ZrO}_{2}$ from tetragonal to monoclinic due to the leaching of the $\mathrm{Y}_{2} \mathrm{O}_{3}$ from 
the YSZ. On the other hand, failure in the GZ-based coating started after 36 hours. This situation showed that GZ-based coating had much better hot corrosion resistance than that of YSZ. In the case of GZ-based coating, molten $\mathrm{Na}_{2} \mathrm{SO}_{4}+\mathrm{V}_{2} \mathrm{O}_{5}$ mixture reacts with the bulk $\mathrm{Gd}_{2} \mathrm{Zr}_{2} \mathrm{O}_{7}$ layer to form $\mathrm{GdVO}_{4}$. However, $\mathrm{Na}_{2} \mathrm{SO}_{4}+\mathrm{V}_{2} \mathrm{O}_{5}$ mixture attacks to the $\mathrm{Y}_{2} \mathrm{O}_{3}$ that is stabilizer of YSZ. Liu et al. [26] investigating hot corrosion behavior of sintered $\mathrm{GZ}$ in the presence of $\mathrm{V}_{2} \mathrm{O}_{5}$ explained the reaction mechanism. According to this, at $700^{\circ} \mathrm{C}$ molten $\mathrm{V}_{2} \mathrm{O}_{5}$ started to react with $\mathrm{Gd}_{2} \mathrm{Zr}_{2} \mathrm{O}_{7}$ to form $\mathrm{ZrV}_{2} \mathrm{O}_{7}$ and $\mathrm{GdVO}_{4}$ (see Eq. (1)). In the case of $750-850^{\circ} \mathrm{C}$, the final reaction products of $\mathrm{GdVO}_{4}$ and $\mathrm{m}-\mathrm{ZrO}_{2}$ formed depleting $\mathrm{V}_{2} \mathrm{O}_{5}$ (see Eq. (2)):

$$
\begin{aligned}
& 3 \mathrm{~V}_{2} \mathrm{O}_{5 \text { (liquid) }}+\mathrm{Gd}_{2} \mathrm{Zr}_{2} \mathrm{O}_{7 \text { (solid) }} \rightarrow 2 \mathrm{ZrV}_{2} \mathrm{O}_{7 \text { (solid) }}+2 \mathrm{GdVO}_{4} \text { (solid) } \\
& \mathrm{V}_{2} \mathrm{O}_{5 \text { (liquid) }}+\mathrm{Gd}_{2} \mathrm{Zr}_{2} \mathrm{O}_{7 \text { (solid) }} \rightarrow 2 \mathrm{GdVO}_{4 \text { (solid) }}+2 \mathrm{~m}-\mathrm{ZrO}_{2 \text { (solid) }}
\end{aligned}
$$

Suspension plasma-sprayed (SPSed) GZ/YSZ TBCs having multilayered designs were subjected to the hot corrosion test [25]. $\mathrm{V}_{2} \mathrm{O}_{5}$ and $\mathrm{Na}_{2} \mathrm{SO}_{4}$ salts were applied to the specimen surface at a concentration of $4 \mathrm{mg} / \mathrm{cm}^{2}$. The test was conducted at $900^{\circ} \mathrm{C}$ for 8 hours. Microstructures revealed that GZ-based coatings had lower reactivity with the corrosive salts and the formation of gadolinium vanadate $\left(\mathrm{GdVO}_{4}\right)$.

Another promising feature of the GZ is its high resistance to CMAS attack. In contrast to conventional YSZ, GZ is highly effective in resistance to the penetration of molten Ca-Mg-Al-silicate (CMAS) glass deposit. This higher resistance of the APSed GZ-based TBC was proven for prolonged durations [40]. The CMAS sand was applied to the surface of the TBCs at a concentration of $35 \mathrm{mg} / \mathrm{cm}^{2}$. Then TBCs were heated to $1200^{\circ} \mathrm{C}$ in air for 24 and 168 hours in a furnace. Results showed that CMAS melt was fully penetrated inside of the YSZ. The penetration depth of YSZ-based TBC was approximately $200 \mu \mathrm{m}$. However, CMAS melt was arrested on the surface of GZ-based coating (at a penetration depth $20 \mu \mathrm{m}$ ). This resistance of the GZ-based TBC was attributed to the formation of a crystalline sealing layer. The chemical composition of the sealing layer was $\mathrm{Ca}_{2} \mathrm{Gd}_{8}\left(\mathrm{SiO}_{4}\right)_{6} \mathrm{O}_{2}$ (apatite phase), and it formed as a result of the high-temperature chemical interactions between the GZ and CMAS melt. Similar results were found for GZ-based TBC that was produced by EB-PVD technique [20]. The mechanism of the CMAS resistance of GZ-based TBC was explained via formation of a highly stable apatite phase. This phase sealed the flow channels of GZ-based SPSed TBC.

In a unique study [14], GZ- and YSZ-based TBCs were produced by APS technique, and they were exposed to CMAS and hot corrosion (CMAS + hot corrosion) test. This test was executed in the same experiment at once. Moreover, a defocused $\mathrm{CO}_{2}$ laser beam was used as heat source, and TBCs were simultaneously cooled from the back surface of the substrate to create a thermal gradient and harsh environment. Hot corrosion and CMAS powders were applied on the surface of the TBCs together at a concentration of $30 \mathrm{mg} / \mathrm{cm}^{2}$, and they were heated by a laser beam to $1250^{\circ} \mathrm{C}$ and held at that temperature for 1 hour. The rodlike structures formed on both YSZ- and GZ-based coatings. The chemical composition of the rodlike structures was in the form of $\mathrm{YVO}_{4}$ and $\mathrm{GdVO}_{4}$ for $\mathrm{YSZ}$ and GZ, respectively. The micrographs of the YSZ-based TBC clearly demonstrate that CMAS + hot corrosion products penetrated through microcracks and pores. However, there was a continuous reaction layer formed at the boundary between CMAS and GZ-based TBC. The thickness of reaction layer was approximately $6 \mu \mathrm{m}$. The lamellar microstructural morphology of APSed TBCs turned into a denser structure seeming to extend crystals into the CMAS. This situation was consistent with the similar studies that investigated interactions between GZ-based TBCs and different CMAS sands [20, 23, 40]. 
Further penetration of the CMAS products into the GZ based was prevented thanks to this reaction (sealing) layer. The formation and sealing mechanism of the reaction layer were defined as follows:

1. The GZ grains were wetted by CMAS melt at the high temperatures.

2. Gd unified with the glass locally.

3. The crystallization initiated in the Gd-rich region of the glass.

4. The apatite $\left(\mathrm{Ca}_{2} \mathrm{Gd}_{8}\left(\mathrm{SiO}_{4}\right)_{6} \mathrm{O}_{2}\right)$ and small amounts of other phases formed after crystallization in the $\mathrm{Gd}$-rich region of the glass.

5. The apatite phase prevented further penetration of the molten CMAS glass into the TBC providing a sealing layer between TBC and CMAS.

Gledhill et al. [2] applied the lignite fly ash on the surface of APSed YSZand GZ-based TBCs at $1200^{\circ} \mathrm{C}$. They showed that the molten lignite fly ash completely penetrated (throughout entire thickness) inside the YSZ-based TBC. Unlike this, the molten lignite fly penetrated only approximately $25 \%$ of the GZ-based TBC thickness thanks to a crystalline reaction layer arresting molten fly ash on the TBC.

\section{Laser surface modification}

\subsection{Laser surface modification of gadolinium zirconate-based thermal barrier coatings}

Surface modification by using laser beam is a new and good technique for improving some of the properties of plasma-sprayed TBCs. According to the studies, laser remelting solidification process has provided a reduction in the surface roughness and specific surface area. Moreover, besides a columnar cross-sectional structure, controlled (varied depending on the laser parameters) segmented crack network that is perpendicular to the surface can be achieved with sealed porosities at the surface of the coatings. Therefore, hardness, thermal cycle lifetime, resistance to hot corrosion, CMAS, and erosion property of TBCs can be further improved by laser surface modification $[1,7,11,13,18,41-43]$. After laser surface-modified process:

1. Erosion, CMAS, and hot corrosion resistance of the TBC can be enhanced owing to reduction in the surface roughness and specific surface area as well.

2. Thermal shock resistance of the TBC can be enhanced due to segment cracks generated on the surface of the TBC.

3. Thermal cycle lifetime of the TBC can be increased thanks to segmented cracks improving strain accommodation capability.

4. Hardness of the TBC can be increased by changing grain size.

After laser surface modification, a TBC surface should:

1. Have a remelted layer having melting depth of $20-50 \mu \mathrm{m}$. 
State of the Art of Gadolinium Zirconate Based Thermal Barrier Coatings: Design, Processing... DOI: http://dx.doi.org/10.5772/intechopen.85451

2. Be nonseparated from the as-sprayed layer.

3. Have a smooth surface (with surface roughness value $\left(R_{a}\right)$ lower than $5 \mu \mathrm{m}$ ).

4. Have a distribution of the crack network that is equiaxed.

All of these properties can be obtained only at optimum laser surface modification parameters. A study of the laser surface modification was made to determine the optimum laser surface modification parameters of APSed GZ-based TBC [13]. The GZ-based TBCs were subjected to the laser surface modification process by using a continuous $\mathrm{CO}_{2}$ laser. Laser parameters were laser power density on the surface, scanning speed, and laser distance (distance to the surface from the laser torch). During studies, single laser beam tracks were generated on the specimens, and they were examined. As seen in Figure 8a, a very successful laser-glazed surface of GZ-based TBC was obtained having a denser microstructure than as-sprayed layer with an average thickness of molten layer $\sim 37 \mu \mathrm{m}$, and a smooth surface $\left(\mathrm{R}_{\mathrm{a}}: 2.9 \mu \mathrm{m}\right)$ was accomplished at the optimum laser parameters (laser power density, $70 \mathrm{MW} / \mathrm{m}^{2}$; scanning speed, $150 \mathrm{~mm} / \mathrm{sn}$; laser distance, $14 \mathrm{~mm}$ ). There was no separation from the as-sprayed layer. Furthermore, the network of cracks were very regular and excellent. These changes in the microstructure of the GZ-based TBC can be clearly noticed in Figure 8a when it is compared with Figure 3a belonging to the as-sprayed GZ-based TBC surface. Figure $\mathbf{8 b}$ shows high magnification microstructure of the fracture surface of GZ-based TBC. Individually, glazed layer and as-sprayed structure can be seen clearly. Characteristic cross-sectional microstructure of APSed TBC having splats, parallel cracks at splat boundaries, and pores transformed to dense and nonporous structure at the laser surface-modified layer. During the laser surface modification
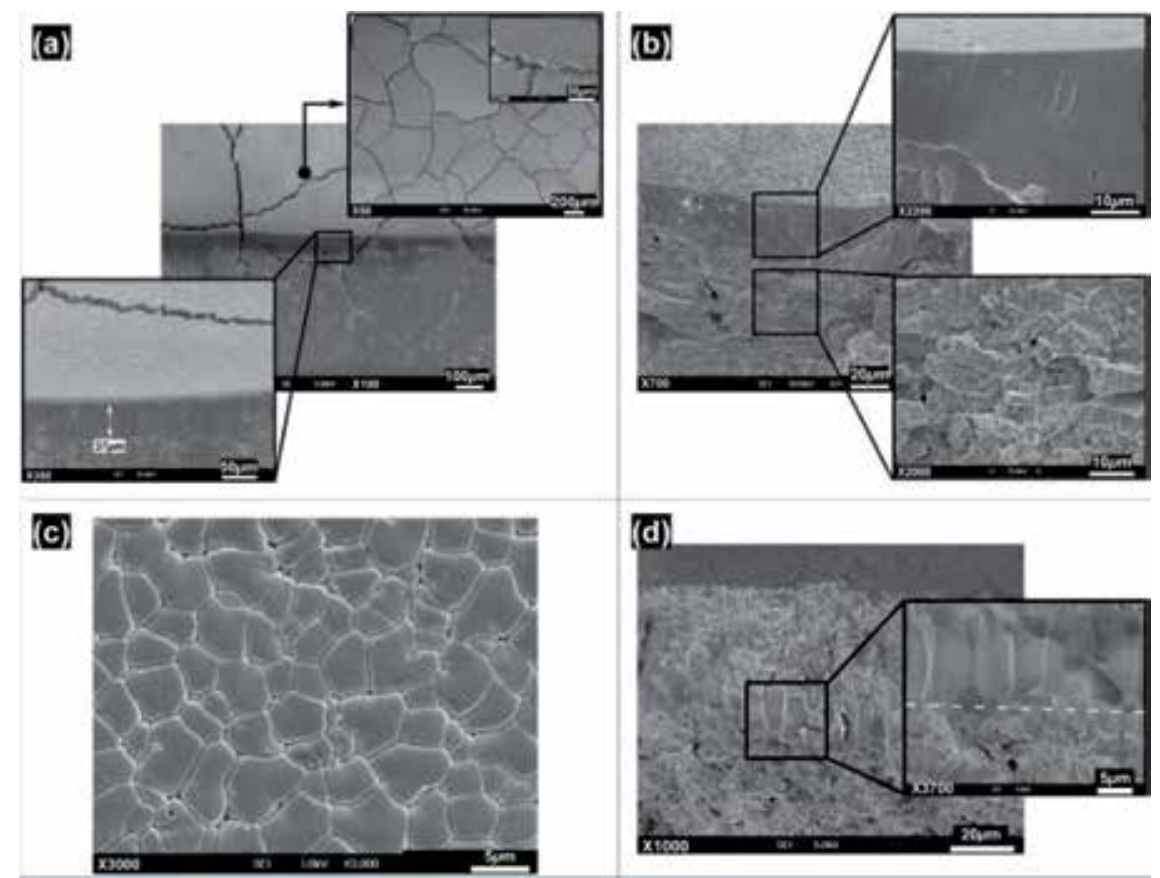

\section{Figure 8.}

(a) Surface and cross-sectional micrograph of the GZ-based TBC after laser surface modification process,

(b) cross-sectional fracture surface micrograph of the GZ-based TBC after laser surface modification process, (c) grain size distribution of the laser surface-modified GZ-based TBC, $(d)$ cross-sectional fracture surface micrograph of the laser surface-modified GZ-based TBC showing columnar grains. 
process, molten liquid GZ is replaced with microholes due to the surface tension force of liquid material. On the other hand, laser surface modification parameters affected the grain size and morphology of the GZ-based TBC due to directional solidification. At the optimum laser surface modification parameters (in terms of melting depth, cross-sectional damage, surface quality, and crack network regularity), distribution of the grain size was almost the same, and grains were equiaxed in the GZ-based TBC (see Figure 8c). Moreover, as seen in Figure 8d, these grains grew as perpendicular to the surface in the laser surface-modified layer of the GZ-based TBC. The structural change from the porous and lamellar plasma-sprayed structure to the columnar laser surface-modified structure could clearly be seen in Figure 8d. This structure was due to the directional solidification of laser-modified layer because the direction of heat flow was from the coating to the surface during solidification. This phenomenon was proved by phase analysis. XRD graphs showed that a preferred orientation on the direction took place after laser surface modification process of the GZ-based TBC. On the other hand, hardness value of the remelted regions was affected from the laser surface modification parameters because the grain size of the modified layer decreased as the parameters approach the optimum. The hardness value of laser-glazed GZ-based TBC increased from 10.66 to $12.73 \mathrm{GPa}$ with decreasing grain size. The estimated cooling rate of the remelted layer of GZ-based TBC was about $10^{3}-10^{4 \circ} \mathrm{C} \mathrm{s}^{-1}$.

\section{Conclusion}

In the present chapter, the potential utilization of gadolinium zirconate (GZ) for thermal barrier coating (TBC) applications had been discussed. The production methods, design process, thermal and mechanical properties, failure mechanism, CMAS and hot corrosion resistance, and laser surface modification process of GZ-based TBCs were evaluated in this chapter.

A variety of coating techniques such as atmospheric plasma spraying (APS), solution plasma spraying (SPS), and electron beam-physical vapor deposition (EB-PVD) exist for the production of GZ-based TBCs. The production technique has a significant influence both on microstructure and properties of the GZ-based TBCs. APS is an effective technique to achieve characteristic TBC structure. Thermal conductivity value of the GZ-based TBCs is lower than that of yttria-stabilized zirconia (YSZ). It is possible to further improve the thermal conductivity and thermal failure properties of the GZ-based TBCs by using different coating architectures such as multilayer and functionally graded designs. GZ-based TBCs have a significant advantage in terms of its CMAS and hot corrosion resistance. After laser surface modification of GZ-based TBC, a thin, dense, and smooth remelted layer can be acquired. Furthermore, an equiaxed continuous segmented crack network forms on the surface of laser surface-modified GZ-based TBC. As a result, it was concluded that GZ is an important and promising alternative TBC material.

\section{Suggestions}

In the future works:

1. New strategies should be introduced to further increase the thermal cycling performance and thermal shock lifetime of the GZ-based TBCs.

2. Mechanical properties of the GZ-based TBCs produced by EB-PVD and SPS techniques should be investigated. 
State of the Art of Gadolinium Zirconate Based Thermal Barrier Coatings: Design, Processing... DOI: http://dx.doi.org/10.5772/intechopen.85451

3. Changes in the bonding strength, thermal conductivity, thermal cycling behavior, CMAS, and hot corrosion resistance properties of the GZ-based TBCs after laser surface modification should be examined.

4. In the experiments used to determine the thermal properties of the GZ-based TBCs, new scenario and/or more harsh conditions that are close to the actual operating conditions of the turbine engine should be created.

\section{Acknowledgements}

The authors thank Prof. Dr. Yilmaz Taptik, Prof. Dr. Ozgul Keles, Assist. Prof. Dr. Nuri Solak, and Hasan Huseyin Sezer for their contributions.

\section{Author details}

Mustafa Guven Gok ${ }^{1}$ and Gultekin Goller ${ }^{2 *}$

1 Department of Materials Science and Engineering, Hakkari University, Hakkari, Turkey

2 Department of Metallurgical and Materials Engineering, Istanbul Technical University, Istanbul, Turkey

*Address all correspondence to: goller@itu.edu.tr

\section{IntechOpen}

(C) 2019 The Author(s). Licensee IntechOpen. This chapter is distributed under the terms of the Creative Commons Attribution License (http://creativecommons.org/licenses/ by/3.0), which permits unrestricted use, distribution, and reproduction in any medium, provided the original work is properly cited. (cc) BY 


\section{References}

[1] Ahmadi-Pidani R, Shoja-Razavi R, Mozafarinia R, Jamali H. Improving the thermal shock resistance of plasma sprayed CYSZ thermal barrier coatings by laser surface modification. Optics and Lasers in Engineering. 2012;50:780-786. DOI: 10.1016/j. optlaseng.2011.12.007

[2] Gledhill AD, Reddy KM, Drexler JM, Shinoda K, Sampath S, Padture NP. Mitigation of damage from molten fly ash to air-plasma-sprayed thermal barrier coatings. Materials Science and Engineering A. 2011;528:7214-7221. DOI: 10.1016/j.msea.2011.06.041

[3] Zhao M, Ren X, Pan W. Mechanical and thermal properties of simultaneously substituted pyrochlore compounds $\left(\mathrm{Ca}_{2} \mathrm{Nb}_{2} \mathrm{O}_{7}\right) \times\left(\mathrm{Gd}_{2} \mathrm{Zr}_{2} \mathrm{O}_{7}\right)_{1-\mathrm{x}}$. Journal of the European Ceramic Society. 2015;35:1055-1061. DOI: 10.1016/j.jeurceramsoc.2014.10.009

[4] Singh R, Rauwald KH, Wessel E, Mauer G, Schruefer S, Barth A, et al. Effects of substrate roughness and spray-angle on deposition behavior of cold-sprayed Inconel 718. Surface and Coatings Technology. 2017;319:249-259. DOI: 10.1016/j.surfcoat.2017.03.072

[5] Di Ferdinando M, Fossati A, Lavacchi A, Bardi U, Borgioli F, Borri $\mathrm{C}$, et al. Isothermal oxidation resistance comparison between air plasma sprayed, vacuum plasma sprayed and high velocity oxygen fuel sprayed CoNiCrAlY bond coats. Surface and Coatings Technology. 2010;204:2499-2503. DOI: 10.1016/j.surfcoat.2010.01.031

[6] Zhang H, Guo L, Ma Y, Peng H, Guo H, Gong S. Thermal cycling behavior of $\left(\mathrm{Gd}_{0.9} \mathrm{Yb}_{0.1}\right)_{2} \mathrm{Zr}_{2} \mathrm{O}_{7} / 8 \mathrm{YSZ}$ gradient thermal barrier coatings deposited on Hf-doped NiAl bond coat by EB-PVD. Surface and Coatings Technology. 2014;258:950-955. DOI: 10.1016/j.surfcoat.2014.07.051
[7] Akdogan V, Dokur MM, Goller G, Keles O. Surface modification of thermal barrier coatings by single-shot defocused laser treatments. Journal of Materials Engineering and Performance. 2013;22:2500-2509. DOI: 10.1007/ s11665-013-0548-5

[8] Guven Gok M, Goller G. Production and characterisation of GZ/ CYSZ alternative thermal barrier coatings with multilayered and functionally graded designs. Journal of the European Ceramic Society. 2015;36:1755-1764. DOI: 10.1016/j. jeurceramsoc.2016.01.036

[9] Mahade S, Curry N, Bj S, Orklund $€$, Markocsan N, En N. Failure analysis of $\mathrm{Gd}_{2} \mathrm{Zr}_{2} \mathrm{O}_{7} / \mathrm{YSZ}$ multi-layered thermal barrier coatings subjected to thermal cyclic fatigue. 2016;689:2-10. DOI: 10.1016/j.jallcom.2016.07.333

[10] Mauer G, Jarligo MO, Mack DE, Vaßen R. Plasma-sprayed thermal barrier coatings: New materials, processing issues, and solutions. Journal of Thermal Spray Technology. 2013;22:646-658. DOI: 10.1007/s11666-013-9889-8

[11] Park JH, Kim JS, Lee KH, Song YS, Kang MC. Effects of the laser treatment and thermal oxidation behavior of $\mathrm{CoNiCrAlY} / \mathrm{ZrO}_{2-8} \mathrm{wt} \% \mathrm{Y}_{2} \mathrm{O}_{3}$ thermal barrier coating. Journal of Materials Processing Technology. 2008;201:331-335. DOI: 10.1016/j. jmatprotec.2007.11.192

[12] Senturk BS, Garces HF, Ortiz AL, Dwivedi G, Sampath S, Padture NP. CMAS-resistant plasma sprayed thermal barrier coatings based on $\mathrm{Y}_{2} \mathrm{O}_{3}$ stabilized $\mathrm{ZrO}_{2}$ with $\mathrm{Al}^{3+}$ and $\mathrm{Ti}^{4+}$ solute additions. Journal of Thermal Spray Technology. 2014;23:708-715. DOI: 10.1007/s11666-014-0077-2

[13] Gok MG, Goller G. Microstructural evaluation of laser remelted gadolinium 
zirconate thermal barrier coatings. Surface and Coatings Technology. 2015;276:202-209. DOI: 10.1016/j. surfcoat.2015.06.074

[14] Gok MG, Goller G. Microstructural characterization of GZ/CYSZ thermal barrier coatings after thermal shock and CMAS + hot corrosion test. Journal of the European Ceramic Society. 2017;37(6):2501-2508. ISSN 0955-2219. https://doi.org/10.1016/j. jeurceramsoc.2017.02.004

[15] Cao XQ, Vassen R, Stoever D. Ceramic materials for thermal barrier coatings. Journal of the European Ceramic Society. 2004;24:1-10. DOI: 10.1016/S0955-2219(03)00129-8

[16] Stover D, Pracht G, Lehmann $\mathrm{H}$, Dietrich M, Doring J-E, Vaben R. New material concepts for the next generation of plasma-sprayed thermal barrier coatings. Journal of Thermal Spray Technology. 2004;13:76-83. DOI: 10.1361/10599630418176

[17] Wu J, Wei X, Padture NP, Klemens PG, Gell M, García E, et al. Lowthermal-conductivity rare-earth zirconates for potential thermalbarrier-coating applications. Journal of the American Ceramic Society. 2002;85:3031-3035. DOI: 10.1111/j.11512916.2002.tb00574.x

[18] Ahmadi-Pidani R, Shoja-Razavi R, Mozafarinia R, Jamali H. Laser surface modification of plasma sprayed CYSZ thermal barrier coatings. Ceramics International. 2013;39:2473-2480. DOI: 10.1016/j.ceramint.2012.09.005

[19] Mensah PF, Diwan R, Nandikolla S, Coker O, Sahoo P. Thermo-mechanical study of the role of $\mathrm{Gd}_{2} \mathrm{Zr}_{2} \mathrm{O}_{7}(\mathrm{GZ})$ in improving life of YSZ and GZ double layered thermal barrier coatings (ASME). In: Proceedings of the International Mechanical Engineering Congress and Exposition. 2012;88279:3083-3088. DOI: 10.1115/ IMECE2012-88279
[20] Kramer S, Yang J, Levi

CG. Infiltration-inhibiting reaction of gadolinium zirconate thermal barrier coatings with CMAS melts. Journal of the American Ceramic Society. 2008;91:576-583. DOI: 10.1111/j.1551-2916.2007.02175.x

[21] Habibi MH, Wang L, Guo S. An investigation on hot corrosion resistance of plasma sprayed composite YSZ$\mathrm{Gd}_{2} \mathrm{Zr}_{2} \mathrm{O}_{7}$ and $\mathrm{Gd}_{2} \mathrm{Zr}_{2} \mathrm{O}_{7}$ thermal barrier coatings in simulated turbine environment at $1050^{\circ} \mathrm{C}$. In: Des. Mater. Manuf. Parts A, B, C, ASME 2012 International Mechanical Engineering Congress and Exposition, Vol. 3; 2012. p. 905. DOI:10.1115/IMECE2012-88435

[22] Bakan E, Mack DE, Mauer G, Vaßen R. Gadolinium zirconate/YSZ thermal barrier coatings: Plasma spraying, microstructure, and thermal cycling behavior. Journal of the American Ceramic Society. 2014;97:4045-4051. DOI: $10.1111 /$ jace.13204

[23] Carpio P, Salvador MD, Borrell A, Sánchez E. Thermal behaviour of multilayer and functionally-graded YSZ/ $/ \mathrm{Gd}_{2} \mathrm{Zr}_{2} \mathrm{O}_{7}$ coatings. Ceramics International. 2016;43(5):40484054. ISSN: 0272-8842. https://doi. org/10.1016/j.ceramint.2016.11.178

[24] Habibi MH, Wang L, Guo SM. Evolution of hot corrosion resistance of $\mathrm{YSZ}, \mathrm{Gd}_{2} \mathrm{Zr}_{2} \mathrm{O}_{7}$, and $\mathrm{Gd}_{2} \mathrm{Zr}_{2} \mathrm{O}_{7}+\mathrm{YSZ}$ composite thermal barrier coatings in $\mathrm{Na}_{2} \mathrm{SO}_{4}$ $+\mathrm{V}_{2} \mathrm{O}_{5}$ at $1050^{\circ} \mathrm{C}$. Journal of the European Ceramic Society. 2012;32:1635-1642. DOI: 10.1016/j. jeurceramsoc.2012.01.006

[25] Jonnalagadda KP, Mahade S, Curry $\mathrm{N}$, et al. Hot corrosion mechanism in multi-layer suspension plasma sprayed $\mathrm{Gd}_{2} \mathrm{Zr}_{2} \mathrm{O}_{7} / \mathrm{YSZ}$ thermal barrier coatings in the presence of $\mathrm{V}_{2} \mathrm{O}_{5}+$ $\mathrm{Na}_{2} \mathrm{SO}_{4}$. Journal of Thermal Spray Technology. 2017;26:140-149. https:// doi.org/10.1007/s11666-016-0486-5 
[26] Liu Z, Ouyang J, Zhou Y, Xia X. Hot corrosion behavior of $\mathrm{V}_{2} \mathrm{O}$-coated $\mathrm{Gd}_{2} \mathrm{Zr}_{2} \mathrm{O}_{7}$ ceramic in air at 700 $850^{\circ} \mathrm{C}$. Journal of the European Ceramic Society. 2009;29:2423-2427. DOI: 10.1016/j.jeurceramsoc.2009.01.001

[27] Ma L, Ma W, Sun X, Ji L, Liu J, Hang $\mathrm{K}$. Microstructures and mechanical properties of $\mathrm{Gd}_{2} \mathrm{Zr}_{2} \mathrm{O}_{7} / \mathrm{ZrO}_{2}(3 \mathrm{Y})$ ceramics. Journal of Alloys and Compounds. 2015;644:416-422. DOI: 10.1016/j.jallcom.2015.05.054

[28] Li M, Guo L, Ye F. Phase structure and thermal conductivities of $\mathrm{Er}_{2} \mathrm{O}_{3}$ stabilized $\mathrm{ZrO}_{2}$ toughened $\mathrm{Gd}_{2} \mathrm{Zr}_{2} \mathrm{O}_{7}$ ceramics for thermal barrier coatings. Ceramics International. 2016;42:16584-16588. DOI: 10.1016/j. ceramint.2016.07.079

[29] Mahade S, Curry N, Björklund $\mathrm{S}$, Markocsan N, Nylén P. Thermal conductivity and thermal cyclic fatigue of multilayered $\mathrm{Gd}_{2} \mathrm{Zr}_{2} \mathrm{O}_{7} / \mathrm{YSZ}$ thermal barrier coatings processed by suspension plasma spray. Surface and Coatings Technology. 2015;283:329-336. DOI: 10.1016/j.surfcoat.2015.11.009

[30] Jonnalagadda KP, Mahade S, Curry $\mathrm{N}$, et al. Hot corrosion mechanism in multi-layer suspension plasma sprayed $\mathrm{Gd}_{2} \mathrm{Zr}_{2} \mathrm{O}_{7} /$ YSZ. Thermal Barrier Coatings in the Presence of $\mathrm{V}_{2} \mathrm{O}_{5}+$ $\mathrm{Na}_{2} \mathrm{SO}_{4}$. Journal of Thermal Spray Technology. 2017;26:140-149. https:// doi.org/10.1007/s11666-016-0486-5

[31] Moskal G, Swadzba L, Hetmanczyk M, Witala B, Mendala B, Mendala J, et al. Characterization of microstructure and thermal properties of $\mathrm{Gd}_{2} \mathrm{Zr}_{2} \mathrm{O}_{7-}$ type thermal barrier coating. Journal of the European Ceramic Society. 2012;32:2025-2034. DOI: 10.1016/j. jeurceramsoc.2011.11.043

[32] Wang L, Eldridge JI, Guo $\mathrm{SM}$. Thermal radiation properties of plasma-sprayed $\mathrm{Gd}_{2} \mathrm{Zr}_{2} \mathrm{O}_{7}$ thermal barrier coatings. Scripta Materialia.
2013;69:674-677. DOI: 10.1016/j.

scriptamat.2013.07.026

[33] Bobzin K, Bagcivan N, Brögelmann $\mathrm{T}$, Yildirim B. Influence of temperature on phase stability and thermal conductivity of single- and doubleceramic-layer EB-PVD TBC top coats consisting of $7 \mathrm{YSZ}, \mathrm{Gd}_{2} \mathrm{Zr}_{2} \mathrm{O}_{7}$ and $\mathrm{La}_{2} \mathrm{Zr}_{2} \mathrm{O}_{7}$. Surface and Coatings Technology. 2013;237:56-64. DOI: 10.1016/j.surfcoat.2013.08.013

[34] Wessel JK. The Handbook of Advanced Materials: Enabling New Designs, Functionally Graded Materials. New Jersey: John Wiley Sons, Inc.; 2004

[35] Schmitt MP, Rai AK, Bhattacharya $\mathrm{R}$, Zhu D, Wolfe DE. Multilayer thermal barrier coating (TBC) architectures utilizing rare earth doped YSZ and rare earth pyrochlores. Surface and Coatings Technology. 2014;251:56-63. DOI: 10.1016/j.surfcoat.2014.03.049

[36] Kelly MJ, Wolfe DE, Singh J, Eldridge J, Zhu DM, Miller R. Thermal barrier coatings design with increased reflectivity and lower thermal conductivity for high-temperature turbine applications. International Journal of Applied Ceramic Technology. 2006;3:81-93. DOI: 10.1111/j.1744-7402.2006.02073.x

[37] Karabaş M, Bal E, Taptık IYY. Effect of air plasma spray parameters on the properties of YSZ and CYSZ thermal barrier coatings. Journal of the Australian Ceramic Society. 2016;52:175-182

[38] Zhou C, Zhang Q, Li Y. Thermal shock behavior of nanostructured and microstructured thermal barrier coatings on a Fe-based alloy. Surface and Coatings Technology. 2013;217:70-75. DOI: 10.1016/j.surfcoat.2012.11.074

[39] Liu ZG, Ouyang JH, Zhou Y, Li $\mathrm{S}$. High-temperature hot corrosion behavior of gadolinium zirconate by vanadium pentoxide and sodium sulfate 
State of the Art of Gadolinium Zirconate Based Thermal Barrier Coatings: Design, Processing... DOI: http://dx.doi.org/10.5772/intechopen.85451

in air. Journal of the European Ceramic Society. 2010;30:2707-2713. DOI: 10.1016/j.jeurceramsoc.2010.05.002

[40] Drexler JM, Chen C-H, Gledhill AD, Shinoda K, Sampath S, Padture NP. Plasma sprayed gadolinium zirconate thermal barrier coatings that are resistant to damage by molten Ca-Mg-Al-silicate glass. Surface and Coatings Technology. 2012;206:3911-3916. DOI: 10.1016/j. surfcoat.2012.03.051

[41] Batista C, Portinha A, Ribeiro RM, Teixeira V, Costa MF, Oliveira CR. Morphological and microstructural characterization of laser-glazed plasmasprayed thermal barrier coatings. Surface and Coatings Technology. 2006;200:2929-2937. DOI: 10.1016/j. surfcoat.2004.10.134

[42] Ghasemi R, Shoja-Razavi R, Mozafarinia R, Jamali H. Laser glazing of plasma-sprayed nanostructured yttria stabilized zirconia thermal barrier coatings. Ceramics International. 2013;39:9483-9490. DOI: 10.1016/j. ceramint.2013.05.066

[43] Morks MF, Berndt CC, Durandet Y, Brandt M, Wang J. Microscopic observation of laser glazed yttriastabilized zirconia coatings. Applied Surface Science. 2010;256:6213-6218. DOI: 10.1016/j.apsusc.2010.03.143 



\title{
Chapter 4
}

\section{The Growth of CdTe Layer on GaAs Substrate by MBE}

\author{
S.A. Dvoretsky, N.N. Mikhailov, D.G. Ikusov, \\ V.A. Kartashev, A.V. Kolesnikov, I.V. Sabinina, Yu. G. Sidorov \\ and V.A. Shvets
}

\begin{abstract}
We present the results of growth of CdTe layer on (013) GaAs substrate. The sequence processes include the preparation of GaAs surface by chemical etching and annealing in ultra-high vacuum, the growth of ZnTe layer on atomically clean GaAs surface and then the growth of CdTe layer on ZnTe/GaAs. All processes were carried out without removing GaAs substrate from MBE set. The processes were controlled by RHEED and single wavelength ellipsometry. We found that the evaporation of arsenic oxides and gallium oxides from the (001) GaAs surface were observed at over 400 and $500^{\circ} \mathrm{C}$, respectively. The growth of CdTe on (001) GaAs leads to appearance of mixture orientations because of large mismatch of lattice parameters. We study the growth of $\mathrm{ZnTe}$ on (001) GaAs and (013) GaAs substrates to prevent the growth of mixture orientations. We study the influence of cadmium and tellurium ratio in molecular fluxes and temperature on the growth mechanism of ZnTe and CdTe, crystal perfection, surface roughness and defects density. The optimal condition for growth of high quality thick CdTe on GaAs substrate were found.
\end{abstract}

Keywords: epitaxy, growth, MBE, ellipsometry, RHEED CdTe, ZnTe, GaAs, surface defects, roughness, ellipsometric parameters $\Delta$ and $\Psi$

\section{Introduction}

The wide gap II-VI telluride compounds (CdTe, ZnTe, CdZnTe) are widely used as materials for different applications such as in solar and high power energetic detectors. The development of epitaxial technologies allows realizing the growth of high quality II-VI compound layers on different substrates. This gives the possibility to create multilayer structures on large in diameter widely used $\mathrm{GaAs}$ and $\mathrm{Si}$ substrate. The one of the important application of CdTe (CdZnTe) layers on GaAs substrate is as alternative substrate for sequence growth of photosensitive material mercury cadmium telluride (MCT) solid solutions [1-3]. This material is very attractive for development and production of thermal imagers that used in civilian life for medical, agricultural, chemical, metallurgical fuel industries, cosmic, etc. The MCT structures on large in diameter GaAs substrates are markedly reduce the cost of the MCT epitaxial photosensitive material and applied to creation large (up to megapixel size) focal plane arrays. 
Molecular beam epitaxy (MBE) is the most appropriate epitaxial method of growing MCT layers due to its low growth temperatures $\left(\sim 180^{\circ} \mathrm{C}\right)$, which prevents the diffusion of impurities from the substrate and reduces the background doping [4]. But the dissociation and re-evaporation of diatomic Te molecules on singular surface at such growth temperatures is very low [5]. To increase the dissociation of diatomic Te molecules it is necessary to provide growth on vicinal surfaces. The development of multi-chamber MBE set allows carrying out the growth of MCT structures on GaAs with preliminary deposited CdTe layer in one process without uploading at air atmosphere. At the growth of CdTe on GaAs substrate $t$ is necessary to solve the physical-chemical and technological problems. The physicalchemical problems are determined by the great differences in mismatch and nature of chemical bonding of conjugation CdTe and GaAs. In first problem the relaxation of induced stress lead to equilibrium state with introducing dislocation. In second ones the appearance of crystalline defects determined by the interaction of molecular beam Cd and Te2 with atomically clean GaAs surface. Actually the investigation of the initial stage of the CdTe growth on GaAs surface showed the formation of different mixture of orientation that seems connected with large mismatch and different surface superstructures which formed at Te interaction with GaAs [6]. The nucleation of one orientation reached by growing of ZnTe layer on $\mathrm{GaAs}$ surface with the sequence growth of CdTe layer.

The purpose of the chapter is to present the study of processes for high quality growth of CdTe on (013) GaAs substrate.

\section{The experimental study of growth processes of CdTe layers on GaAs substrates}

\subsection{Pre-epitaxial preparation of substrates}

The critical stage to obtain reproducible epitaxial growth of films with high structural perfection is the pre-epitaxial preparation of the substrate surface. The substrate surface must be atomically clean before epitaxial growth without any chemical contamination. We studied pre-epitaxial preparation of (001)GaAs surface substrate. There are two stages: chemical etching and thermal annealing in ultra-high vacuum (UHV) at heating in the temperature over $500^{\circ} \mathrm{C}$ in pre-epitaxial chamber of the MBE set "Katun" type equipped by RHHED and ultra-high velocity single wavelength ellipsometer [7].

\subsubsection{The study of the chemical etching of GaAs substrate}

It had been clear that the most stable surface contaminations on GaAs surface substrate is carbon that cannot be removed by desorption in UHV $\sim 10^{-8} \mathrm{~Pa}$ at temperatures up to $600^{\circ} \mathrm{C}[8,9]$. It had been found that the presence of carbon contamination over $6 \%$ of the monolayer is the reason of disturbed $2 \mathrm{D}$ growth by MBE [8]. To prevent each contamination of GaAs substrate surface it is necessary to create protective films with the following requirements: have a low carbon adhesion coefficient; to be thick and uniform enough to encapsulate the GaAs surface; have high vapor pressure and completely desorbed from substrate temperatures below the decomposition temperature for $\mathrm{GaAs}$ which is equal over $600^{\circ} \mathrm{C}$.

Such requirements are satisfied by creation oxides film formed on the surface of (001) GaAs during chemical etching which was developed by Cho [10] and used by other researchers. 
This technique was used for study in-situ the mechanism of removal of the oxides film by heating of (001)GaAs surface [9]. High-resolution X-ray photoelectron spectroscopy (XPS) reveals that the original oxide film contains oxidized $\mathrm{As}^{+5}$ and $\mathrm{As}^{+3}, \mathrm{Ga}_{2} \mathrm{O}_{3}$ and $\mathrm{As}^{0}$ (elementary arsenic). The heating up to $350^{\circ} \mathrm{C}$ leads to remove $\mathrm{As}^{+5}$ oxide. At temperature over $500^{\circ} \mathrm{C}$ it was observed desorption of $\mathrm{As}^{+3}$ oxide and $\mathrm{As}^{0}$. The evaporation of $\mathrm{Ga}^{+3}$ oxides occurs at temperature $570-600^{\circ} \mathrm{C}$.

It was found that the level of carbon pollution (less $0.5 \%$ of the monolayer) decreases with the final etching in $\mathrm{HCl}$ in a high purity nitrogen atmosphere [9]. In this case, both arsenic and gallium oxides are removed from the surface and only a small amount of elemental arsenic remains on the surface. The advantage of this modification method is the removal oxides at room temperature, prevents violation of the stoichiometry of the GaAs surface and reduces the possible formation of defects at high temperatures.

In accordance with the above, we had developed a method of chemical cleaning of substrates for epitaxial growth of CdTe layers on GaAs substrate by MBE.

The chemical preparation technique of the GaAs surface substrates includes:

- cleaning by freshly prepared organic solvents such as ethanol, boiling toluene;

- etching in mixture $\mathrm{H}_{2} \mathrm{SO}_{4} / \mathrm{H}_{2} \mathrm{O}_{2} / \mathrm{H}_{2} \mathrm{O}(3: 1: 1)$;

- rinsing with demonized water flow;

- drying under the IR lamp; and

- finish etching in boiling isopropanol and then in a boiling solution of $\mathrm{HCl}$ in isopropanol.

Further, the samples are placed on the substrate holder and moved to loading chamber where after pumping created vacuum $\sim 5 \times 10^{-6} \mathrm{~Pa}$.

\subsubsection{The study of the thermal annealing of GaAs substrate}

The study of desorption protective film in UHV after chemical cleaning of (001) $\mathrm{GaAs}$ surface substrate was carried out in preparation chamber. The reflection high energy diffraction (beam voltage $12 \mathrm{keV}$ ) and single wavelength ellipsometry (wavelength $\lambda=632.8 \mathrm{~nm}$ ) were used for monitoring process in-situ [11, 12]. The diffraction pattern during substrate heating was consistently photographed in [011] and [0-11] azimuths. The substrate temperature was controlled by a thermocouple. The vacuum was less than $3 \times 10^{-8} \mathrm{~Pa}$. After loading the GaAs substrate to preparation chamber the diffraction patterns in [011] and [0-11] azimuths at room temperature were observed as weakly elongated strips slightly visible on the background phone. At temperature increasing up to $250-300^{\circ} \mathrm{C}$ the diffraction reflexes brightness were increase on the background phone. In the temperature interval $300-540^{\circ} \mathrm{C}$ there is no noticeable change in diffraction reflexes in two azimuths. Since $540^{\circ} \mathrm{C}$, there is observed sharp decreasing of the background phone with simultaneous elongating strips. Above $570^{\circ} \mathrm{C}$ the reconstruction of the surface and formation superstructures $2 \times 1$ and $3 \times 1$ was observed.

Figure 1 shows the changing the intensity of I1/I0 and I1/I2 ratios (curves 1, 3 and 2, 4 for azimuths in [011] and [0-11]) of diffraction patterns in central (I1) and edge (I2) parts of strip and diffused background (I0) of the (001) GaAs surface on the temperature. The intensities normalized to the background ones. It should be noted that in the temperature range of $20-300^{\circ} \mathrm{C}$ there is a sharp increase in I1, 

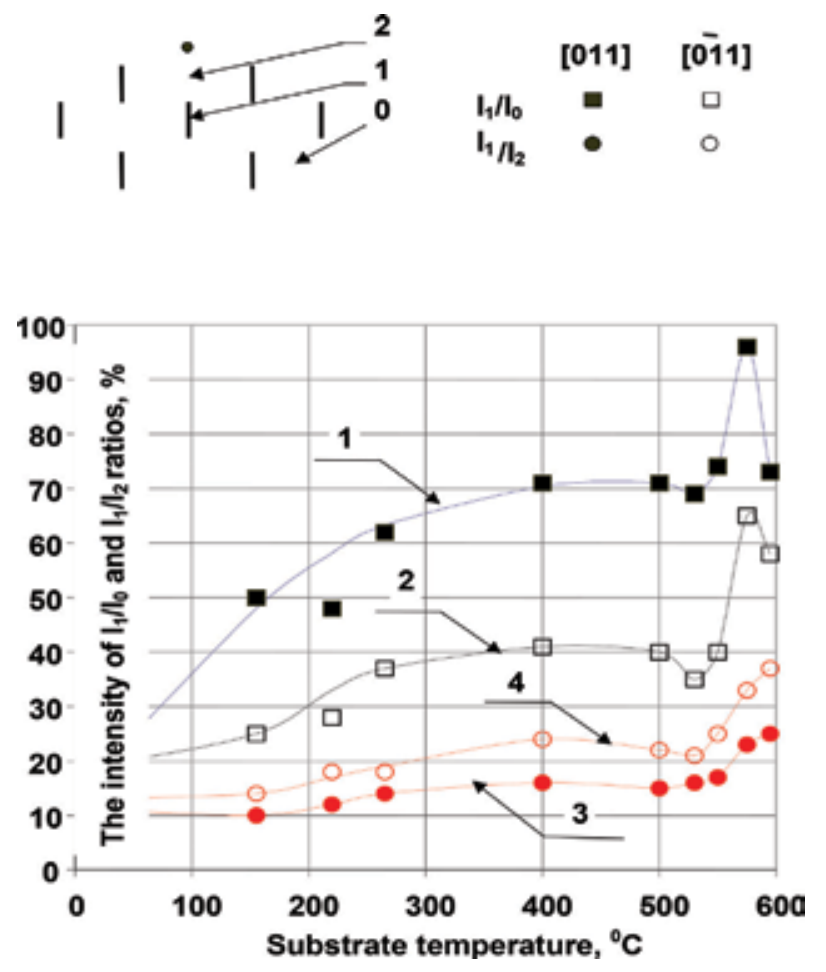

Figure 1.

The temperature dependences of RHEED intensity reflexes ratios (001) GaAs surface. Curves 1 and 3 for azimuth [011], curves 2 and 4 for azimuth [0-10].

which corresponds to the evaporation of volatile arsenic oxides. Then the noticeable change in the diffraction pattern intensities is not observed at temperature increasing up to $540^{\circ} \mathrm{C}$. The sharp increase I1/I0 ratio and I1/I2 is observed at temperature above $540^{\circ} \mathrm{C}$. At these temperatures gallium oxides are desorbed that lead to smooth (001) GaAs surface [8]. The exposition at temperature $570-580^{\circ} \mathrm{C}$ intensity reflexes decrease and strips pass into spots that associated with roughness and $\mathrm{Ga}$ enrichment of the surface.

The ellipsometric parameters $\Delta$ and $\Psi$ were measured in the process of heating the GaAs substrate up to temperature $580^{\circ} \mathrm{C}$ and its subsequent cooling to room temperature. Figure 2 shows the typical changes of $\Delta$ and $\Psi$ for three (001)GaAs samples. The dependence of $\Psi$ strictly increases at heating GaAs substrate and decrease at cooling. The dependence of $\Delta$ on the substrate temperature of $\mathrm{N}$-shaped type curves (section $\mathrm{AB}$ ) up to $150^{\circ} \mathrm{C}$ is due to removal of adsorbed arsenic oxides from the GaAs surface because of weaker chemical bonds compared to gallium oxides ones. Moreover, the value of the maximum in this area weakly varies from the conditions of chemical preparation of surface substrate. Further increase in temperature leads to $\Delta$ saturation in the range $250-280^{\circ} \mathrm{C}$ and slightly decreasing at $450^{\circ} \mathrm{C}$. This dependence $\Delta$ is well correlated with the following evaporation of arsenic oxides and temperature changes of the optical constants of GaAs. In the range of $450-580^{\circ} \mathrm{C}$ a sharp increase $\Delta$ is due to the removal of gallium oxides $[4,8]$. The ellipsometric data correlated with RHEED ones which at $580^{\circ} \mathrm{C}$ show the strikes with Kikuchi lines that indicated the absence of any oxide films and the atomically clean and smooth (001) GaAs surface.

At temperature cooling from $580^{\circ} \mathrm{C}$ to room temperature $\Delta$ gradually increases due to the change of the optical constants of GaAs (section BC). The same picture 


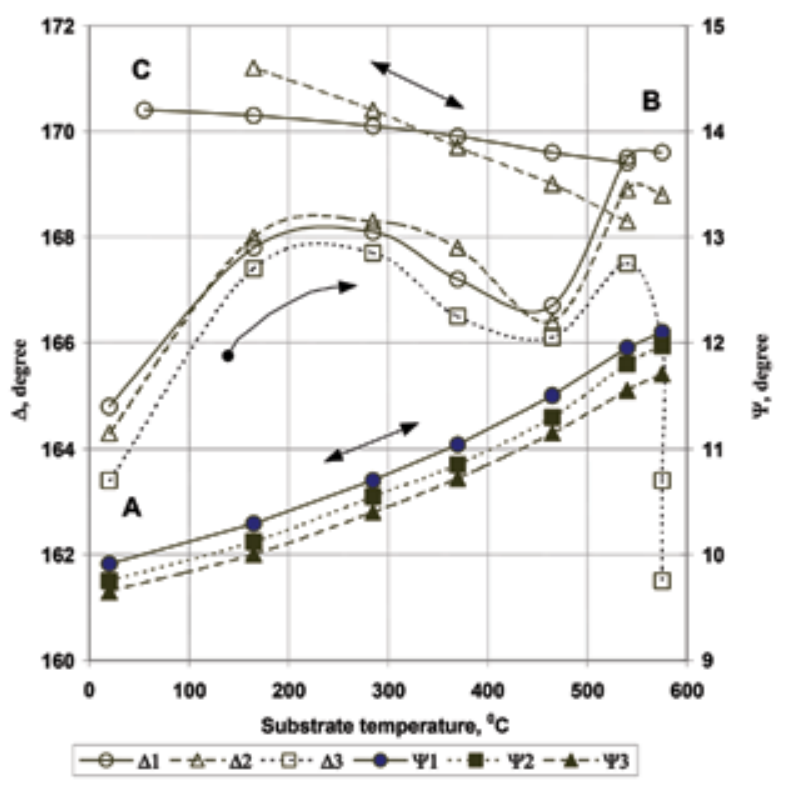

Figure 2.

The dependences of the ellipsometric parameters $\Delta$ and $\Psi$ on temperature for three different samples of (oo1) GaAs. The arrows show the direction of changing $\Delta$ and $\Psi$ along the curves.

of changing $\Delta$ repeated at thermal cycling. At temperatures above $580^{\circ} \mathrm{C}$ there was a sharp $\Delta$ decreasing ( $\Delta 3$, Figure 2 ) due to decomposition of GaAs and evaporation As atoms from the surface leading to roughness surface and $\mathrm{Ga}$ droplet formation. At heating GaAs substrates in As molecular flux parameter $\Delta$ stabilized at temperature range $170-600^{\circ} \mathrm{C}$.

Thus, it was shown that in-situ ellipsometric control can be effectively used for thermal cleaning in UHV of the surface of GaAs substrate. It should be noted that the procedure of pre-epitaxial preparation of (013) GaAs does not differ from (001) $\mathrm{GaAs}$. So the evaporation of oxides from the (013) GaAs surface during thermal heating in UHV is also not significantly different from (001) GaAs ones. The ellipsometric technique of surface control is not sensitive to the surface orientation. So we observed the same behavior of ellipsometric parameters in the case of heating (013) GaAs as for (100) GaAs.

\subsection{The epitaxial growth of ZnTe and CdTe layers on GaAs substrate}

The ZnTe layer 20-300 nm in thickness from elemental Zn and Te molecular sources preliminary must be grown on atomically clean GaAs substrate surface to prevent the formation mixture orientation [6]. This procedure helps us to conserve the original substrate orientation.

\subsubsection{The epitaxial growth of ZnTe on GaAs substrates}

The study of the growth process of ZnTe on (013) GaAs substrate for determination of optimal condition to realized high-quality $\mathrm{ZnTe}$ layers were carried out using ellipsometric technique $[11,13,14]$. ZnTe layer is transparent for using wavelength $\lambda=632.8 \mathrm{~nm}$ (He-Ne laser) of ellipsometer. In this case we observed periodic changing of ellipsometric parameters $\Delta$ and $\Psi$ with $\mathrm{ZnTe}$ thickness associated with interference oscillations. The period of oscillations is equal to $\lambda / 2\left(n^{2}-\sin \varphi\right)^{1 / 2}$ where 
$\mathrm{n}$ and $\varphi$ is the refractive index of ZnTe and the angle of incidence of the ellipsometer beam on the substrate surface, respectively. The changing $\Delta$ and $\Psi$ in $\Delta-\Psi$ plane has closed bell-shaped curve.

The simulation of the changing of $\Delta$ and $\Psi$ during the growth of ZnTe was carried out for different cases: the growth with roughness surface or/and appearance of radiation adsorption $(k \neq 0)$. The first reason is connected with changing of molecular fluxes $\mathrm{Zn}$ and $\mathrm{Te} 2\left(\mathrm{~J}_{\mathrm{Zn}} / \mathrm{J}_{\mathrm{Te} 2}\right)$ or/and growth temperature. The second reason is connected with changing in crystal perfection or inclusion of gallium or tellurium at high or low growth temperatures, respectively [15]. Figure 3 shows the simulation results of changing $\Delta$ and $\Psi$ for above mentioned cases. At the $\mathrm{ZnTe}$ growth with developed roughness surface there is a gradual $\Delta$ decreasing at the constant $\Psi$ (see Figure 3a). The curves $\Delta$ and $\Psi$ in $\Delta-\Psi$ plane are similar one another. In the case of growth of a weakly absorbing ZnTe layer $(\mathrm{k}=0.05)$ the curves $\Delta$ and $\Psi$ in $\Delta-\Psi$ plane are spiral that convergent more quickly with increasing of absorption in ZnTe layer (see Figure 3b). At growth of roughness and appearance of absorbed $\mathrm{ZnTe}$ layer the curves $\Delta$ and $\Psi$ in $\Delta-\Psi$ plane summarized the phenomena observed in figures (see Figure 3c).

These data were used in determination of growth mechanism of $\mathrm{ZnTe}$ on $\mathrm{GaAs}$ at different $\mathrm{J}_{\mathrm{Zn}} / \mathrm{J}_{\mathrm{Te} 2}$ ratio and temperature. The growth was carried out at constant substrate temperature and different $\mathrm{J}_{\mathrm{Zn}} / \mathrm{J}_{\mathrm{Te} 2}$ ratios. In a series of sequence experiments the $\mathrm{J}_{\mathrm{Zn}} / \mathrm{J}_{\mathrm{Te} 2}$ ratio was reduced that allows determining the transition from $2 \mathrm{D}$ to 3D growth mechanism for a given temperature. Similar the experiments were carried out at different temperatures. Figure 4 shows the results of experiments. The experimental results are presented by dots. The area of $3 \mathrm{D} \mathrm{ZnTe}$ growth is represented by gray color. As a result there is found the optimal growth condition: the $\mathrm{J}_{\mathrm{Zn}} / \mathrm{J}_{\mathrm{Te} 2}=2.75-3$ and the growth temperatures $280-300^{\circ} \mathrm{C}$.

Figure 5 shows the experimental change of $\Delta$ and $\Psi$ in $\Delta-\Psi$ plane at optimal condition growth of ZnTe on (013) GaAs substrate (rhombs). The solid curve is calculated data at constant values of optical constants and roughness of growing ZnTe layer. The arrows show the direction of changing of $\Delta$ and $\Psi$ with increasing ZnTe thickness. Such behavior of $\Delta$ and $\Psi$ does not change with the growth of thick ZnTe layer. The diffraction patent shows the extended clear strips.

\subsubsection{The epitaxial growth of CdTe on GaAs substrates}

At the initial stage of CdTe direct growth on atomically clean (001) GaAs substrate surface the convergent spiral curve of ellipsometric parameters in $\Delta$ and $\Psi$ in $\Delta-\Psi$ plane was observed for three experiments (see Figure 6).

The starting point $\mathrm{O}$ corresponds to $\Delta$ and $\Psi$ of $(001) \mathrm{GaAs}$ substrate. The final point A corresponds to the $\Delta$ and $\Psi$ for the bulk CdTe. The calculation curves $\Delta$ and $\Psi$ was compared with experimental data basis on model of homogeneous crystalline perfect system CdTe/GaAs. It is apparently clear that the direct growth of CdTe on (001) GaAs gives poor crystalline perfection. The reason of such behavior is the formation of mixture orientations (001)CdTe and (111)CdTe [6]. The analogous data were suggested by the systematic deviation of the measured ellipsometric parameters from the calculated curve at growth up to $100 \mathrm{~nm}$ (noticeable see for curve 2 with triangular markers in Figure 6). The observed deviation of calculated $\Delta$ and $\Psi$ at growth from experimental was explained by suppose the difference of optical constant values of growth CdTe layer from analogous for CdTe bulk or layers in thicknesses $2-3 \mu \mathrm{m}$. The good agreement between experimental results and calculation was observed at practically constant refractive index $n=3$ which is typical for thick films and higher $\mathrm{k}$ which approached to CdTe volume value (see inset 
The Growth of CdTe Layer on GaAs Substrate by MBE DOI: http://dx.doi.org/10.5772/intechopen.85563

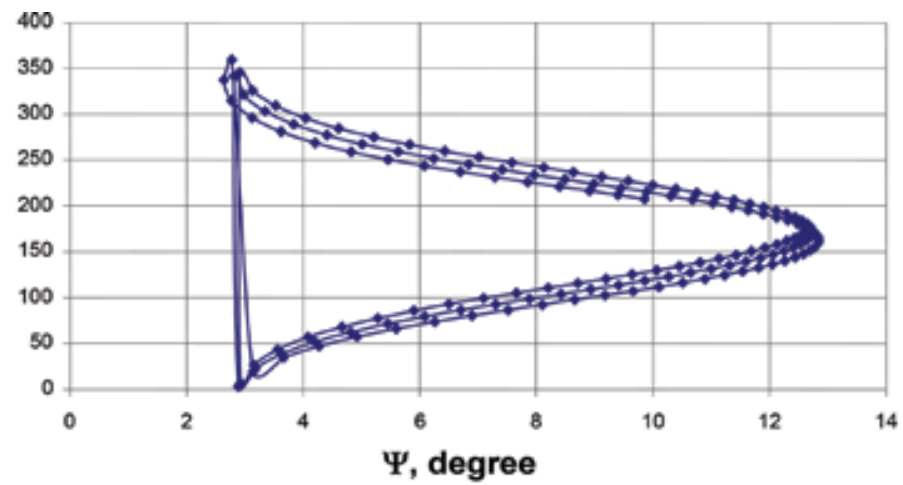

a)

ব

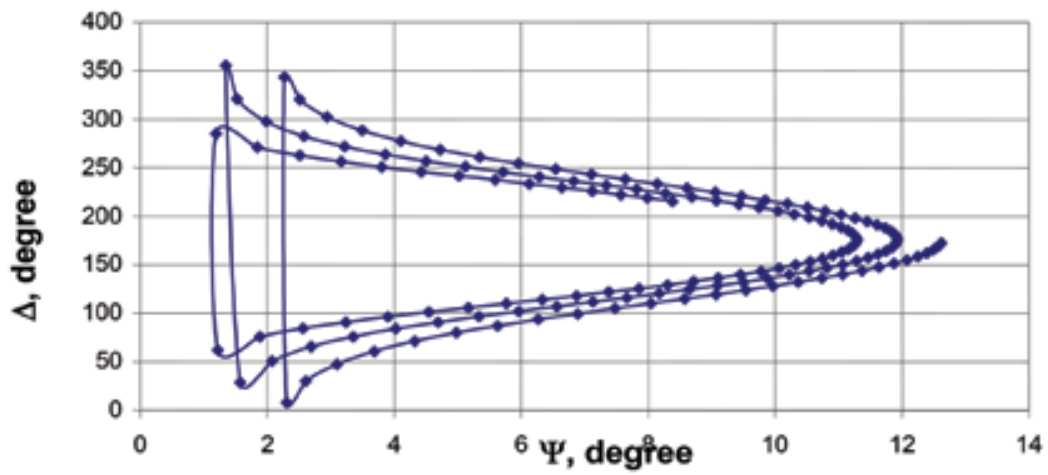

b)

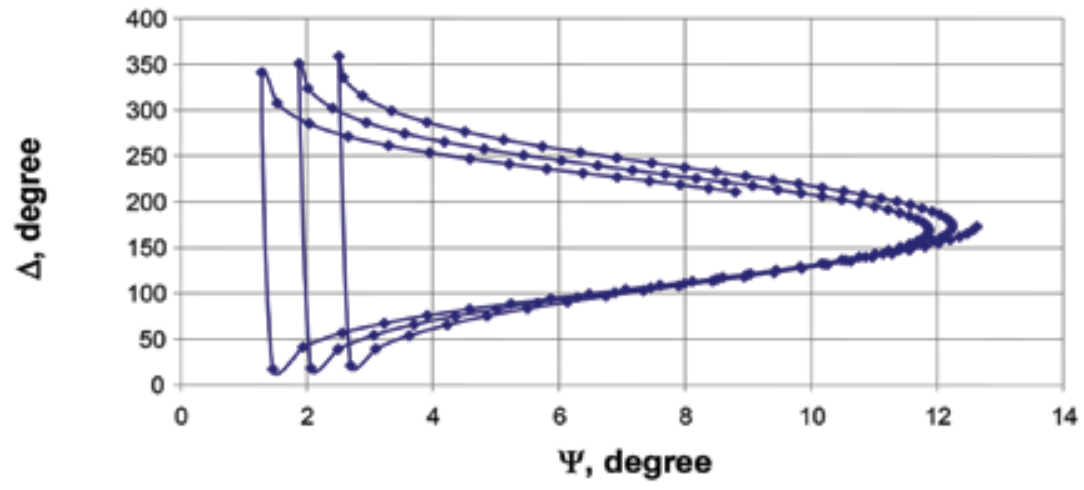

c)

Figure 3.

The results of calculations of ellipsometric parameters changing for the growth of the ZnTe film on the GaAs substrate: (a) the roughness develops from o to $5 \mathrm{~nm}$; (b) the absorption with $k=0.05$; (c) the roughness develops from 0 to $2.5 \mathrm{~nm}$ and the absorption with $k=0.03$. 


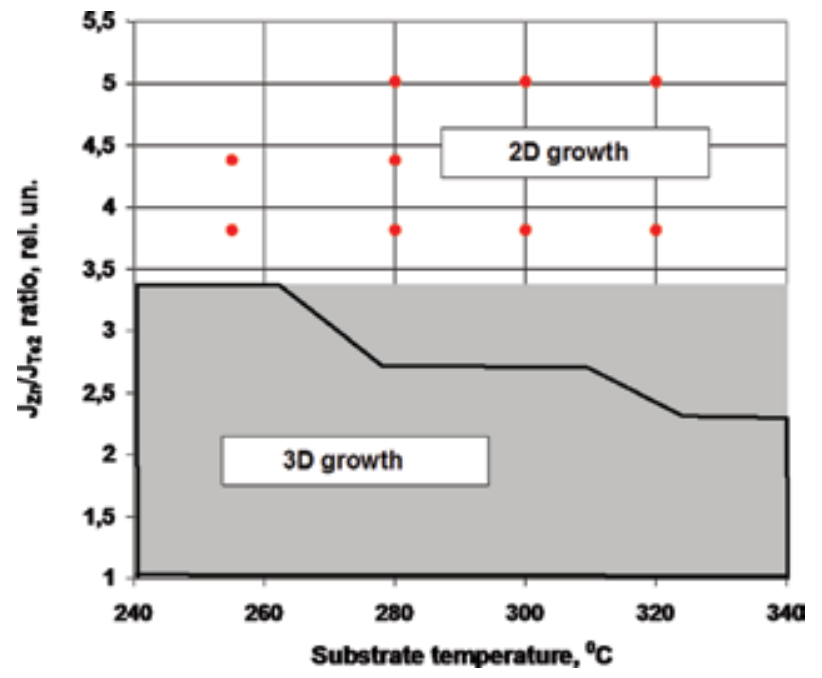

Figure 4.

Transition from $2 D$ to $3 D$ growth mechanism ZnTe growth.

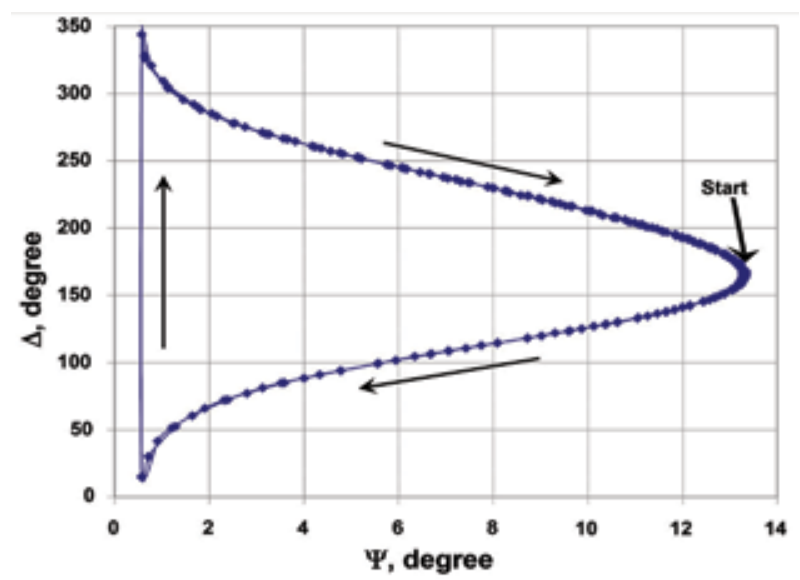

Figure 5.

The change of ellipsometric parameters $\Delta$ and $\Psi$ in $\Delta-\Psi$ plane in case of growth of ZnTe on (013) GaAs in optimal conditions. The arrows show the start of growth ZnTe and direction of changing parameter with increasing thickness. The rhombs is experimental data. The solid curve id calculated data.

to Figure 6). This means that the adsorption at the interface CdTe/GaAs is higher at the beginning of growth and decrease from $\mathrm{k}=0.6 \mathrm{up}$ to $\mathrm{k}=0.25$ at thickness $200 \mathrm{~nm}$ characterized for bulk CdTe values. Such behavior of k can be explained by formation poor crystalline structure formation of CdTe at initial growth stage of because of great mismatch $13.6 \%$ at conjugation of CdTe and GaAs.

So for growing of high quality $\mathrm{CdTe}$ layer on $\mathrm{GaAs}$ it is necessary to introduce the additional layer with appropriate mismatch to GaAs and with the same crystalline structure as CdTe.

At growth of CdTe on (013)ZnTe/GaAs the changing of $\Delta$ and $\Psi$ in $\Delta-\Psi$ plane represents by convergent spiral curve. For high quality crystalline CdTe layer on (013) ZnTe/GaAs there is the optimal growth condition which depends on $\mathrm{J}_{\mathrm{Cd}} /$ $\mathrm{J}_{\mathrm{Te} 2}$ ratio and temperature. For this purpose we used measurement of $\Delta$ and $\Psi$ during the growth in-situ at changing of $\mathrm{J}_{\mathrm{Cd}} / \mathrm{J}_{\mathrm{Te} 2}$ ratio and temperature. The first requirement for high quality CdTe layer is the $2 \mathrm{D}$ growth that determines flatness 
of growing surface and creates minimal defects density. Figure 7 shows the change of the ellipsometric parameter $\Delta$ for CdTe growth for different $\mathrm{J}_{\mathrm{Cd}} / \mathrm{J}_{\mathrm{Te} 2}$ ratio and constant temperature. The growth rate was $2.1 \mu \mathrm{m} / \mathrm{h}$. Growth temperatures $\mathrm{T}=290^{\circ} \mathrm{C}$. In the case of $\mathrm{J}_{\mathrm{Cd}} / \mathrm{J}_{\mathrm{Te} 2}=3.5$ there is no changes in the ellipsometric parameters $\Delta$. At large $\mathrm{J}_{\mathrm{Cd}} / \mathrm{J}_{\mathrm{Te} 2}=27$ a weak monotonic decrease in the ellipsometric parameter $\Delta$ is observed. But at low $\mathrm{J}_{\mathrm{Cd}} / \mathrm{J}_{\mathrm{Te} 2}=1$ there is observed sharp decreasing $\Delta$ practically from the beginning of growth. So it means that it is necessary to have the excess of $\mathrm{Cd}$ over Te in molecular fluxes. The observed decreasing of surface roughness is can be explained low sticking coefficient of $\mathrm{Cd}$ at growth temperature. This factor can influence on other CdTe characteristic such as: crystalline perfection and surface morphological defects.

We study in detail the influence of $\mathrm{J}_{\mathrm{Cd}} / \mathrm{J}_{\mathrm{Te} 2}$ ratio on $\mathrm{FWHM}$, roughness and surface defects density at different growth temperature (Figures 8-10) The structural perfection of the grown films was characterized by the full width at half maximum (FWHM) of the rocking curve measured on a double crystal X-ray diffractometer

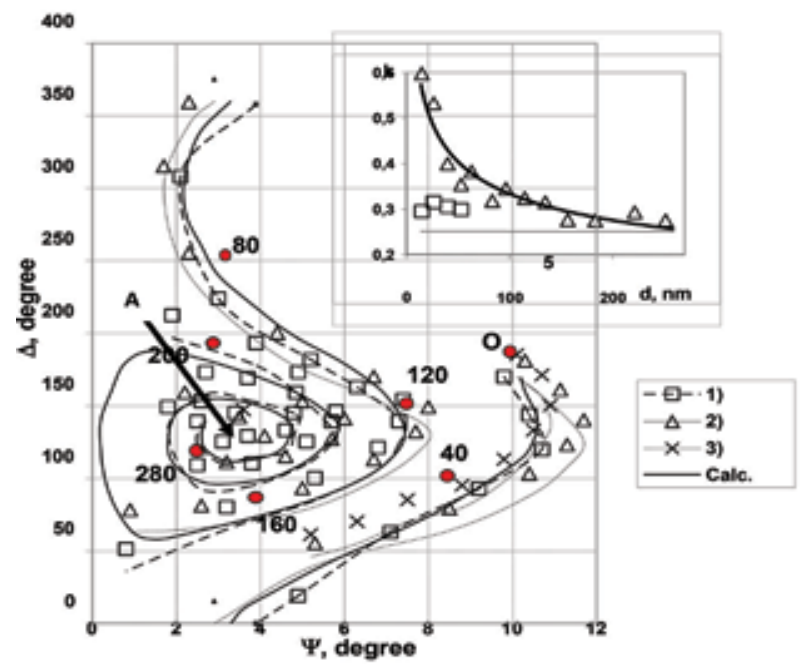

Figure 6.

The ellipsometric parameters change in $\Delta-\Psi$ plane at growth of CdTe on (o01)GaAs. Markers show experimentally measured values for three experiments. The lines show the calculated changing of ellipsometric parameters. The red circles correspond to the CdTe layer thickness in $n m$. In insert the absorption coefficient changing with thickness used for fit calculation and experimental data sample 1 and 2. O-start of growth.

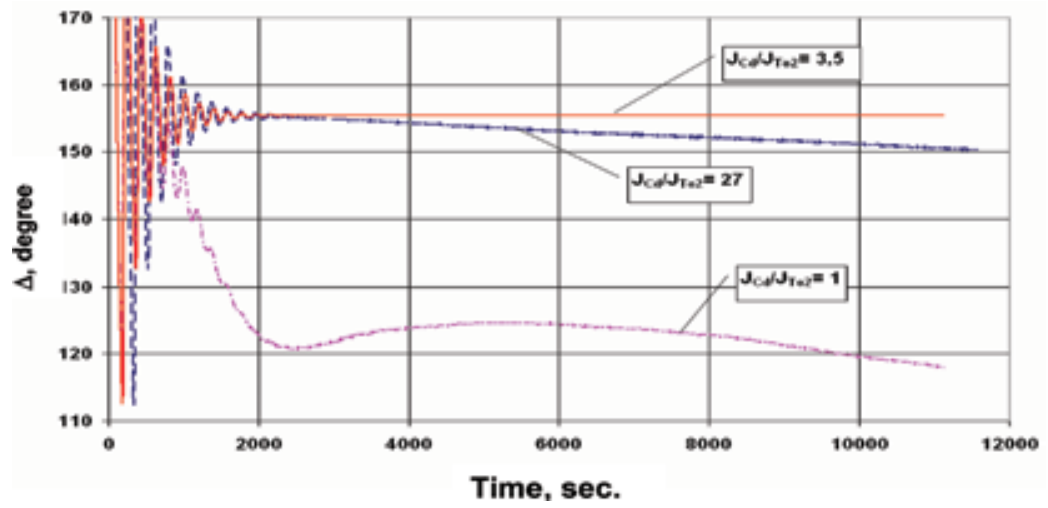

Figure 7 .

The change of ellipsometric parameter $\Delta$ with the time at the growth of CdTe on (013)ZnTe/GaAs. 


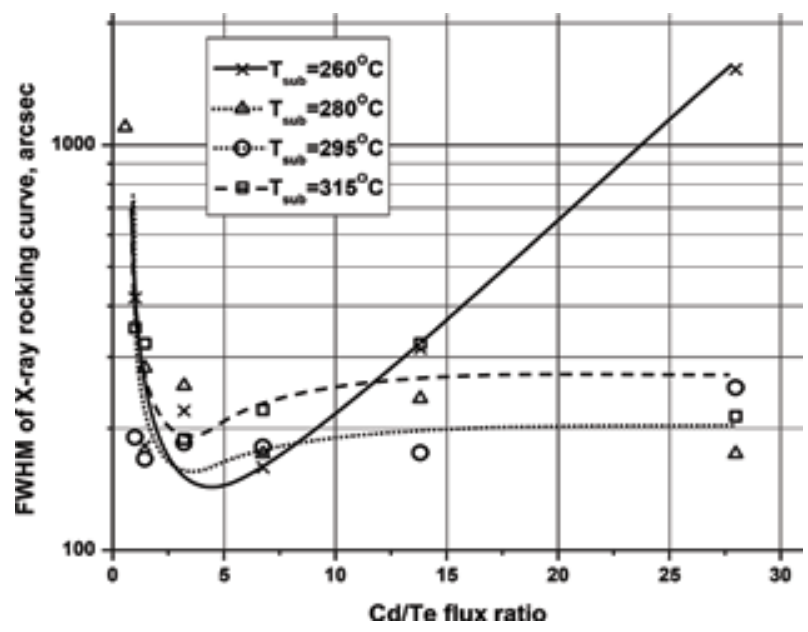

Figure 8.

The FWHM dependences on $J_{C d} / J_{T e 2}$ ratio at different growth substrate temperatures.

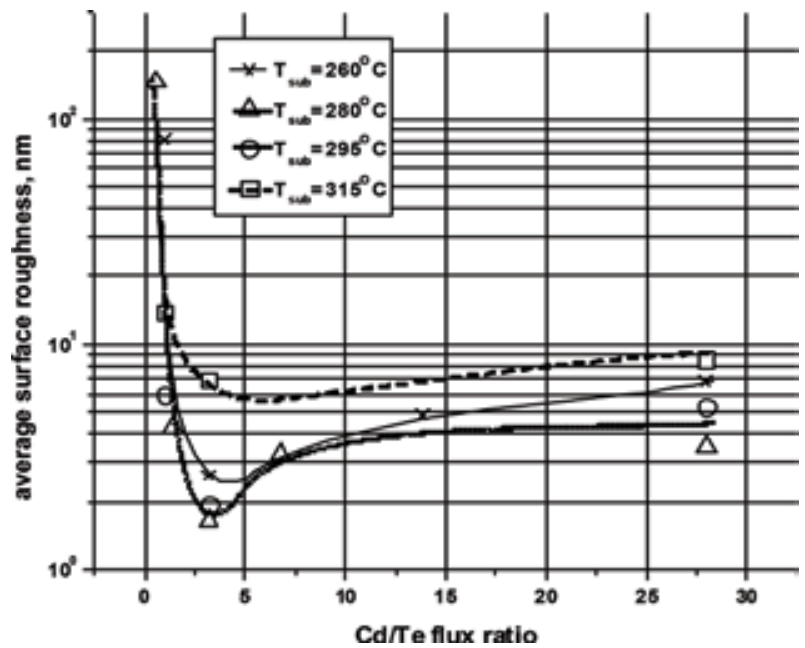

Figure 9.

The surface roughness dependences on $J_{C d} / J_{T e 2}$ ratio at different growth substrate temperatures.

with a germanium monochromator for reflex (004). It is seen in Figure 8 that in region $\mathrm{J}_{\mathrm{Cd}} / \mathrm{J}_{\mathrm{Te} 2}$ ratio $<1$ there is a sharp increase $\mathrm{FWHM}$ for all growth temperatures. In RHEED pattern point reflexes are observed that indicated 3D growth. We think that 3D growth is determined by the presence of adsorption of Te 2 on the growing surface [9]. At increasing $\mathrm{J}_{\mathrm{Cd}} / \mathrm{J}_{\mathrm{Te} 2}$ over $1 \mathrm{FWHM}$ slightly varied up to $\mathrm{J}_{\mathrm{Cd}} / \mathrm{J}_{\mathrm{Te} 2}=28$, except the case of growth temperature $260^{\circ} \mathrm{C}$. RHEED patterns show $2 \mathrm{D}$ growth mechanism. Thus, FWHM reaches minimum at $\mathrm{J}_{\mathrm{Cd}} / \mathrm{J}_{\mathrm{Te} 2}$ in range 1.5-7 for all temperatures of the substrate.

The surface roughness of the grown CdTe films was determined by scanning area $47 \times 47 \mu \mathrm{m}^{2}$ with the help of AFM Solver P-47 H (NT-MDT). Yet at initial stage of growth CdTe at $\mathrm{J}_{\mathrm{Cd}} / \mathrm{J}_{\mathrm{Te} 2}<1.5$ the parameter $\Delta$ is dramatically decreased (tens of degrees at a thickness less than $1 \mu \mathrm{m}$ ). The RHEED reflexes change from the extended strips to spots. This is due to 3D growth of CdTe because of enrichment tellurium on the growing surface. The roughness of CdTe surface slightly developed over all growth condition at $\mathrm{J}_{\mathrm{Cd}} / \mathrm{J}_{\mathrm{Te} 2}$ in range 2.5-28 up to $6 \mu \mathrm{m}$ in thickness of CdTe 


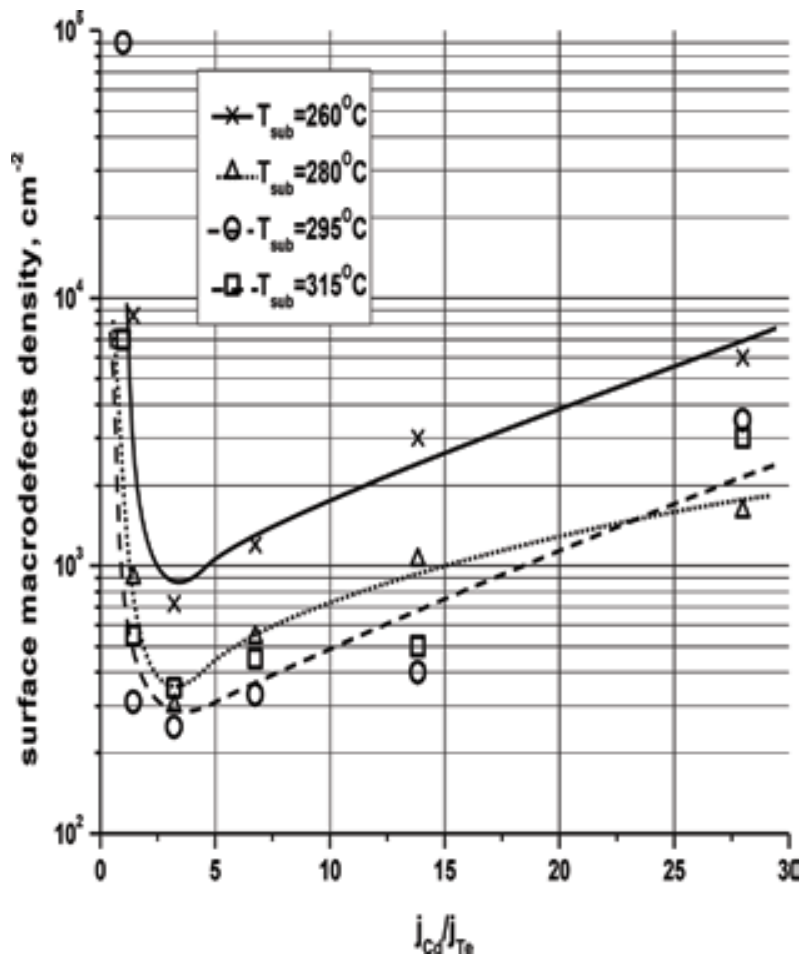

Figure 10.

The surface defects dependences on $J_{C d} / J_{T e 2}$ ratio at different growth substrate temperatures.

layer with observed slightly reduction in parameter $\Delta$. So the height of the surface roughness at $\mathrm{J}_{\mathrm{Cd}} / \mathrm{J}_{\mathrm{Te} 2}=2-5$ is $2-4 \mathrm{~nm}$ and at $\mathrm{J}_{\mathrm{Cd}} / \mathrm{J}_{\mathrm{Te} 2}=28$ increases approximately two times. The minimum roughness less that $1 \mathrm{~nm}$ reveals at $\mathrm{J}_{\mathrm{Cd}} / \mathrm{J}_{\mathrm{Te} 2}=6$.

The experimental data analysis of development roughness of CdTe surface at growth allows to determine the optimal growth conditions, such as growth temperatures $260-295^{\circ} \mathrm{C}$ and $\mathrm{J}_{\mathrm{Cd}} / \mathrm{J}_{\mathrm{Te} 2}=1.5-7$, for which the surface roughness is $2-3 \mathrm{~nm}$.

The density of surface defects density of CdTe layer was determined by measuring the density of brilliant points on the surface with the help of optical microscope in reflected light with a built-in CCD camera. The dependences of the density of surface defects density on $\mathrm{J}_{\mathrm{Cd}} / \mathrm{J}_{\mathrm{Te} 2}$ ratio at different growth temperatures are presented in Figure 10. There is a sharp increase in surface defects density at $\mathrm{J}_{\mathrm{Cd}} / \mathrm{J}_{\mathrm{Te} 2}<1.5$. The same changing in surface defects density is observed with increasing $\mathrm{J}_{\mathrm{Cd}} / \mathrm{J}_{\mathrm{Te} 2}$ in the range 5-28. It should be noted that surface defects density are minimal for grown temperature $295^{\circ} \mathrm{C}$ at any $\mathrm{J}_{\mathrm{Cd}} / \mathrm{J}_{\mathrm{Te2}}$. We found the optimal growth conditions for CdTe layer with a minimal surface defects density are as the growth temperature $280-315^{\circ} \mathrm{C}$ at $\mathrm{J}_{\mathrm{Cd}} / \mathrm{J}_{\mathrm{Te} 2}=1.5 \div 7$.

The analysis of total data represented in Figures 8-10 allows to determine the optimal growth condition for growth of high-quality CdTe films on (013)ZnTe/ GaAs substrates. The CdTe growth at $\mathrm{J}_{\mathrm{Cd}} / \mathrm{J}_{\mathrm{Te} 2}=5 \div 7$ and temperatures $285-295^{\circ} \mathrm{C}$ gives the following parameters: FWHM 160-190 arcsec, surface roughness 2-4 nm and the surface defects density $200-300 \mathrm{~cm}^{-2}$.

\section{Conclusion}

The study of preparation of atomically clean GaAs surface by sequence processes of special chemical etching and thermal annealing has been done and studied by both RHEED and ellipsometric control in-situ. 
The changing of RHEED patents and parameter $\Delta$ reveals the changing in surface adsorbed contamination and roughness at heating up to $580^{\circ} \mathrm{C}$ connected with desorbing of arsenic oxides at low temperatures $400^{\circ} \mathrm{C}$ and then gallium oxides at high temperatures over $500^{\circ} \mathrm{C}$. The comparison of the temperature dependence of the diffraction reflexes intensity with in-situ ellipsometric measurements showed the efficiency of ellipsometric control during thermal cleaning of the surface of GaAs substrates in ultrahigh vacuum.

The ellipsometric control in-situ was used in the growth of ZnTe on the (013) GaAs substrate. We found the influence of roughness and absorption on changing of ellipsometric parameters $\Delta$ and $\Psi$. This gives us to determine the areas of $2 \mathrm{D}$ and $3 \mathrm{D} \mathrm{ZnTe}$ growth depending on growth temperatures and zinc to tellurium ratios in molecular fluxes. We found the optimal growth condition for epitaxy of high quality ZnTe layer on (013) GaAs substrate.

The dependences of FWHM, roughness and surface density defects on growth temperatures and cadmium to tellurium ratios in molecular fluxes reveals the growth condition for epitaxy of high quality CdTe layer on (013)ZnTe/GaAs substrate.

The high quality (013) CdTe/ZnTe/GaAs substrate is can be used as an alternative substrate and material for solar, high power energetic and IR photonics.

\title{
Acknowledgements
}

The authors express their sincere gratitude to L.D. Burdina for the chemical preparation of GaAs substrates. The work was carried out with partial financial support from the Program of the Russian Academy of Sciences No. 110.

\section{Author details}

\author{
S.A. Dvoretsky*, N.N. Mikhailov, D.G. Ikusov, V.A. Kartashev, A.V. Kolesnikov, \\ I.V. Sabinina, Yu. G. Sidorov and V.A. Shvets \\ Rzhanov Institute of Semiconductor Physics, Siberian Branch of Russian Academy \\ of Sciences, Novosibirsk, Russia
}

*Address all correspondence to: dvor@isp.nsc.ru

\section{IntechOpen}

(C) 2019 The Author(s). Licensee IntechOpen. This chapter is distributed under the terms of the Creative Commons Attribution License (http://creativecommons.org/licenses/ by/3.0), which permits unrestricted use, distribution, and reproduction in any medium, provided the original work is properly cited. (cc) BY 


\section{References}

[1] Varavin VS, Vasiliev VV, Dvoretsky SA, Mikhailov NN, Ovsyuk VN, Sidorov YG, et al. HgCdTe epilayers on GaAs: Growth and devices. Opto-Electronics Review. 2003;11(2):99-111

[2] Koike K, Tanaka N, Li S, Yano $\mathrm{M}$. High-quality CdTe growth in the (100)-orientation on (100)GaAs substrates by molecular beam epitaxy. Journal of Crystal Growth. 2001;227-228:671-676

[3] Ari O, Polat M, Karakaya M, Selamet Y. Growth and characterization of CdTe absorbers on GaAs by MBE for high concentration PV solar cella. Physica Status Solidi C. 2015;12:1211-1214. DOI: 10.1002/pssc201510068

[4] Faurie JP, Million A. Molecular beam epitaxy of II-VI compounds: CdxHg1-xTe. Journal of Crystal Growth. 1981;54(3):582-585. DOI: 10.1016/0022-0238(81)90515-9

[5] Daudin B, Cunff DB, Tatarenko S. Stoichiometry determination of the Te-rich (100)CdTe and (100) ZnTe surfaces. Surface science. 1996;352-354:99-104

[6] Zubkov VA, Kalinin VV, Kuzmin VD, Sidorov YG, Dvoretsky SA, Stenin SI. Poverkhnost. 1991;9:45-51 (In Russian)

[7] Sidorov YG, Dvoretsky SA, Mikhhailov NN, Yakushev MV, Varavin VS, Antsiferov AP. Molecular-beam epitaxy of narrow-band CdxHg1-xTe. Equipment and technology. Journal of Optical Technology. 2000;67:31-36. DOI: 10.1364/JOT.67.000031

[8] Chang C, Helblum M, Ludeke R, Natan MI. Effect of substrate surface treatment in molecular beam epitaxy on the vertical electronic transport through the film-substrate interface. Applied
Physics Letters. 1981;39:229-231. DOI: 10.1063/1.92689

[9] Vasques RP, Lewis BF, Grunthaner FJ. X-ray photoelectron spectroscopic study of the oxide removal mechanism of (001) GaAs molecular beam epitaxial substrates in in situ heating. Applied Physics Letters. 1983;42(3):293-295. DOI: $10.1364 / 1.93884$

[10] Cho AI. Growth of III-V semiconductors by molecular beam epitaxy and their properties. Thin Solid Films. 1983;100:291-296. DOI: 10.1016/0040-6090(83)90154-2

[11] Spesivtsev EV, Rykhlitski SV. Useful model "Ellipsometer". Licence No 16314. Bulletin "Useful Models. Industrial Samples”. 35 (In Russian) [Accessed: 20 December 2000]

[12] Gu Y, Zheng H-J, Chen X-R, Li J-M, Nie T-X, Kou X-F. Influence of surface structures on quality of $\mathrm{CdTe}(100)$ thin films grown on $\mathrm{GaAs}(100)$ substrates. Chinese Physics Letters. 2018;8:086801

[13] Sidorov YG, Yakushev MV, Kolesnikov AV. Dislocation in CdTe heterostructures on GaAs(301) and $\mathrm{Si}(301)$ substrates. Optoelectonics, Instrumentation and Data Processing. 2014;50(3):234-240

[14] Latyshev AV. Advances Semiconductor Nanostructures. Growth, Characterization, Properties and Applications. Vol. 17. Nethrlands; United Kindom; United States: Elsevier; 2017. pp. 305-308. ISBN: 978-0-12-810512-2

[15] Otsuka N, Kolodziejski LA, Gunshor RL, Datta S. High resolution electron microscope study of epitaxial CdTe-GaAs interfaces. Applied Physics Letters. 1985;46(9):860 



\title{
High Temperature Oxidation and Wear Resistant Bi-Layer Coating for Turbocharger Housing
}

\author{
Hitesh Vasudev, Lalit Thakur and Amit Bansal
}

\begin{abstract}
An upsurge in the demand of higher power generation has been observed in the last few decades. Consequently, the mechanical components of power generation are forced to operate in the extreme working conditions for longer duration, which results in the accelerated wear and corrosion of the material. Conventional material such as grey cast iron (GCI) is a preferred material of components used for power generation at high temperature. Grey cast iron exhibits poor wear and corrosion resistance at high temperature. On the other hand, an advanced material such as Alloy-718 is capable to withstand the high-temperature wear and oxidation for prolonged duration of time. In the current research, high temperature corrosion and erosive wear performance of grey cast iron (GCI) components has been enhanced by depositing a bi-layerAlloy-718/NiCrAlY coating by using high velocity oxy-fuel (HVOF) thermal spray process. Furthermore, the high temperature corrosion and erosion behaviour of GCI substrate and the deposited coating has been discussed. The various characterization techniques such as scanning electron microscopy (SEM) X-ray diffraction, and Vickers micro-hardness testing were conducted for the GCI substrate and Alloy-718 coating, respectively. The Alloy-718 coting showed the increased resistance against high-temperature erosion and oxidation, which can be attributed to its good bonding with the substrate, high hardness and formation of protective phases at high-temperature.
\end{abstract}

Keywords: high-temperature, turbocharger, Alloy-718/NiCrAlY, HVOF, grey cast iron

\section{Introduction}

The present scenario of the automotive engineering is concerned with the higher power generation. There is a huge requirement of the materials which can sustain the high temperature in order to increase the power generation of the systems. These materials require high thermo-mechanical properties to withstand the hostile conditions like oxidation and erosion at elevated temperatures up to $900^{\circ} \mathrm{C}$. The surface of the components deteriorates rapidly at such aggressive conditions. Grey cast iron (GCI) is one of the most commonly used materials in the turbocharger housing and its integral parts such as housing of bearing. The GCI components must work satisfactorily for prolonged duration of time under such aggressive working condition [1-4]. However, the GCI alone cannot provide enough oxidation and erosion 
resistance at high temperature. Thus, there is a need to modify the surface properties of the GCI component which enables it to work under high temperature oxidation and erosion environment. There are number of methods to modify the surface properties of materials such as by changing the surface chemistry of the materials with the help of surface modification techniques such as carburizing, nitriding and cyaniding, etc. The various methods of surface engineering applied for surface modification are given in Table 1. The methods employing the deposition of a layer of superior material is commonly employed in surface engineering. This can be

\begin{tabular}{|c|c|c|}
\hline S. no. & Surface treatment/coating type & Primary property benefits \\
\hline \multirow[t]{4}{*}{1} & \multicolumn{2}{|l|}{ Changing the surface metallurgy } \\
\hline & $\begin{array}{l}\text { Localized surface hardening } \\
\text { (flame, induction, laser, and } \\
\text { electron-beam hardening) }\end{array}$ & $\begin{array}{l}\text { Improved wear resistance through the development of a } \\
\text { hard martensitic surface }\end{array}$ \\
\hline & Laser melting & $\begin{array}{l}\text { Improved wear resistance through grain refinement and the } \\
\text { formation of fine dispersions of precipitates }\end{array}$ \\
\hline & Shot peening & $\begin{array}{l}\text { Improved fatigue strength due to compressive stresses } \\
\text { induced on the exposed surface, also relieves tensile stresses } \\
\text { that contribute to stress-corrosion cracking }\end{array}$ \\
\hline \multirow[t]{7}{*}{2} & \multicolumn{2}{|l|}{ Changing the surface chemistry } \\
\hline & Carburizing & $\begin{array}{l}\text { Used primarily for steels for increased resistance to wear, } \\
\text { bending fatigue, and rolling-contact fatigue }\end{array}$ \\
\hline & Nitriding & $\begin{array}{l}\text { Used primarily for steels for improved wear resistance, } \\
\text { increased fatigue resistance, and improved corrosion } \\
\text { resistance (except stainless steels) }\end{array}$ \\
\hline & Carbonitriding & Used primarily for steels for improved wear resistance \\
\hline & Boronizing (boriding) & $\begin{array}{l}\text { Improved wear resistance, oxidative wear, and surface } \\
\text { fatigue }\end{array}$ \\
\hline & Ion implantation & $\begin{array}{l}\text { Improved friction and wear resistance for a variety of } \\
\text { substrates }\end{array}$ \\
\hline & Laser alloying & Improved wear resistance \\
\hline \multirow[t]{7}{*}{3} & \multicolumn{2}{|c|}{ Adding a surface layer or coating/cladding } \\
\hline & $\begin{array}{l}\text { Physical vapour deposition } \\
\text { (PVD) }\end{array}$ & $\begin{array}{l}\text { Improved wear (e.g. tools and dies) and corrosion resistance } \\
\text { improved optical and electronic properties }\end{array}$ \\
\hline & $\begin{array}{l}\text { Chemical vapour deposition } \\
\text { (CVD) }\end{array}$ & $\begin{array}{l}\text { Improved wear (e.g. tools and dies), erosion, and corrosion } \\
\text { resistance; also used for epitaxial growth of semiconductors }\end{array}$ \\
\hline & Thermal spraying & $\begin{array}{l}\text { Primarily used for improved wear resistance (many coating } \\
\text { systems including Ni-based alloys, ceramics and cermets), } \\
\text { but also used for improved corrosion resistance (aluminum, } \\
\text { zinc, and their alloys) and oxidation resistance (e.g. } \\
\text { MCrAlY), thermal barrier protection (partially stabilized } \\
\text { zirconia), electrically conductive coatings (e.g. copper and } \\
\text { silver), and dimensional restoration }\end{array}$ \\
\hline & Electroless plating & $\begin{array}{l}\text { Improved corrosion resistance (nickel-phosphorus) and } \\
\text { wear resistance (nickel-phosphorus and nickel-boron) }\end{array}$ \\
\hline & Weld overlays & $\begin{array}{l}\text { Improved wear resistance (hardfacing alloys) and corrosion } \\
\text { resistance (stainless steel or nickel-base overlays) and } \\
\text { dimensional restoration (buildup alloys) }\end{array}$ \\
\hline & Laser cladding & Improved wear and corrosion resistance \\
\hline
\end{tabular}

Table 1.

Surface engineering options and property enhancement. 
done by number of methods such as weld overlaying, cladding and thermal spraying, etc. Nowadays, the thermal spraying methods are used in various industries due to their specific advantages such as ease of operation, enhanced surface properties, less detrimental effects to the substrate and to produce the coatings on any intricate shaped components [5-7]. This process is utilized in the deposition of almost all class of engineering materials like polymers, ceramic, metal, and composite $[8,9]$.

There are various techniques of thermal spraying but the high velocity oxy-fuel (HVOF) process is gaining popularity due to its specific characteristics such as corrosion and wear resistant coating, high velocity up to $1000 \mathrm{~m} / \mathrm{s}$, lower porosity content and dimensional restoration. This high velocity in this technique causes feedstock powder to deform plastically on the surface of the substrate [10]. Moreover, this technique has taken up by numerous industries due to its mobility, economical processing and ease of operation with safety along with excellent quality of the coating. High velocity oxy-fuel (HVOF) process provides the coatings with high hardness, very low oxidation, good abrasion resistance, lower porosity levels and high erosion resistance as compared to the other thermal spray coating techniques [11]. The characteristics of high velocity makes it enable to deposit coatings with improved bonding with the substrate that results in higher hardness, less porosity and high density. The various attributes of different thermal spray methods involves the type of heat source used, which is responsible for the temperature of the process, the velocity of powder particles and the rate at which powder is being feed for the deposition purpose. The comparison of various characteristics of thermal spray coating processes is given in Table 2 .

Oxidation is related to the formation of some undesired phases like porous and non-coherent oxides on the surface of the material, which is responsible for the failure of the component. The oxidation generally starts from the surface due to diffusion of oxygen and further propagates to the sub-surface of the material in an aggressive thermal cycling condition. This problem is observed in turbocharger housing and bearing housing. These components also suffer from an erosive wear along with the oxidation. In the erosion of components, the hot air strikes on the surface of the components in cyclic and repetitive manner, and this air contains some unwanted dust particles. The intensity of these particles and hostile environment are two major reasons responsible for the degradation of the surface with erosion at elevated temperature above $500^{\circ} \mathrm{C}[12]$. The oxidation of component is not only a single problem to solved by using Ni-based coatings, the erosion is also present due to the erodent particles impacting on materials surface at high velocities; thus there is a requirement of feasible solution which can help to minimise both the problems of oxidation and erosion at a same time.

\begin{tabular}{lccccc}
\hline $\begin{array}{l}\text { Coating } \\
\text { process }\end{array}$ & Source of heat & $\begin{array}{c}\text { Feedstock } \\
\text { material }\end{array}$ & $\begin{array}{c}\text { Feedstock } \\
\text { powder } \\
\text { temp }\left({ }^{\circ} \mathbf{C}\right)\end{array}$ & $\begin{array}{c}\text { Velocity of } \\
\text { powder }(\mathbf{m} / \mathbf{s})\end{array}$ & $\begin{array}{c}\text { Deposition } \\
\text { rates }(\mathbf{k g} / \mathbf{h})\end{array}$ \\
\hline Flame spray & Oxy-acetylene & $\begin{array}{c}\text { Powder or } \\
\text { wire }\end{array}$ & 3100 & 40 & $2-5$ \\
\hline Plasma spray & Plasma arc & Powder & 10,000 & $200-400$ & $3-8$ \\
\hline LPPS & Plasma arc & Powder & 11,000 & $200-400$ & $3-8$ \\
\hline $\begin{array}{l}\text { Detonation } \\
\text { spray }\end{array}$ & $\begin{array}{c}\mathrm{O}_{2} \text {-acetylene- } \mathrm{N}_{2}+\text { gas } \\
\text { detonation }\end{array}$ & Powder & 4700 & 800 & 0.6 \\
\hline HVOF & Oxy-fuel combustion & Powder & 3000 & 800 & $2-4$ \\
\hline
\end{tabular}

Table 2.

Attributes for different thermal spray processes. 
Nowadays, the $\mathrm{Ni}-\mathrm{Cr}$ coatings are used as a most preferred candidate for the oxidation resistance of components operated at high temperature range up to $650^{\circ} \mathrm{C}$. However, these coatings suffered a problem of diffusion of Fe element from the substrate to the coating, when applied on the ferrous materials against oxidation at high temperature. The $\mathrm{Ni}-50 \mathrm{Cr}$ coatings were also used to minimize this problem by using HVOF process [13]. The composite coatings then came into use and were utilized to provide resistance against erosion and corrosion at high temperature. The $\mathrm{Cr}_{3} \mathrm{C}_{2}-\mathrm{NiCr}, \mathrm{NiAl}-40 \mathrm{Al}_{2} \mathrm{O}_{3}$, and $\mathrm{Cr}_{3} \mathrm{C}_{2} / \mathrm{TiC}-\mathrm{NiCrMo}$ composite coatings were deposited on low carbon steel to check its performance against erosion-corrosion at $400^{\circ} \mathrm{C}$. The inter-metallic present in NiAl- $40 \mathrm{Al}_{2} \mathrm{O}_{3}$ was responsible for the maximum resistance to the erosion-corrosion [14].

In the recent time, the superalloy materials are extensively used for high temperature applications. Their versatile use in these applications is due to fact that they can maintain their high strength, low temperature ductility and excellent thermal stability. Superalloys are mainly precipitation hardened or solid solution hardened nickel, iron, and cobalt based heat resistant alloys, which exhibit various properties such as good mechanical strength, wear resistance and high temperature stability. These superalloys are further classified into cast, wrought and powder metallurgy alloys. A general classification of superalloys is shown in Figure 1. More than 50\% of the primary materials used in the hot portions of the gas turbine engines such as blades, vanes and combustion chamber are superalloys. Typical applications of superalloys include gas turbines and jet engines [15]. The versatile use of superalloys in such applications is due to fact that the thermodynamic efficiency of turbine engines is increased with increased turbine inlet temperature. These motivated the designers for increasing the maximum operating temperature using the superalloys. The Ni-based superalloys are most commonly used in high temperature applications, followed by the cobalt-based alloys and then the iron-nickel alloys. The $\mathrm{Ni}$-based alloys are preferred for high temperature applications because of their excellent oxidation resistance at high temperature. The Ni-based superalloys are most stable materials at high temperature due to their face-centered cubic (FCC) crystal structure. FCC crystal structure is required at high temperature because

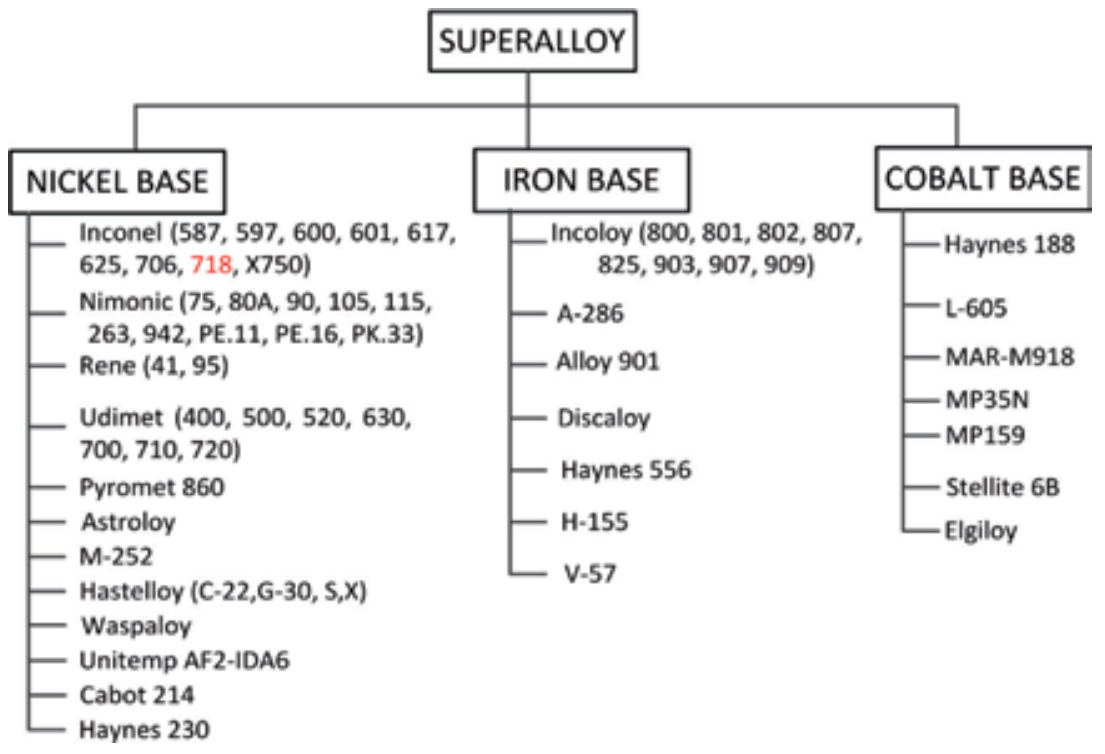

Figure 1.

Classification of superalloys [25]. 
of its close packed structure. Consequently, the creep, which is more prominent at high temperature, is less in FCC crystal structure. Thus, in the current research work, a nickel based superalloy Alloy-718 was selected as a feedstock powder for increasing performance of GCI at high temperature application. Alloy-718 is well known for its thermo-mechanical strength at elevated temperatures [16]. The NiCrAlY was also deposited before the coating of Alloy-718 as a bond coat material. The NiCrAlY also provides a rough surface for Alloy-718 top coat and also restricts the diffusion of elements from substrate to coating and vice-versa [17]. Hence, a bi-layer of Alloy-718/NiCrAlY was deposited on the GCI substrate by using thermal coating technique known as high velocity oxy-fuel (HVOF) spray process. The deposited bi-layer coating was investigated for its performance against high temperature erosion and oxidation. The oxidation test was conducted for 50 cycles at $900^{\circ} \mathrm{C}$ in a tube furnace, whereas the erosion test was conducted by using high temperature air-jet erosion testing rig at $800^{\circ} \mathrm{C}$. The microstructure and mechanical characterization were performed to analyse the properties and performance of deposited bi-layer coating. The mechanical characterization mainly included the micro-hardness testing and erosion test, whereas, the microstructural analysis covers the porosity analysis, inter-splat bonding and morphology of the sprayed coating.

\section{Experimentation}

\subsection{Materials and coating deposition}

In the present work, the grey cast iron (GCI) was selected as a substrate material due to its extensive use in the manufacturing of turbocharger housing, turbocharger core and bearing housing in the turbocharger. The Alloy-718 feedstock powder was used as a coating material and NiCrAlY was selected as a bond coat between the top coat (Alloy-718) and the GCI substrate material. Therefore, bi-layer coatings consisting of Alloy-718/NiCrAlY were deposited on a grey cast iron substrate using the HVOF process. The GCI was cast into a flat plate and further machined into coupons as per the sizes required for characterization and testing purpose. The chemical composition of the GCI, and feedstock powder was checked by using optical spectrometer (Make: Metal Vision, Model: 1008i). The chemical composition of GCI in wt\% was found to be 3-3.5 wt\% C, $2.7 \mathrm{wt} \% \max \mathrm{Si}, 1 \mathrm{wt} \% \max \mathrm{P}$, $1 \mathrm{wt} \% \max \mathrm{Mn}, 0.15 \mathrm{wt} \% \mathrm{~S}$, balance Fe. The chemical composition of Alloy-718 in the wt\% comprises of $\mathrm{Ni}-55.0, \mathrm{Cr}-21.0, \mathrm{Fe}-19.0, \mathrm{Nb}-5.1, \mathrm{Mo}-3.2, \mathrm{Al}-0.5$, $\mathrm{Ti}-1.2$ and $\mathrm{C}-0.08 \mathrm{Ni}, \mathrm{Cr}$ and $\mathrm{Fe}$ are the major elements of Alloy-718 powder, whereas, $\mathrm{Nb}, \mathrm{Mo}$ and $\mathrm{Al}$ are some other important elements of Alloy-718.

The coating powders (Alloy-718, and NiCrAlY) were purchased from MECPL, Jodhpur, India, and $\mathrm{f}$ the deposition of the bi-layer coatings was also performed at MECPL, Jodhpur, India. The bi-layer coating was deposited with the help of a HVOF system Hipojet-2700 (manufactured by MECPL, Jodhpur, India). The various coating process parameters of the HVOF process include stand-off distance $235 \mathrm{~mm}$, oxygen flow rate of 250 SLPM, oxygen pressure of $9 \mathrm{bar}$, powder feed rate of $40 \mathrm{~g} / \mathrm{min}$, LPG fuel gas flow rate of 39 SLPM and fuel gas pressure of 5 bar.

\subsection{Material characterization}

The characterization of as-sprayed, oxidized and eroded coatings was carried out on the surface and the cross-section by using scanning electron microscopy (SEM) equipped with energy dispersive spectroscopy (Model: Gemini ultra plus, Zeiss). 
The various phases formed in the as-sprayed, oxidized and eroded coating were revealed by using X-ray diffraction (XRD) analysis with $\mathrm{Cu}-\mathrm{K} \alpha$ as source of radiation at $40 \mathrm{kV}$ and $40 \mathrm{~mA}$. The micro-hardness of the bi-layer coating was measured by using Vickers micro-hardness tester, where the 10 indents were taken across the cross-section of coated sample at a test load of $200 \mathrm{~g}$ with a dwell period of $10 \mathrm{~s}$. Porosity of the coating was measured on the cross-section by using optical images taken from an optical microscope attached with an image analysis software (Dewinter Material Plus, Version 4.3).

\subsection{Oxidation and erosion testing}

The coated and bare GCI specimen were subjected to high-temperature oxidation at $900^{\circ} \mathrm{C}$ for 50 cycles of thermal cyclic operation. In the oxidation test, 1 cycle was comprised of $1 \mathrm{~h}$. heating of sample followed by air cooling for $20 \mathrm{~min}$. The six sided coated samples having dimensions of $25 \times 15 \times 5 \mathrm{~mm}^{3}$ were placed in an alumina crucible and fed inside the tube furnace for oxidation test. Thermogravimetric analysis was used to measure the weight loss $\left(\mathrm{mg} / \mathrm{cm}^{2}\right)$ of the coating and substrate during oxidation test.

The erosion test was also performed by using hot-air jet erosion test rig at a high temperature of $800^{\circ} \mathrm{C}$ as per the ASTM G76-02 standard. The erosion rate $(\mathrm{g} / \mathrm{g})$ ) (ratio of wear loss of mass in grams to the erodent mass in grams) was calculated after measuring the change in the weight of the coating and substrate by using weighing balance (Model: ML-220, Make: Mettler Toledo). The impingement angles of 30 and $90^{\circ}$ were considered in the present study to compare the erosion rates of the substrate and coating. The various process parameters of erosion test include erodent feed rate of $6 \mathrm{~g} / \mathrm{min}$, erodent velocity of $60 \mathrm{~m} / \mathrm{s}$, and exposure time of $10 \mathrm{~min}$. The aluminum oxide having an average particle size of about $60 \mu \mathrm{m}$ was used as the erodent in the present study.

\section{Results and discussion}

\subsection{Microstructural study}

The SEM micrograph indicating the spherical morphology of the Alloy-718 powder along with its EDS is shown in Figure $\mathbf{2} \mathbf{a}$ and $\mathbf{b}$, respectively. The XRD spectrum of the Alloy-718 powder is shown in Figure 2c. From SEM micrograph, the average powder particle size of Alloy-718 powder was observed to be around $45 \mu \mathrm{m}$. The XRD spectrum of Alloy-718 powder indicates that $\mathrm{Ni}, \mathrm{Cr}$, and $\mathrm{Fe}$ are present as major elements in the form of a solid solution and EDS spectrum (Figure 2b) confirms the presence of these elements in the powder.

The SEM/EDS analysis of the NiCrAlY powder is shown in Figure 3a and c respectively. The SEM micrograph of NiCrAlY powder shows the average powder particle size of $45 \mu \mathrm{m}$ which is approximately same as that of Alloy-718 powder. The XRD pattern of NiCrAlY powder is depicted in Figure 3b; it shows the presence of $\mathrm{Ni}$ and $\mathrm{Cr}$ as major elements and further EDS confirms the presence of these elements in the powder. The XRD pattern of NiCrAlY shows the $\beta$-phase of NiAl, $\mathrm{Cr}$, and $\mathrm{Ni}$.

The as-sprayed Alloy-718 coating shows (Figure 4) the presence of some un-melted, melted, and semi-melted particles. The proper interference between melted and un-melted splats can be observed. The various powder particles seem to have flattened and spherical appearance. The powder particles were not completely melted due to moderate flame temperature of HVOF process as compared to the 

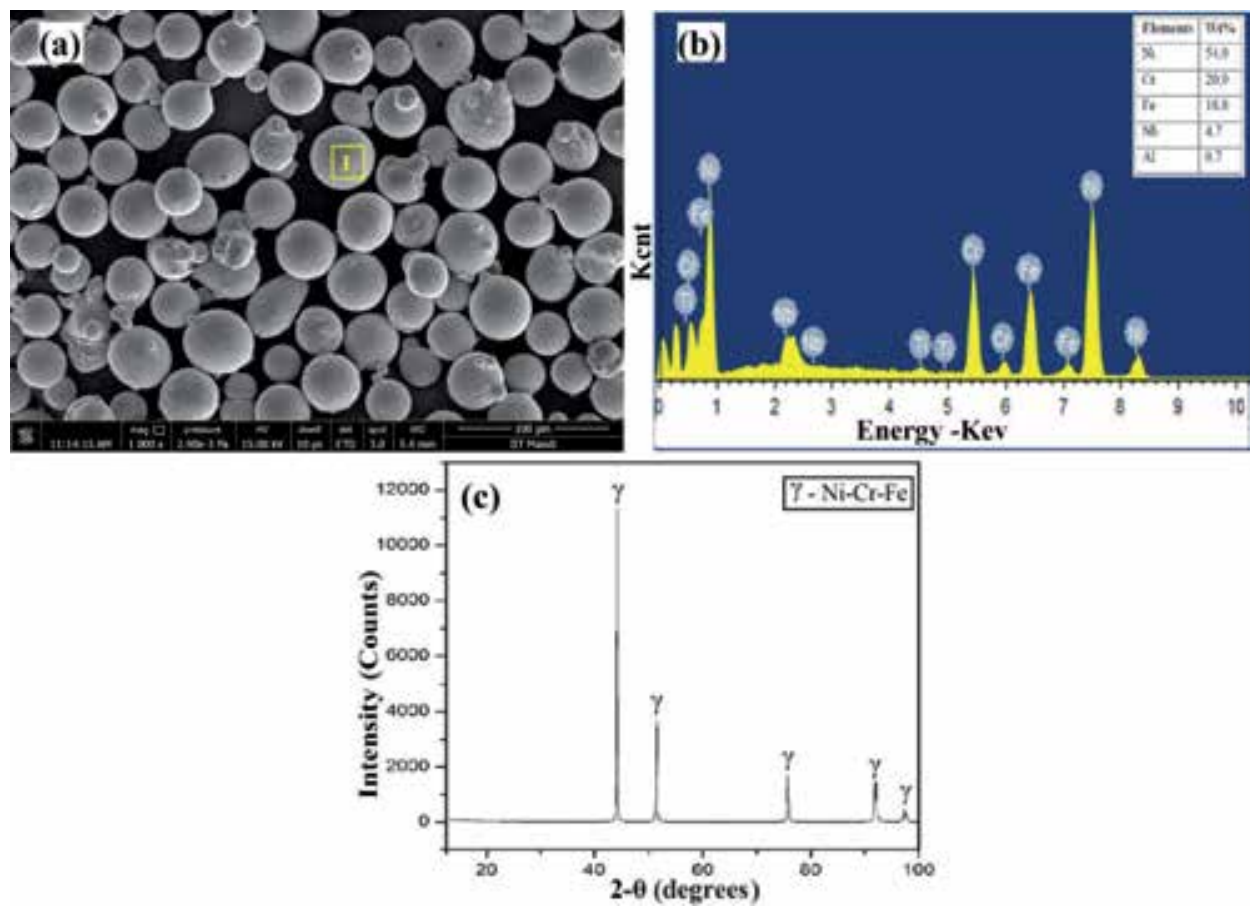

Figure 2.

(a) SEM micrograph of Alloy-718 powder, (b) EDS corresponding to point 1 and (c) XRD pattern of Alloy-718 powder.

plasma spray (PS) process. The temperature range in HVOF thermal spray process is around $2900^{\circ} \mathrm{C}$, which is significantly low as compared to the temperature range in plasma spray process. The melted/semi-melted powder particles were splashed throughout the surface of coating without the absence of cracks. The EDS spectrum (Figure 4b) taken on the melted particle corresponding to point 3 confirms the presence of $\mathrm{Ni}, \mathrm{Fe}, \mathrm{Cr}, \mathrm{O}$, and $\mathrm{Al}$ elements. The XRD pattern (Figure 4c) of assprayed coating of Alloy-718 showed the solid solution of $\mathrm{Ni}-\mathrm{Cr}-\mathrm{Fe}$ as a major phase along with some oxides such as $\mathrm{Al}_{2} \mathrm{O}_{3}, \mathrm{Cr}_{2} \mathrm{O}_{3}$, and $\mathrm{NiO}$. The oxides may be formed due to oxidation of in-flight powder particles during the deposition of coating [18].

The SEM micrograph and X-ray maps were acquired on the cross-section of bi-layer coating, as presented in Figure 5. From the SEM micrograph, it is clear that a NiCrAlY bond coat of about 50-60 $\mu \mathrm{m}$ thickness is introduced between substrate and top coat (Alloy-718). The coating shows well bonded interfaces with excellent mechanical anchorage. The splat formation of the deposited coating resulted in good inter-splat bonding. The X-ray maps show the intense presence of $\mathrm{Fe}$ in the substrate, whereas the bond coat region has a $\mathrm{Ni}$ and $\mathrm{Cr}$ in high density. The top coat (Alloy718) region shows the presence of major elements $\mathrm{Ni}, \mathrm{Cr}$ and $\mathrm{Fe}$ along with $\mathrm{O}$. The presence of $\mathrm{O}$ in the Alloy-718 coatings in the $\mathrm{X}$-ray mapping endorsed the formation of oxides such as $\mathrm{Al}_{2} \mathrm{O}_{3}, \mathrm{Cr}_{2} \mathrm{O}_{3}$, and $\mathrm{NiO}$. The porosity across the cross section was measured, as described in the Section 2.3 was found to be in a range of $1-1.5 \%$.

\subsection{Micro-hardness study}

The micro-hardness of the bi-layer coating on the cross-section was measured, as described in Section 2.2. The micro-hardness of HVOF sprayed coating was found to be higher than that of the GCI. There is an increase in the micro-hardness values for the GCI substrate at the interface of bond coat-substrate, which may be attributed to 

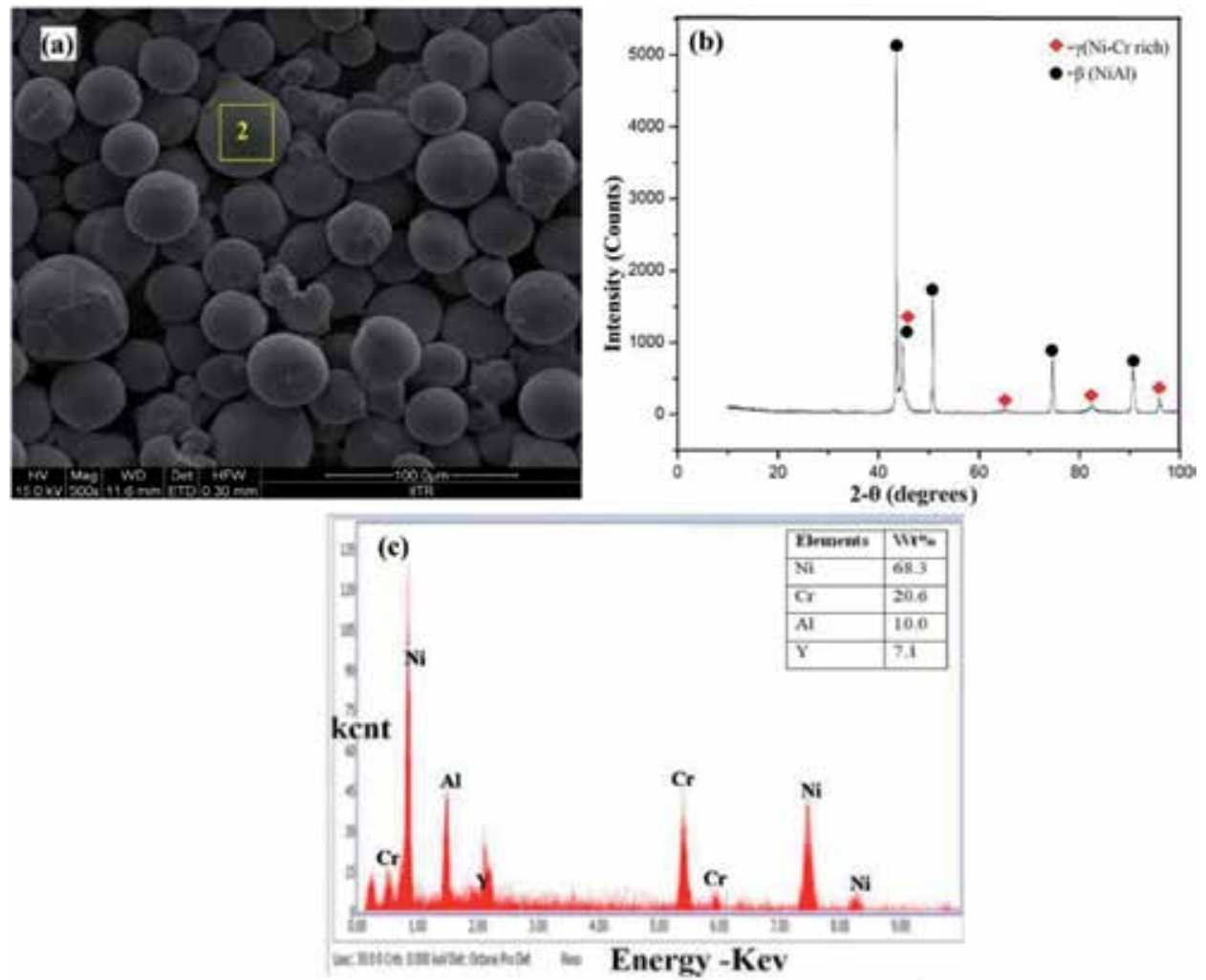

Figure 3.

(a) SEM micrograph of NiCrAlY powder, (b) XRD pattern of NiCrAlY powder and (c) EDS corresponding to point-2.

the grit blasting operation prior to the coating, which produces the strain hardening effect on the substrate before the deposition of coating process [13]. The hardening of the coated substrates in the present research work might also have occurred due to the impacts of high velocity powder particles during the HVOF deposition process. Similar kind of effect has also been reported by some researchers [11]. The microhardness values of the coatings are measured to be greater than the GCI substrates. High micro-hardness value is attributed due to the high kinetic energy of feedstock powder particles which ensures an excellent cohesion of powder particles; it results in denser coatings and with homogeneous microstructure and absence of unwanted oxides. Moreover, the effect of solid solution hardening is significant in case of Alloy-718 and it is intrinsically harder than GCI. The micro-hardness of the HVOF coating deposited in present work is in good agreement with the earlier research work [14]. The variation in micro-hardness value across the cross-section of coating and substrate was measured by taking 10 indents and their average hardness value was reported. The measured micro-hardness of the GCI substrate was found to be $230 \pm 12 \mathrm{HV}$. The average micro-hardness of the bond coat was $350 \pm 15 \mathrm{HV}$ and for the Alloy-718 coating, it was $565 \pm 18 \mathrm{HV}$. The higher hardness value is also attributed to the closely packed structure, and good inter-splat bonding due to high velocity of HVOF process [19].

\subsection{Oxidation study}

The oxidation behaviour of the coated specimen was investigated, as described in Section 2.3. In high temperature oxidation study, a change in weight gain 


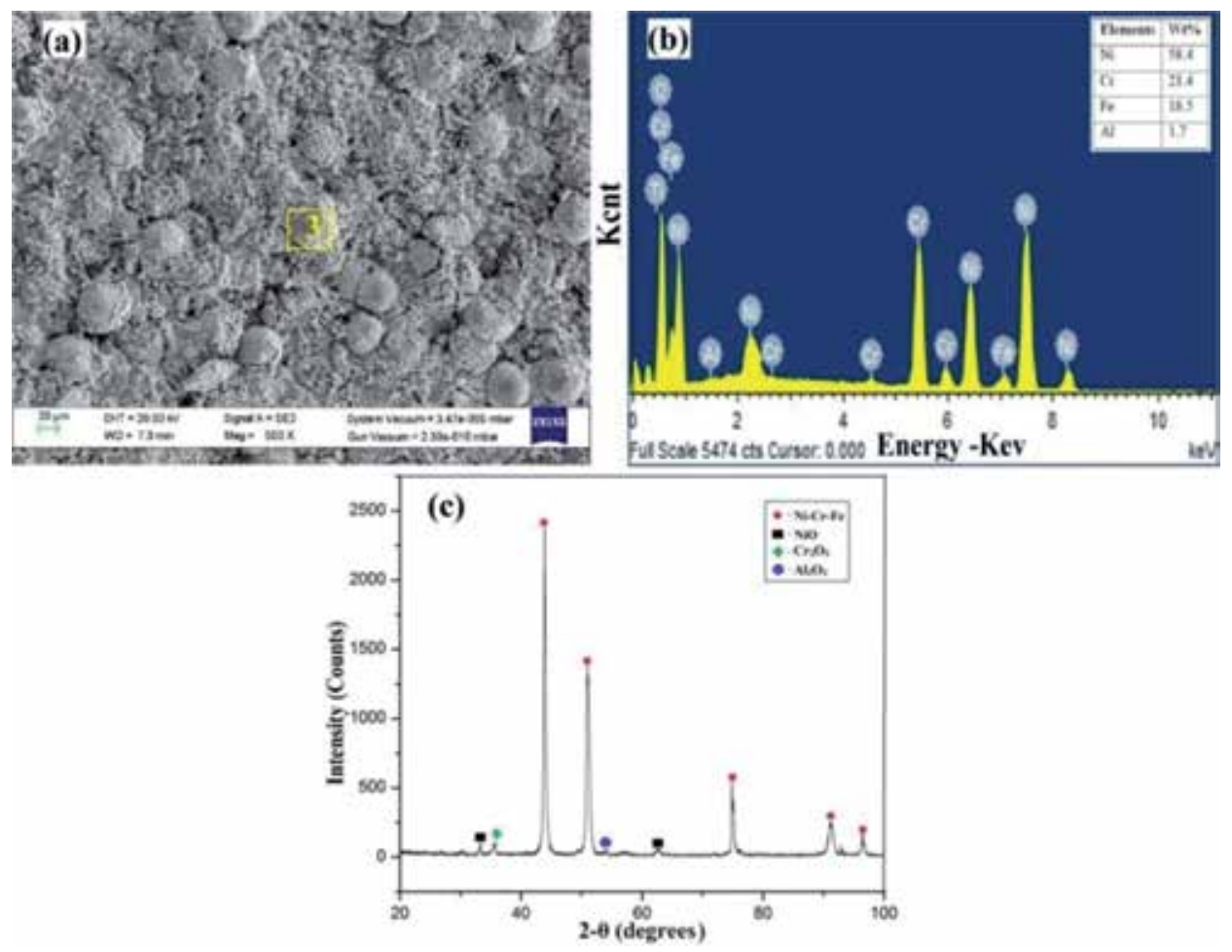

Figure 4 .

(a) Surface morphology of Alloy-718 coating, (b) EDS corresponding to point 3 and (c) XRD pattern of Alloy-718 coating.

$\left(\mathrm{mg} / \mathrm{cm}^{2}\right)$ of the uncoated and as-sprayed Alloy-718 coating specimens was recorded for 50 cycles. The GCI substrate and Alloy-718 coating showed the weight gain of 123.4 and $2.10 \mathrm{mg} / \mathrm{cm}^{2}$, respectively. The weight gain in case of Alloy-718 coated cast iron has reduced to large extent, which shows the oxidation resistance at high temperature as compared with the bare GCI substrate. The calculations of parabolic rate constants $\left(K_{P}\right)$ indicate the lesser oxidation rate of the Alloy-718 coating as compared to GCI substrate, as shown in Table 3. The calculations of the parabolic rate constants were obtained by using linear least square algorithm- $\left(\chi^{2}=K_{P} t\right)$, where " $x$ " is the gain in weight/unit of surface area $\left(\mathrm{mg} / \mathrm{cm}^{2}\right), K_{P}$ is a parabolic rate constant and " $t$ " is the number of thermal oxidation cycles to which specimens were exposed. The data of bare GCI substrate and Alloy-718 coated specimens confirms the parabolic oxidation law and the coating showed a superior resistance to oxidation. The value of parabolic rate constants showed the higher resistance of Alloy-718 coating as compared to bare GCI.

The SEM/EDS analysis and XRD of GCI substrate corresponding to 50 cycles of air oxidation at $900^{\circ} \mathrm{C}$ is shown in Figure 6. The SEM micrograph shows the oxidized layer of scale of around $280 \mu \mathrm{m}$. The EDS corresponding to point 1 shows the presence of $\mathrm{Fe}$ and $\mathrm{O}$ elements. The GCI is composed of ferrite matrix with graphite flakes. These flakes are the preferred sites for oxidation. During oxidation at hightemperature, the oxygen enters into the subsurface through the interconnected graphite flakes and form cracks inside the sub-surface. This phenomenon occurred rapidly after $570^{\circ} \mathrm{C}$ by means of diffusion according to $\mathrm{Fe}-\mathrm{O}$ phase diagram [20]. The XRD pattern of oxidized GCI shows the formation of iron oxides such as $\mathrm{FeO}$, $\mathrm{Fe}_{2} \mathrm{O}_{3}$, and $\mathrm{Fe}_{3} \mathrm{O}_{4}$. These oxides are well known for their non-coherent and porous nature which results in intense oxidation of GCI at high temperature [20]. 

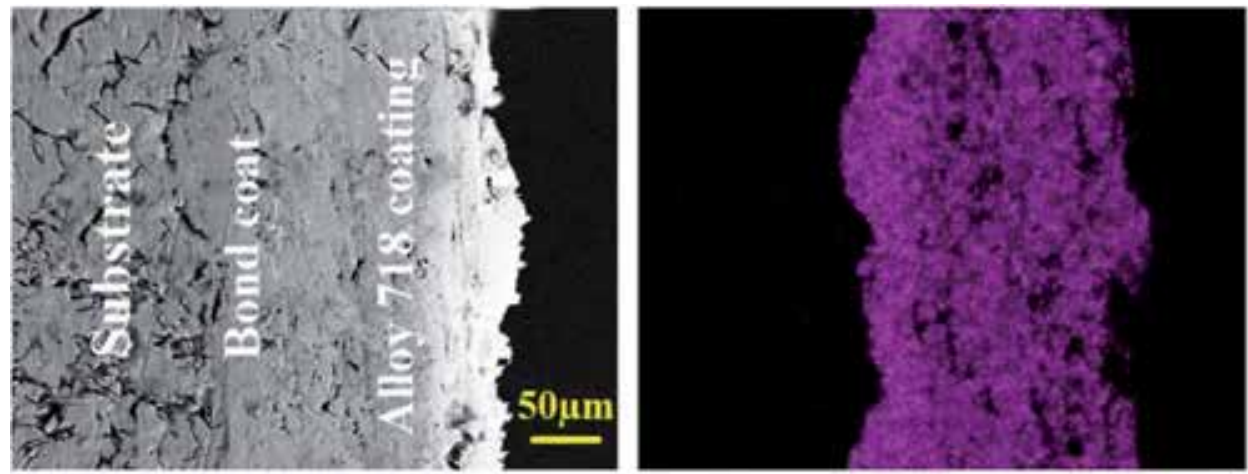

\section{Ni Ka1}
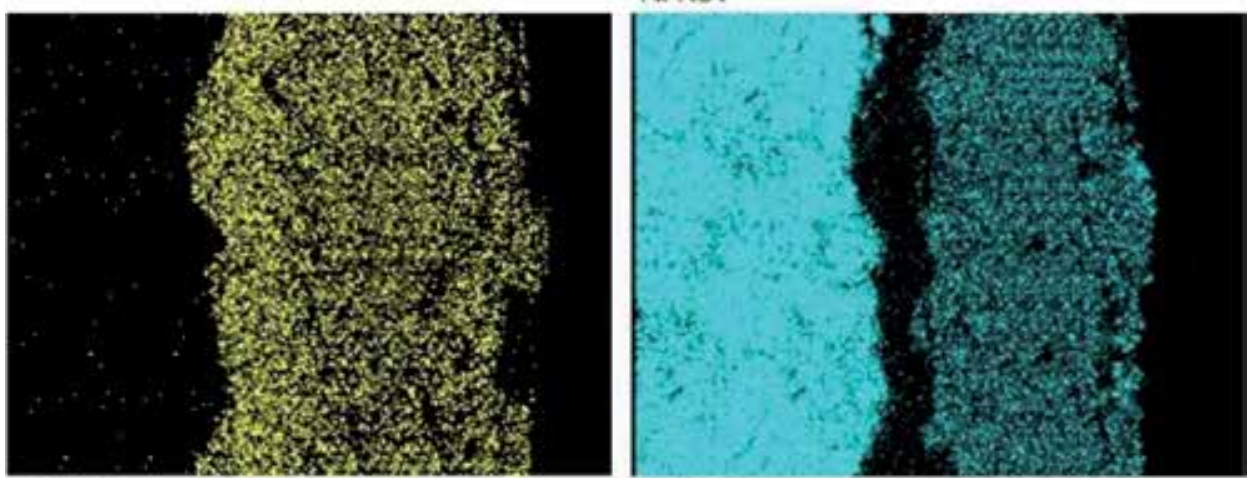

Cr Ka1

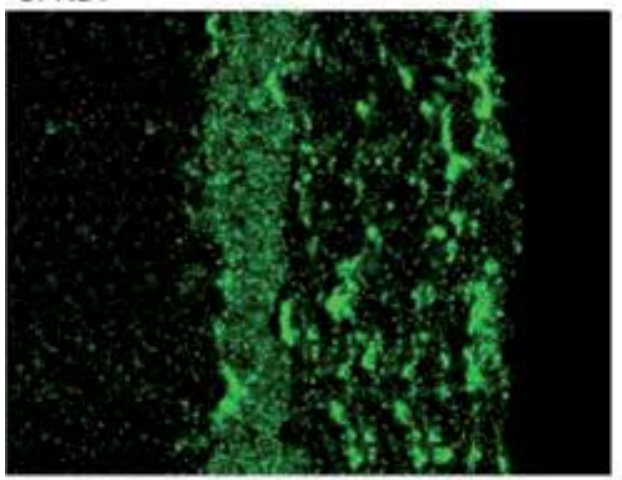

Fe Ka1

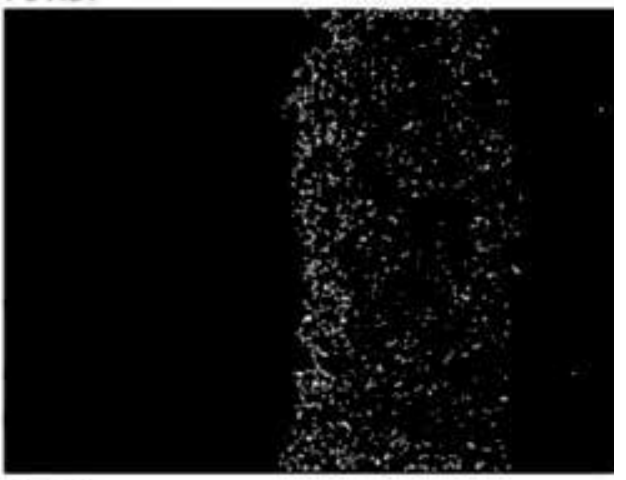

Al Ka1

TiKa1

Figure 5.

SEM micrograph and X-ray maps of Alloy-718/NiCrAlY bi-layer coating [30].

\begin{tabular}{lc}
\hline Specimens & $\mathbf{K}_{\mathbf{P}}\left(\mathbf{1 0}^{-\mathbf{3}} \mathbf{m g}^{\mathbf{2}} \mathbf{~ c m}^{-\mathbf{4}} \mathbf{s}^{\mathbf{- 1}}\right)$ \\
\hline Bare GCI & 84.05 \\
\hline IN718 coated cast iron & 0.02 \\
\hline
\end{tabular}

Table 3.

Parabolic rate constants for bare and Alloy-718 coated GCI.

The weight gain and parabolic rate constant values of substrate and Alloy-718 coatings after the oxidation test are presented in Table 3. The high weight gained by the GCI during oxidation test was attributed due to the formation of iron oxides. On the other hand, the bi-layer Alloy-718/NiCrAlY coating showed a decreased weight gain and parabolic rate constant. 
High Temperature Oxidation and Wear Resistant Bi-Layer Coating for Turbocharger Housing DOI: http://dx.doi.org/10.5772/intechopen.86806

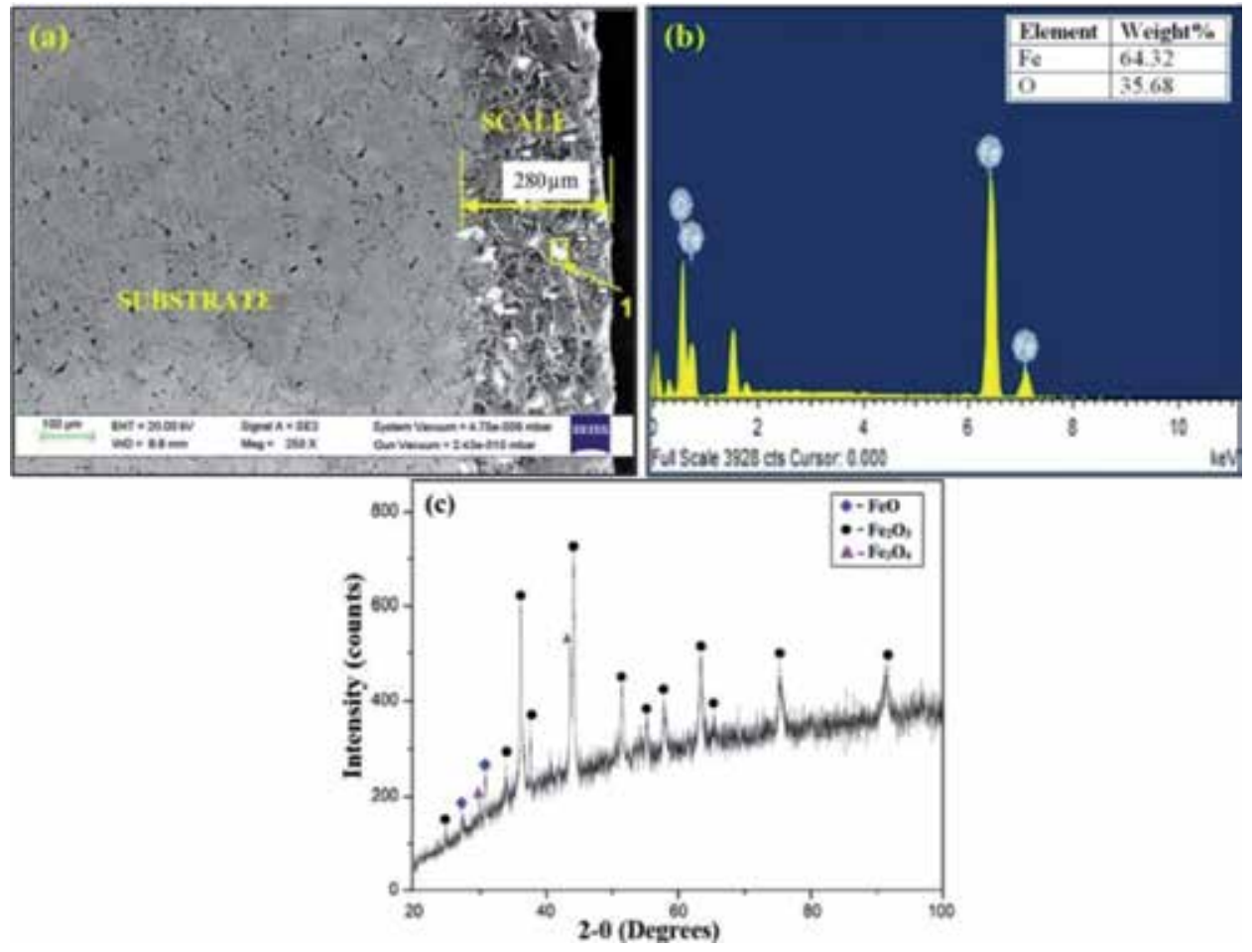

Figure 6.

(a) SEM micrograph, (b) EDS spectrum corresponding to location 1, and (c) XRD of GCI subjected to 50 cycles of air oxidation at $900^{\circ} \mathrm{C}$.

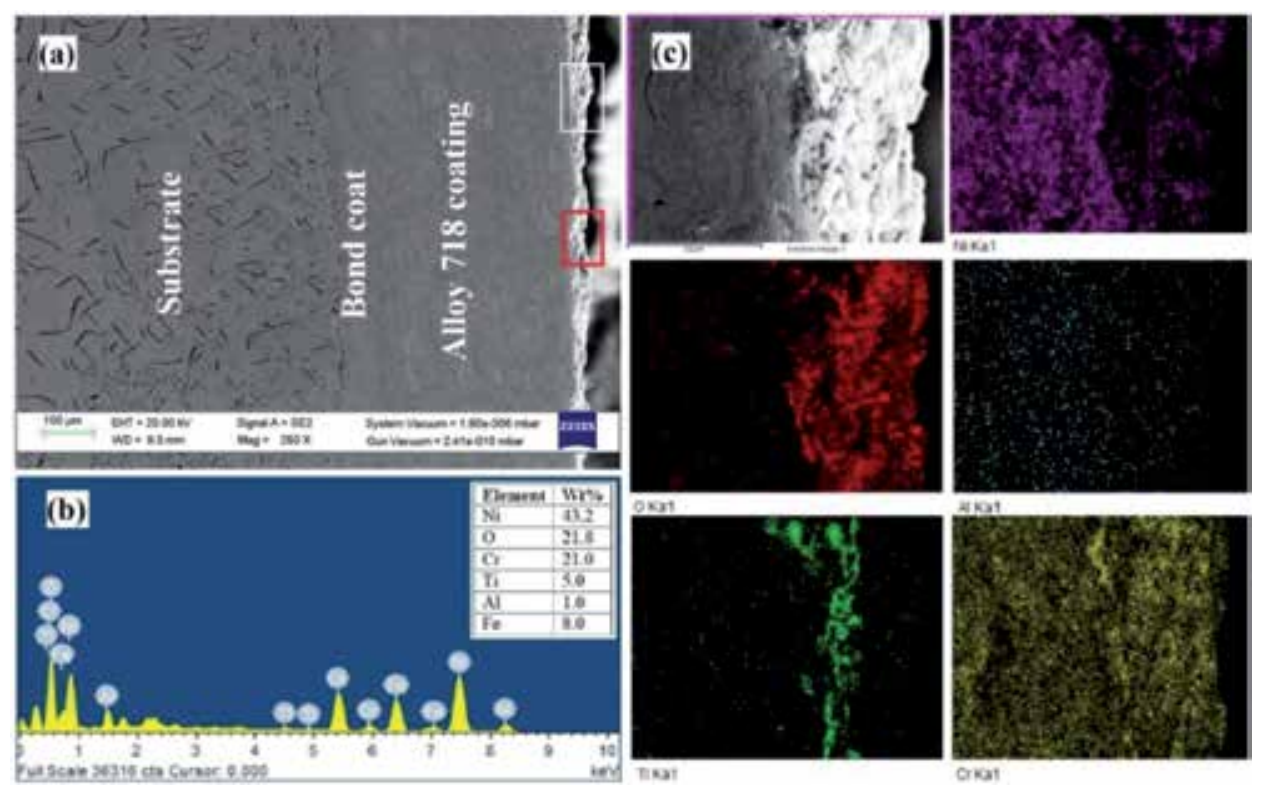

Figure 7.

(a) SEM micrograph along with EDS corresponds to white rectangle area as shown in (b), and (c) X-ray mapping of oxidized bi-layer Alloy-718/NiCrAlY coating at $900^{\circ} \mathrm{C}$ corresponds to red rectangle area [30].

The SEM micrograph along with EDS of the oxidized layer and X-ray mapping of oxidized bi-layer Alloy-718/NiCrAlY coating is shown in Figure 7. The SEM micrograph indicates the formation of oxide scale with at thickness of about $20 \mu \mathrm{m}$. 
The decrease in thickness of the oxidized layer as compared to the thickness of scale formed in the GCI substrate indicated the high oxidation resistance of the deposited coating. The dense layer of scale is formed on the surface of the bilayer Alloy-718/ $\mathrm{NiCrAlY}$ coating. The presence of the $\mathrm{Cr}$ and $\mathrm{O}$ can be observed in this layer which ensures the formation of $\mathrm{Cr}_{2} \mathrm{O}_{3}$ by selective oxidation. The $\mathrm{Cr}_{2} \mathrm{O}_{3}$ provides a thermal stability at high temperature and prevents the substrate from oxidation [21]. The $\mathrm{TiO}_{2}$ was also formed at the interface of the scale and top coating. The oxide scale is rich in $\mathrm{Cr}$ and $\mathrm{O}$ confirmed by EDS mapping and further the presence of $\mathrm{Cr}_{2} \mathrm{O}_{3}$ is endorsed by XRD pattern of oxidized Alloy-718/NiCrAlY coating, as shown in Figure 8.

The XRD pattern (Figure 8) of oxidized bilayer coatings also shows the presence of protective phases such as $\mathrm{NiCr}_{2} \mathrm{O}_{4}$ and $\mathrm{Al}_{2} \mathrm{O}_{3}$ along with the $\mathrm{Cr}_{2} \mathrm{O}_{3}$ and $\mathrm{TiO}_{2}$. The presence of these protective phases is mainly responsible for the increased oxidation resistance of bilayer Alloy- $718 / \mathrm{NiCrAlY}$ coating.

\subsection{Erosion testing}

There are two ways to analyse the wear erosion mechanism for material removal and these include the analysis of erosion mechanism on the basis of nature of material and secondly, on the basis of the impact angles of the erodent striking at the surface of the material. In first method, the ductile and brittle nature of the material is considered as material removal mechanism in the erosive wear. The repetitive plastic deformation causing the strain hardening and cutting are the two possible mechanisms which take place during the erosive wear, which leads to surface degradation. In case of ductile material, the micro-cutting followed by the separation of material from its surface is a responsible mechanism of material removal [22]. On contrary to that, brittle materials fail by fatigue process which is due to repetitive impacts of the erodent particles striking on the surface of the material. These particles transfers their energy to the surface in repetitive and continues manner so as to produce repetition and eventually results in fatigue failure. Therefore, the repetitions of impacts create cracks on the surface and debonding of the splats revealing the brittle nature of the coating. The impact angle is also another factor for defining the material removal mechanism and the erosion mechanism is directly affected by the impact angle of impingement of the erodent particles [23]. There is variability in the impact angles of the actual

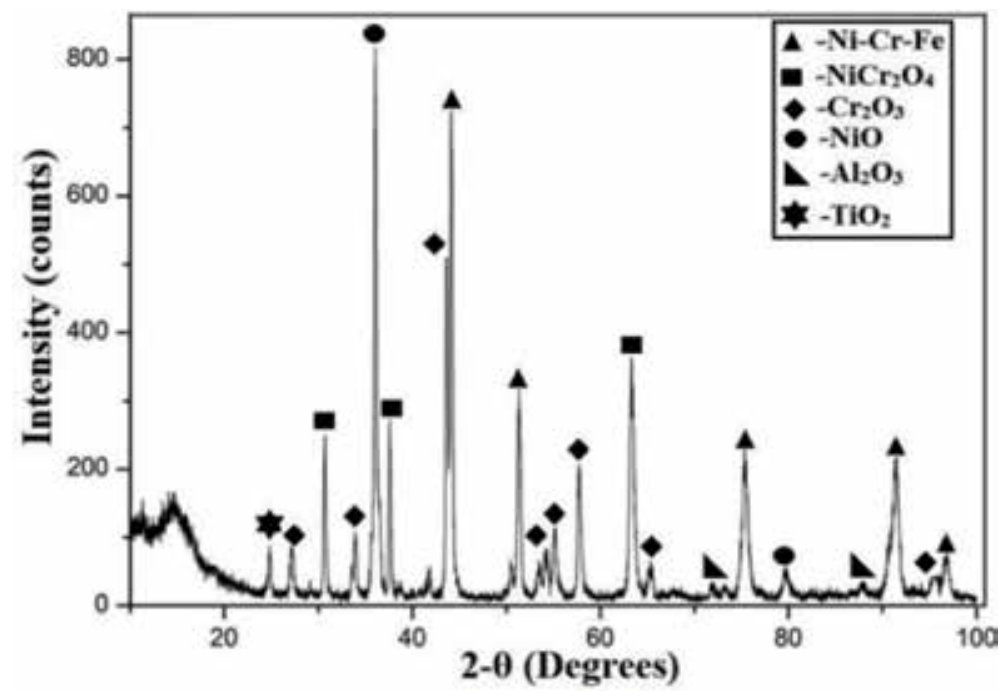

Figure 8.

XRD pattern of oxidized Alloy-718/NiCrAlY coating at $900^{\circ} \mathrm{C}[30]$. 
applications like hydrodynamic turbine, boilers, heat exchangers, rocketry components and gas turbines at which the working fluid enters in the system and strikes the surface to cause material degradation at the working surface of the component. There are different angles from low to high and material removal mechanism varies according to variation in the impact angles. For low impact angles, cutting of material and chip formation leads to the material removal process. The ductile mechanism of erosion is analysed for higher erosion rates at lower angles of 20 and $30^{\circ}$. The angle is at or close to $90^{\circ}$ for erosion failure includes lips formation mainly for the material which deforms at higher rate and the removal of material takes place in the form of platelets on repetitive striking of impacted erodent particles. However, the materials with minimum erosive wear resistance at $90^{\circ}$ fall under the category of brittle mode [24].

The high-temperature erosion test was conducted at $800^{\circ} \mathrm{C}$ for two impact angles viz. 30 and $90^{\circ}$, respectively. The erosion rates of GCI and Alloy-718/ $\mathrm{NiCrAlY}$ coating were measured, which showed the significant increase (around three times) in erosion resistance by using coating as compared to GCI. The erosion resistance of coating has improved in both impact angles condition. This increased erosion resistance is attributed to the solid solution hardening effect in Alloy-718 coating [25]. The presence of $\mathrm{Cr}_{2} \mathrm{O}_{3}$ and $\mathrm{Al}_{2} \mathrm{O}_{3}$ on the surface also contributed to the erosion resistance due to their hardness and thermal stability of these oxides $[3,26]$.

The SEM micrographs were used to analyse the eroded surface of the GCI and Alloy-718/NiCrAlY coating, as shown in Figure 9. The SEM micrographs of GCI showed the cracks on the surface when impacted at $90^{\circ}$ and this can attributed to the repetitive impacts of erodent particles at normal angle. The repetitive impacts has led to the surface cracking and eventually the material is pulled out from the surface, as shown in eroded surface of GCI at $90^{\circ}$. Hence, brittle fracture mechanism is responsible for the surface degradation of GCI material during the erosion
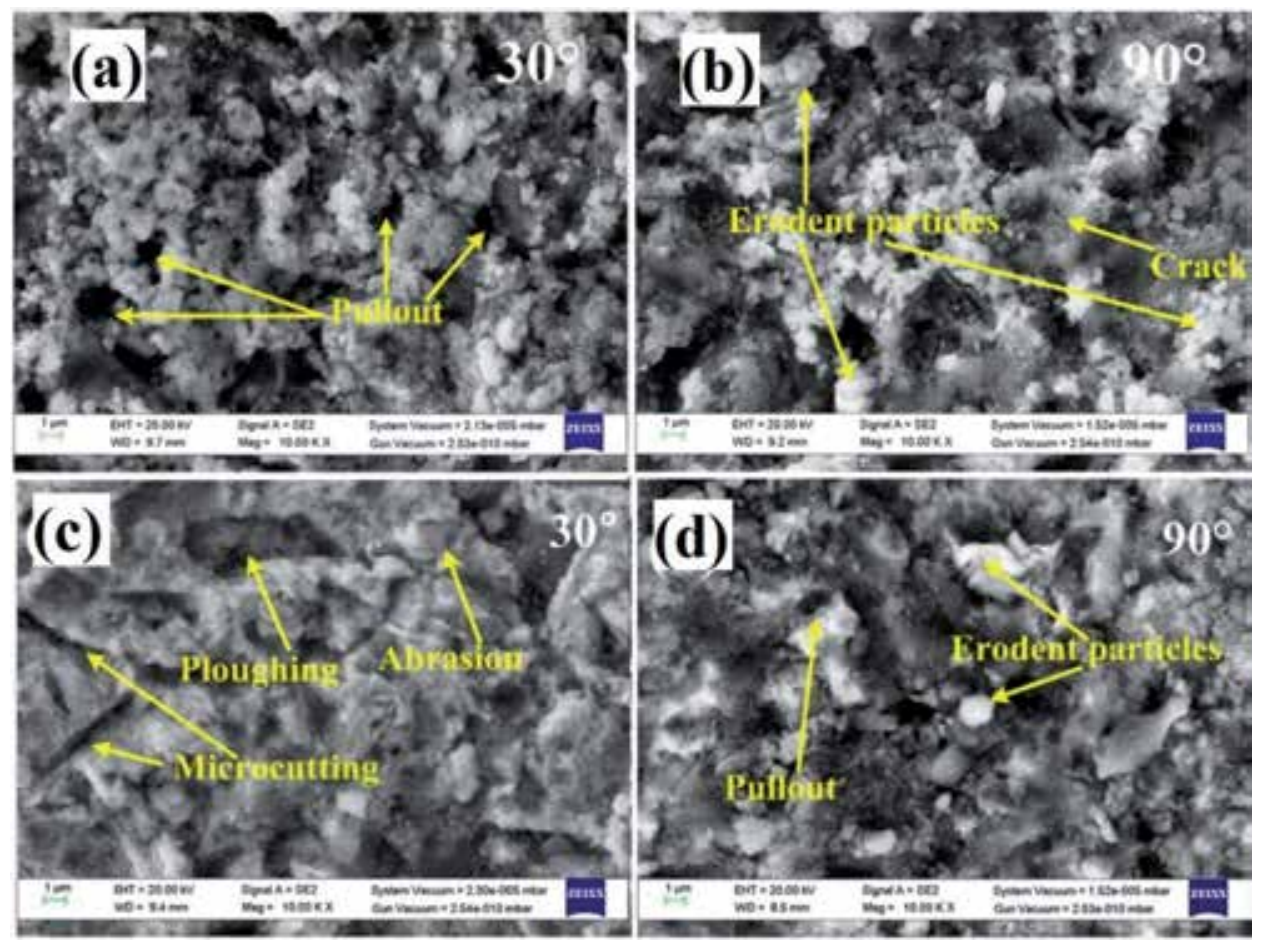

Figure 9.

Surface topology of eroded GCI at (a) at $30^{\circ}$ impact angle (b) at $90^{\circ}$ impact angle. Surface topology of eroded Alloy-718/NiCrAlY coating (c)at $30^{\circ}$ impact angle $(d)$ and at $90^{\circ}$ impact angle [30]. 
at $90^{\circ}$ impact angle [27]. The GCI showed the micro-cutting marks along with some craters formed on the surface due to impact of erodent particles at $30^{\circ}$.

In case of Alloy-718/NiCrAlY coating, some cavities were formed and microcutting marks were seen in case of erosion conducted at $30^{\circ}$ impact angle. The topology of coated samples showed the micro-cutting and abrasion marks along with lip formation in the periphery of craters at $30^{\circ}$ impact angle. Hence, the abrasion and plastic deformation of coating surface is responsible for erosion of material in ductile mode at $30^{\circ}$ impact angle. The Alloy-718/NiCrAlY coating also showed the presence of fine cracks, material pullout and some erodent particles embedded on the surface due to the repetitive impacts at $90^{\circ}$ impact angle $[28,29]$.

\section{Summary}

The successful deposition of bi-layer Alloy718/NiCrAlY coating on the GCI substrate was carried out using HVOF process. The coatings were further characterized in terms of their microstructure, micro-hardness, high temperature erosion and oxidation behaviour. The following conclusions have been drawn from the present study:

As-sprayed Alloy718/NiCrAlY coating showed well bonded interfaces due to the well-defined inter-splat bonding of splats.

The Alloy718/NiCrAlY coating showed the increased micro-hardness as compared to GCI; the high hardness of the Alloy-718 coatings was due to solid solution hardening provided by various alloying elements and presence of various oxides such as $\mathrm{Cr}_{2} \mathrm{O}_{3}$ and $\mathrm{Al}_{2} \mathrm{O}_{3}$ in the coatings.

High temperature oxidation resistance of the bilayer Alloy718/NiCrAlY coating is attributed to the formation of protective oxides such as $\mathrm{NiCr}_{2} \mathrm{O}_{4}, \mathrm{Cr}_{2} \mathrm{O}_{3}, \mathrm{Al}_{2} \mathrm{O}_{3}$, and $\mathrm{TiO}_{2}$ in the coating.

The micro-cutting, ploughing, brittle fracture and formation of craters were the different erosion wear mechanisms.

The brittle and ductile modes of erosion were observed for GCI and Alloy718/ NiCrAlY coating, respectively.

\section{Author details}

Hitesh Vasudev ${ }^{1}$, Lalit Thakur ${ }^{2 *}$ and Amit Bansal ${ }^{3}$

1 Mechanical Engineering Department, Lovely Professional University, India

2 Mechanical Engineering Department, NIT, Kurukshetra, India

3 Department of Mechanical Engineering, IKG Punjab Technical University, Kapurthala, India

*Address all correspondence to: lalitthakur@nitkkr.ac.in

\section{IntechOpen}

(C) 2019 The Author(s). Licensee IntechOpen. This chapter is distributed under the terms of the Creative Commons Attribution License (http://creativecommons.org/licenses/ by/3.0), which permits unrestricted use, distribution, and reproduction in any medium, provided the original work is properly cited. (cc) BY 


\section{References}

[1] Akdogan AN, Durakbasa MN. Thermal cycling experiments for glass moulds surface texture lifetime prediction-evaluation with the help of statistical techniques. Measurement. 2008;41:697-703

[2] Vasudev H, Thakur L, Singh H. A review on tribo-corrosion of coatings in glass manufacturing industry and performance of coating techniques against high temperature corrosion and wear. i-manager's Journal on Material Science. 2017;3:38-48

[3] Lin MB, Wang CJ, Volinsky AA. High temperature oxidation behavior of flake and spheroidal graphite cast irons. Oxidation of Metals. 2011;76:161-168

[4] Vasudev H, Thakur L, Singh H, Bansal A. Mechanical and microstructural behaviour of wear resistant coatings on cast iron lathe machine beds and slides. Metallic Materials. 2018;56(1):55-63

[5] McCune RC, Papyrin AN, Hall JN, Riggs WL, Zajchowski PH, Berndt CC, et al. Advances in Thermal Spray Science and Technology. Materials Park, OH: ASM International; 1995

[6] Singh H. Plasma Spray Coatings for Superalloys: Characterization and High Temperature Oxidation Behavior. KGaA, Weinheim: WILEY-VCH Verlag $\mathrm{GmbH} \& \mathrm{Co} ; 2009$

[7] Davis JR. Handbook of Thermal Spray Technology. Novelty, OH, USA: ASM International; 2004

[8] Jacobs L, Hyland H, De Bonte M. Comparative study of WC-cermet coatings sprayed via the HVOF and the HVAF process. Journal of Thermal Spray Technology. 1998;7:213-219

[9] Kaur M, Singh H, Prakash S. A survey of the literature on the use of high velocity oxy-fuel spray technology for high temperature corrosion and erosion-corrosion resistant coatings. Anti-Corrosion Methods and Materials. 2008;55:86-96

[10] Kaur M, Singh H, Prakash S. Hightemperature behavior of a highvelocity oxy-fuel sprayed $\mathrm{Cr}_{3} \mathrm{C}_{2}-\mathrm{NiCr}$ coating. Metallurgical and Materials Transactions A. 2012;43:2979-2993

[11] Sidhu T, Agrawal RD, Prakash S. Hot corrosion of some superalloys and role of high-velocity oxyfuel spray coatings-A review. Surface and Coatings Technology. 2005;198:441-446

[12] Levy AV. The erosion-corrosion behavior of protective coating. Surface and Coatings Technology. 1988;36:387-406

[13] Sundararajan T, Kuroda S, Nishida K, Itagaki T, Abe F. Behaviour of Mn and $\mathrm{Si}$ in the spray powders during steam oxidation of $\mathrm{Ni}$-Cr thermal spray coatings. ISIJ International. 2004;44:139-144

[14] Wang B, Lee SW. Erosion-corrosion behaviour of $\mathrm{HVOF} \mathrm{NiAl}-\mathrm{Al}_{2} \mathrm{O}_{3}$ intermetallic ceramic coating. Wear. 2000;239:83-90

[15] Thomas A, Wahabi ME, Cabrera JM, Prado JM. High temperature deformation of alloy 718. Journal of Materials Processing Technology. 2006;177:469-472

[16] Fecht H, Furrer D. Processing of nickel-base superalloys for turbine engine disc applications. Advanced Engineering Materials. 2000;2:777-787

[17] Mishra SB, Prakash S, Chandra K. Studies on erosion behaviour of plasma sprayed coatings on a Ni-based superalloy. Wear. 2006;260:422-432 
[18] Ramesh CS, Devaraj DS, Keshavamurthy R, Sridhar BR. Slurry erosive wear behaviour of thermally sprayed alloy 718 coatings by APS process. Wear. 2011;271:1365-1371

[19] Delaunay F, Berthier C, Lenglet M, Lameille J. SEM-EDS and XPS studies of the high temperature oxidation behaviour of alloy 718. Mikrochimica Acta. 2000;132:337-343

[20] Khanna AS. High Temperature Oxidation and Corrosion. Novelty, $\mathrm{OH}$, USA: ASM International; 2002

[21] Gaskell DR. Introduction to the Thermodynamics. New York: McGrawHill International. 1973. p. 585

[22] Grewal HS, Singh H, Agarwal A. Understanding liquid impingement erosion behaviour of nickel-alumina based thermal spray coatings. Wear. 2013;301:424-433

[23] Mann BS, Arya V. An experimental study to correlate water jet impingement erosion resistance and properties of metallic materials and coatings. Wear. 2002;253:650-661

[24] Grewal HS, Bhandari S, Singh H. Parametric study of slurry-erosion of hydroturbine steels with and without detonation gun spray coatings using taguchi technique. Metallurgical and Materials Transactions A. 2012;43:3387-3401

[25] Campbell FC. Manufacturing technology for aerospace structural materials. Superalloys. Amsterdam, Netherlands: Elsevier Science; 2006. pp. 211-272

[26] Pawlowski L. The Science and Engineering of Thermal Spray Coatings. New York, USA: John Wiley \& Sons; 2008

[27] Finnie I. Some reflections on the past and future of erosion. Wear. 1995;186-187:1-10
[28] Finnie I. Erosion of surfaces by solid particles. Wear. 1960;3:87-103

[29] Vasudev H. To investigate INCONEL718 $+\mathrm{Al}_{2} \mathrm{O}_{3}$ coatings for high temperature wear and corrosion resistance [thesis]. I.K. Gujral Punjab Technical University; 2018

[30] Vasudev H, Thakur L, Bansal A, Singh H, Zafar S. High temperature oxidation and erosion behaviour of HVOF sprayed Inconel-718 coating. Surface and Coatings Technology. 2019;362:366-380 
Section 2

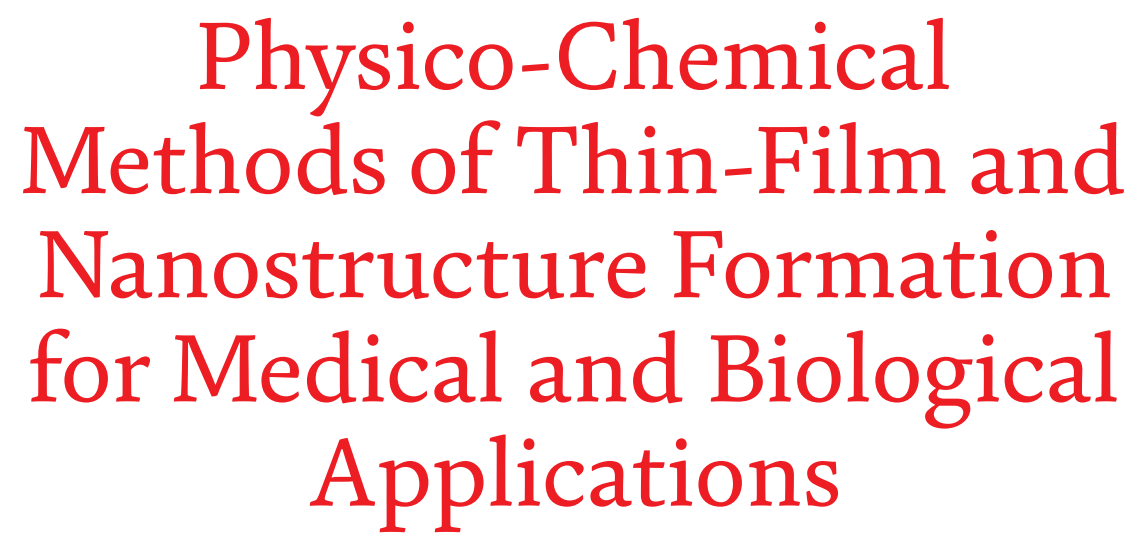





\title{
Prologue: Thin-Film Synthesis and Application for Medical and Biological Use
}

\author{
László Fábián and László Nánai
}

\section{Introduction}

With the advent of nanotechnology, researchers started almost simultaneously the use of nanophysics in medical industry and life sciences. The extreme and device-specific physicochemical properties and comparable molecular size scales of 'nanoproducts' had initiated a wide range of efforts searching useful applications and utilizations of the whole objects of macromolecules, systems and organisms. On the other hand, very rapid development in the field of fabrication technologies is introduced into the area of manufacturing with tailored properties. Different thin-film technologies enable the growth of coherent mono- or multilayer composite films with quite large surface areas. The possible utilizations and applications of different kind of thin-film structures in life sciences will be shortly discussed.

Nanotechnology is the study of extremely small structures, having size of 0.1-100 nm. The prefix 'nano' is a Greek word which means 'dwarf'. The word 'nano' means very small or miniature size in real life. These materials should show/ represent different properties, e.g. chemical reactivity, magnetic and optoelectronical effects, conductance, mechanical and plastic properties, etc. As a result of their small size, the bulk and surface properties are strictly different. But the most important property for us is their biocompatibility.

\section{Historical background}

'There's Plenty of Room at the Bottom: An Invitation to Enter a New Field of Physics' was a lecture given by physicist Richard Feynman at the annual American Physical Society meeting at Caltech on December 29, 1959. Feynman considered the possibility of direct manipulation of individual atoms as a more powerful form of synthetic chemistry. Feynman also suggested that it should be possible, in principle, to make nanoscale machines that 'arrange the atoms the way we want' and do chemical synthesis by mechanical manipulation. These sentences can be seen as the birth of the 'nanoworld' [1].

Norio Taniguchi has introduced the term of nanotechnology in order to describe some physical processes running on the scale of nanometres. These phenomena are related to processing of separation, deformation and consolidation on the basis of some atoms and molecules [2]. Some important milestones in nanotechnology are the following: 
- 1981, IBM: development of the scanning tunnelling microscope (STM) [3, 4].

- 1985: invention of Bucky Ball by Kroto [5]. A buckyball is a molecule called Buckminsterfullerene. Consisted of 60 carbon atoms arranged in the shape of a hollow ball, buckyballs have, as yet, little practical use, although they do make up nanotubes, which have some uses.

- 1986: the first book about nanotechnology [6].

- 1991: lijima discovered carbon nanotubes (CNT) for the first time [7].

- 1999: first nanomedicine book by Freitas was published [8].

- 2011: the era of molecular nanotechnology started.

\section{Classification of nanomaterials}

A plenty of experimental methods are available for the fabrication of nanosized structures, but each of them can be put into one of the two main classes. Nanomaterials and nanostructures can be fabricated by removing some part of a bulk material to sculpture the desired shape that can be constructed from much smaller parts. These two main classes are termed as 'top-down' and 'bottom-up' approaches $[9,10]$.

\subsection{Top-down methods}

Top-down manufacturing method deals with mechanical operations, for example, cutting, moulding and carving. Because of size limitations, we will get highly specialised nanostructures. Some manufacturing methods involve laserbased ones like ablation, deposition and milling; some of them use hydrothermal techniques like liquid- or gas-phase deposition. Electromechanical and electrochemical methods are also widely used (electroplating, etching, etc.).

Most top-down nanofabrication methods are for surface patterning. By patterning local surface regions of a solid substrate with nanoscale features, the substrate has the ability to recognise specific nanostructures. For instance, when the substrate is placed in a solution, millions of nanostructures can self-assemble in parallel. Some patterning methods are developed to write nanoscale features, others are to replicate.

\subsection{Bottom-up approach}

Bottom-up methods represent a wide range of component-construction techniques. The building blocks are probably simple molecules held together by their covalent bonds. The resulted macroscale components are strong enough and stable. Many different techniques like atomic force microscopy (AFM), liquid- and gasphase techniques, consisting sol-gel processes, and inverse micelles are involved. One of the most important characteristics is the molecular self-assembly.

\subsection{Deposition techniques}

Thin-film deposition involves processing above the substrate surface (typically a silicon wafer with a thickness of 300-700 $\mu \mathrm{m}$ ), where different materials are 
added to substrates in form of simple or structured layers (thin films or composed aggregates with discrete spacers later to be removed). Deposition techniques fall into two categories, depending on whether the process is primarily chemical or physical.

Chemical deposition means deposition of layers via chemical reactions. The deposition rate on the substrate is governed by the properties of materials like pressure, temperature, etc. Based on the precursor phase, deposition processes can be classified as plating, spin coating, low-pressure deposition, plasma-enhanced deposition or layer-by-layer (atomic) deposition.

In the process of physical deposition, the material (solid, liquid or vapour) is physically transferred to the substrate (heated). These processes are thermal deposition, sputtering, ion plating, etc. The main operating factors are the substrate structure and temperature. The rate of deposition describes the volume/mass of the deposited material in unit time.

These layers are deposited and subsequently patterned using photolithographic (induced by laser or electron beam) techniques and then etched or washed away to release the final structure. We should also mention the electrophoretic deposition (EPD) that is a wet electrolytic deposition technology for thin films. EPD employs the mechanism of electrophoresis. Electric field is applied between two electrodes and charged particles dispersed or suspended in a liquid medium moving towards the oppositely charged electrode (electrophoresis), followed by the accumulation of particles on the deposition electrode in an ordered manner, producing a relatively compact and homogeneous film.

\section{Some advantages and limitation of thin films: Drug delivery}

Thin-film drug delivery stands as an alternative method to the traditional pills and capsules. Thin films and strips of a few centimetres in size might be subjected to oral or under tongue administrations. As the strip dissolves, the drug enters the bloodstream (buccally or sublingually). These drug delivery options allow the bypass of the metabolic pathway; therefore, this medication method is more bioavailable.

Polymeric thin films can also be beneficial for bedridden and non-cooperative patients. Thin films are useful in cases where rapid onset of action is required, such as in motion sickness, sudden episodes of allergic attack or coughing, bronchitis or asthma.

The use of thin films is sometimes limited due to low drug loading capacity compared to a less potent drug given at high dose. Thin films are usually very hygroscopic in nature, and sometimes it is difficult to obtain them in high degree of accuracy.

The most important polymeric films used in pharmaceutical and medical applications are hydroxypropyl methylcellulose (HPMC), carboxymethyl cellulose (CMC), hydroxypropyl cellulose (HPC), poly(vinyl pyrrolidone) (PVP), poly(ethylene oxide) (PEO), pullulan, pectin, chitosan, carrageenan and gelatin.

\section{Biocompatibility}

Biocompatibility is related to the behaviour of biomaterials in various contexts. It means that the biomaterial is able to get prompt and exact response from the host/tissue materials in different and specific situations. The most important common definitions related to the term of biocompatibility are the following: 
1. The quality of not having toxic or injurious effects on biological systems.

2. The ability of a material to perform with an appropriate host response in a specific application.

3. The tissue response to the implanted/added material should be recognized as suitable with control materials.

4. The biomaterial should carry out its prescribed function by medical therapy. No other eliciting and undesirable effects are allowed. From the part of recipient, the most desirable tissue response should be realized.

5. In the case of a prosthetic implant, the harmonic tissue reflectance is of firstorder importance. No any deleterious change is allowed.

\section{Nanotechnology in life sciences}

The major problems like cancer, Parkinson's disease and Alzheimer's disease are subject to nanoparticle utilizations for surgery and therapy. Also some other diseases like cardiovascular ones, multiple sclerosis and inflammatory or other infectious diseases are subjects for nanotechnology interference. This field is called nanomedicine. Different researches are conducted on nanocomposites or doped nanocomposites for use as interventions involving bones, cartilages, muscles, etc.

Molecules can be absorbed on the surface of single-walled carbon nanotubes. They could greatly influence the electrical properties or could serve as sensors with very high sensitivity and selectivity.

Advanced biosensors with novel features can be developed with the help of carbon nanotubes (CNT). This technology is also being used to develop sensors for cancer diagnostics. Though CNT is inert, it can be functionalized at the tip with a probe molecule. Their study uses atomic force microscopy (AFM) as an experimental platform.

Some of the researches in biomedicine have shown that carbon nanotubes can also be used for drug delivery. Magnetic nanoparticles are used to isolate and group stem cells. They also can be used in digital imaging methods of cells. Because of their very small size, nanoparticles represent a good candidate to be used in oncology imaging studies. Due to the quantum confinement properties, they can be used in imaging of tumour sites. Compared to organic dyes, nanoparticles have higher brightness and more efficient fluorescence efficiency leading to higher contrast in image reconstructions. Due to their high surface-area-to-volume ratio, it is possible to bind them to tumour cells. Because of their small size, they can accumulate on tumour sites with high probability.

\subsection{Cancer research}

Due to the small size of nanoparticles, they can be of great use in oncology, particularly in imaging. Nanoparticles, such as quantum dots with quantum confinement properties, such as size-tunable light emission, can be used in conjunction with magnetic resonance imaging, to produce exceptional images of tumour sites. As compared to organic dyes, nanoparticles are much brighter and need only one light source for excitation. Thus, the fluorescent quantum dots could produce a higher contrast image at a lower cost than organic dyes used as contrast media. But quantum dots are usually made of quite toxic elements. 
Nanoparticles have a special property of high surface-area-to-volume ratio, which allows various functional groups to get attached to a nanoparticle and thus bind to certain tumour cells. Furthermore, the 10-100 nm size of nanoparticles allows them to preferentially accumulate at tumour sites as tumours lack an effective lymphatic drainage system. Multifunctional nanoparticles can be manufactured that would detect, image and then treat a tumour in future cancer. Nanowires are used to prepare sensor chips, which can detect proteins and other biomarkers left behind by cancer cells and detect and make diagnosis of cancer possible in the early stages from a single drop of a patient's blood.

The possible applications of various nanosystems in cancer therapy [12]:

- Carbon nanotubes, with 0.5-3 nm in diameter and length of 20-1000 nm, are used for detection of DNA mutation and for detection of disease protein biomarker.

- Dendrimers, less than $10 \mathrm{~nm}$ in size, are useful for controlled release in drug delivery and as image contrast agents.

- Nanocrystals, with a size of 2-10 nm, could serve as breast cancer markers.

- Nanoparticles are of 10-1000 $\mathrm{nm}$ in size and can be used in MRI and as contrast agents in ultrasound image formation.

- Nanoshells find application in tumour-specific imaging and deep tissue thermal ablation.

- Nanowires are useful for disease protein biomarker detection.

- Quantum dots with size of 2-10 nm can help in optical visualisation of genes tumour and lymph nodes.

\section{Specific materials}

\subsection{Polymers}

Despite the classical clinical biomaterials/implants such as pacemaker, catheter, modern implants and prostheses consist of several materials therefore the biocompatibility means multicomponent guest materials in host (tissue) environment. The plastic materials_-nowadays-are undergoing rapid development. Especially due to the high compact of plastic industry, the materials are more aesthetic, safe and of better quality.

Among plastics, the most commonly used biocompatible materials are:

- Polyvinyl chloride (PVC)

- Polytetrafluoroethylene (PTFE, Teflon)

- Polypropylene (PP)

- Polyurethane (PU)

- Polymethyl metacrylate (PMAA) 
- Polycarbonate (PC)

- Polyether ether ketone (PEEK)

- Ultrahigh molecular weight polyethylene (UHMWPE)

- Polydimethyl-siloxane (PDMS)

\subsection{Diamond}

One such substrate material that has recently been gaining in popularity is thin-film diamond. In early reports, very low toxicity was observed when diamond particles were injected as a suspension into live animals. Subsequently, it was established that diamond films as a cell culture substrate can successfully support a wide range of adherent cells. One of the most important properties of the diamond film is that it is bioinert, no coagulation and no inflammatory reactions [11]. One of its further advantages is the controllable electrical conductivity and the possibility of surface patterning.

\subsection{Graphene oxide (GO)}

Graphene oxide (GO) is a unique material that can be viewed as a single monomolecular layer of graphite with various oxygen containing functionalities such as epoxide, carbonyl, carboxyl and hydroxyl groups. The reduced GO forms (rGO) which contains residual oxygens, some structural defects and other heteroatoms make it more functionally. Nevertheless, since rGO can be made as a thin film from an aqueous dispersion of GO in water and has moderate conductivity, it is attractive for use in electronic devices. In addition to being components in electronic devices, $\mathrm{GO}$ and rGO have been used in nanocomposite materials, polymer composite materials, energy storage devices, biomedical applications and catalysis and as a surfactant [12].

One use of GO in the biomedical field is as a component in drug delivery. Functionalized nanographene oxide (nGO) has been used in several studies on targeted delivery of anticancer drugs. Polyethylene glycol (PEG)-functionalized nGO with a champotecin derivative (nGO-PEG-SN38), adsorbed onto the surface, was used as a water- and serum-soluble source of the drug. nGO-PEG-SN38 was shown to be three orders of magnitude more effective than irinotecan (CPT-11), an FDAapproved SN38 prodrug, at reducing the cell viability of human colon cancer cell lines HTC-116 [13]. GO has also been used as a fluorescence quenching material in biosensors which utilise the fluorescence resonance energy transfer (FRET) effect.

\section{Conclusions}

Nanostructures in their different forms, thin films, matrices, etc., have a wide range of possible utilizations due to their small_comparable to molecules-sizes, their physicochemical activity, etc. Applications/manufacturing methods are presented in this chapter focusing on making interest in life and medical sciences. 
Prologue: Thin-Film Synthesis and Application for Medical and Biological Use

DOI: http://dx.doi.org/10.5772/intechopen.84968

\section{Author details}

László Fábián ${ }^{1}$ and László Nánai ${ }^{2 *}$

1 Institute of Biophysics, Biological Research Centre of the HAS, Szeged, Hungary

2 Department of Experimental Physics, University of Szeged, Szeged, Hungary

*Address all correspondence to: nanai@physx.u-szeged.hu

\section{IntechOpen}

(C) 2019 The Author(s). Licensee IntechOpen. This chapter is distributed under the terms of the Creative Commons Attribution License (http://creativecommons.org/licenses/ by/3.0), which permits unrestricted use, distribution, and reproduction in any medium, provided the original work is properly cited. (cc) BY 


\section{References}

[1] Feynman RP. There is a plenty of room at the bottom. Engineering and Science. 1960;23(5):22-36

[2] Taniguchi N, Arakawa C, Kobayashi $\mathrm{T}$, editors. On the basic concept of nano-technology. In: Proceedings of the International Conference on Production Engineering, 1974-78; Tokyo. 1974

[3] Binnig G, Rohrer H. Scanning tunneling microscope [google patents]; 1982

[4] Binnig G, Rohrer H, Gerber C, Weibel E. Surface studies by scanning tunneling microscopy. Physical Review Letters. 1982;49(1):57

[5] Kroto HW, Heath JR, O’Brien SC, Curl RF, Smalley RE. C60: Buckminsterfullerene. Nature. 1985;318(6042):162

[6] Drexler KE. Engines of Creation: The Coming Era of Nanotechnology. Anchor Book. Doubleday; 1986

[7] Iijima S. Helical microtubules of graphitic carbon. Nature. 1991;354(6348):56

[8] Freitas RA. Nanomedicine, Volume I: Basic capabilities. Georgetown, TX: Landes Bioscience; 1999

[9] Karki S, Kim H, Na S-J, Shin D, Jo $\mathrm{K}$, Lee J. Thin films as an emerging platform for drug delivery. Asian Journal of Pharmaceutical Sciences. 2016;11(5):559-574

[10] Nikalje AP. Nanotechnology and its applications in medicine. Medicinal Chemistry. 2015;5(2):081-089

[11] Nistor PA, May PW. Diamond thin films: Giving biomedical applications a new shine. Journal of the Royal Society Interface. 2017;14(134):20170382
[12] Mao S, Pu H, Chen J. Graphene oxide and its reduction: Modeling and experimental progress. RSC Advances. 2012;2(7):2643-2662

[13] Liu Z, Robinson JT, Sun X, Dai H. PEGylated nanographene oxide for delivery of waterinsoluble cancer drugs. Journal of the American Chemical Society. 2008;130(33):10876-10877 


\title{
Numerical Simulation of the Spin Coating of the Interior of Metal Beverage Cans
}

\author{
David E. Weidner
}

\begin{abstract}
Using scaling arguments and perturbation theory, we derive the lubrication form of the fluid mechanical equations governing the motion of a thin liquid film on an arbitrarily curved, rotating, axisymmetric substrate. The resulting equations are discretized and then solved numerically using an efficient implicit finite difference algorithm. The primary application for this work is to model the spin coating of the interior of two-piece metal beverage cans, and we consider this problem in some depth. Specifically, we show how adjusting several parameters can eliminate one possible defect in the spin coating process: the tendency for droplets to detach from the substrate when the can is spun at high rotation rates.
\end{abstract}

Keywords: thin liquid films, spin coating, spray coating, numerical modeling

\section{Introduction}

When a liquid is applied to a spinning substrate, or if a pre-wetted substrate is spun, centrifugal forces act to drive any irregularities in the film thickness outward, away from the axis of rotation. The result is that the film becomes thinner and more uniform as the rotation proceeds. Consequently spin coating is used in such applications as coating magnetic storage discs, optical devices, and semiconductor wafers to obtain very thin but uniform films on flat substrates.

When the substrate is curved, centrifugal forces will act to produce a uniform layer only in horizontal regions where the substrate is perpendicular to the axis of rotation. But the coating layer may be very irregular in regions where the substrate is highly curved and the normal vector from the surface is not parallel to the axis of rotation.

In this work we will derive the lubrication form of the fluid mechanical equations for a thin liquid film sprayed on an arbitrarily curved, rotating, axisymmetric substrate. Our goal is to predict how the coating thickness changes with time as a function of the substrate geometry, the rotation rate, the rheological properties of the coating liquid, and the geometry and flux of the spray gun. We then discretize the equations and solve the partial differential equations governing the flow. Using an implicit method of solving the finite difference representation of the partial differential equations, we require a minimum of computer resources.

The theory we develop in this work is used to analyze one specific application: the spray/spin coating of the interior of aluminum beverage containers. When a 
spinning can is spray painted, centrifugal forces help to cause a more uniform coating layer on the can substrate. Indeed this is the purpose of rotating the can a high spin rates while spray coating the interior. But centrifugal forces can also cause such coating irregularities as drop formation. In this work we will demonstrate how such parameters as the spray gun placement and the rotation rate contribute to how long the beverage can may remain in the spin phase of its coating process before this potential defect occurs.

\section{Derivation of the evolution equation}

Consider an arbitrarily curved, axisymmetric substrate with the parameter $s$ representing arc length along the substrate. The parameter $\phi$ represents the circumferential angle and $n$ is the distance normal to the substrate (see Figure 1). $u$ is the velocity parallel to the substrate, in the $s$ direction; $v$ is the velocity normal to the substrate, in the $n$ direction; and $w$ the velocity in the circumferential direction $\phi . \omega$ is the rotation rate around the $z$ axis. Note that while the substrate is axisymmetric, the coating need not be. $r$ is the distance from the can centerline to a given point $(s, \phi)$ on the can substrate. For this geometry, the metric coefficients are listed in Table 1. The Appendix of a text book on fluid mechanics by Kee et al. [1] lists the momentum and continuity equations governing the motion of Newtonian fluids on orthogonal, curved substrates. From here we find that for our geometry the continuity equation is given by Figure 1.

$$
\frac{\partial(r u)}{\partial s}+\frac{\partial(r v)}{\partial n}+\frac{\partial(w)}{\partial \phi}=0
$$
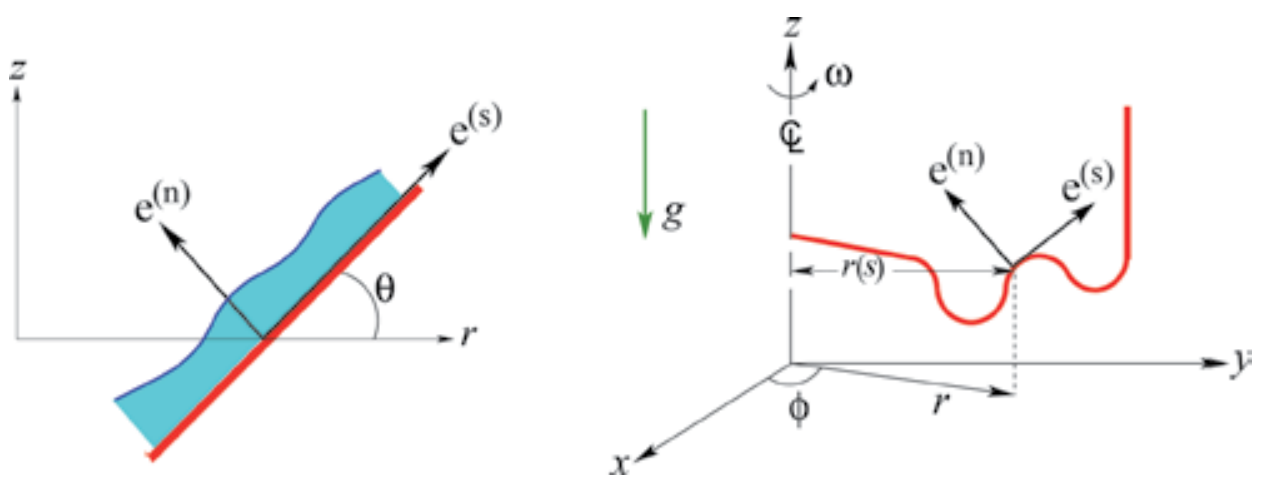

Figure 1.

Curvilinear coordinate system. $\phi$ is the circumferential angle, $\mathrm{e}^{(\mathrm{s})}$ is the unit vector parallel to the substrate, $\mathrm{e}^{(\mathrm{n})}$ the unit vector perpendicular to the substrate, and $\mathrm{r}(\mathrm{s})$ is the distance from the centerline to a given point on the substrate. $\theta$ is the angle of the substrate with respect to the horizontal, $\omega$ is the rotation rate, and $\mathrm{g}$ is the acceleration of gravity.

\begin{tabular}{ccc}
\hline Metric coefficient & Coordinate & Velocity \\
\hline$a_{1}=1$ & $x_{1}=s$ & $u$ \\
\hline$a_{2}=1$ & $x_{2}=n$ & $v$ \\
\hline$a_{3}=r$ & $x_{3}=\phi$ & $w$ \\
\hline
\end{tabular}

Table 1.

Coordinates and their metric coefficients. 
If $\theta$ is the angle the substrate makes with the horizontal, and the gravity vector points in the negative $z$ direction, and then if the can is set upright during the coating process, $\rho g \sin \theta$ is the force parallel to the substrate, and $\rho g \cos \theta$ is the force perpendicular to the substrate. The centrifugal force points in the $r$ direction due to a rotation about the $z$ axis; consequently $\rho \omega r \sin \theta$ is the centrifugal force on the coating perpendicular to the substrate and $\rho \omega r \cos \theta$ the force parallel to the substrate. When the coating layer is sufficiently thin and the Reynolds number is sufficiently small that we can neglect the inertial terms, the momentum equations governing the motion of the liquid coating reduce to

$$
\begin{aligned}
& \frac{\partial p}{\partial s}=-\rho g \sin \theta+\rho \omega^{2} r \cos \theta+\mu\left[2 u_{s s}+v_{s n}+u_{n n}\right]+\frac{\mu}{r}\left[2 r_{s} u_{s}+w_{s \phi}\right]+\frac{\mu}{r^{2}}\left[w_{\phi \phi}-w_{\phi}-2 r_{s}\left(w_{\phi}+u\right)\right], \\
& \frac{\partial p}{\partial n}=\rho g \cos \theta+\rho \omega^{2} r \sin \theta+\mu\left\{\left[v_{s s}+u_{n s}+2 r v_{n n}+w_{n \phi}\right]+\frac{\left[2 r_{s} v_{s}+2 r_{s} u_{n}+2 w_{n}-v_{\phi \phi} / r\right]}{r}\right\}, \\
& \frac{1}{r} \frac{\partial p}{\partial \phi}=\mu\left\{\left[w_{s s}+v_{\phi n}+w_{s} r_{s}\right]+\frac{\left[u_{\phi s}+w_{s}+r w_{n n}+2 w_{\phi \phi}+2 u_{\phi} r_{s}^{2}\right]}{r}\right\} .
\end{aligned}
$$

Here $p$ is the pressure, $\rho$ is the density of the liquid, and $\mu$ is the viscosity of the liquid. Meyers et al. [2] found that the Coriolis forces were of the same magnitude as the inertial forces. Because we have neglected the inertial forces on the grounds that the Reynolds number is small, we shall also neglect Coriolis forces in our analysis. We assume that the coating layer obeys the no-slip boundary condition at the surface of the substrate, $n=0$

$$
u(s, n=0, \phi)=v(s, n=0, \phi)=w(s, n=0, \phi)=0 .
$$

If $F$, a function of $s, n, \phi$, and time $t$, is always zero at the free surface, then it must be given by the coating thickness $h$ minus the value of the coordinate $n$

$$
F(s, n, \phi, t)=h(s, \phi, t)-n=0 .
$$

We define $e^{(s)}$ as the unit vector in the direction parallel to the substrate $s, e^{(n)}$ as the unit vector in the direction perpendicular to the substrate $n$, and $e^{(\phi)}$ as the unit vector in the circumferential direction $\phi$. From Eq. (3) we find that the unit vector perpendicular to the coating surface, denoted by $\hat{\mathbf{f}}$, is defined by

$$
\hat{\mathbf{f}}=\frac{\nabla F}{|\nabla F|}=\frac{h_{s} \mathbf{e}^{(\mathbf{s})}-\mathbf{e}^{(\mathbf{n})}+\left(h_{\phi} / r\right) \mathbf{e}^{(\phi)}}{\sqrt{\left(h_{s}\right)^{2}+1+\left(h_{\phi} / r\right)^{2}}} .
$$

At the free surface, the substantial derivative of $F$ must be zero. Consequently the kinematic condition on the free surface is given by

$$
\frac{D F}{D t}=0=h_{t}-u h_{s}+v+w\left(\frac{h_{\phi}}{r}\right) .
$$

Employing the substitution

$$
\mathcal{L}=\sqrt{\left(h_{s}\right)^{2}+1+\left(\frac{h_{\phi}}{r}\right)^{2}},
$$

the mean curvature of the free surface for this geometry is given by 


$$
\kappa=-\nabla \cdot \hat{\mathbf{f}}+\frac{1}{R^{(\mathrm{sub})}}=-\frac{r_{s} h_{s}+r h_{s s}}{r \mathcal{L}}+\frac{h_{s}^{2} h_{s s}}{(\mathcal{L})^{3}}-\frac{h_{\phi \phi}}{r^{2} \mathcal{L}}+\frac{h_{\phi}^{2} h_{\phi \phi}}{r^{4}(\mathcal{L})^{3}}+\frac{1}{R^{(\mathrm{sub})}},
$$

at $n=h$. Here $R^{(\mathrm{sub})}$ is the radius of curvature of the substrate. Adding the curvature of the free surface relative to the substrate with the curvature of the substrate, given by $1 / R^{(\mathrm{sub})}$, to obtain the total curvature of the free surface has been shown to be valid by Schwartz and Weidner [3] as long as $h_{s} \ll 1$ and $h \kappa \ll 1$.

If the atmospheric pressure is zero, then the tensor equation relating the change in pressure across the free surface due to surface tension is given by

$$
\left[\tau_{i j}+p \delta_{i j}\right] \hat{f}_{j}=-\sigma \kappa \hat{f}_{i}
$$

Here $\sigma$ is the surface tension of the liquid, and $\tau_{i j}$ is the stress tensor in the liquid at the free surface. For our geometry, the components of the stress tensor are given by

$$
\begin{aligned}
& \tau_{s s}=2 \mu u_{s}, \quad \tau_{n n}=2 \mu v_{n}, \quad \tau_{\phi \phi}=\frac{2 \mu}{r}\left[w_{\phi}+u r_{s}\right], \\
& \tau_{s n}=\tau_{n s}=\mu\left[v_{s}+u_{n}\right], \quad \tau_{n \phi}=\tau_{\phi n}=\mu\left[w_{n}+\frac{v_{\phi}}{r}\right], \\
& \tau_{s \phi}=\tau_{\phi s}=\mu\left[\frac{u_{\phi}}{r}+w_{s}-\frac{w r_{s}}{r}\right] .
\end{aligned}
$$

If we sum the three equations found in Eq. (5) over $j=s, n, \phi$ for each $i=s, i=n$, and $i=\phi$, we have the following three equations:

$$
\begin{gathered}
-\sigma \kappa h_{s}=p h_{s}+\tau_{s s} h_{s}+\tau_{s n}+\tau_{s \phi} \frac{h_{\phi}}{r}, \\
-\sigma \kappa=p+\tau_{n s} h_{s}+\tau_{n n}+\tau_{n \phi} \frac{h_{\phi}}{r}, \\
-\sigma \kappa \frac{h_{\phi}}{r}=p \frac{h_{\phi}}{r}+\tau_{\phi s} h_{s}+\tau_{\phi n}+\tau_{\phi \phi} \frac{h_{\phi}}{r},
\end{gathered}
$$

all evaluated at the free surface $n=h$. Because we have assumed that the pressure in the air is zero, the pressure in the liquid is positive if $\kappa$ is negative. If we eliminate the pressure $p$ and the curvature of the free surface $\kappa$ from the three Eqs. (6)-(8), we find the following equations are valid at the free surface $n=h$ :

$$
\begin{array}{r}
\tau_{s n}\left(1-h_{s}^{2}\right)+\left(\tau_{s s}-\tau_{n n}\right) h_{s}-\tau_{n \phi} \frac{h_{s} h_{\phi}}{r}+\tau_{s \phi} \frac{h_{\phi}}{r}=0 \\
\tau_{n \phi}\left(1-\left[\frac{h_{\phi}}{r}\right]^{2}\right)+\tau_{\phi \phi} \frac{h_{\phi}}{r}+\tau_{s \phi} h_{s}-\tau_{s s} h_{s} \frac{h_{\phi}}{r}-\tau_{n s} \frac{h_{s} h_{\phi}}{r}=0 .
\end{array}
$$

We now scale the dependent and independent variables with various characteristic lengths of the substrate geometry. These include $h_{0}$, a characteristic coating thickness, $R_{c}$ the maximum radius of the substrate, $u_{0}$ a characteristic velocity, and $\alpha$ a small parameter representing the ratio of a typical length perpendicular to the substrate to a typical length parallel to the substrate. Denoting dimensionless variables by bars, we have 


$$
\begin{aligned}
& \bar{\phi}=\frac{\alpha R_{c} \phi}{h_{0}}, \quad \bar{s}=\frac{\alpha s}{h_{0}}, \quad \bar{n}=\frac{n}{h_{0}}, \quad \bar{w}=\frac{w}{u_{0}}, \quad \bar{u}=\frac{u}{u_{0}}, \quad \bar{v}=\frac{v}{\alpha u_{0}}, \\
& \bar{r}=\frac{r}{R_{c}}, \quad \bar{t}=\frac{\alpha u_{0} t}{h_{0}}, \quad \bar{\kappa}=R_{c} \kappa, \quad \bar{p}=\frac{p h_{0}}{u_{0} \mu}, \quad \bar{Q}=\frac{Q}{u_{0} h_{0}} .
\end{aligned}
$$

If $Q$ is the flux, with units of length cubed over time, then the flux in the $s$ and $\phi$ directions are defined by

$$
\bar{Q}^{(\bar{s})}=\int_{0}^{\bar{h}} \bar{u} d \bar{n}, \quad \bar{Q}^{(\bar{\phi})}=\int_{0}^{\bar{h}} \bar{w} d \bar{n} .
$$

We can eliminate the pressure from the $s, n$, and $\phi$ momentum equations using identities for partial differentiation of functions:

$$
\begin{aligned}
\left(\bar{p}_{\bar{s}}\right)_{\bar{n}}-\left(\bar{p}_{\bar{n}}\right)_{\bar{s}}=0= & \mu \bar{u}_{\overline{n n n}}+\alpha \mu\left(\frac{-\bar{w}_{\bar{\phi} \bar{n}}}{\bar{r}^{2}}-\frac{2 \bar{u}_{\bar{n}} \bar{r}_{\bar{s}}}{\bar{r}^{2}}+\frac{\bar{w}_{\overline{n s}}}{\bar{r}}\right) \\
+ & \alpha\left[-\frac{\rho g \sin \theta \theta_{\bar{s}}}{R_{c}}+\rho \omega^{2} \bar{r}_{\bar{s}} \sin \theta+\frac{\rho \omega^{2} \cos \theta \theta_{\bar{s}}}{R_{c}}\right]+O\left(\alpha^{2}\right), \\
& \left(\bar{p}_{\bar{\phi}}\right)_{\bar{n}}-\left(\bar{p}_{\bar{n}}\right)_{\bar{\phi}}=0=\mu \bar{w}_{\overline{n n n}} \bar{r}+O\left(\alpha^{2}\right) .
\end{aligned}
$$

The scaled form of the continuity equation is given by

$$
\frac{\partial}{\partial \bar{s}}(\overline{r u})+\frac{\partial}{\partial \bar{n}}(\overline{r v})+\frac{\partial}{\partial \bar{\phi}}(\bar{w})=0 .
$$

At the substrate, $\bar{n}=0$, we have the scaled representation of the no-slip boundary conditions:

$$
\bar{u}(\bar{s}, \bar{n}=0, \bar{\phi}, \bar{t})=\alpha \bar{v}(\bar{s}, \bar{n}=0, \bar{\phi}, \bar{t})=\bar{w}(\bar{s}, \bar{n}=0, \bar{\phi}, \bar{t})=0 .
$$

The scaled form of the kinematic condition is shown to be

$$
\bar{h}_{\bar{t}}=\bar{u} \bar{h}_{\bar{s}}-\bar{v}+\bar{w} \frac{\bar{h}_{\bar{\phi}}}{\bar{r}}
$$

at $\bar{n}=\bar{h}$. The boundary conditions, Eq. (9) and Eq. (10), are given by

$$
\bar{u}_{\bar{n}}+O\left(\alpha^{2}\right)=0, \quad \bar{w}_{\bar{n}}+O\left(\alpha^{2}\right)=0,
$$

at $\bar{n}=\bar{h}$.

Instead of transforming the equations representing the pressure discontinuity across the liquid interface, given by Eq. (9) and Eq. (10), we will eliminate the pressure term in Eqs. (9) and (10) using the momentum equations and the identities for the partial differentiation of implicit functions. Eq. (7) gives the pressure in the liquid at the free surface $\bar{p}(\bar{s}, \bar{n}=\bar{h}, \bar{\phi}, \bar{t})$. The momentum equations give us $\bar{p}_{\bar{n}}$, $\bar{p}_{\bar{s}}$, and $\bar{p}_{\bar{\phi}}$ in the liquid. The directional derivatives of $\bar{p}$, along with $\bar{n}=\bar{h}(\bar{s}, \bar{\phi}, \bar{t})$, in the $\bar{s}$ and $\bar{\phi}$ directions, respectively, are 


$$
\begin{aligned}
& {\left.\left[\bar{p}_{\bar{s}}+\bar{p}_{\bar{n}} \bar{h}_{\bar{s}}\right]\right|_{\bar{n}=\bar{h}}=\frac{\partial}{\partial \bar{s}} \bar{p}(\bar{s}, \bar{n}=\bar{h}, \bar{\phi}, \bar{t}),} \\
& {\left.\left[\bar{p}_{\bar{\phi}}+\bar{p}_{\bar{n}} \bar{h}_{\bar{\phi}}\right]\right|_{\bar{n}=\bar{h}}=\frac{\partial}{\partial \bar{\phi}} \bar{p}(\bar{s}, \bar{n}=\bar{h}, \bar{\phi}, \bar{t}) .}
\end{aligned}
$$

Plugging the pressure at the interface, found by Eq. (7), into the momentum equations yields

$$
\begin{aligned}
&\left.\mu \bar{u}_{\overline{n n}}\right|_{n=h}= \lambda \sin \theta-\Gamma(\bar{r} \cos \theta)+\alpha\left[\frac{\Lambda}{H} \bar{\kappa}_{\bar{s}}+\lambda \sin \theta \bar{h}_{\bar{s}}+\Gamma \bar{r} \cos \theta \bar{h}_{\bar{s}}\right] \\
&+\alpha \mu\left[\frac{2 \bar{r}_{\bar{s}} \bar{u}}{\bar{r}^{2}}+\frac{\bar{w}_{\phi}}{\bar{r}}-\frac{2 \bar{w}_{\bar{n}}}{\bar{r}^{2}} \bar{h}_{\bar{s}}\right]+O\left(\alpha^{2}\right), \\
&\left.\mu \bar{w}_{\overline{n n}}\right|_{\bar{n}=h}=\alpha\left[\frac{\Lambda}{H} \frac{\bar{\kappa}_{\bar{\phi}}}{\bar{r}}+\lambda \cos \theta \bar{h}_{\bar{\phi}}+\Gamma \bar{r} \sin \theta \bar{h}_{\bar{\phi}}\right]+\alpha \mu \frac{\bar{w}_{\bar{s}}}{r}+O\left(\alpha^{2}\right),
\end{aligned}
$$

where

$$
\lambda=\frac{\rho g R_{c}^{2}}{\mu u_{0}}, \quad \Gamma=\frac{\rho \omega^{2} R_{c}^{3}}{\mu u_{0}}, \quad \Lambda=\frac{\sigma \alpha}{\mu u_{0}}, \quad H=\frac{h_{0}}{R_{c}} .
$$

Here the $\kappa$ terms have been assumed to be of order $O(1)$, while Eq. (4) would indicate that they are $O\left(\alpha^{2}\right)$. In order to bring the surface tension terms into the $O(\alpha)$ problem, we are in effect assuming that $\Lambda$ is $O\left(1 / \alpha^{2}\right)$. Others, including Benney [4] and Atherton and Homsy [5], have used a similar "specific promotion" for similar thin film problems.

We now expand the scaled velocities in a regular perturbation series expansion in powers of the small parameter $\alpha$ :

$$
\begin{aligned}
& \bar{u}=\bar{u}^{(0)}+\alpha \bar{u}^{(1)}+\ldots \alpha^{m} \bar{u}^{(m)}, \\
& \bar{v}=\bar{v}^{(0)}+\alpha \bar{v}^{(1)}+\ldots \alpha^{m} \bar{v}^{(m)}, \\
& \bar{w}=\bar{w}^{(0)}+\alpha \bar{w}^{(1)}+\ldots \alpha^{m} \bar{w}^{(m)} .
\end{aligned}
$$

We then use boundary conditions to determine the appropriate constants of integration and solve for $\bar{u}^{(0)}, \bar{v}^{(0)}$, and $\bar{w}^{(0)}$ and $\bar{u}^{(1)}, \bar{v}^{(1)}$, and $\bar{w}^{(1)}$. The $O(1)$ velocities are given by

$$
\bar{u}^{(0)}(\bar{s}, \bar{n}, \bar{\phi})=A_{0}\left[\frac{\bar{n}^{2}}{2}-\bar{h} \bar{n}\right], \quad \bar{w}^{(0)}=0,
$$

where $A_{0}=\lambda \sin \theta-\Gamma \bar{r} \cos \theta$. We now determine the order $\alpha$ velocities

$$
\begin{gathered}
\bar{u}^{(1)}=A_{0} \frac{2 \bar{r}_{\bar{s}}}{\bar{r}^{2}}\left[\frac{\bar{n}^{4}}{24}-\frac{\bar{h}^{3}}{6}+\frac{\bar{h}^{2} \bar{n}^{4}}{4}-\frac{\bar{h}^{3} \bar{n}}{6}\right]+B_{0}\left[\frac{\bar{n}^{2}}{2}-\bar{h} \bar{n}\right]+C_{0}\left[\bar{h}^{2} \bar{n}-\frac{\bar{h}^{2}}{2}\right], \\
\bar{w}^{(1)}=D_{0}\left[\frac{\bar{n}^{2}}{2}-\bar{h} \bar{n}\right]
\end{gathered}
$$

with the constants $B_{0}, C_{0}$, and $D_{0}$ given by 


$$
\begin{aligned}
B_{0} & =\left[\frac{\Lambda}{H} \bar{\kappa}_{\bar{s}}+\lambda \cos \theta \bar{h}_{\bar{s}}+\Gamma \bar{r} \sin \theta \bar{h}_{\bar{s}}\right], \\
C_{0} & =\left[-\lambda \sin \theta \theta_{\bar{s}}+\Gamma \bar{r}_{\bar{s}} \sin \theta+\Gamma \bar{r} \cos \theta \theta_{\bar{s}}\right], \\
D_{0} & =\left[\frac{\Lambda}{H} \frac{\bar{\kappa}_{\bar{\phi}}}{\bar{r}}+\lambda \cos \theta \frac{\bar{h}_{\bar{\phi}}}{\bar{r}}+\Gamma \bar{r} \sin \theta \frac{\bar{h}_{\bar{\phi}}}{\bar{r}}\right] .
\end{aligned}
$$

Using the appropriate boundary conditions, the order $\alpha$ velocity in the normal direction $n$ may be determined by integrating the continuity equation. But if we limit our consideration to the order $\alpha$ problem, we can write the evolution equation in divergence form, negating the necessity of determining $\bar{v}^{(1)}$. Integrating Eq. (13) between the boundaries $\bar{n}=0$ and $\bar{n}=\bar{h}$, and employing Leibniz's rule, we have the kinematic condition

$$
\bar{h}_{\bar{t}}=-\frac{1}{\bar{r}}\left[\frac{\partial\left(\bar{r} \bar{Q}^{(\bar{s})}\right)}{\partial \bar{s}}+\frac{\partial \bar{Q}^{(\bar{\phi})}}{\partial \bar{\phi}}\right] .
$$

The evolution equation, to order $\alpha$, is then determined to be

$$
\begin{aligned}
\bar{h}_{\bar{t}}= & -\frac{1}{\bar{r}} \frac{\partial}{\partial \bar{s}}\left[\left[(-\lambda \sin \theta+\Gamma \bar{r} \cos \theta)-\alpha\left(+\frac{\Lambda}{H} \bar{\kappa}_{\bar{s}}+\lambda \cos \theta \bar{h}_{\bar{s}}-\Gamma \bar{r} \sin \theta \bar{h}_{\bar{s}}\right)\right] \overline{\bar{r}} \frac{\bar{h}^{3}}{3}\right. \\
& \left.+\alpha\left(-\lambda \sin \theta \theta_{\bar{s}}+\Gamma \bar{r}_{\bar{s}} \sin \theta+\Gamma \bar{r} \cos \theta \theta_{\bar{s}}\right) \bar{r} \frac{\bar{h}^{4}}{8}+\alpha(-\lambda \sin \theta+\Gamma \bar{r} \cos \theta) \frac{\bar{r}_{\bar{s}}}{\bar{r}} \frac{\bar{h}^{5}}{3}\right] \\
& -\frac{1}{\bar{r}} \frac{\partial}{\partial \bar{\phi}}\left[\alpha\left(-\frac{\Lambda}{H} \frac{\bar{\kappa}_{\bar{\phi}}}{\bar{r}}-\lambda \cos \theta \frac{\bar{h}_{\bar{\phi}}}{\bar{r}}-\Gamma \bar{r} \sin \theta \frac{\bar{h}_{\bar{\phi}}}{\bar{r}}\right) \frac{\bar{h}^{3}}{3}\right] .
\end{aligned}
$$

The dimensional evolution equation is found to be given by

$$
\begin{aligned}
h_{t}= & -\frac{1}{\mu r} \frac{\partial}{\partial s}\left[\left(-\rho g \sin \theta+\rho \omega^{2} r \cos \theta-\sigma \kappa_{s}-\rho g \cos \theta h_{s}-\rho \omega^{2} r \sin \theta h_{s}\right) r\left(\frac{h^{3}}{3}\right)\right] \\
& -\frac{1}{\mu r} \frac{\partial}{\partial s}\left[\left(-\rho g \sin \theta \theta_{s}+\sigma r_{s} \sin \theta+\rho \omega^{2} r \cos \theta \theta_{s}\right) r\left(\frac{h^{4}}{8}\right)\right. \\
& \left.+\frac{r_{s}}{r}\left(-\rho g \sin \theta+\rho \omega^{2} r \cos \theta\right)\left(\frac{h^{5}}{3}\right)\right] \\
& -\frac{1}{\mu r} \frac{\partial}{\partial \phi}\left[\left(-\sigma \frac{\kappa_{\phi}}{r}-\rho g \cos \theta \frac{h_{\phi}}{r}-\rho \omega^{2} r \sin \theta \frac{h_{\phi}}{r}\right)\left(\frac{h^{3}}{3}\right)\right] .
\end{aligned}
$$

\section{Nondimensionalization}

We shall employ the maximum radius of the substrate as our length scale, $r_{\max }=R_{c}$, and scale time with the quantity $t^{*}=3 \mu R_{c} / \sigma$. We include the following substitutions: 


$$
\hat{h}=\frac{h}{R_{c}}, \quad \hat{r}=\frac{r}{R_{c}}, \quad \hat{s}=\frac{s}{R_{c}}, \quad \hat{\kappa}=\kappa R_{c}, \quad \hat{\phi}=\phi, \quad \hat{t}=\frac{t}{t^{*}} .
$$

Substituting these scale factors in the dimensional evolution equation, Eq. (22), leads to the nondimensional evolution equation

$$
\begin{aligned}
\hat{h}_{\hat{t}}= & -\frac{1}{\hat{r}} \frac{\partial}{\partial \hat{s}}\left[\left(-\lambda_{2} \sin \theta+\Gamma_{2} \hat{r} \cos \theta-\hat{\kappa}_{\hat{s}}-\lambda_{2} \cos \theta \hat{h}_{\hat{s}}-\Gamma_{2} \hat{r} \sin \theta \hat{h}_{\hat{s}}\right) \hat{r}^{3}\right] \\
& -\frac{1}{\hat{r}} \frac{\partial}{\partial \hat{s}}\left[\left(+\lambda_{2} \sin \theta \theta_{\hat{s}}-\Gamma_{2} \hat{r}_{\hat{s}} \sin \theta+\Gamma_{2} \hat{r} \cos \theta \theta_{\hat{s}}\right) \hat{r}\left(\frac{3 \hat{h}^{4}}{8}\right)\right] \\
& -\frac{1}{\hat{r}} \frac{\partial}{\partial \hat{s}}\left[\left[-\lambda_{2} \sin \theta+\Gamma_{2} \cos \theta\right] \frac{\hat{r}_{\hat{s}}}{\hat{r}}\left(\hat{h}^{5}\right)\right], \\
& -\frac{1}{\hat{r}} \frac{\partial}{\partial \hat{\phi}}\left[\left[-\frac{\hat{\kappa}_{\hat{\phi}}}{\hat{r}}-\lambda_{2} \cos \theta \frac{\hat{h}_{\hat{\phi}}}{\hat{r}}-\Gamma_{2} \hat{r} \sin \theta \frac{\hat{h}_{\hat{\phi}}}{\hat{r}}\right] \hat{h}^{3}\right],
\end{aligned}
$$

in nondimensional units. Here $\lambda_{2}$ and $\Gamma_{2}$ are given by

$$
\lambda_{2}=\frac{\rho g R_{c}^{2}}{\sigma}, \quad \Gamma_{2}=\frac{\rho \omega^{2} R_{c}^{3}}{\sigma} .
$$

The geometry of the substrate is delineated by a schematic drawing which gives us the radius of each circular arc, $R_{\mathrm{i}}$, the subtended angle $\varphi_{\mathrm{i}}$ of each element, and the length of each straight segment (see Figure 2). Consequently there is a discontinuity in the curvature between adjacent elements, but the slope is always continuous. In order to use the lubrication approximations, the coating thickness must

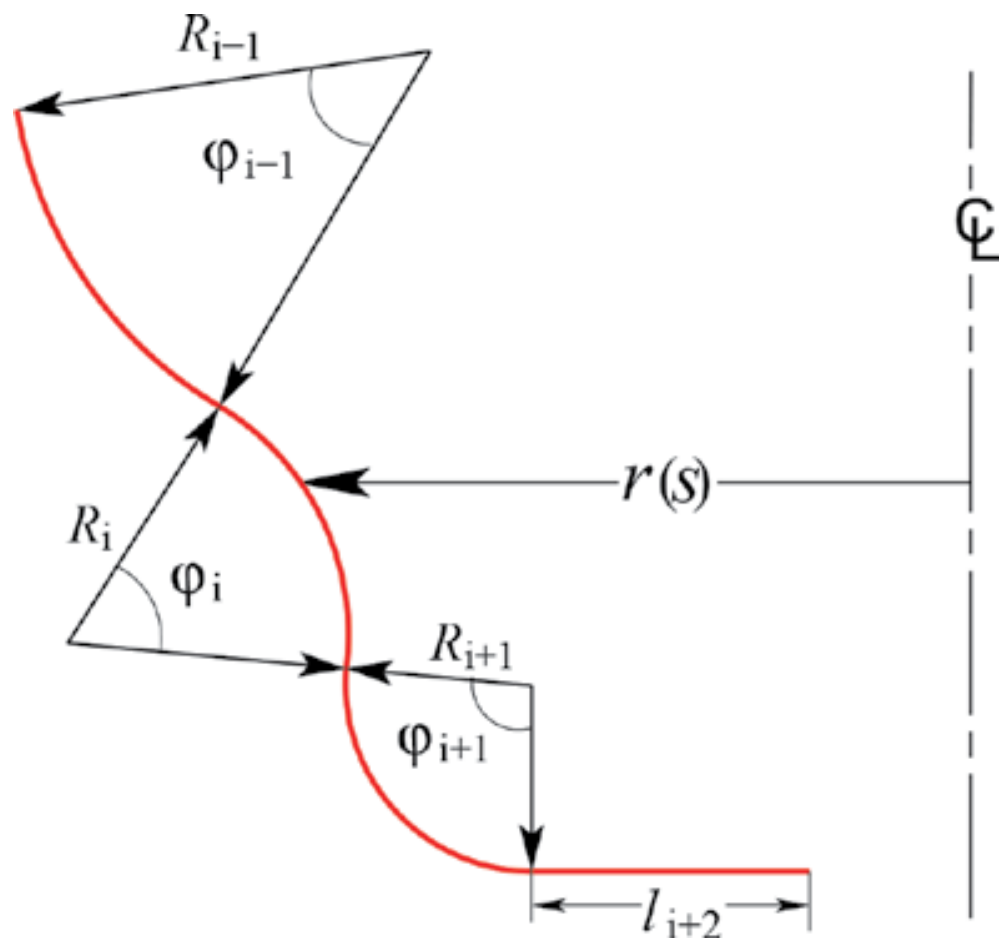

Figure 2.

Substrate made up of straight segments and circular arcs of radius $\mathrm{R}_{\mathrm{i}}$ and subtended angle $\varphi_{\mathrm{i}}$. 
always be much smaller than a typical substrate length, $R_{\mathrm{i}} \varphi_{\mathrm{i}}$ or $l_{\mathrm{i}}$. At $t=0$ we assume that there is already a very thin paint layer on the substrate and always use a sufficiently small time step such that $\hat{h}(\hat{s}, \hat{t})$ is never zero. Consequently we do not have to introduce the effects of a contact angle in our analysis. We not only assume that there is no $\phi$ variation in the substrate but that the coating is also axisymmetric. Consequently we only have to solve for the coating height as a function of $s$ and $t$.

\section{Application of coating layer}

We assume that the coating layer is laid down over time by a spray gun that emits a fan of gas that is directed toward the can substrate. Thus the accumulation of coating with time due to this fan is a function of $s$ and $t: \partial h^{\mathrm{fan}}(s, t) / \partial t$. The spray sector is bounded by the angles $\Delta \varphi$ and $\Delta \psi$ as shown in Figure 3. We assume that the subtended angle $\Delta \psi$ is significantly smaller than the angle $\Delta \varphi$ so that if the spray fan geometry is an ellipse, it will have an eccentricity near 1.0.

If $Q_{\text {tot }}^{\text {fan }}$ is the total flux from the fan, and $q$ the flux in an elemental area of the fan, then

$$
Q_{\mathrm{tot}}^{\mathrm{fan}}=\int_{\varphi_{1}}^{\varphi_{2}} \int_{\psi_{1}}^{\psi_{2}} q(\varphi, \psi) d \varphi d \psi
$$

If the flux does not vary significantly in the $\psi$ direction, then the flux is constant in the elemental shaded sector in Figure 3. Consequently the flux per unit distance across the thin dimension of the fan is given by $q(\varphi) /(\epsilon v)$, where $\epsilon=\Delta \psi$. When the width of the spray fan in the $\psi$ direction is less than one-half the circumference $2 \pi r(s)$ wetted by an element of the fan (see Figure 4), the average flux deposited per revolution is given by

$$
(q / \epsilon v)(\epsilon v /(2 \pi r(s)))=q /(2 \pi r(s)) .
$$

When expressed as a function of $\partial h^{\mathrm{fan}} / \partial t$, Eq. (24) becomes

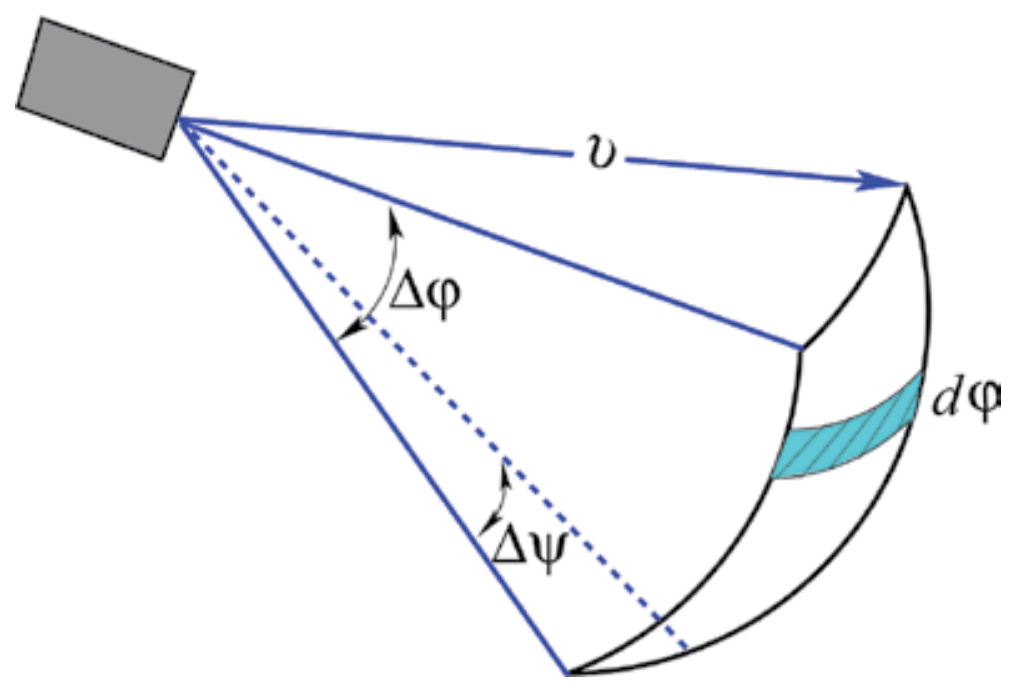

Figure 3.

Assumed spray pattern. 


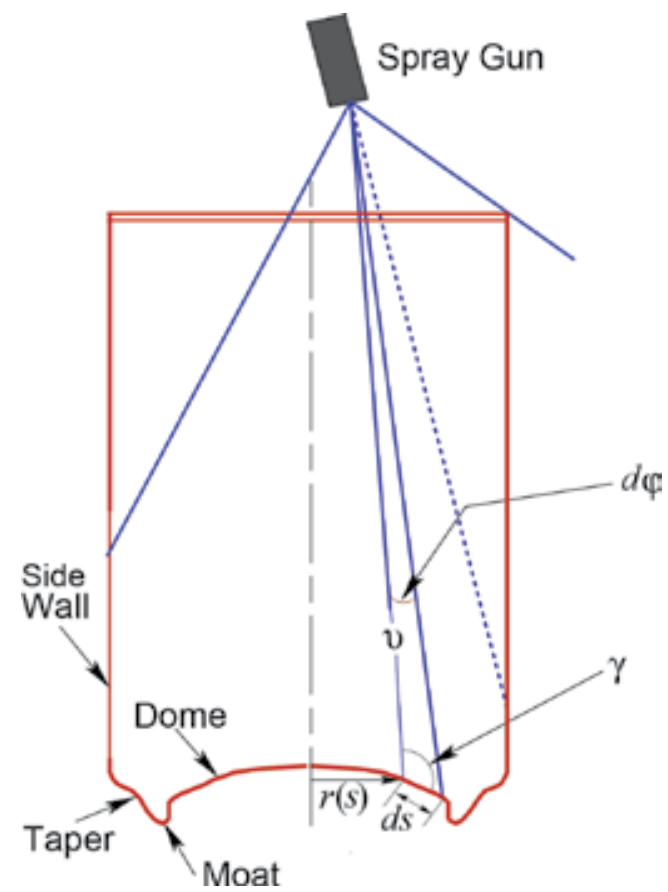

Figure 4.

Beverage can and spray pattern geometry. Here $v$ is the distance from the orifice of the spray gun to a given point on the can substrate.

$$
q d \varphi=\frac{\partial h^{\mathrm{fan}}}{\partial t} d s 2 \pi r(s)
$$

From Figure 4 we have the relation

$$
\sin \gamma=v d \varphi / d s,
$$

For a sufficiently thin fan, where the point on the substrate is sufficiently far from the centerline $r=0$, the circumferential-average rate of increase of height is given by

$$
\frac{\partial h^{\mathrm{fan}}}{\partial t}=q(\varphi) \sin \gamma /(2 \pi r(s) v)
$$

When we are near the centerline, this formula must be modified to

$$
\frac{\partial h^{\mathrm{fan}}}{\partial t}=[1 / v(s)][q(s) /(\epsilon v(s))] \sin \gamma(s) \cdot \operatorname{Min}[(\epsilon v(s) / 2 \pi r(s), 1 / 2]
$$

to account for the fact that here the substrate is constantly being reached by the spray fan.

We also assume that there is a secondary "gas" which is uniform in the interior of the can and results in a constant $\partial h_{\mathrm{gas}} / \partial t$. If $0<\zeta<100$ represents the percentage of secondary gas, then $\partial h_{\text {gas }} / \partial t$ from this source is given by

$$
\frac{\partial h_{\mathrm{gas}}^{\mathrm{fan}}}{\partial t}=\frac{\zeta}{100} \frac{Q_{\mathrm{tot}}}{\mathrm{A}_{\mathrm{tot}}},
$$


where $A_{\text {tot }}$ is the total area of the interior of the can. We also must include the effects of geometric shading. For example, the dome blocks some flux from the spray gun from reaching the inner wall of the moat.

\section{Pendant drop of maximum volume}

In an effort to determine the maximum value a droplet can form without detaching from the substrate, we will consider an axisymmetric droplet forming on the underside of a ceiling, as illustrated in Figure 5. Here $z$ is the distance perpendicular to the substrate, $x$ is the distance from the centerline of the drop parallel to the substrate, and $h$ is the distance from the substrate to the free surface of the drop. $g$ is the acceleration of gravity, and the contact angle with the substrate $z=0$ is given by $\theta_{c}$. The pressure jump across the free surface due to surface tension is given by $\sigma \kappa$. At equilibrium this must equal the hydrostatic pressure due to gravity, or

$$
\sigma \kappa-\rho g z=\text { constant. }
$$

If we nondimensionalize the problem by scaling $z, x$, and $h$ with the capillary length, $l_{c}=\sqrt{\sigma /(\rho g)}$, then the drop shape is defined by the following differential equation:

$$
\frac{x_{z z}}{\left(1+x_{z}^{2}\right)^{3 / 2}}-\frac{1}{x\left(1+x_{z}^{2}\right)^{1 / 2}}+z=\kappa_{0} .
$$

Here $\kappa_{0}$ is the mean curvature at $x=0$ and $z=h$.

Using a standard Runge-Kutta method, we can numerically integrate Eq. (27) assuming $\theta_{c}=0$. We find that the maximum volume is given by $V_{\max } \approx 19.0 l_{c}^{3}$ and the maximum height is given by $h_{\max } \approx 2.2 l_{c}$. For a curved, rotating substrate, the body force $g$ is replaced by a centrifugal force that is a function the rotation rate $\omega$,

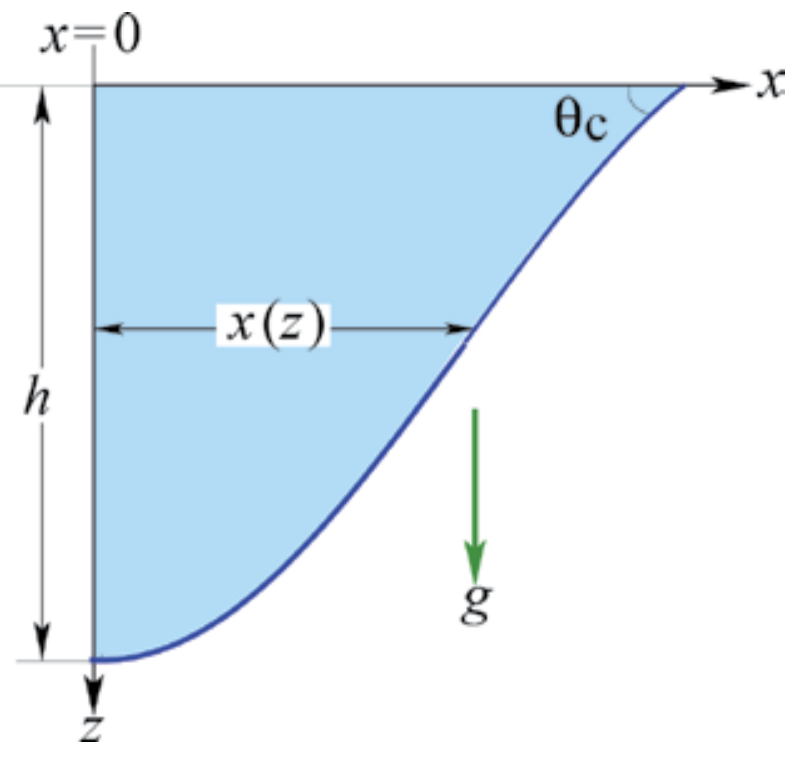

Figure 5 .

Profile view of axisymmetric pendant drop. 
radius from the axis of rotation $r(s)$, and the inclination angle of the substrate $\theta(s)$. For this case $l_{c}$ is modified to

$$
l_{c}=\sqrt{\frac{\sigma}{\left(\rho r \sin \theta \omega^{2}\right)}} .
$$

If $h(s, t)$ is greater than $2.2 l_{c}$, we assume that the drop has detached from the substrate and name this time as $t_{\max }$.

\section{Applications}

Approximately 400 billion two-piece, all-aluminum cans are produced annually for the purpose of storing beverages for distribution worldwide. The interior of each of these cans must be coated to protect the aluminum from onslaught due to corrosive elements in the contained beverage, and the beverage must be protected from picking up metal ions or other off-flavors from the aluminum substrate. Consequently the coating must be as uniform as possible for thick regions may slough off and thin regions may not offer adequate protection. To achieve a uniform film thickness, spin coating is employed using a spray fan to distribute the coating on the can substrate. But because the can is highly curved due to structural considerations, achieving a uniform final film thickness is much more complicated than for a flat substrate. In this section we will apply the analytical and numerical model we developed in previous sections to determine how the many parameters are influencing the flow of the paint coating. These parameters include the rotation rate, the shape of the can, the coating fluids physiochemical properties, and the geometry and flux of the spray fan, all affecting the final film thickness distribution.

The can body is initially punched from sheet aluminum and then goes through a washing process to produce a substrate suited for the spray coating. The can is then spun at between 2500 and 3500 rotations per minute, and one or two spray guns spray the interior with the liquid paint film. Centrifugal and gravitational forces redistribute this liquid layer as the can continues to spin after the initial spray process. The can is then placed in an oven where the solvent is allowed to evaporate leaving only the hardened resin. Then the can is filled with the beverage and the top of the can is attached in place. This conveyer process can produce as many as 1700 filled cans per minute.

In practice, one or two spray guns are used to coat the interior of the spinning cans. These are oriented at between $5^{\circ}$ and $30^{\circ}$ with respect to the vertical axis of the can and placed between 0.5 and $1.5 \mathrm{~cm}$ vertically from the top of the sidewall $[6,7]$. Typically the can is sprayed for between 0.05 and $0.2 \mathrm{~s}$ and spun for an additional $0.1-0.5 \mathrm{~s}$ [6] so that centrifugal forces can act to redistribute the coating layer.

The industry uses schematic drawings which plot the substrate as a function of circular arcs of radius $R_{i}$, and subtended angles $\varphi_{\mathrm{i}}$, as shown in Figure 2. Consequently the slope is always continuous, but there is a discontinuity in the radius of curvature between adjacent segments. Figure $\mathbf{6}$ shows a profile view of a typical can bottom, as well as a possible coating distribution, during the course of the fast spin with spray phase of the coating process. The functions $\kappa(s), \theta(s)$, and $r(s)$ were derived from a published schematic drawing of a typical beverage can from a can manufacturer [8]. We define the "dome" of the can as the region from the centerline to the first inflection point, as labeled by the symbol A. The "moat" is defined as the region from $A$ to $D$, with the inner moat defined as the region from $A$ to $B$, and 
Numerical Simulation of the Spin Coating of the Interior of Metal Beverage Cans DOI: http://dx.doi.org/10.5772/intechopen.90381

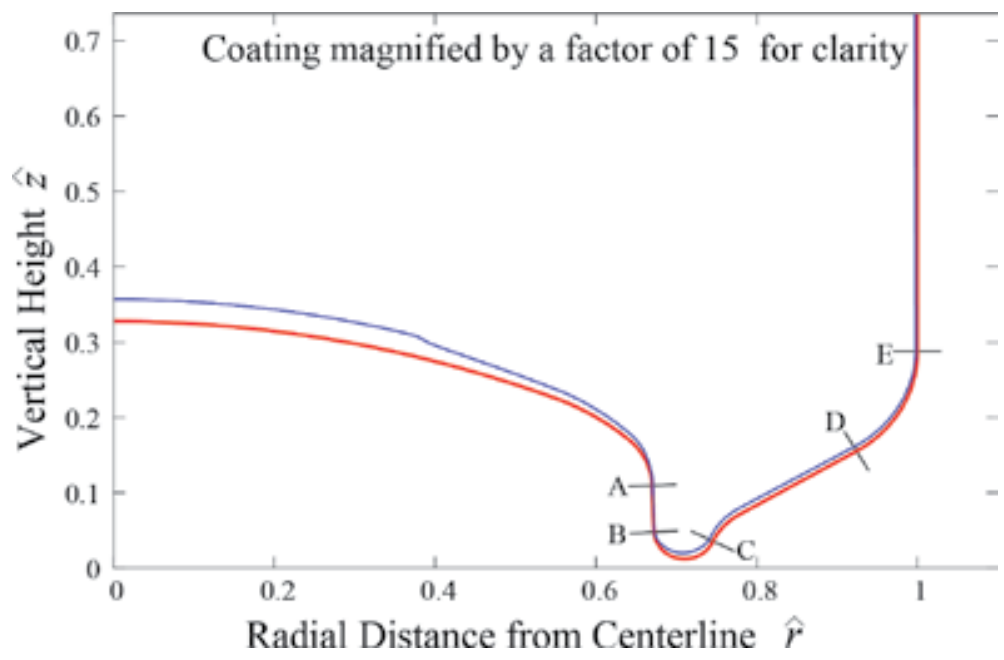

Figure 6.

Profile of the can substrate in red lines and the coating layer in blue lines at $\hat{\mathrm{t}}=.10$, in the middle of fast spin with spray phase. Dimensionless variables are used.

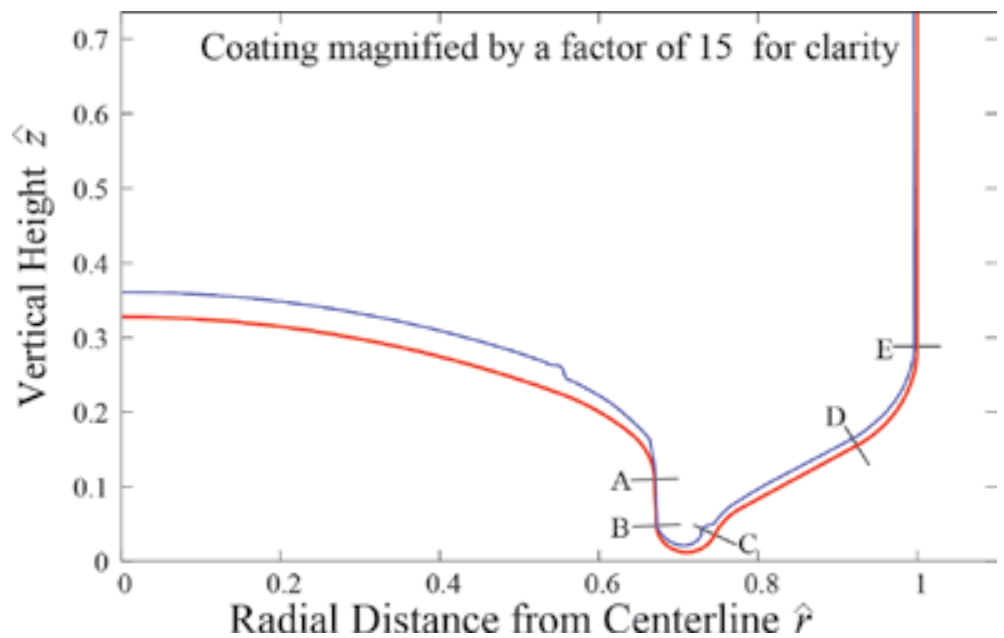

Figure 7.

Profile of the can substrate in red lines and coating layer in blue at $\hat{\mathrm{t}}=.20$, in the middle of the fast spin phase. Dimensionless variables are used.

the outer portion of the moat from $\mathrm{C}$ to $\mathrm{D}$. The intersection of the bottom of the can with the side wall occurs at E. In this study we will consider one phenomenon in the can coating process that can lead to a defect in the final coating layer. As centrifugal forces drive the coating outward along the dome, they can form a "front" which if it reaches the moat can form pendant drops on the inner wall of the moat. If centrifugal forces are sufficiently large, these drops can detach from the substrate and flung horizontally outward to the outer side of the moat. This can create a coating that is too thin on the inner wall of the moat and too thick on the opposite side (Figures 7 and 8 ).

We will assume that the spray fan has an elliptical cross section with a ratio of the major axis to the length of the minor axis of 10. The parameters determining the placement and orientation of the spray gun are illustrated in Figure 9. For the simulation considered in this work, the nondimensional parameters are listed in 


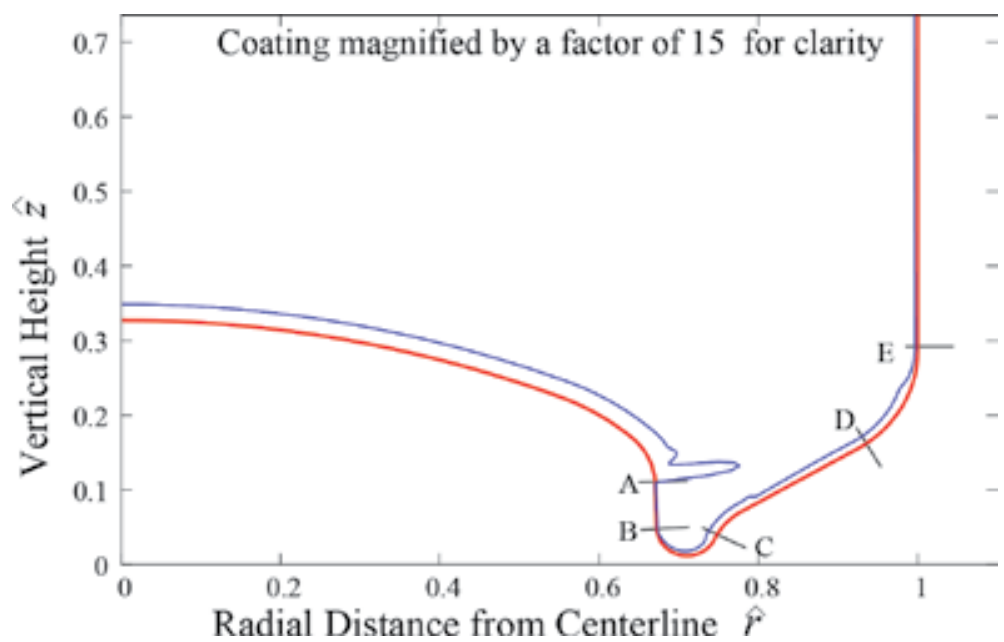

Figure 8.

Profile of the can substrate in red lines and coating layer in blue at $\hat{\mathrm{t}}=\hat{\mathrm{t}}_{\max }=.45$, near the end of the fast spin phase. Dimensionless variables are used.

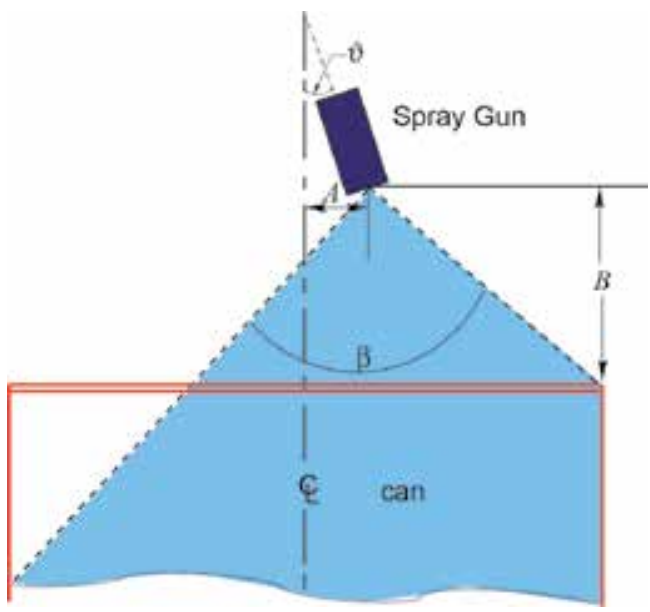

Figure 9.

Profile view of can and spray gun placement and orientation parameters.

\begin{tabular}{lcc}
\hline Parameter & Symbol & Value \\
\hline Distance of spray gun from centerline: fan \#1, fan $\# 2$ & $\hat{A}$ & $-0.15,-0.45$ \\
\hline Distance of spray gun above can: fan $\# 1$, fan $\# 2$ & $\hat{B}$ & $0.15,0.45$ \\
\hline Angle of spray gun wrt vertical: fan $\# 1$, fan $\# 2$ & $\vartheta$ & $28^{\circ}, 15^{\circ}$ \\
\hline Subtended angle of spray fan & $\beta$ & $100^{\circ}$ \\
\hline Time spray gun acts in fast spin phase & $\hat{t}_{\text {spray }}$ & 0.15 \\
\hline Percent of secondary spray & $\zeta$ & $5 \%$ \\
\hline
\end{tabular}

Table 2.

Nondimensional parameters for this simulation. 
Table 1, the dimensional parameters in Table 2, and typical properties of the coating liquid in Table 3.

From Eq. (26), we see that the coating applied by the spray gun is an inverse function of the radius of the can substrate $r$. Consequently, the coating thickness near the centerline will be significantly greater than that far away from the centerline. This effect is illustrated in Figure 6 which shows a profile view of the can substrate and the coating thickness in the middle of the spray phase at time $\hat{t}=0.10$. Centrifugal forces are mostly parallel to the substrate in the dome region and act to drive liquid outward toward the moat region, as shown in Figure 7. At the start of the inner wall of the moat, near symbol A in Figure 8, the can substrate becomes perpendicular to the centrifugal force, and the coating liquid tends to accumulate at this point. If the coating becomes too thick in this region, centrifugal forces can overcome surface tension forces and cause a pendant drop of liquid to form, which can detach from the inside of the dome edge and be thrown to the region between $\mathrm{D}$ and E. Surface tension forces act against the centrifugal forces in this region and reduce the chance that a pendant drop will detach from the coating. But if a droplet does detach, it will cause a starving of coating liquid in the inner wall region and an excess in the outer wall region, possibly leading to coating irregularities such as blisters after the final bake.

The dimensionless parameter $\rho R^{2} \omega^{2} /(\sigma / R)$ expresses the ratio of the pressure drop across the interface due to centrifugal forces versus surface tension forces. The dimensionless characteristic time for droplet detachment is plotted versus this dimensionless parameter in Figure 10. This graph estimates the maximum value of $\hat{t}$, termed $\hat{t}_{\text {max }}$, before droplet ejection occurs for a Newtonian liquid. Here we estimate the value of $\hat{t}$ when droplet detachment occurs using the criteria developed in Eq. (5) in Section 5. One can then determine how long the can may remain in the fast spin phase to avoid this coating irregularity.

The surface tension, density, and viscosity of the coating liquid are difficult to significantly alter as they depend on the required organic solvent content and surfactant levels in the paint formula. Similarly, $R$, the beverage can radius, is fixed by industry production standards. This leaves the rate of rotation as the only significant production parameter for changing the nondimensional (centrifugal force)/(surface tension force) parameter.

The centrifugal ejection of coating liquid from the inner wall of the moat is also predicted to be a strong function of the position and orientation of the spray gun. In the above example, the gun is placed 0.5 to the left of the centerline, is $0.5 \mathrm{~cm}$ above the top of the can, and is angled at $28^{\circ}$ with respect to the vertical. For our second simulation, the gun is placed $1.5 \mathrm{~cm}$ to the left of the centerline, $1.5 \mathrm{~cm}$ above the top of the can, and angled at $15^{\circ}$ with respect to the vertical. All other parameters are the same as in the previous example. This second spray gun position results in

\begin{tabular}{lcc}
\hline Parameter & Symbol & Value \\
\hline Can radius & $R$ & $3.33 \mathrm{~cm}$ \\
\hline Rotation rate & $\omega$ & $2500-3500 \mathrm{RPM}$ \\
\hline Distance of spray gun from centerline: fan \#1, fan \#2 & $A$ & $-0.5 \mathrm{~cm},-1.5 \mathrm{~cm}$ \\
\hline Distance of spray gun above can: fan \#1, fan \#2 & $B$ & $0.5 \mathrm{~cm}, 1.5 \mathrm{~cm}$ \\
\hline Average wet coating thickness & $h_{\text {avg }}$ & $0.0028 \mathrm{~cm}$ \\
\hline Time spray gun acts in fast spin phase & $t_{\text {spray }}$ & $0.05 \mathrm{~s}$ \\
\hline
\end{tabular}

Table 3.

Dimensional parameters for this simulation. 


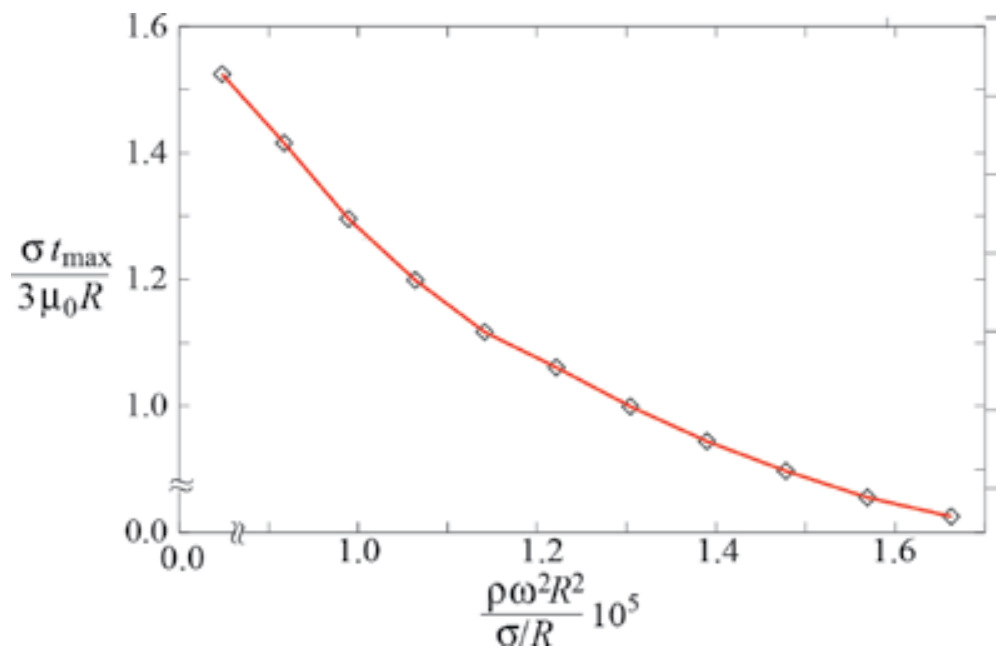

Figure 10.

Critical time for droplet formation, $\hat{\mathrm{t}}_{\mathrm{max}}$, versus centrifugal force parameter. Here dimensionless variables are used.

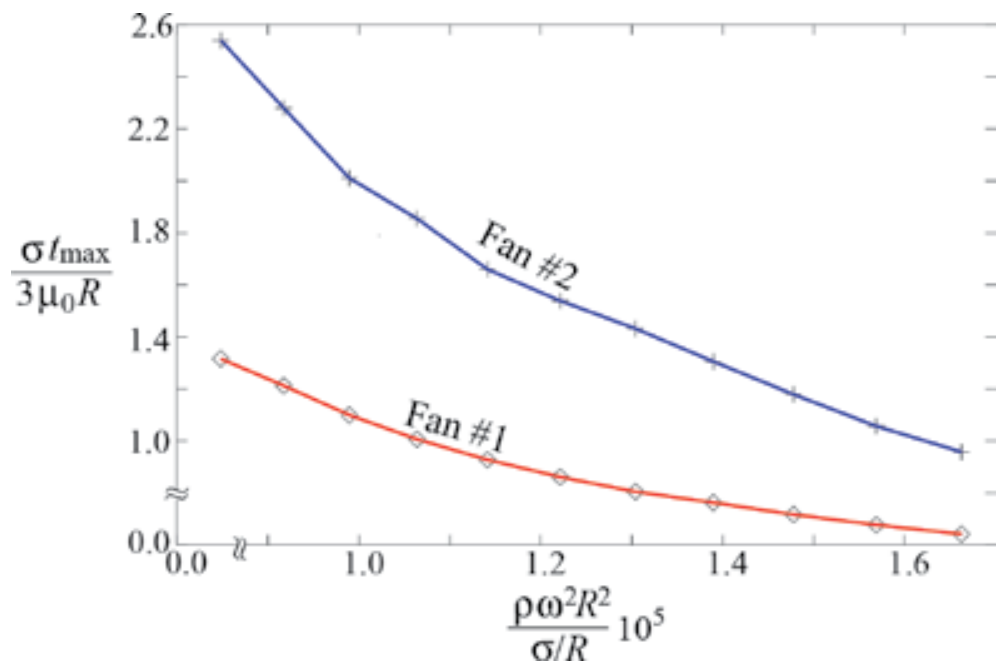

Figure 11.

Critical time for droplet formation, $\hat{t}_{\text {max }}$, versus centrifugal force parameter for two different spray gun placements. For fan \#1, the angle of inclination is $28^{\circ}, A_{1}=-0.15, B_{1}=0.45$. For fan \#2, the angle of inclination is $15^{\circ}, A_{2}=-0.45, B_{2}=0.45$. Dimensionless variables are used.

approximately $40 \%$ less spray falling on the dome and approximately $10 \%$ more coating on the sidewall than the first case. The total liquid volume emitted from the two spray guns is identical. Because the flux parallel to the substrate $Q^{(s)}$ is a function of the coating thickness cubed, we would expect that it would take longer before the coating is driven off the dome due to centrifugal forces for the second spray gun placement than the first spray gun placement. This is illustrated in Figure 11 where we plot $\hat{t}_{\max }$ versus the dimensionless centrifugal force parameter for the two spray gun positions. With the new gun placement and orientation, one may keep the can in the fast spin phase for between 150 and 190\% longer than the original spray gun configuration. 


\section{Conclusion}

In this work we have used scaling arguments and perturbation theory to derive the lubrication form of the governing fluid mechanical equations for a thin liquid film coating an arbitrarily curved, axisymmetric, rotating substrate. Our main purpose has been to develop mathematical model that can be employed to numerically simulate the application of a paint film to the interior of beverage cans, though the basic algorithm may be useful in other applications. We have used our algorithm to predict the time of centrifugal ejection of coating from the inner moat wall as a function of several input parameters: the physiochemical properties of the coating liquid, the rotation rate, and the spray gun placement. The model can also be used to predict other coating defects and how the input parameters can be used to avoid them. The effect of solvent evaporation during the drying phase, when gravity and surface tension forces affect the coating distribution as the viscosity increases until only a final, hard, film remains, may also be modeled. With so many parameters regulating the final coating thickness, using experiments to model the coating evolution and measure the final, dry, film thickness is an almost impossible task. Instead we can utilize the power and versatility of computer simulation to predict the coating profile as a function of input parameters. This understanding will be useful in optimizing the current application process. It may also be essential in acquiring a satisfactory coating when environmental regulations require a change to high solids and latex paints.

\section{Author details}

David E. Weidner

Department of Mechanical Engineering, University of Delaware, Newark, Delaware, USA

*Address all correspondence to: weidner@udel.edu

\section{IntechOpen}

(C) 2019 The Author(s). Licensee IntechOpen. This chapter is distributed under the terms of the Creative Commons Attribution License (http://creativecommons.org/licenses/ by/3.0), which permits unrestricted use, distribution, and reproduction in any medium, provided the original work is properly cited. (c) BY 


\section{References}

[1] Kee R, Coltrin M, Glarborg P.

Navier-Stokes equations. In: Chemically

Reacting Flow Theory and Practice.

Hoboken NJ: John Wiley \& Sons; 2003.

p. 766

[2] Meyers T, Lombe M. The importance of the coriolis on axisymmetric horizontal rotating thin film flows.

Chemical Engineering and Processing. 2006;45:908

[3] Schwartz L, Weidner D. Modeling of coating flows on curved surfaces.

Journal of Engineering Mathematics. 1995;29(1):91

[4] Benney D. Long waves on liquid films. Journal of Mathematics and Physics. 1966;45:150

[5] Atherton R, Homsy G. On the derivation of evolution equations for interfacial waves. Chemical Engineering Communications. 1976;2(2):57

[6] Gerek G, Coucher R. Coated container. US Patent 3,947,617. 1976

[7] Coucher R, Gerek G. Container coating method. US Patent 4,183,974. 1980

[8] Dervy L, Gogola M, Walsh W. Bottom profile for drawn and ironed can body. US Patent App. 11/890,107. 2007 


\title{
Thin Films for Medical and Environmental Applications
}

\author{
Ana P. Piedade, Francisco Romeu, Rita Branco and \\ Paula V. Morais
}

\begin{abstract}
A material that presents both the appropriate set of bulk properties in conjunction with an optimal surface performance is hardly found. For this reason, there is the need of modifying its surface. This is a standard procedure in many application fields but particularly important in the medical and environmental research. In this chapter, we describe the use of sputtering, as the chosen technology for the deposition of thin films. The use of the modified surfaces in the medical and environmental fields will be highlighted by two case studies in each one. In biomedicine, the surface modification of medical invasive devices for orthopedic and neural applications will be presented. For the environmental aspect, the results of two bioremediation tools, for arsenic and uranium removal, based on the immobilization of bacterial cells will be discussed.
\end{abstract}

Keywords: thin films, sputtering, orthopedic implants, neural implants, bioremediation, biotools, arsenic, uranium

\section{Introduction}

Although genetic engineering and tissue culture are very promising fields for the regeneration of tissues and organs of the human body, these areas are in the early stages of their development and far from a systematic and reliable application for the majority of the population. Therefore, it is still urgent to develop/modify nonbiological materials to be used as medical invasive devices.

The field of application of thin films in Biomedicine is very broad, but the main objective is always to modify the surface of a medical invasive device in order to confer to its surface a set of properties that the bulk material fails to present. These properties include antibacterial action [1], improving the adhesion and proliferation of specific eukaryotic cells [2,3], inhibiting the immunological reaction of the organism [4], enhancing the compatibility of mechanical properties between invasive device and biological tissue [5], among others. Nowadays, due to the problem of bacterial resistance to antibiotics, there has been an enormous development in thin films that are able to reduce or even prevent bacterial adhesion/proliferation. However, for some applications, the development of thin films that allows the formation of bacterial biofilms is very important. One example is their use in bioremediation, which comprises the use of organisms, for example, bacteria, algae and plants, to alter or reduce the toxic impact of contaminants. 
Arsenic (As) is a natural metalloid widely distributed in the air, water and soil and is considered as a major public health concern. Arsenic occurs in the environment as the structural analogue of phosphate, arsenate $[\mathrm{As}(\mathrm{V})]$ and as the most toxic form of arsenic oxyanions, arsenite $[\mathrm{As}(\mathrm{III})][6,7]$.

A large number of microorganisms have been described as arsenic resistant and different strategies have been connected to their ability to grow in environments contaminated with this metalloid. Based on this remarkable capacity, the use of microorganisms to remove arsenic from polluted environments has been seen as a promising solution for arsenic remediation. The arsenic bioaccumulation or biosequestration abilities exhibited by some strains have been used or enhanced in order to obtain efficient organisms to deal with arsenic-contaminated waters $[8,9]$.

On the other hand, former uranium mines are a source of environmental contamination, since the leaching of acid water resulting from mining activity can transfer heavy metals and radioisotopes to the surrounding environmental compartments. $U$ in the environment occurs mainly as three different isotopes ( $238 \mathrm{U}, 235 \mathrm{U}$ and $234 \mathrm{U}$ ), all of them being radioactive; however, it is its chemical toxicity that is of greatest ecological risk. $U$ at contaminated sites has two major oxidation states stable in aqueous media: $\mathrm{U}(\mathrm{VI})$, the most common oxidation state of the uranyl ions, $\left(\mathrm{UO}_{2}\right)^{2+}$, which is highly soluble and mobile; and U(IV), which is extremely insoluble and usually precipitates as uraninite, $\mathrm{UO}_{2}$. $\mathrm{U}(\mathrm{VI})$ is therefore considered to be more toxic since it is highly mobile in the environmental systems.

Microorganisms can use different mechanisms to immobilize U: (1) biosorption, by establishing nonspecific interactions between the $U$ and the extracellular surfaces of microorganisms [10]; (2) bioaccumulation of U within the cells; (3) oxidation-reduction processes which transform soluble $U$ forms, $U(V I)$, into more stable forms, U(IV) [11] and (4) biomineralization by U precipitation as minerals [12]. Among the previous mechanisms, under aerobic conditions, biomineralization is the process that can be more feasible since it implies the immobilization of $\mathrm{U}(\mathrm{VI})$ soluble species with enzymatically-generated ligands like phosphate and sulfides.

\section{Production of thin films}

There is a myriad of technologies that can be used for the deposition of thin films. The choice of deposition process is dependent upon several factors, such as substrate structure and operating temperature. Several attempts have been made to classify deposition process, but they differ from the perspective of the authors that make these efforts. It is not the goal of this chapter to exhaustively list all the technologies. For that excellent books and reviews can be consulted, such as those of references [13-15].

Considering only the vacuum technologies, more recently, it is generally accepted that there are four general categories of thin film deposition: atomistic growth, particulate deposition, bulk coating and surface modification. Within these technologies especially emphasis will be given to sputtering, which is the technology used for the production of the thin films that are used for the medical and environmental applications described in the next section. Sputtering is one of the techniques of physical vapor deposition (PVD).

The properties of the films deposited by this sputtering depend on the material of the target, the gas used for the discharge and deposition parameters such as pressure, target-distance, polarization of the substrate and the chemical composition of the discharge gas. In fact, in addition to the nonreactive noble gas, the discharge gas, others can be added such as oxygen, nitrogen or methane. In this case, the sputtering is said to occur in a reactive mode. The use of a magnetron associated with 
the cathode creates a magnetic field that imposes compulsory trajectories to the electrons ejected by the target, increasing the bombardment density.

The use of different power sources enables not only the deposition of electric conductive materials, direct current (DC) power supply, but also the deposition of ceramic and polymers, when radio frequency $(\mathrm{RF})$ generators are used. Therefore, any material can have its surface changed by the deposition of any other type of material, similar or dissimilar, by sputtering. In order to better understand the enormous advantages of the use of sputtering, many excellent reviews have been published, namely a very recent one with an overview from the 1800 s to 2017 [16].

\section{Application of thin films}

\subsection{Medical applications}

The use of thin films for medical applications arises from the fact that most bulk biomaterials that are currently used as invasive devices were not developed for this specific purpose. In fact, most bulk materials used as biomaterials can be found in our garages because they were developed for different purposes. Examples are light titanium alloys used in cars parts or carbon reinforced composites in bicycles. The experience has proven that the body more or less tolerates these materials and their overall set of properties/characteristics (mechanical, electrical, etc.) is appropriated for a specific use inside the body. However, in the majority of the cases the surface is not optimized for biological environment and, no matter how good and appropriate the bulk material is, if the surface does not present the adequate combination of chemical composition, wettability, surface charge and morphology/topography, the abiotic/biotic interface is never going to reach its full potential. Consequently, the bulk material is often modified by the deposition of a thin film.

The first example of the use of thin films for medical applications concerns work developed in our laboratories, never published before. This study arose from the fact that in most of the recently published literatures concerning the use of Ti6Al4V alloy for medical invasive devices in contact with hard tissue, such as for orthopedic and orthodontic applications, refer the need to substitute vanadium (V) by another element. This fact, from the biochemical point of view, has no sustainability. In fact, $\mathrm{V}$ is a key element in some of the metabolic pathways of our organism and is being considered in some pharmaceutical drugs, due to its antidiabetic effect [17]. Moreover, there are no metabolic pathways that use titanium (Ti) or aluminum $(\mathrm{Al})$ and these elements are present in much higher contents than V. Therefore, our study had the goal to access the difference between an unmodified bulk Ti6Al4V femur implant and the sputter modified implant. For the surface modification, two chemical compositions were produced: Ti6Al4V and Ti6Al. With this approach, it would be possible to study the effect of vanadium in the Ti-based thin film and also compare the same chemical composition (Ti6Al4V) in bulk and thin film form.

Both thin films presented a thickness of $750 \mathrm{~nm}$, and from the X-ray diffractograms, it was possible to calculate the crystallite size of the thin films: 17.5 and $20 \mathrm{~nm}$ for Ti6Al and Ti6Al4V, respectively. This indicated that, in opposition to the microscopic grain size of the bulk material, the thin films were nanostructured. The hardness of both bulk and thin films was determined by ultra-micro hardness test and, due to the nanometric crystallite size, the hardness of the thin films was higher than the bulk material (Table 1). This was expected according to Hall-Petch relation [18]. Nevertheless, the presence of vanadium in the thin film reduced the hardness value in comparison with the Ti6Al thin film. 


\begin{tabular}{llll}
\hline Surfaces & Hv $(\mathrm{GPa})$ & Lc1 $(\mathbf{N})$ & Lc2 $(\mathbf{N})$ \\
\hline Bulk Ti6Al4V & $4.0 \pm 0.5$ & - & - \\
\hline Ti6Al thin film & $7.3 \pm 0.6$ & 35 & 44 \\
\hline Ti6Al4V thin film & $4.9 \pm 0.7$ & $>70$ & $>70$ \\
\hline
\end{tabular}

Table 1.

Hardness and adhesion of the bulk and thin films Ti-alloys.

Another important characterization was the evaluation of the adhesion of the thin films to the Ti6Al4V bulk substrate. In fact, the presence of an interface between the substrate and the thin film is often related with the development of stress that result in the detachment of the thin film when in use. The characterization was performed by a scratch indentation test and the results (Table 1) allow to determine both cohesive (Lc1) and adhesive failures (Lc2) values. Due to the perfect chemical compatibility between the Ti6Al4V thin film and bulk material, both cohesive and adhesive failures are higher than $70 \mathrm{~N}$ (the maximum value determined by the equipment). For the Ti6Al thin film, despite the similar chemical composition, the adhesive failure (detachment of the thin film from the substrate) occurred at $44 \mathrm{~N}$.

The wettability was accessed by static contact angle measurements between $10 \mu \mathrm{L}$ of water and the three surfaces (Figure 1).

The results showed that the bulk material presented the highest contact angle $\left(78^{\circ}\right)$, followed by Ti6Al thin film $\left(62^{\circ}\right)$ and finally Ti6Al4V thin film which presented a zero-contact angle revealing a completely wettable surface. This fact indicates that the ion exchange between the Ti6Al4V thin film and the biological fluid is enhanced, indicating that the formation of an apatite-like layer on this surface will be easier to occur than on the other two materials and, therefore, a better osseoinductive behavior is expected from Ti6Al4V thin film.

In fact, when the unmodified and sputter modified bulk Ti6Al4V were immersed for 60 days in Hanks' simulated body fluid, at $37^{\circ} \mathrm{C}$ with $100 \mathrm{rpm}$, the previous expectations were confirmed (Figure 2). The analysis of chemical distribution of calcium on the surface of the materials (Figure 2) unequivocally showed a higher surface coverage on the surface of the Ti6Al4V thin film.

Therefore, the surface of this specific thin film demonstrated, by the in vitro tests, to be the most promising for the osseointegration of medical invasive devices that contact with hard tissue. The presence of $\mathrm{V}$ in the thin film seems to be essential for the better performance of the Ti alloy, when in comparison with the Ti6Al thin film. Also, due to its nanostructured structure, Ti6Al4V thin films outperform the chemical mimetic bulk material.

The second example of applications of thin films for medical applications is also based on work developed in our laboratory and never published before and is
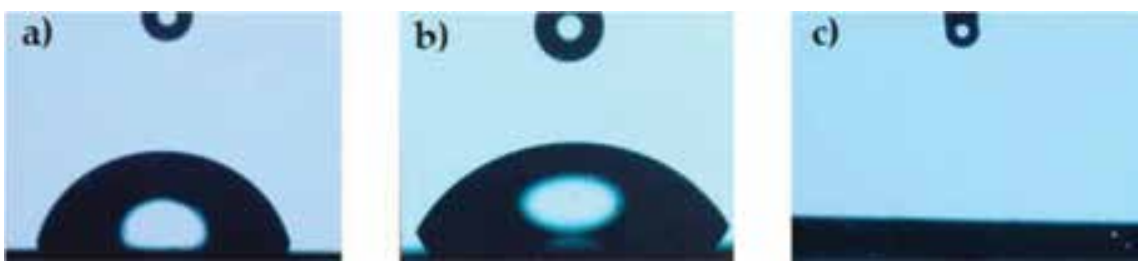

Figure 1.

Contact angle between a drop of water and Ti6Al4V bulk material (a), Ti6Al thin film (b) and Ti6Al4V thin film (c). 


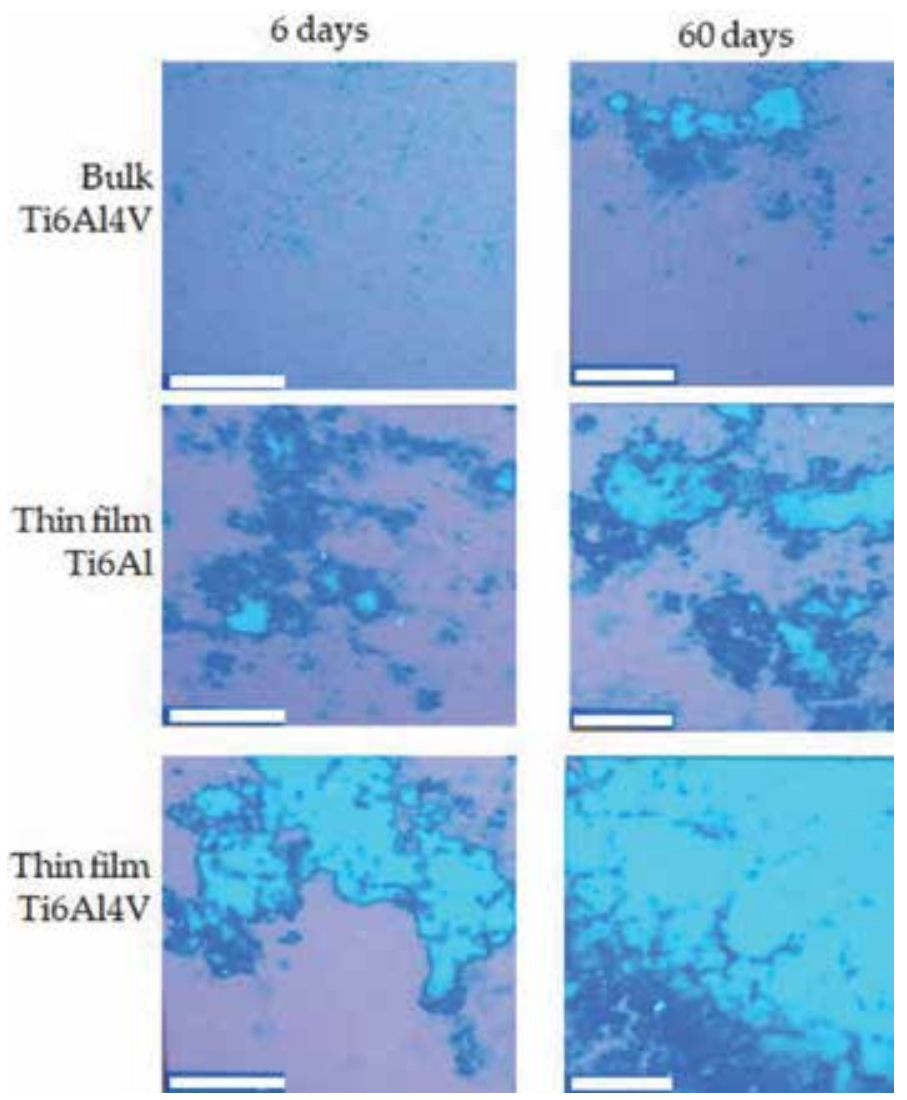

Figure 2.

Elemental map distribution of calcium (light blue) on the surface of the modified and unmodified bulk Ti6Al4V bulk implant after 6 and 60 days of immersion in Hanks' solution (bar $=80 \mu \mathrm{m})$.

related with neural implants. Some examples of the use of materials in neurosciences include the monitoring of intracranial pressure, the regeneration of nervous tissue of the medulla region, for controlled drug delivery systems and microelectrodes for the nervous system. In the latter case, the devices may be used to increase or decrease a certain neurological function. Focusing of this type of application, one of the major problems in this field of Biomedicine is the lack of mechanical and biological compatibility between the tissue and the materials used as implants: silicon, tungsten, gold, iridium and stainless steel. In fact, although tests carried out in accordance with ISO 10993 have demonstrated the noncytotoxicity of the abovementioned materials, the results of in vitro and in vivo experiments show a very different reality. The development of a glia scar around the nervous tissue inhibits, after few weeks, the stimulation and recording of neurons. Several examples are present in the literature of research addressing this problem by modifying the surface of neural electrodes by different strategies [19-22], but mostly with polymeric materials.

Our work addressed this issue by modifying silicon neural implants by sputter depositing hybrid nanostructured thin films of silica, gold and silver $\left(\mathrm{SiO}_{2} / \mathrm{Ag} / \mathrm{Au}\right)$ [23]. $\mathrm{SiO}_{2}$ was chosen due to its chemical compatibility with the base material thus preventing the lack of adhesion between substrate and thin film. The nanocomposite system was designed to induce the release of one metal, which has been described as having antimicrobial properties, silver. In order to ensure that silver was oxidized, gold was added. 
Several chemical compositions were tested and characterized in order to select the best one for the in vitro tests with prokaryotic and eukaryotic cells. If was confirmed, by transmission electron microscopy (TEM) characterization, the nanocomposite nature of the hybrid deposited thin films (Figure 3). They all consisted of an amorphous silica layer with dispersed nanometric size metal grains.

All the films presented a mean surface roughness, determined by atomic force microscopy, lower than $20 \mathrm{~nm}$ and hardness values, determined by nanoindentation, of around $2 \mathrm{GPa}$. The thin film with the chemical composition (in atomic \%) of $\mathrm{Si}=25.8 ; \mathrm{O}=53.4 ; \mathrm{Ag}=9.6$ and $\mathrm{Au}=11.2$, was chosen for the remaining characterizations and the biological tests. This surface presents a static contact angle with water of $26^{\circ}$ and a zeta potential value of $-70 \pm 4 \mathrm{mV}$.

The first in vitro tests were made with Pseudomonas aeruginosa bacteria in order to test the antimicrobial activity of the developed hybrid nanostructured tin film. After $24 \mathrm{~h}$ of incubation, the halo inhibition test (Figure 4) demonstrated that neither silicon (result not shown), nor $\mathrm{SiO}_{2}$ presented any antimicrobial effect. On the contrary, the $\mathrm{SiO}_{2} / \mathrm{Ag} / \mathrm{Au}$ thin film presented a $4 \mathrm{~mm}$ inhibition halo indicating that the Si modified surface was able to inhibit the growth of these strain of bacteria, which is considered one of the most harmful in nosocomial related infections.

The tests with rat embryo cortex cells, within the conditions usually used for this type of tests in neurosciences, and after 15 days of incubation, the cells were prepared for the immunocytochemistry tests. The observation in an optical fluorescent microscope (Figure 5), where the neurons nuclei are marked in blue, showed that unmodified silicon presents a very poor cell density, while $\mathrm{SiO}_{2} / \mathrm{Ag} / \mathrm{Au}$ presented

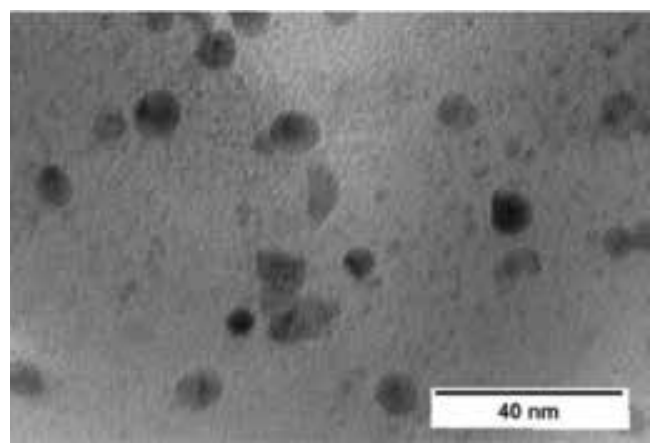

Figure 3.

Bright field TEM micrograph of a $\mathrm{SiO}_{2} / \mathrm{Ag} / \mathrm{Au}$ hybrid nanocomposite thin film.
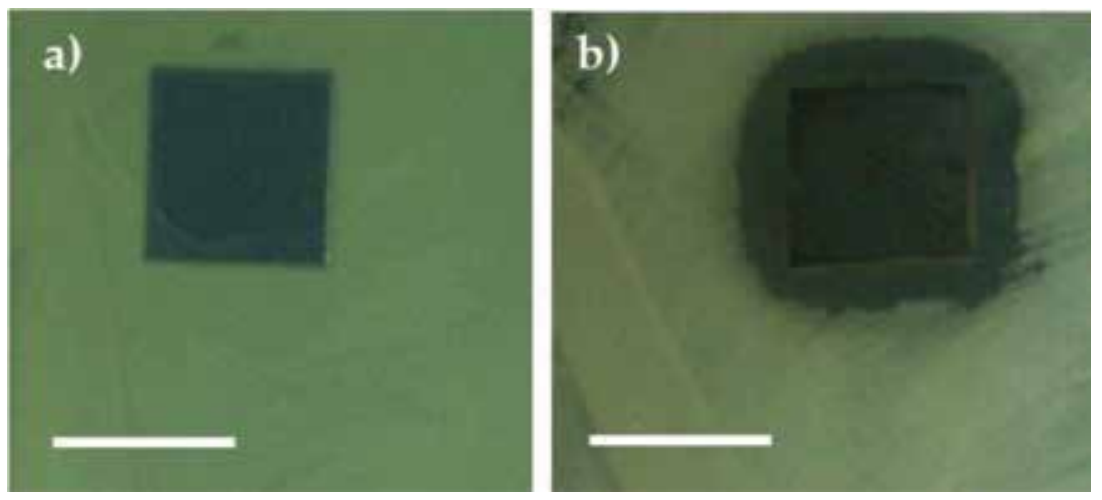

Figure 4.

Optical micrographs of the inhibition growth halo tests, with P. aeruginosa, of silicon modified with $\mathrm{SiO}_{2}$ (a) and $\mathrm{SiO}_{2} / \mathrm{Ag} / \mathrm{Au}(\mathrm{b})$ thin films (bar $=10 \mathrm{~mm}$ ). 

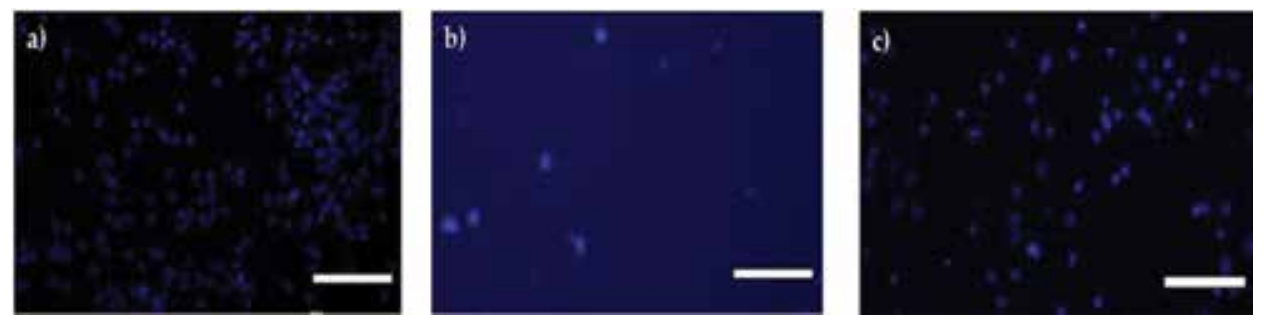

Figure 5.

Optical fluorescent micrographs of rat embryo cortex cells after 14 days of incubation with polylysine (a), silicon (b) and $\mathrm{SiO}_{2} / \mathrm{Ag} / \mathrm{Au}$ (c) surfaces (bar $=200 \mu \mathrm{m}$ ).

a higher cell density, almost similar do the one observed on the "gold standard" of these type of tests, polylysine.

\subsection{Environmental applications}

Environmental degradation is a very challenging field. Natural resources are being enormously harnessed and their stock is exhausted every day. Moreover, the ecological balance is disturbed and the natural resources are being polluted.

For the removal of contaminants from the environment, several strategies are available. In the past, classic remediation strategies were mainly used. An example of innovation for sustainable development is to use alternative remediation strategies as bioremediation. Although the Romans already used organisms to clean their wastewater in $600 \mathrm{BC}$, it was only after 1972 that the first official bioremediation strategies were tested.

Microbial responses to metals with potential for bioremediation include chelation, compartmentalization, exclusion and immobilization [24]. The use of these bacterial abilities is an important strategy for the development of the bioremediation tools. Often, their application to the environment requires the immobilization of the cells to obtain an effective bioremediation. Bacterial cells can be immobilized in different supports. Briefly, cells can be immobilized by covalent coupling, affinity immobilization, adsorption, confinement in liquid-liquid emulsion, capture in a semipermeable membrane and entrapment in polymers [25].

When genetically modified organisms are used, their covalent immobilization is mandatory in order to prevent their release into the environment. However, the covalent immobilization of the cells always requires that the biological entities keep their metabolic abilities, useful for bioremediation. Moreover, immobilization of microorganisms presents several major advantages such as: (1) continuous supply of nutrients without competition with other microorganisms [26]; (2) increase of biomass of specialized microorganisms with specific desired metabolic activity [27, 28]; (3) protection of the cells against the environmental stress, toxic chemicals and UV irradiation [27, 29]; (4) easier control of the bioprocess [29] and (5) easy, cheap and feasible technique to be used since the immobilized microorganisms can be used several times without significant loss of activity [30].

The use of thin films in the design of biotools for environmental application is here illustrated by two case studies. The first describes the development of an arsenic biofilter [31]. The environmental contamination with arsenic is a worldwide problem, and the development of new strategies for arsenic removal is an ever ongoing research. In this study, genetically modified bacteria able to accumulate arsenic were generated by modification of the arsenic resistant strain Ochrobactrum tritici SCII24T [32]. The O. tritici As5 mutant cells, exhibiting a high percentage of arsenite accumulation, were immobilized on a commercial polyethylene (PE) net after sputtered 

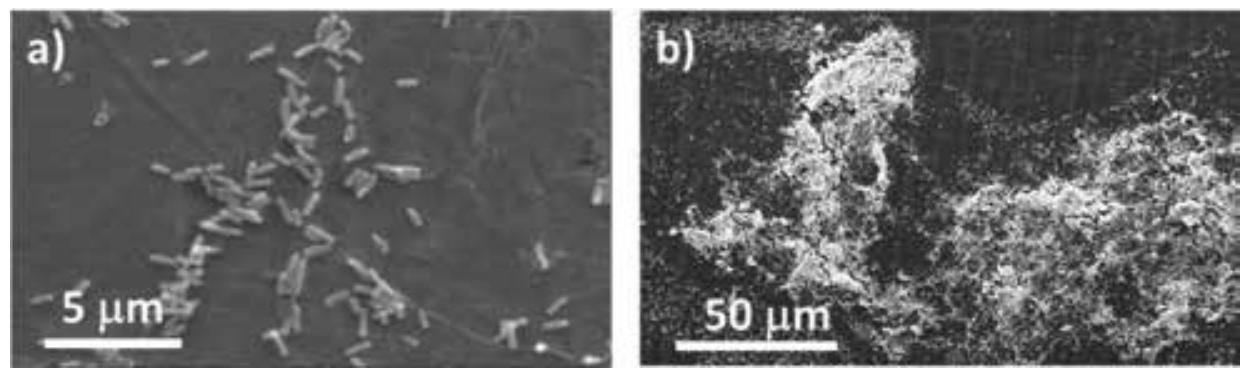

Figure 6.

SEM micrographs of immobilized cells of O. tritici mutant As5 onto PTFE thin films showing an early stage after inoculation $(a)$ and the development of the biofilm (b).

modified by the deposition of poly(tetrafluoroethylene) (PTFE) thin films, with approximately $500 \mathrm{~nm}$ thick. Different PTFE thin films were tested regarding their ability to immobilize cells in an active form that enabled the microorganisms to form a biofilm and work as a biofilter for arsenic. The surface that exhibited a mild zeta potential value, hydrophobic characteristics, the lowest surface free energy but with a high polar component and the appropriate ratio of chemical reactive groups showed to be the optimal for bacteria development (Figure 6). The immobilized cells maintained their ability to accumulate the surrounding arsenite.

The second case study describes the application of thin films for bacterial cells immobilization in the construction of a biofilter for the removal of uranium from contaminated water. The biofilter was constructed by the immobilization of the strain Rhodanobacter A261 onto the PTFE thin films. Under batch conditions, low nutrient content, $\mathrm{pH} 5$ and different uranium concentrations, this strain was able to remove approximately $120 \mu \mathrm{M}$ of $\mathrm{U}(\mathrm{VI})$ when grown aerobically in the presence of $500 \mu \mathrm{M} U$ (Figure 7). As described earlier, the strain was inoculated in PTFE thin films deposited with different deposition parameters, which led to surfaces with distinct values of zeta potential, hydrophobic characteristics, surface free energy, polar component and ratio of chemical reactive groups.

After being evaluated for their ability to immobilize uranium, the optimized PTFE thin film was used to modify PE commercial nets and, after bacterial cells immobilization, the filters were applied in a wastewater treatment plant from a uranium closed mine (Urgeiriça, Portugal). The filters were submerged during 3 months in the last tank of the wastewater treatment station. After 1 and 3 months, they were removed, and their ability to be colonized (biomass in the filter) and uranium detection (Figure 8) was evaluated.
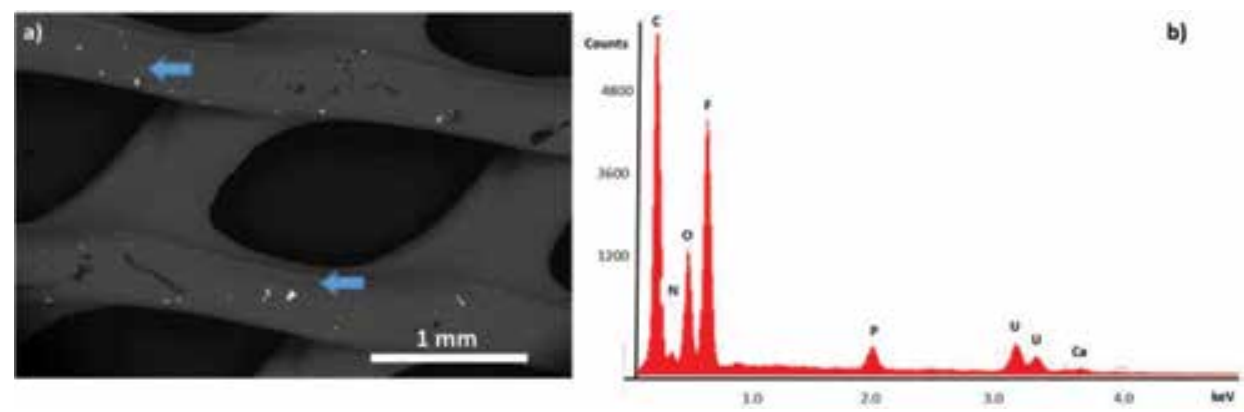

Figure 7.

The backscattered mode SEM micrograph (a) showed the presence of $U$ (brighter spots) and the qualitative energy dispersive spectroscopy (EDS) (b) confirmed uranium detection in PTFE thin film of Rhodanobacter A2-61 microcolonies after being in contact with a $500 \mu \mathrm{M}$ uranium solution. 

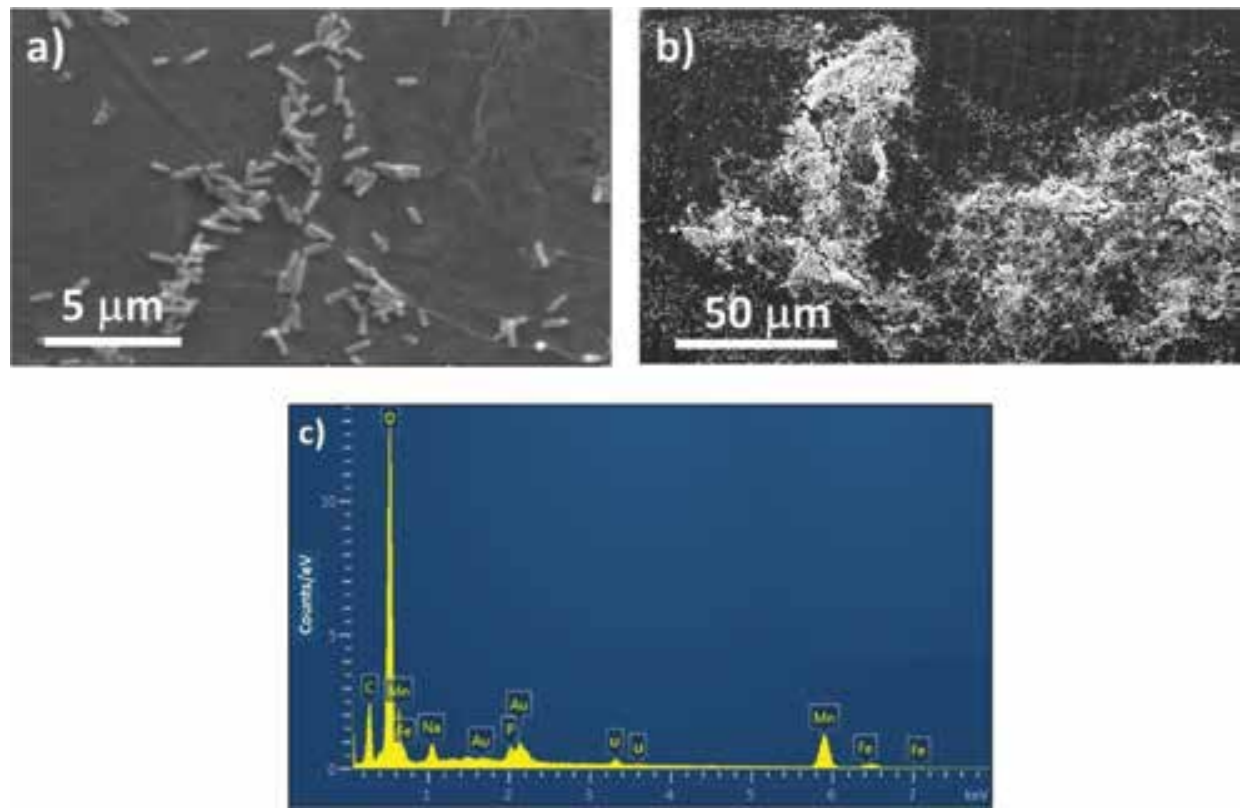

Figure 8.

SEM micrographs of noninoculated (a) and inoculated (b) PTFE thin films with Rhodanobacter A2-61 after 3 months submerged in a mine wastewater passive treatment plant; EDS analysis (c) inoculated surface of the region marked with blue arrow in (b).

The thin films demonstrated its ability to immobilize the cells and stabilize a thick biofilm which was able to be metabolic active in the remediation of metals. Although after 3 months all filters showed microbial colonization, from native species, a difference in thickness and structure was visible between inoculated and noninoculated biofilters. The presence of the thin film showed to be essential for the immobilization of Rhodanobacter A2-61 that, in turn, was mandatory for $\mathrm{U}$ accumulation. In fact, only these biofilters showed U immobilization. Besides the uranium, other metals were detected in the biofilm, such as Mn and Fe.

\section{Conclusions}

In this chapter, the production of thin films by sputtering and their uses in medical and environmental fields were exemplified. The ability of the sputtering technique to produce metastable materials, which are not predicted by the traditional chemistry thermodynamic, allows to produce tailor-made surfaces that present the optimized set of properties for specific applications.

A nanostructured Ti6Al4V thin film showed to have better osseointegration properties than in its bulk form. Also, the presence of vanadium proved to be essential to achieve the best performance.

The modification of silicon, used as neural implant, with a hybrid nanocomposite thin film of $\mathrm{SiO}_{2} / \mathrm{Au} / \mathrm{Ag}$ demonstrated to induce a surface that provides a better adhesion and proliferation of rat embryo cortex cells concomitantly with an antibacterial effect against some of the bacteria responsible for nosocomial infections.

The deposition of PTFE thin films, with optimized surface properties, onto the surface of a commercial PE net allowed to develop biotools for the bioremediation of two elements considered very hazardous both for humans and environment: arsenic and uranium. 


\section{Acknowledgements}

This work was partially supported by the Foundation of Science and Technology of Portugal through the projects UID/EMS/00285/2013 and ERA-MIN/0002/2015. The work was also supported by projects POCI-01-0145-FEDER-016757 and PTDC/ AAGREC/3839/2014 from the Programa Operacional da Região Centro e Programa Operacional da Região Lisboa, respectively. Rita Branco was funded by grant SFRH/ BPD/110807/2015 and Romeu Francisco by SFRH/BPD/103241/2014. The authors also acknowledge A. Silva and J. Nunes for their contribution in some of the presented results.

\section{Conflict of interest}

The authors declare no conflict of interest.

\section{Author details}

Ana P. Piedade ${ }^{1 *}$, Francisco Romeu ${ }^{2}$, Rita $_{\text {Branco }}{ }^{2}$ and Paula V. Morais ${ }^{2}$

1 CEMMPRE_-Department of Mechanical Engineering, University of Coimbra, Coimbra, Portugal

2 CEMMPRE—Department of Life Sciences, University of Coimbra, Coimbra, Portugal

*Address all correspondence to: ana.piedade@dem.uc.pt

\section{IntechOpen}

(C) 2018 The Author(s). Licensee IntechOpen. This chapter is distributed under the terms of the Creative Commons Attribution License (http://creativecommons.org/licenses/ by/3.0), which permits unrestricted use, distribution, and reproduction in any medium, provided the original work is properly cited. (cc) BY 


\section{References}

[1] Carvalho D, Sousa T, Morais PV, Piedade AP. Polymer/metal nanocomposite coating with antimicrobial activity against hospital isolated pathogen. Applied Surface Science. 2016;379:489-496. DOI: 10.1016/j.apsusc.2016.04.109

[2] Arias CJ, Surmaitis RL, Schlenoff JB. Cell adhesion and proliferation on the living surface of a polyelectrolyte multilayer. Langmuir. 2016;32:5412-5421. DOI: 10.1021/acs. langmuir.6b00784

[3] Daw R, O’Leary T, Kelly J, Short RD, Cambray-Deakin M, Devlin AJ, Brook IM, Scutt A, Kothari S. Molecular engineering of surfaces by plasma copolymerization and enhanced cell attachment and spreading. Plasmas and Polymers. 1999;4:113-132. DOI: 10.1023/A:102184482

[4] Pinho AC, Piedade AP. Zeta potential, contact angles, and AFM imaging of protein conformation adsorbed on hybrid nanocomposite surfaces. ACS Applied Materials and Interfaces. 2013;5:8187-8194. DOI: 10.1021/am402302r

[5] Nunes J, Santos RJ, Loureiro V, Piedade AP. Nanocomposite thin films with hybrid inorganic/organic matrix for the modification of siliconbased implants. Plasma Processes and Polymers. 2012;9:709-717. DOI: 10.1002/ ppap.201100089

[6] Mukhopadhyay R, Rosen BP, Phung LT, Silver S. Microbial arsenic: From geocycles to genes and enzymes. FEMS Microbiology Reviews. 2002;26:311325. DOI: 10.1111/j.1574-6976.2002. tb00617.x

[7] Ordonez E, Letek M, Valbuena N, Gil JA, Mateos LM. Analysis of genes involved in arsenic resistance in Corynebacterium glutamicum
ATCC 13032. Applied Environmental Microbiology. 2005;71:6206-6215. DOI: 10.1128/AEM.71.10.6206-6215.2005

[8] Mondal P, Majumder CB, Mohanty B. Treatment of arsenic contaminated water in a batch reactor by using Ralstonia eutropha MTCC 2487 and granular activated carbon. Journal of Hazardous Materials. 2008;153:588-599. DOI: 10.1016/ j.jhazmat.2007.09.028

[9] Villadangos AF, Ordonez E, Pedre B, Messens J, Gil JA, Mateos LM. Engineered coryneform bacteria as a bio-tool for arsenic remediation. Applied Microbiology Biotechnology. 2014;98:10143-10152. DOI: $10.1007 /$ s00253-014-6055-2

[10] Nedelkova M, Merroun ML, Rossberg A, Hennig C, Selenska-Pobell C. Microbacterium isolates from the vicinity of a radioactive waste depository and their interactions with uranium. FEMS Microbiology Ecology. 2007;59:694-705. DOI: 10.1111/j.1574-6941.2006.00261.x

[11] Gargarello RM, Di Gregorio D, Huck H, Niello JF, Curutchet G. Reduction of uranium(VI) by Acidithiobacillus thiooxidans and Acidithiobacillus ferrooxidans. Hydrometallurgy. 2010;104:529-532. DOI: 10.1016/j. hydromet.2010.03.032

[12] Beazley MJ, Martinez RJ, Sobecky PA, Webb SM, Taillefert $\mathrm{M}$. Nonreductive biomineralization of uranium(VI) phosphate via microbial phosphatase activity in anaerobic conditions. Geomicrobiology Journal. 2009;26:431-441. DOI: 10.1080/01490450903060780

[13] Griesser HJ. Thin Film Coatings for Biomaterials and Biomedical Applications. Oxford: Elsevier; 2016. 310 p. ISBN: 978-1-78242-453-6 
[14] Martin PM, editor. Handbook of Deposition Technologies for Films and Coatings. Science, Applications and Technology. 3rd ed. Burlington: Elsevier; 2010. 912 p. ISBN-13: 978-0-8155-2013-3

[15] Shim E. Smart surface treatments for textiles for protection. In: Chapman RA, editor. Smart Textiles for Protection. 2nd ed. Oxford: Elsevier; 2013. pp. 87-126. DOI: 10.1533/9780857097620.1.87

[16] Greene JE. Tracing the recorded history of thin-film sputter deposition: From the 1800s to 2017. Journal of Vacuum Science and Technology A. 2017;35:05C204. DOI: 10.1116/1.4998940

[17] Rehder D. Vanadium: Its role for humans. Metal Ions in Life Sciences. 2013;13:139-169. DOI: 10.1007/978-94-007-7500-8_5

[18] Hansen N. Hall-Petch relation and boundary strengthening. Scripta Materialia. 2004;51:801-806. DOI: 10.1016/j.scriptamat.2004.06.002

[19] Chen S, Pei Q, Tang R, Chen Y, Zhao $\mathrm{S}$, Wang H, Chen H. PEDOT/MWCNT composite film coated microelectrode arrays for neural interface improvement. Sensors and Actuators A. 2013;193:141148. DOI: 10.1016/j.sna.2013.01.033

[20] Green RA, Lovell NH, Wallace GG, Poole-Warren LA. Conducting polymers for neural interfaces: Challenges in developing an effective long-term implant. Biomaterials. 2008;29:3393-3399. DOI: 10.1016/j. biomaterials.2008.04.047

[21] Rao L, Zhou H, Li T, Li T, Duan YY. Polyethylene glycol-containing polyurethane hydrogel coatings for improving the biocompatibility of neural electrodes. Acta Biomaterialia. 2012;8:2233-2242. DOI: 10.1016/j. actbio.2012.03.001
[22] Zhou H, Li T, Duan YY. Reduce impedance of intracortical iridium oxide microelectrodes by hydrogel coatings. Sensors and Actuators B. 2012;161: 198-202. DOI: 10.1016/j.snb.2011.10.019

[23] Nunes J. Nanostructured hybrid thin films compatible with the nervous tissue [PhD thesis]. Coimbra: University of Coimbra; 2015

[24] Tsai SL, Singh S, Chen W. Arsenic metabolism by microbes in nature and the impact on arsenic remediation. Current Opinion in Biotechnology. 2009;20:659-667. DOI: 10.1016/j. copbio.2009.09.013

[25] Mallick N. Biotechnological potential of immobilized algae for wastewater $\mathrm{N}, \mathrm{P}$ and metal removal: A review. Biometals. 2002;15:377-390. DOI: 10.1023/A:102023852

[26] de-Bashan LE, Bashan

Y. Immobilized microalgae for removing pollutants: Review of practical aspects. Bioresource Technology. 2010;101:1611-1627. DOI: 10.1016/j. biortech.2009.09.043

[27] An T, Zhou L, Li G, Fu J, Sheng G. Recent patents on immobilized microorganism technology and its engineering application in wastewater treatment. Recent Patents in Engineering. 2008;2:28-35. DOI: $10.2174 / 187221208783478543$

[28] Martins SCS, Martins CM, Fiúza LMCG, Santaella ST. Immobilization of microbial cells: A promising tool for treatment of toxic pollutants in industrial wastewater. African Journal of Biotechnology. 2013;12:4412-4418. DOI: $10.5897 / A J B 12.2677$

[29] Covarrubias S, de-Bashan LE, Moreno M, Bashan Y. Alginate beads provide beneficial physical barrier against native microorganisms in wastewater treated with immobilized bacteria and microalgae. Applied 
Microbiology and Biotechnology.

2012;93:2669-2680. DOI: 10.1007/

s00253-011-3585-8

[30] Cai T, Chen L, Ren Q, Cai S, Zhang

J. The biodegradation pathway of triethylamine and its biodegradation by immobilized Arthrobacter protophormiae cells. Journal of Hazardous Materials.

2011;186:59e66. DOI: 10.1016/

j.jhazmat.2010.10.007

[31] Branco R, Sousa T, Piedade AP, Morais PV. Immobilization of Ochrobactrum tritici As5 on PTFE thin films for arsenite biofiltration. Chemosphere. 2016;146:330-337. DOI: 10.1016/j.chemosphere.2015.12.025

[32] Sousa T, Chung AP, Pereira A, Piedade AP, Morais PV. Aerobic uranium immobilization by Rhodanobacter A2-61 through formation of intracellular uranium-phosphate complexes. Metallomics. 2013;5:390-397. DOI: $10.1039 / \mathrm{c} 3 \mathrm{mt} 00052 \mathrm{~d}$ 



\title{
Nanostructuring Indium- Tin-Oxide Thin Films by Femtosecond Laser Processing
}

\author{
Phuoc Huu Le and Chih-Wei Luo
}

\begin{abstract}
This chapter reviews the nanostructuring fabrications and properties of indium-tin-oxide (ITO) thin films by femtosecond laser annealing. Fundamental mechanisms of laser-induced periodic surface structures (LIPSS) and other nanostructures on ITO films are presented and discussed in detail. ITO films with large-area surface ripple structures with a multiperiodic spacing of $\sim 800, \sim 400$, and $200 \mathrm{~nm}$ were successfully fabricated by femtosecond laser pulses, without scanning. The ITO films exhibited significant enhancement in electrical conductivity by 30 times because of the formation and distribution of indium metal-like clusters. This metallic content of the laser-induced nanodots and nanolines further causes the anisotropic transmission characteristics in the visible range. In addition, by varying the laser fluences, nanostructures with cotton, brick, and ripple forms are generated on the surface of ITO films, which produce cyan, yellow, and orange colors. Intriguingly, the ITO films with laser-induced nanostructures can significantly attenuate blue light, thus they are potential for applications such as eye protection and information security.
\end{abstract}

Keywords: indium-tin-oxide (ITO), femtosecond laser annealing, laser-induced periodic surface structures (LIPSS), anisotropic transmission, laser-colorized ITO film

\section{Introduction}

Transparent conducting oxide (TCO) film is one of the essential components in various state-of-the-art optoelectronic devices, including liquid crystal displays (LCDs), organic solar cells, touch screens, and organic light emitting devices (OLEDs). Among TCOs, indium-tin-oxide (ITO) is a well-known wide bandgap semiconductor that has metal-like electrical properties and high optical transmission in the visible region $[1,2]$. Indeed, ITO possesses high electrical conductivity $\left(\sim 10^{-4} \Omega-\mathrm{cm}\right)$ and high transmission $(\sim 90 \%)$ in the visible range [3, 4]. In OLED applications, surface properties of ITO films, such as their electron affinity and work function, play a key role in determining the characteristics of OLEDs, owing to their direct contact with the organic materials, as a hole injection layer [5]. ITO has also been extensively used as a good ohmic contact material owing to the excellent surface conductivity in GaN-base light emitting diodes (LEDs) [6]. 
Recently, material processing by femtosecond (fs) laser irradiation has attracted a great deal of attention because the energy of fs pulses can be precisely and rapidly transferred to the film without thermal effects. This is so-called femtosecond laser annealing (FLA). FLA demonstrates as a good method to induce crystallization within a thin layer of materials and avoid thermal melting in materials. Thus, FLA can be employed in flexible technology, where thin films are coated on polymer substrates with low glass transition temperature $\left(T_{\mathrm{g}}\right)$. For example, Pan et al. reported near-infrared femtosecond laser-induced crystallization in amorphous silicon [7]. Recently, laser-induced periodic surfaces structures (LIPSS) or ripples have been observed for various materials, under pulsed laser illumination near their ablation thresholds [8-14]. Materials with LIPSSs also possess modified physical properties, such as the friction [15], the hydrophobicity/hydrophilicity [16], the conductivity [11-13] and the absorptance [16-18].

This chapter reviews recent advances on fabrication of various nanostructures on the surface of ITO films by using femtosecond laser processing. In addition, it reports detailed property modification of fs-laser treated ITO films, including enhanced electrical conductivity, anisotropic optical transmission, laser-colorized effect, and performance of the organic photovoltaic devices using ITO with LIPSSs. This chapter also gives an insight into the formation mechanisms for LIPSSs, the relationship between fs-laser processing and properties of fs laser-treated ITO films, and potential applications of nanostructuring ITO films.

\section{Fabrication and characterizations of nanostructuring indium-tin-oxide films}

\subsection{ITO thin film preparation}

ITO thin films were deposited on a glass (a size of $1 \times 1 \mathrm{~cm}$ ) using magnetron sputtering deposition at room temperature, $\mathrm{O}_{2} /\left(\mathrm{Ar}+\mathrm{O}_{2}\right)$ flow ratio of 0.047 , and a power of $1000 \mathrm{~W}$. The ITO target $(58 \times 15 \mathrm{~cm})$ was composed of $\operatorname{In}_{2} \mathrm{O}_{3}$ with $10 \mathrm{wt} \%$ $\mathrm{SnO}_{2}$. The as-deposited ITO thin films have a thickness of $30-80 \mathrm{~nm}$ and a resistivity of $\sim 4 \times 10^{-2} \Omega$-cm.

\subsection{Experimental setups}

For fabricating nanostructures, the ITO films were irradiated using a regenerative-amplified Ti:sapphire laser (Legend USP, Coherent), with a central wavelength of $800 \mathrm{~nm}$, a pulse duration of $100 \mathrm{fs}$, a pulse energy of $\sim 0.5 \mathrm{~mJ}$, and a repetition rate of $5 \mathrm{kHz}$ (Figure 1a). The diameter of the laser beam was adjusted to $\sim 14 \mathrm{~mm}$, which can cover fully the sample size of $1 \times 1 \mathrm{~cm}$. The samples were irradiated with different fs laser shots $(N)$ of $0,5 \times 10^{3}, 2.5 \times 10^{4}, 1 \times 10^{5}, 3 \times 10^{5}$, and $3 \times 10^{6}$.

For studying the anisotropic optical transmission of nanostructured ITO films, all optical spectra were measured through an iris with a 0.1-mm-diameter hole located at a position close to the central region of the laser-induced nanostructures (or laser spot). The fs laser-treated ITO films had ripple structures of nanodots and nanolines on the film surfaces. The transmission spectra of the films were measured using polarized light with a direction of polarization $(\mathrm{P})$ parallel or perpendicular to the direction of the long axis of the nanodots or nanolines (L) on the ITO films (see Figure 1b and the inset of Figure 6c).

For fabricating the various surface modifications in Section 5, the ITO films with a thickness of $80 \mathrm{~nm}$ were mounted on an xyz stage and irradiated at room temperature and ambient pressure using a commercial Ti:sapphire amplifier (Solstice Ace, 

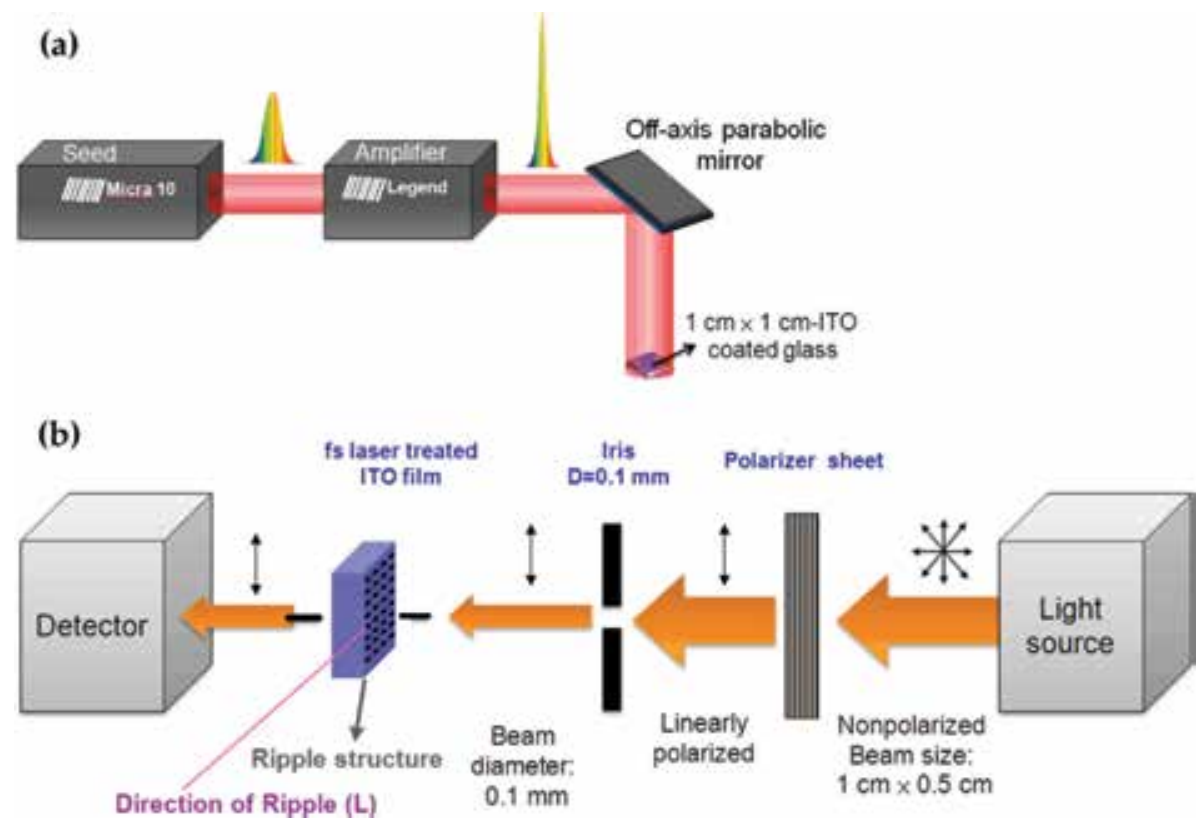

Figure 1.

Experimental setup for (a) the fabrication of nanostructuring ITO films and (b) the characterizations of anisotropic optical properties on ITO films with periodic nanostructures on the surfaces.

Spectra-Physics) with a central wavelength of $800 \mathrm{~nm}$, a pulse duration of $35 \mathrm{fs}$, and a repetition rate of $2 \mathrm{kHz}$. The laser beam with line spot (a length of $4.6 \mathrm{~mm}$ and a width of $21 \mu \mathrm{m})$ was focused by a cylindrical lens $(f=40 \mathrm{~mm})$. The scanning speed was approximately $160 \mu \mathrm{m} / \mathrm{s}$.

\subsection{Characterizations}

The optical transmission of as-deposited and fs laser-treated ITO films was measured using an UV-visible-near-IR spectrophotometer (Shimadzu SolidSpec-3700). The morphology of the films was examined using a scanning electron microscope (SEM) (HITACHI-S2500 JSM-6500F). The film thicknesses were determined by surface contour measurement (KOSAKA ET4000A), with a vertical resolution of $0.1 \mathrm{~nm}$. The resistivity, carrier concentration, and the Hall mobility of the ITO films were measured by the Hall measurements (Bio-Rad Microscience HL5500) using the Van der Pauw method. The surface composition and chemical bonding were studied by X-ray photoelectron spectroscopy (XPS, PHI Quantera AES 650), with source of $\mathrm{Al} \mathrm{K} \alpha$ at $1486.7 \mathrm{eV}$, passing an energy of $15 \mathrm{keV}$, and analyzed a spot size of $100 \mu \mathrm{m}$. The XPS spectra were calibrated by using Au at binding energy of $84.0 \mathrm{eV}$. XPS curve fitting was performed using free-ware XPSPEAK4.1 from Dr. R.M. Kwok, the Shirley background subtraction, and assuming a GaussianLorentzian peak shape. Auger electron spectroscopy (AES, ULVAC-PHI 700) with a spatial resolution of $\sim 30 \mathrm{~nm}$ under $5 \mathrm{keV}$ operating voltage was used to study the local compositions of the as-deposited and fs laser-irradiated ITO films.

In Section 5, the morphology of the colorized ITO films was measured using high resolution field emission SEM (JEOL). To determine the relationship between the reflectance/transmittance spectra and the colors of fs laser-colorized ITO films, we used a spectrometer (U3310, Hitachi) with both deuterium and tungsten iodide lamps (allowing for a scanning range from 190 to $900 \mathrm{~nm}$ with a resolution of $0.3 \mathrm{~nm})$. 


\section{Superior local conductivity in self-organized nanodots on indium-tin-oxide films induced by femtosecond laser pulses}

Figure 2a-f shows the surface morphology of ITO films after normal-incidence irradiation with different pulse numbers from 0 to $5 \times 10^{3}$ (fluence: $0.1 \mathrm{~mJ} / \mathrm{cm}^{2}$ ). The film only exhibits few small dots for $N=5 \times 10^{3}$ shots (Figure 2b). Meanwhile, the laser-induced periodic structure is clearly observed on the surface of ITO films for $N \geq 2.5 \times 10^{4}$ shots (Figure $2 \mathbf{c}-\mathbf{f}$ ). In the inset of Figure $2 \mathbf{f}$, the submicron ripple structure is composed of self-organized line dots (size: $20-500 \mathrm{~nm}$ ). The periodic ripple pattern has long axis perpendicular to the direction of the laser polarization (the arrow in Figure 2f). The mixture of the dotted and ripple structures is attributed to the interference of scattered and diffracted waves at the grains and/or defects. This is similar to ordered YBCO array structures, formed by the solidification of melted dot patterns, under conditions of constructive interference and minimized surface energy $[11,19]$.

The present periodic ripple structures have spacing of approximately $798 \pm 15$, $420 \pm 14$, and $230 \pm 15 \mathrm{~nm}$. The formation of the two large ripple spacing cases (i.e., $798 \pm 15$ and $420 \pm 14 \mathrm{~nm}$ ) can be easily explained by classical scattering model [20]:

$$
\Lambda=\frac{\lambda}{1 \pm \sin \theta}
$$

where $\Lambda$ is the ripple spacing, $\lambda$ is the laser wavelength, and $\theta$ is the incident angle of the laser beam onto the target. However, the classical scattering model with Eq. (1) cannot be used to predict for the shorter ripple spacing of $230 \pm 15 \mathrm{~nm}$, which is much smaller than the laser wavelength of $800 \mathrm{~nm}$. We noted that the spacing value is close to $200 \mathrm{~nm}$, thus it could be induced by second harmonic generation (SHG) with a shorter wavelength of $400 \mathrm{~nm}$ around the surface of ITO film. It is reasonable for occurring SHG owing to the surface asymmetry when the subwavelength ripple with $\sim 200 \mathrm{~nm}$ is indeed observed in high intensity regions, especially in the center of laser Gaussian beam (Figure 2f).

Figure 3 shows the effects of number of pulses $(N)$ from 0 to $3 \times 10^{6}$ shots on the carrier concentration $(n)$, carrier mobility $(\mu)$, and resistivity $(\rho)$ of the ITO films. For $N \leq 10^{3}$, the laser-treated ITO films almost remain the same as that of the asdeposited ITO films. As further increasing $N$ from $5 \times 10^{3}$ to $3 \times 10^{6}$, the $n$ increases noticeably from $\sim 1 \times 10^{19}$ to $\sim 1.6 \times 10^{19} \mathrm{~cm}^{-3}$. In contrast, the $\mu$ decreases correspondingly from 12.3 to $10.2 \mathrm{~cm}^{2} / \mathrm{V}$-s (i.e., $17 \%$ reduction), after fs laser annealing with $3 \times 10^{6}$ shots at a fluence of $0.1 \mathrm{~mJ} / \mathrm{cm}^{2}$. Reasonably, by using the Hall measurement, it is hard to detect a slight difference in $n$ for $N \leq 10^{3}$. However, for larger $N$ ( $>10^{3}$ shots), the accumulated number of pulses induces the thicker laser-irradiated area for detecting the variation in $n$ using the Hall measurement. Due to the aforementioned variation of $n$ and $\mu$, the resistivity presents a $14 \%$ reduction from $4.3 \times 10^{-2}$ at $N=0$ to $3.7 \times 10^{-2} \Omega$-cm for $N=3 \times 10^{6}$ shots, which is primarily due to the increased $n$. Noticeably, the thickness the ITO films before and after irradiation are $30 \pm 1.5 \mathrm{~nm}$, and the thickness variation is not noticeable, and thus, the effect of thickness on the electrical properties can be eliminated.

The optical transmittance of the as-deposited ITO and fs-laser treated ITO films for $3 \times 10^{5}$ and $3 \times 10^{6}$ shots is shown in Figure 3b. Obviously, the optical transmittance of fs laser-treated ITO films remains about the same as that of the asdeposited ITO film, and they achieve a high transmittance of approximately $85 \%$ in the visible to near-infrared (NIR) range. The electrical and optical results indicate that fs laser annealing represents a new method to enhance the electrical properties of ITO films and retain their high optical transmittance.

To identify the cause of surface conductivity enhancement for fs laser-treated ITO films, we performed the X-ray photoelectron spectroscopy (XPS) experiments 

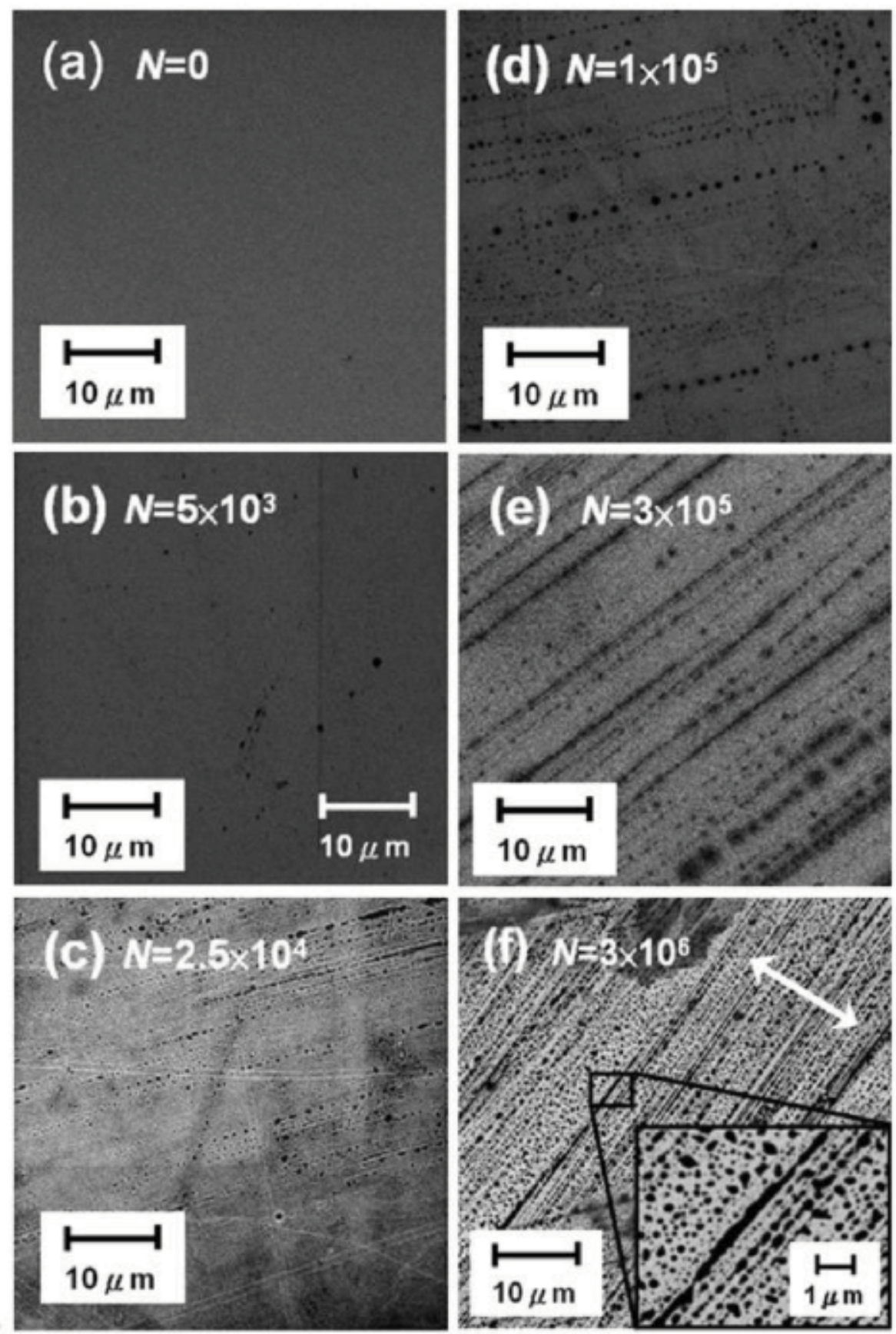

Figure 2.

$(a-f)$ SEM images of periodic surface structures induced by $800 \mathrm{~nm} f$ s laser pulses at a fluence of $0.1 \mathrm{~mJ} / \mathrm{cm}^{2}$ and with various pulse numbers $\left(N=0,5 \times 10^{3}, 2.5 \times 10^{4}, 1 \times 10^{5}, 3 \times 10^{5}\right.$, and $3 \times 10^{6}$, respectively $)$. The black-square inset shows the enlarged surface features at corresponding locations in $(f)$. The arrow indicates the direction of the laser polarization [11].

on the as-deposited and fs laser-treated ITO films in comparison with $\operatorname{In}_{2} \mathrm{O}_{3}$ powder. Figure 4a shows Donley's model of surface composition of an ITO film, which has $\mathrm{In}_{2} \mathrm{O}_{3}$-like sites, oxygen-deficient sites, and hydroxide and oxyhydroxide groups [21]. Figure 4d-g shows the O1s XPS spectra of fs laser-treated ITO films with $N$ from $5 \times 10^{3}$ to $3 \times 10^{6}$. Figure $4 \mathrm{c}$ presents the O1s XPS spectrum of 

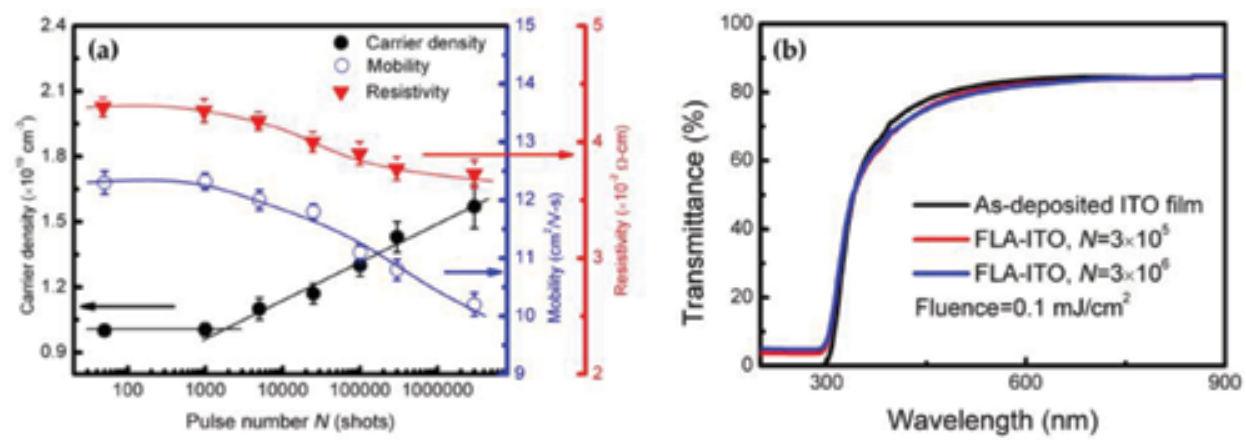

Figure 3.

(a) The carrier concentration, mobility, and resistivity in the $f$ s laser-treated ITO films as a function of the pulse numbers (the solid lines are a guide to the eyes). (b) The transmittance in the fs laser-treated ITO films as a function of wavelengths with various pulse numbers $\left(N=0,3 \times 10^{5}\right.$, and $3 \times 10^{6}$, respectively) at a fluence of $0.1 \mathrm{~mJ} / \mathrm{cm}^{2}[11]$.

as-deposited ITO films. It can be fitted well with three peaks, namely the $\operatorname{In}_{2} \mathrm{O}_{3}$-like oxygen at $529.6 \pm 0.1 \mathrm{eV}[21,22]$, oxygen adjacent to the oxygen-deficient sites at $531.0 \pm 0.1 \mathrm{eV}[21,22]$, and hydroxide and/or oxyhydroxide peak at $532.0 \pm 0.1 \mathrm{eV}$ [21-23]. Compared with a reference sample of $\operatorname{~}_{2} \mathrm{O}_{3}$ powder (Figure 4b), the oxygen peak (at $531.0 \pm 0.1 \mathrm{eV}$ ) that is adjacent to the oxygen-deficient sites of as-deposited ITO film (Figure 4c) increases because of the formation of oxygen vacancies during the thin film growth using sputtering [23].

Furthermore, the XPS spectra of In $3 \mathrm{~d}_{5 / 2}$, for In metals, $\operatorname{In}_{2} \mathrm{O}_{3}$ powders, and fs laser-treated ITO films, are shown in Figure $5 a$. The In $3 d_{5 / 2}$ peak of In metal locates at a lower binding energy of $443.7 \mathrm{eV}$, corresponding to the In bonding state of In-In bonds [23]. However, the In $3 \mathrm{~d}_{5 / 2}$ peak of the $\operatorname{In}_{2} \mathrm{O}_{3}$ powder shifts to the higher binding energy of $444.6 \mathrm{eV}$, corresponding to the $\operatorname{In}^{3+}$ bonding state of $\operatorname{In}_{2} \mathrm{O}_{3}[22,24]$. Thus, the valence states of $\operatorname{In}_{2} \mathrm{O}_{3}$ for the as-deposited ITO film can be demonstrated by the In $3 \mathrm{~d}_{5 / 2}$ peak at $444.4 \mathrm{eV}$. As increasing the number of fs laser pulses, there is a gradual shift in the In $3 \mathrm{~d}_{5 / 2}$ peak from the In-O bonding state to In-In bonding state. Particularly, the peak of In $3 \mathrm{~d}_{5 / 2}$ for $N=3 \times 10^{6}$ is located at $443.9 \mathrm{eV}$, which is close to the binding energy of In-In bonds. This result strongly indicates that the existence of In metal-like clusters on the surfaces of fs laser-treated ITO films, particularly inside the self-organized nanodots that result in the enhanced electrical conductivity for the films. Similarly, upon fs laser irradiation, the aggregation of metal nanoparticles was observed in thin plasma polymer films due to the strong interaction via dipolar forces of the metals [25].

Figure $5 \mathbf{b}$ summarizes the findings that periodic self-organized nanodots are formed on the surfaces of the ITO films treated by fs laser pulses because of constructive interference of fs laser. The nanodots are In-like clusters, which induce superior local surface conductivity, and consequently offer reducing the electrical resistivity for the films. The approach for finding the self-organized nanodots with superior local surface conductivity may be suitable for applications such as nanolithography, nanophotoelectrons, and nanomechanics, in large-area nanotechnology.

In brief, periodic ripple structures with a multiperiodic spacing of $\sim 800, \sim 400$, and $\sim 200 \mathrm{~nm}$ were successfully fabricated by fs laser pulse irradiation. The ripple structure is composed of self-organized nanodots with a size of 20-500 nm, which are presumably formed by the solidification of melted dot patterns, under conditions of constructive interference and minimized surface energy. The ITO films with ripple structures on the surfaces exhibited significant enhancement in electrical conductivity, which is attributed to the formation of In metal-like nanodots/clusters. 
(a) ITO surface model
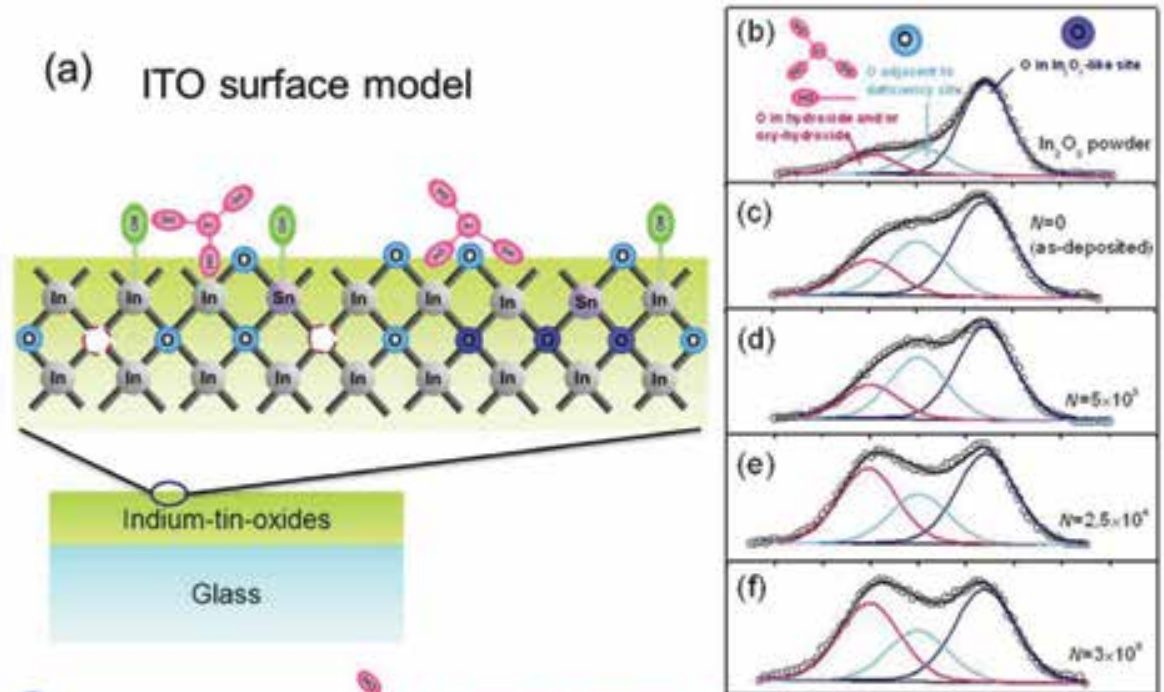

D) Oxygen in inj $\mathrm{O}_{\mathrm{j}}$-like site

(O) Oxygen is adjecont to the

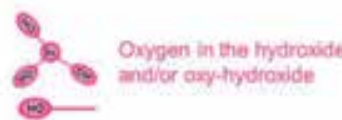

Oxypen vacancy site

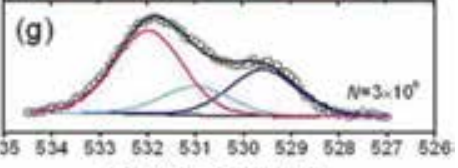

Binding Energy (eV)

Figure 4.

(a) Schematic representation of as-deposited ITO surface composition based on Donley's model [21]. (b) The O1s XPS spectra of $I_{2} \mathrm{O}_{3}$ powder and fs laser-treated ITO films with various pulse numbers $\left(N=0,5 \times 10^{3}\right.$, $2.5 \times 10^{4}, 3 \times 10^{5}$, and $3 \times 10^{6}$, respectively) [11].

(a)

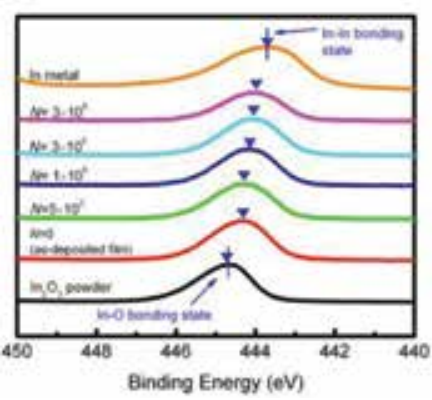

(b)

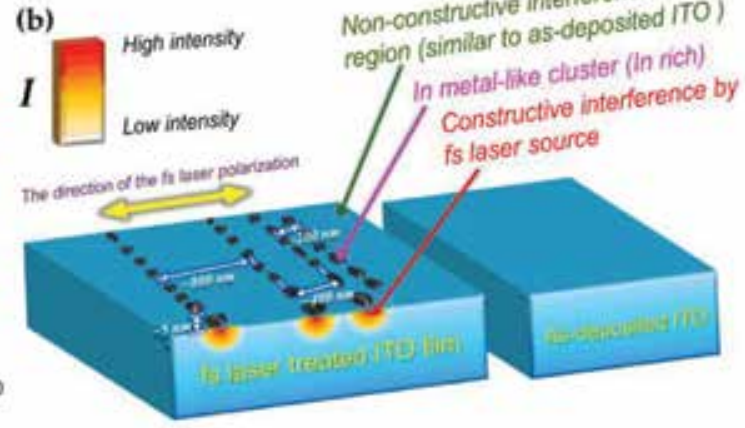

Figure 5 .

(a) The In $3 d_{5 / 2}$ XPS spectra of $I_{2} \mathrm{O}_{3}$ powder, In metal, and $f$ s laser-treated ITO films with various pulse numbers $\left(N=0,5 \times 10^{3}, 1 \times 10^{5}, 3 \times 10^{5}\right.$, and $3 \times 10^{6}$, respectively). (b) A schematic illustration for the formation of self-organized nanodots induced by the constructive interference of $f$ s laser at near-surface region. The dot is composed of In-rich clusters with a height of $\sim 5 \mathrm{~nm}$ as a result of In-O bonding breaking into In-In under local-field enhancement [11].

\section{Anisotropic optical transmission of femtosecond laser-induced periodic surface nanostructures on indium-tin-oxide films}

This section focuses on the anisotropic optical properties of the nanostructures, including nanodots and nanolines, on ITO films fabricated by fs laser irradiation [12]. Figure $6 \mathbf{a}$ and $\mathbf{b}$ shows the surface morphology of nanodots and nanolines on ITO films. The solid line in Figure $6 \mathbf{c}$ presents the optical transmission of an 
as-deposited ITO film in the visible range of nonpolarized light. The transmission spectra of the fs laser-treated ITO films were measured using polarized light with $\mathrm{L} / / \mathrm{P}$ or $\mathrm{L} \perp \mathrm{P}$, as shown in Figure 6e. The transmission of $\mathrm{L} / / \mathrm{P}\left(T_{\mathrm{L} / / \mathrm{P}}\right)$ for visible light was lower than that of $\mathrm{L} \perp \mathrm{P}\left(T_{L \perp P}\right)$ in the ITO films with structures of nanodots and nanolines in which the nanoline structure exhibited larger difference between the transmittances of $T_{L / P}$ and $T_{L \perp P}$ in visible range than that of nanodot structure. Indeed, the extinction ratio $\left(T_{L \perp P} / T_{L / P}\right)$ in the nanoline film was enhanced by $42 \%$ at a wavelength of $400 \mathrm{~nm}$ (Figure 6d). The laser-induced periodic nanostructures on the film surfaces induced this dichroic or anisotropic transmission property for the fs laser-treated ITO films.

A schematic illustration for the dichroic optical property of the nanoline film is shown in the inset of Figure 6c. The vertically polarized light $\left(\mathrm{P}_{\mathrm{V}}\right)$, which is parallel to the long axis of the nanoline structure (L), was significantly blocked by the nanostructured ITO films. Meanwhile, the horizontally polarized light $\left(\mathrm{P}_{\mathrm{H}}\right)$ can pass through the nanoline structure, which is perpendicular to the long axis of the nanoline structure $(\mathrm{L})$. These results demonstrate that anisotropic optical transmission can be simply induced and manipulated by using ITO films treated under fs laser irradiation. This property may have potential in applications such as optical devices for polarization control in the visible range [26]. We note that the anisotropic reflection property of the nanostructured ITO films was not evident because the films had a relatively low reflectance compared to the transmittance.
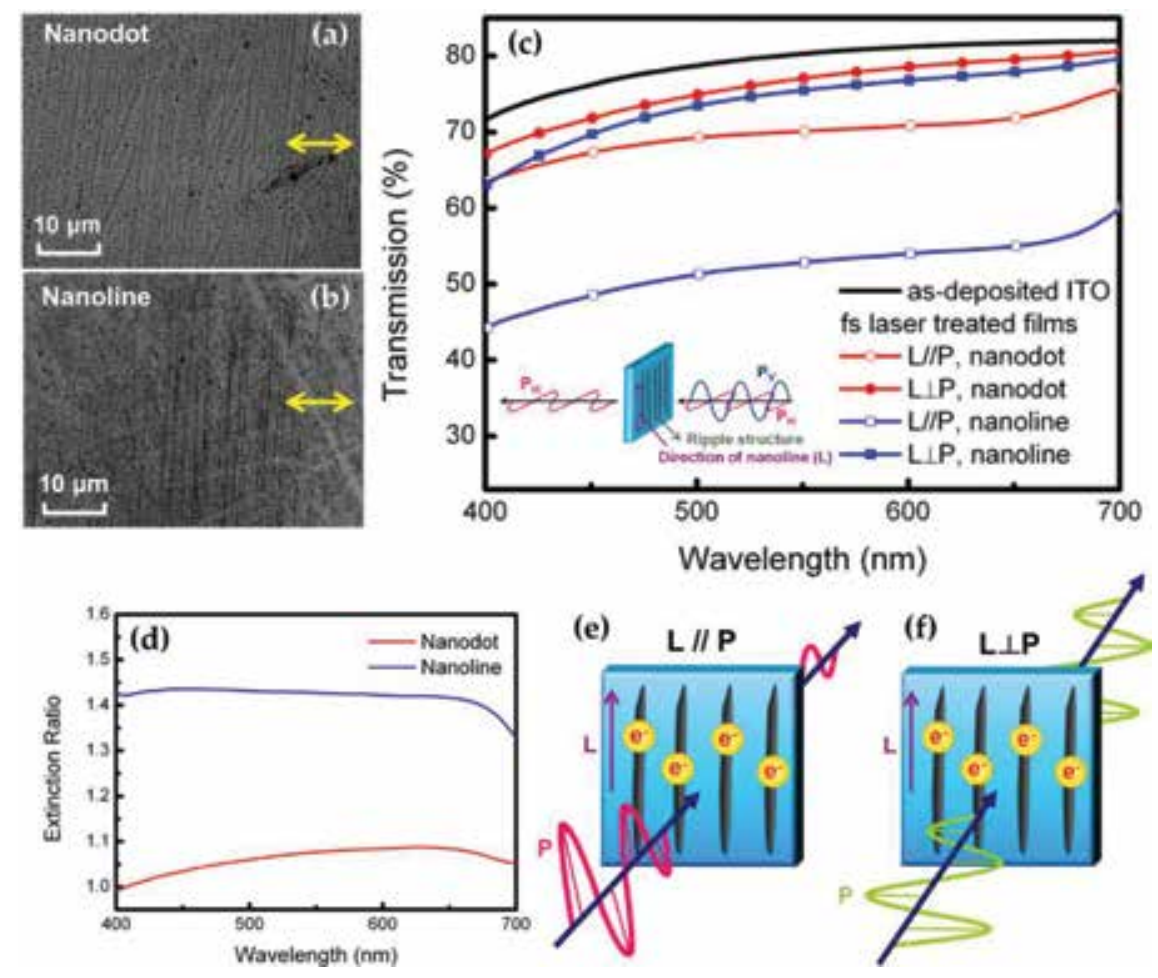

Figure 6.

( $a$ and b) SEM images of nanodots and nanolines on ITO films. The arrows indicate the polarization direction of the irradiated $f$ s laser. (c) The optical transmission spectra of as-deposited ITO and $f$ s laser-treated films with the structures of nanodot and nanoline; the inset in (c) shows a schematic illustration of the two forms of polarized light $\left(P_{V}\right.$ and $\left.P_{H}\right)$ passing through a fs laser-treated ITO film. L: the directions of nanolines. $(d)$ The extinction ratio $\left(T_{L \perp P} / T_{L / / P}\right)$ for the $f$ s laser-treated films with structures of nanodot and nanoline. $T_{L \perp P}$ $\left(T_{L / / P}\right)$ is the transmittance in the configuration, $L \perp P(L / / P)$, as shown in $(e)$ [12]. 
For the case of L//P in Figure 6e, the metallic and periodic nanoline structure on the ITO films reflects or absorbs the incoming electromagnetic (EM) wave due to the movement of electron along the metallic nanolines and Joule heating loss, consequently leading to blocking of the EM wave. However, the movement of electrons along the metallic nanolines is not in the same manner for the case of EM wave with $L \perp P$ (Figure 6f). The loss caused by Joule heating and reflection is limited, and thus, the EM wave is transmitted highly through the ITO films with periodic nanodot or nanoline structures (Figure 6f).

To get an insight into the responsible mechanism for the anisotropic optical properties, the compositions of fs laser-treated ITO films were investigated using AES. Figure 7a shows the first derivative $(d N / d E)$ AES peaks (i.e., In(MNN) at $410 \mathrm{eV}, \mathrm{Sn}(\mathrm{MNN})$ at $433 \mathrm{eV}$, and $\mathrm{O}(\mathrm{KLL})$ at $519 \mathrm{eV}$ [27]) of an as-deposited film and a nanoline film. The point A (outside a nanoline) and point $\mathrm{B}$ (inside a nanoline) are shown by the SEM image in Figure 7b. Obviously, for the fs lasertreated ITO film, the $d N / d E$ signals of $\operatorname{In}(\mathrm{MNN}), \operatorname{Sn}(\mathrm{MNN})$, and $\mathrm{O}(\mathrm{KLL})$ slightly reduced at point $A$ as compared with those of as-deposited ITO film. Meanwhile, the $d N / d E$ signals (top-pink line in Figure 7a) reduced remarkably at point B (inside a nanoline, see Figure 7b). The reduction in AES signals indicates that the composition of fs laser-treated ITO films is modified, especially at the nanoline locations. According to the results in the previous section and further examination [12], the surface compositions at nanodot and nanoline structures deviated from the stoichiometry of ITO and are metal-like area in particular. Consequently, the ITO films with a nanoline structure functioned as a grid of regular metallic wires, which induced the movement of electron along the metallic nanolines and Joule heating loss to block the EM wave for the case of L//P. However, the energy loss caused by Joule heating and reflection is limited for $\mathrm{L} \perp \mathrm{P}$ because an EM wave cannot induce electron movement along the metallic nanolines in the same manner to result in high EM wave transmission. Since the total area of nanoline is larger than that of nanodot, the anisotropic optical property of the former is more critical than the latter [12].

In summary, the fs laser-treated ITO films with the structures of nanodot and nanoline on the surfaces possessed anisotropic optical transmission properties (i.e., $T_{L \perp P}>T_{L / / P}$ ). The fs laser-treated ITO films may be applied to optoelectronics as the polarizing optical elements and smart window technology in the visible spectroscopy.
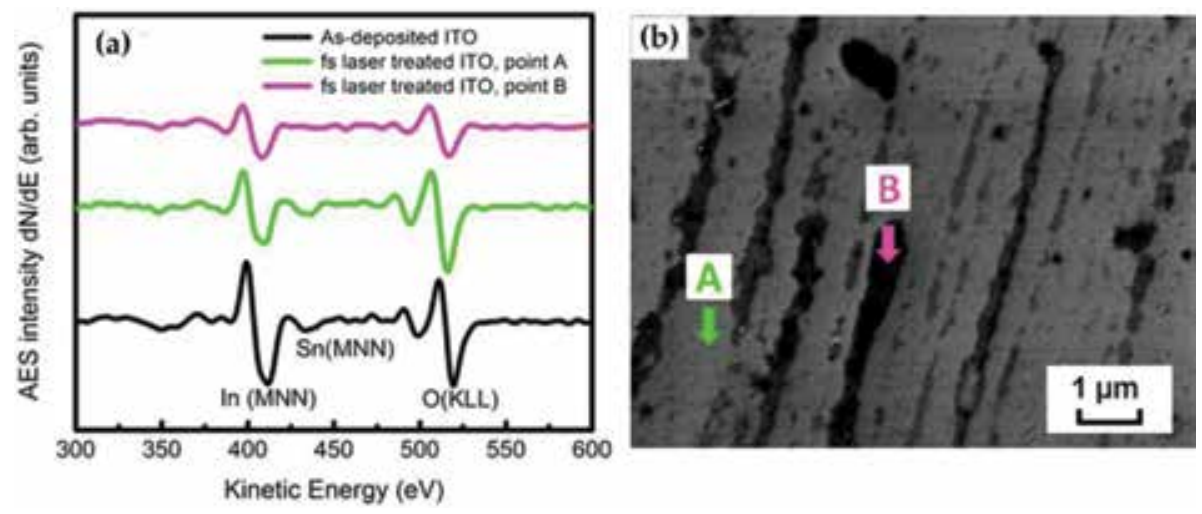

Figure 7.

(a) The first derivative (dN/dE) of AES peaks, In (MNN), Sn (MNN), and O (KLL), measured for an as-deposited ITO film and a fs laser-treated ITO film with a nanoline structure. The point $A$ (outside a nanoline) and point $B$ (inside a nanoline) correspond to the arrows marked in (b), the SEM image of a $f s$ laser-treated ITO film [12]. 


\section{Femtosecond laser-colorized indium-tin-oxide films for blue light attenuation and image screening}

This section further demonstrates the development of various nanostructuring patterns on ITO films by fs laser annealing. Figure 8 presents the surface morphology of an untreated ITO film and five laser-annealed ITO films. Table 1 summarizes the experimental conditions and the nanostructures on the film surfaces. Differ from the flat surface of as-deposited ITO film in Figure 8a, the UDL-1 presents a densely cotton-like structure on the surface when the fluence of $646.1 \mathrm{~mJ} / \mathrm{cm}^{2}$ is employed (Figure 8b). By decreasing the laser fluence to $216.7 \mathrm{~mJ} / \mathrm{cm}^{2}$, the film has a brick-like structure. At a low fluence of $59.6 \mathrm{~mJ} / \mathrm{cm}^{2}$, a regular ripple structure (composed of nano-bricks) is obtained on the surface (Figure 8f). Figure 8c-f shows all of the ripple structures (formed by nano-bricks), which were fabricated by scanning a laser spot along the $y$-axis and parallel to the polarization of laser beam. The spatial period along the $y$-axis is much smaller than the wavelength of the radiation, which is the so-called high spatial frequency LIPSS (HSFL). Usually, in transparent materials, HSFLs are generated under hundreds to thousands of ultra-short laser pulses [28] perpendicular to the direction of laser polarization with a fluence below the damage threshold of materials [29]. With a scanning speed of $\sim 12.5$ pulses $/ \mu \mathrm{m}$ and a spot size of $21 \mu \mathrm{m}$ in width, the ITO films were irradiated by about 260 pulses at a single point. All laser-annealed ITO films obtained surface nanostructures with HSFLs.

For sample UDL-5 in Figure 8f, the nano-bricks exhibited a length of $\sim 250 \mathrm{~nm}$ (along the $\mathrm{x}$-axis) and a width of $\sim 70 \mathrm{~nm}$ (along the $\mathrm{y}$-axis), and they are regularly separated by around $500 \mathrm{~nm}$ along the $\mathrm{x}$-axis. This 500-nm-period structure, so-called low spatial frequency LIPSS (LSFL), is parallel to the polarization of laser beam. Usually, LSFL is observed on the surface of dielectric materials. The spatial period can be estimated by $\Lambda_{\text {parallel }}=\lambda / n$, where $n$ is the refractive index of

(a)
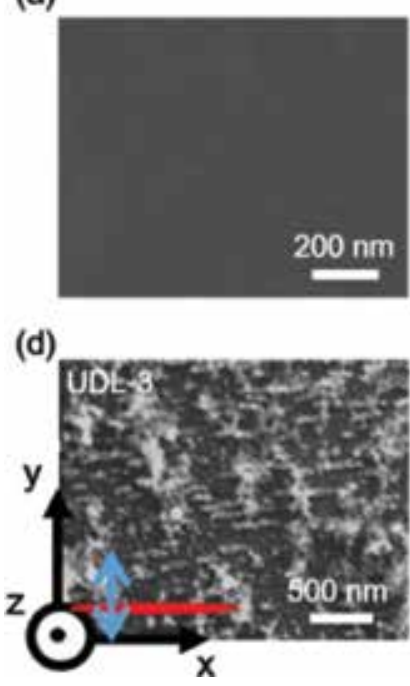

(b)

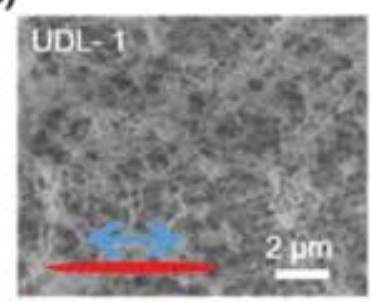

(e)

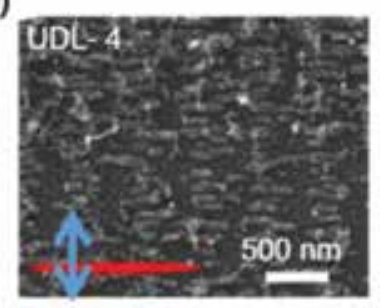

(c)

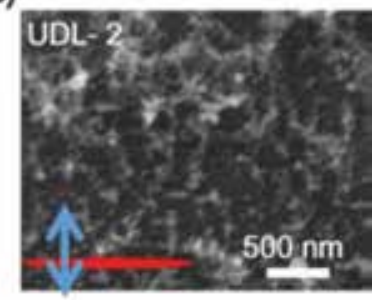

(f)

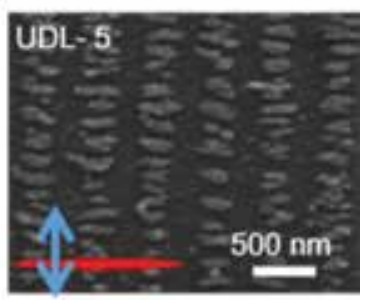

Figure 8.

SEM images showing the morphology of the ITO films before and after $f$ s laser annealing. (a) The surface morphology of an untreated ITO film. (b) A laser-annealed ITO film (UDL-1, fluence $=646 \mathrm{~mJ} / \mathrm{cm}^{2}$ ) with scanning along the $y$-axis and polarization (blue arrow) parallel to the laser line-spot (red). (c-f) Laser-annealed ITO films [UDL-2 (fluence $\left.=217 \mathrm{~mJ} / \mathrm{cm}^{2}\right), U D L-3\left(\right.$ fluence $\left.=197 \mathrm{~mJ} / \mathrm{cm}^{2}\right), U D L-4$ $\left(\right.$ fluence $\left.=68 \mathrm{~mJ} / \mathrm{cm}^{2}\right)$, and UDL-5 (fluence $\left.\left.=60 \mathrm{~mJ} / \mathrm{cm}^{2}\right)\right]$ with scanning along the $y$-axis and polarization (blue arrow) perpendicular to the laser line-spot (red) [14]. 
Nanostructuring Indium-Tin-Oxide Thin Films by Femtosecond Laser Processing

DOI: http://dx.doi.org/10.5772/intechopen.8279o

\begin{tabular}{ccccc}
\hline Sample no. & Fluence $\left(\mathbf{m} \mathbf{J} / \mathbf{c m}^{2}\right)$ & \multicolumn{2}{c}{ Nanostructure } & \multirow{2}{*}{ Color } \\
\cline { 3 - 5 } & & Cotton-like structure & Brick-like structure & \\
\hline UDL-1 & 646.1 & $\mathrm{~V}$ & - & Cyan \\
\hline UDL-2 & 216.7 & $\mathrm{~V}$ & $\mathrm{~V}$ & Yellow \\
\hline UDL-3 & 197.0 & $\mathrm{~V}$ & $\mathrm{~V}$ & Yellow \\
\hline UDL-4 & 67.7 & $\mathrm{~V}$ & $\mathrm{~V}$ & Orange \\
\hline UDL-5 & 59.6 & - & $\mathrm{V}$ & Orange \\
\hline
\end{tabular}

Table 1.

Laser fluence and the structure formation on the colorized ITO films.

the dielectric material, when the photon energy is smaller than the bandgap of the material [30]. The LIPSS theory of Sipe et al. for transparent materials has also predicted the spatial period of $\Lambda_{\text {parallel }}=\lambda / n$ that is attributed to radiation remnants [31]. Radiation remnants could be generated at the solid/air interface by absorbing photons from the incident radiation and then transfer to the materials at the associated spatial frequencies. Additionally, when the photon energy is smaller than the bandgap of the material, electrons can be excited to higher energy levels by absorbing multiple photons. In other words, laser provides a sufficient strong electric field to drive the electrons to tunneling out and consequently induces the ablation on the surface of materials. The bandgap for ITO is around $3.7 \mathrm{eV}$ [32], and refractive index $n$ is $\sim 1.60$ at $800 \mathrm{~nm}$ [33]. Here the photon energy of the irradiated laser is $1.55 \mathrm{eV}$, so it is estimated that $\Lambda_{\text {parallel }}=500 \mathrm{~nm}$, agreeing well with the experimental result for sample UDL-5.

Figure 9a shows the laser fluence dependence of the colors of laser-annealed ITO films. The untreated ITO film exhibits purple color, while laser-annealed ITO films become cyan, yellow, or orange, depending on the nanostructures on their surfaces. The reflectance and transmittance spectra of all ITO films in the visible region were measured to clarify the origin of laser-colorized ITO films. For an untreated ITO film, the reflectance is relatively high for wavelength ranges below $425 \mathrm{~nm}$ and above $650 \mathrm{~nm}$ (Figure 9b). Thus, the untreated ITO film is purple. Intriguingly, the reflectance spectra for the laser-annealed ITO films are significantly different. For high fluence (UDL-1), the reflectance spectrum in a range of 450-600 nm is substantially higher than that of the untreated ITO film, with a 2.2-fold increase at around $550 \mathrm{~nm}$; meanwhile, the reflectance spectra below $400 \mathrm{~nm}$ and above $650 \mathrm{~nm}$ reduce remarkably. Therefore, the laser-colorized ITO film of UDL-1 is cyan. When the laser fluence reduces, the broad main peak in Figure 9c gradually shifts from 550 to $575 \mathrm{~nm}$, and thus, the color changes from cyan to yellow and then to orange.

As shown in Figure 9d, all of the transmittance spectra for ITO films are reduced after fs laser annealing. Interestingly, the transmittance reduction in the region of 390-480 $\mathrm{nm}$ is significantly greater than that in long-wavelength region.

It is worthy of mentioning that blue light is dominated in the region of $390-480 \mathrm{~nm}$, and it has been demonstrated to cause damage to eyes [34]. Among the treated samples, UDL-5 sample treated under low fluence offers a larger reduction in the blue-light region and a smaller suppression in the red-light region. This study has demonstrated that the fs laser-colorized ITO films can be directly used for LCD displays in which the films maintain their original function as an electrode and act as a blue light filter to protect eyes.

When laser-colorized ITO films are used in the LCD displays, the image displayed on the LCD can be selectively screened by varying the view angle. Figure 10a shows the schematics for testing this concept. If the view angle $\theta$ is close to 0 (i.e., 
watching the panel normally), the image on the panel is normal. However, the image on the panel is blocked by the strong reflected light with colors that depend on view angle $\theta$ as watching the panel obliquely (Figure 10b-e). As a result, due to strong reflection of certain colors, the image on the panel cannot be seen. This finding is potential for information security and the protection of privacy [14].

(a)

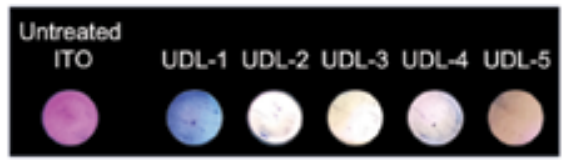

(c)

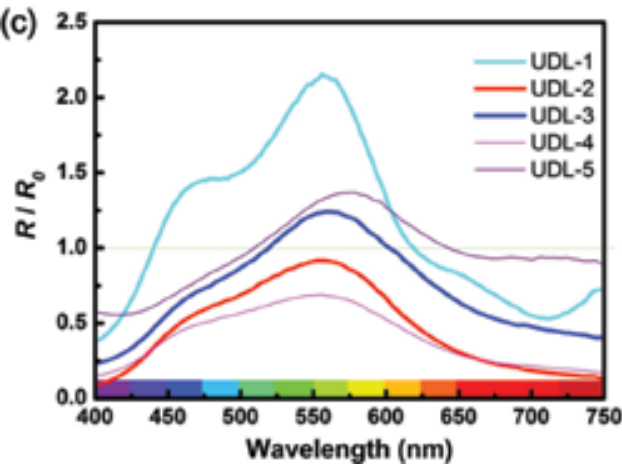

(b)
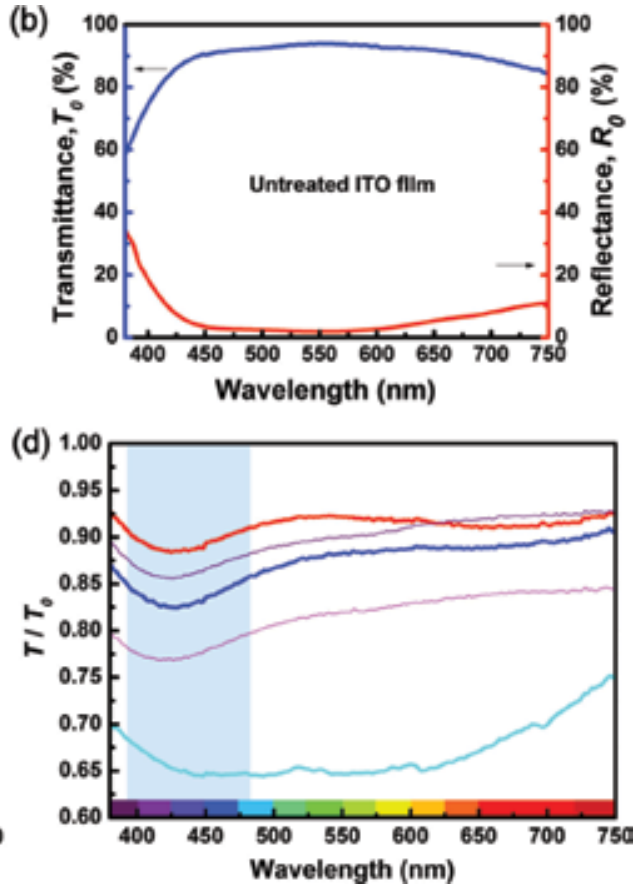

Figure 9.

(a) The colors of ITO films before and after $f$ s laser annealing. (b) The reflectance $\left(R_{0}\right)$ and transmittance $\left(T_{0}\right)$ spectra for an ITO film before fs laser annealing. (c) The ratio of the reflectance spectra for the ITO films before $\left(R_{0}\right)$ and after $(R) f$ s laser annealing. $(d)$ The ratio of the transmittance spectra for the ITO films before $\left(T_{0}\right)$ and after $(T) f$ s laser annealing. The blue-shaded area covers the wavelengths that cause damage to eyes [14].

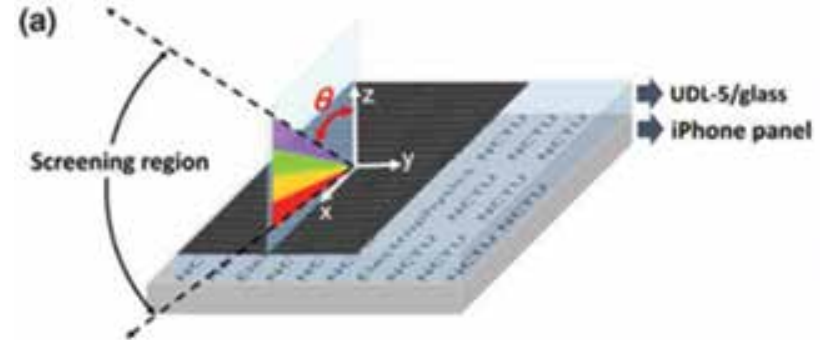

(c) $\theta \sim 45$

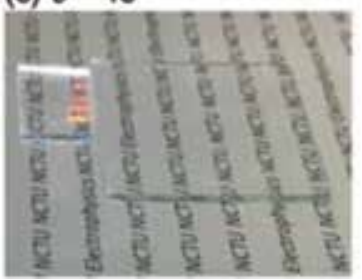

(d) $\theta \sim 35^{\circ}$

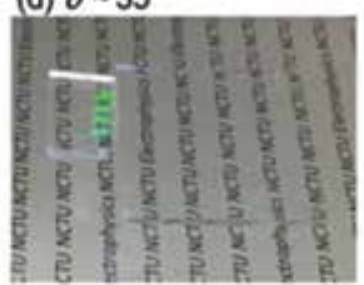

(b) $\theta<10^{\circ}$

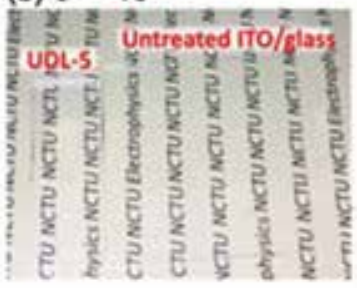

(e) $\theta \sim 25^{\circ}$

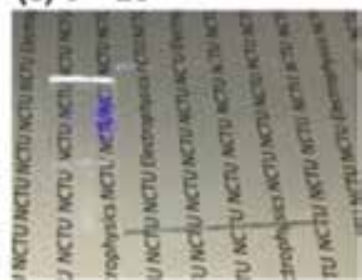

Figure 10.

(a) The schematics for capturing the images in $(b-e)$, where $\theta$ is the view angle. $(b-e)$ observing the image on a screen through an untreated ITO film and a laser-colorized ITO film (UDL-5) at various view angles [14]. 


\section{Conclusions}

In this chapter, we review the fabrications of various periodic nanostructures, that is, ripple structures of self-organized nanodots, nanolines, nano-cottons, and nano-bricks on the surfaces of ITO thin films after fs laser pulse irradiation. The ITO films with surface ripple structures were successfully prepared at a fluence of $0.1 \mathrm{~mJ} / \mathrm{cm}^{2}$ and numbers of pulses from $5 \times 10^{3}$ to $3 \times 10^{6}$, without scanning. The fs laser-annealed ITO films exhibited a great enhancement in electrical conductivity ( $\sim 30$ times) due to the presence of indium-like clusters in ripple structures. In addition, the ITO films obtained nanodot structure at a fluence of $0.1 \mathrm{~mJ} / \mathrm{cm}^{2}$ and a pulse number of $3 \times 10^{6}$ and nanoline structure at a fluence of $0.2 \mathrm{~mJ} / \mathrm{cm}^{2}$ and a pulse number of $2 \times 10^{7}$. The fs laser-annealed ITO films presented interesting anisotropic transmission properties $\left(T_{L \perp P}>T_{L / / P}\right)$ because the nanostructures functioned as a metallic grid that induced the electron movement along the nanolines and Joule heating loss to block the EM wave for the case of L//P (i.e., the direction of nanolines, $\mathrm{L}$, is parallel to the polarization direction, $\mathrm{P}$, of fs laser pulses). Moreover, nanostructures with cotton, brick, and ripple forms are generated on the surface of ITO films by controlling the laser fluences from 60 to $646 \mathrm{~mJ} / \mathrm{cm}^{2}$ and a scanning speed of $\sim 12.5$ pulses $/ \mu \mathrm{m}$, which produce cyan, yellow, and orange colors. These nanostructures can significantly attenuate blue light, and thus, they are possible for applications such as eye protection and information security.

\section{Acknowledgements}

This work was also supported by the Ministry of Science and Technology of the Republic of China, Taiwan (Grant nos. 107-2119-M-009-010-MY2, 106-2119-M-009-013-FS, and 106-2628-M-009-003-MY3). Besides, this work was financially supported by the Center for Emergent Functional Matter Science of National Chiao Tung University from the Featured Areas Research Center Program and the Research Team of Photonic Technologies and Intelligent Systems at NCTU within the framework of the Higher Education Sprout Project by the Ministry of Education (MOE) in Taiwan.

\section{Author details}

\section{Phuoc Huu Le $e^{1}$ and Chih-Wei Luo ${ }^{2 *}$}

1 Department of Physics and Biophysics, Faculty of Basic Sciences, Can Tho University of Medicine and Pharmacy, Can Tho, Vietnam

2 Department of Electrophysics, National Chiao Tung University, Hsinchu, Taiwan, Republic of China

*Address all correspondence to: cwluo@mail.nctu.edu.tw

\section{IntechOpen}

(C) 2018 The Author(s). Licensee IntechOpen. This chapter is distributed under the terms of the Creative Commons Attribution License (http://creativecommons.org/licenses/ by/3.0), which permits unrestricted use, distribution, and reproduction in any medium, provided the original work is properly cited. (cc) BY 


\section{References}

[1] Kim CE, Yun I. Effects of nitrogen doping on device characteristics of InSnO thin film transistor. Applied Physics Letters. 2012;100:013501. DOI: 10.1063/1.3673556

[2] Zhao Y, Duan L, Zhang D, Hou L, Qiao J, Wang L, et al. Small molecular phosphorescent organic lightemitting diodes using a spin-coated hole blocking layer. Applied Physics Letters. 2012;100:083304. DOI: $10.1063 / 1.3688300$

[3] Kim H, Gilmore CM, Piqué A, Horwitz JS, Mattoussi $\mathrm{H}$, Murata $\mathrm{H}$, et al. Electrical, optical, and structural properties of indium-tin-oxide thin films for organic light-emitting devices. Journal of Applied Physics. 1999;86:6451. DOI: 10.1063/1.371708

[4] Guillén C, Herrero J. Structure, optical, and electrical properties of indium tin oxide thin films prepared by sputtering at room temperature and annealed in air or nitrogen. Journal of Applied Physics. 2007;101:073514. DOI: 10.1063/1.2715539

[5] Wu CC, Wu CI, Sturm JC, Kahn A. Surface modification of indium tin oxide by plasma treatment: An effective method to improve the efficiency, brightness, and reliability of organic light emitting devices. Applied Physics Letters. 1997;70:1348-1350. DOI: 10.1063/1.118575

[6] Horng RH, Wuu DS, Lien YC, Lan WH. Low-resistance and hightransparency $\mathrm{Ni}$ /indium tin oxide ohmic contacts to p-type GaN. Applied Physics Letters. 2001;79:2925-2927. DOI: 10.1063/1.1415048

[7] Shieh J-M, Chen Z-H, Dai B-T, Wang Y-C, Zaitsev A, Pan C-L. Nearinfrared femtosecond laser-induced crystallization of amorphous silicon. Applied Physics Letters. 2004;85:1232. DOI: $10.1063 / 1.1782267$
[8] Huang M, Zhao F, Cheng Y, Xu N, $\mathrm{Xu} \mathrm{Z}$. Origin of laser-induced nearsubwavelength ripples: Interference between surface plasmons and incident laser. ACS Nano. 2009;3:4062. DOI: $10.1021 / \mathrm{nn} 900654 \mathrm{v}$

[9] Zhao QZ, Malzer S, Wang LJ.

Formation of subwavelength periodic structures on tungsten induced by ultrashort laser pulses. Optics Letters. 2007;32:1932-1934. DOI: 10.1364/ OL.32.001932

[10] Jia X, Jia TQ, Zhang Y, Xiong PX, Feng DH, Sun ZR, et al. Periodic nanoripples in the surface and subsurface layers in $\mathrm{ZnO}$ irradiated by femtosecond laser pulses. Optics Letters. 2010;35:1248-1250. DOI: 10.1364/OL.35.001248

[11] Wang C, Wang HI, Tang WT, Luo CW, Kobayashi T, Leu J. Superior local conductivity in self-organized nanodots on indium-tin-oxide films induced by femtosecond laser pulses. Optics Express. 2011;19:24286-24297. DOI: 10.1364/OE.19.024286

[12] Wang C, Wang HI, Luo CW, Leu J. Anisotropic optical transmission of femtosecond laser induced periodic surface nanostructures on indiumtin-oxide films. Applied Physics Letters. 2012;101:101911. DOI: $10.1063 / 1.4751983$

[13] Chen MH, Tseng YH, Chao YP, Tseng SY, Lin ZR, Chu HH, et al. Effects on organic photovoltaics using femtosecond-laser-treated indium tin oxides. ACS Applied Materials and Interfaces. 2016;8(38):24989-24993. DOI: 10.1021 /acsami.6b06263

[14] Tseng YH, Yang H, Luo CW. Femtosecond laser-colorized indiumtin-oxide films for blue light attenuation and image screening. Optics Express. 
2017;25:33134-33142. DOI: 10.1364/

OE. 25.033134

[15] Eichstät J, Römer GRBE, Huis

AJ. Towards friction control using laserinduced periodic surface structures. Physics Procedia. 2011;12:7-15. DOI: 10.1016/j.phpro.2011.03.099

[16] Vorobyev AY, Guo C.

Multifunctional surfaces produced by femtosecond laser pulses. Journal of Applied Physics. 2015;117:033103. DOI: $10.1063 / 1.4905616$

[17] Vorobyev AY, Guo C. Metallic light absorbers produced by femtosecond laser pulses. Advances in Mechanical Engineering. 2010;2010:452749. DOI: $10.1155 / 2010 / 452749$

[18] Vorobyev AY, Guo C. Enhanced absorptance of gold following multipulse femtosecond laser ablation. Physical Review B. 2005;72:195422. DOI: 10.1103/PhysRevB.72.195422

[19] Luo CW, Lee CC, Li CH, Shih HC, Chen YJ, Su CH, et al. Ordered YBCO sub-micron array structures induced by pulsed femtosecond laser irradiation. Optics Express. 2008;16:20610. DOI: 10.1364/OE.16.020610

[20] Guosheng Z, Fauchet PM, Siegman AE. Growth of spontaneous periodic surface structures on solids during laser illumination. Physical Review B. 1982;26:5366. DOI: 10.1103/ PhysRevB.26.5366

[21] Donley C, Dunphy D, Paine D, Carter C, Nebesny K, Lee P, et al. Characterization of indium-tin oxide interfaces using X-ray photoelectron spectroscopy and redox processes of a chemisorbed probe molecule: Effect of surface pretreatment conditions. Langmuir. 2002;18:450-457. DOI: 10.1021/la011101t

[22] Szörényi T, Laude LD, Bertóti I, Kántor Z, Geretovszky Z. Excimer laser processing of indium-tin-oxide films: An optical investigation. Journal of Applied Physics. 1995;78:6211. DOI: 10.1063/1.360567

[23] Zhu F, Huan CHA, Zhang K, Wee ATS. Investigation of annealing effects on indium tin oxide thin films by electron energy loss spectroscopy. Thin Solid Films. 2000;359:244-250. DOI: 10.1016/S0040-6090(99)00882-2

[24] Fan JCC, Goodenough JB. X-ray photoemission spectroscopy studies of Sn-doped indium-oxide films. Journal of Applied Physics. 1977; 48:3524-3531. DOI: $10.1063 / 1.324149$

[25] Loeschner K, Seifert G, Heilmann A. Self-organized, gratinglike nanostructures in polymer films with embedded metal nanoparticles induced by femtosecond laser irradiation. Journal of Applied Physics. 2010;108:073114. DOI: 10.1063/1.3490191

[26] Elliott J, Smolyaninov II, Zheludev NI, Zayats AV. Polarization control of optical transmission of a periodic array of elliptical nanoholes in a metal film. Optics Letters. 2004;29:1414. DOI: 10.1364/OL.29.001414

[27] Chaney JA, Pehrsson PE. Work function changes and surface chemistry of oxygen, hydrogen, and carbon on indium tin oxide. Applied Surface Science. 2001;180:214-226. DOI: 10.1016/S0169-4332(01)00347-6

[28] Bonse J, Rosenfeld A, Krüger J. On the role of surface plasmon polaritons in the formation of laser-induced periodic surface structures upon irradiation of silicon by femtosecondlaser pulses. Journal of Applied Physics. 2009;106:104910. DOI: 10.1063/1.3261734

[29] Dufft D, Rosenfeld A, Das SK, Grunwald R, Bonse J. Femtosecond laser-induced periodic surface 
structures revisited: A comparative study on $\mathrm{ZnO}$. Journal of Applied Physics. 2009;105:034908. DOI: 10.1063/1.3074106

[30] Bonse J, Höhm S, Kirner SV, Rosenfeld A, Krüger J. Laser-induced periodic surface structures (LIPSS) - A scientific evergreen. IEEE Journal of Selected Topics in Quantum Electronics. 2016;23:9000615. DOI: 10.1364/CLEO_ SI.2016.STh1Q.3

[31] Sipe JE, Young JF, Preston JS, van Driel HM. Laser-induced periodic surface structure. I. Theory. Physical Review B. 1983;27:1141. DOI: 10.1103/ PhysRevB.27.1141

[32] Ray S, Banerjee R, Basu N, Batabyal AK, Barua AK. Properties of tin doped indium oxide thin films prepared by magnetron sputtering. Journal of Applied Physics. 1983;54:3497-3501. DOI: $10.1063 / 1.332415$

[33] Konig TAF, Ledin PA, Kerszulis J, Mahmoud MA, El-sayed MA, Reynolds $\mathrm{JR}$, et al. Electrically tunable plasmonic behavior of nanocube-polymer nanomaterials induced by a redox-active electrochromic polymer. ACS Nano. 2014;8(6):6182-6192. DOI: 10.1021/ nn501601e

[34] Jaadane I, Boulenguez P, Chahory S, Carré S, Savoldelli M, Jonet L, et al. Retinal damage induced by commercial light emitting diodes (LEDs). Free Radical Biology and Medicine. 2015;84:373-384. DOI: 10.1016/j. freeradbiomed.2015.03.034 


\title{
Stress among the APS-Prepared TBCs: Testing and Analysis
}

\author{
Zhaoliang Qu, Rujie He and Daining Fang
}

\begin{abstract}
Stress state in thermal barrier coatings (TBCs) has an influence on the service property and safety of coatings. The stress in TBCs should be characterized and measured. This is helpful for the guidance of design and preparation, the study of failure mechanism and the promotion of application of TBCs. This chapter reviewed the research progress on the stress measurement for air plasma spray (APS)-prepared TBCs. The origin and category of stress during preparation process and service were discussed. Then, the measurement technology and characterization method for stress in APS-prepared TBCs were focused. The common stress measurement techniques such as X-ray diffraction, neutron diffraction, Raman spectroscopy, photoluminescence piezospectroscopy, curvature measurement, material removal and indentation method were detailed. Furthermore, some suggestions were presented for the future work by summarizing the shortcomings of the exiting research.
\end{abstract}

Keywords: air plasma spray process, thermal barrier coatings, stress testing, stress analysis

\section{Introduction}

Gas-turbine engine, which is known as the heart of aircraft, covers many leading-edge technologies in advanced manufacturing industry, and represents the level of a nation's science and technology. Higher thrust-weight ratio, longer service lifetime and better reliability are regarded as the development trend for the gasturbine engine. Increasing the turbine inlet temperature is an important method for increasing the thrust-weight ratio. Key technologies for increasing the turbine inlet temperature include single crystal superalloy, air cooling and thermal barrier coatings (TBCs) technology. Specially, TBCs can lower the operating temperature of superalloy blade. The temperature reduction caused by TBCs is equal to the sum of temperature rise induced by superalloy over the last 30 years. Besides, TBCs can protect the metallic blade from oxidizing, and improve the service safety and lifetime of the blade [1-3].

Among traditional TBCs, porous ceramics with low thermal conductivity are prepared on superalloy substrate to achieve heat insulation effect. But the mismatch of thermo-mechanical properties between porous ceramics and superalloy leads to the difficulty in reliable bonding. A bond coat is necessary [2]. Thus, TBCs is a typical multilayer, multi-material system, as shown in Figure 1. TBCs mainly include (1) the ceramic top coat, (2) the thermally grown oxide (TGO), (3) the bond coat, and (4) superalloy substrate. The ceramic top coat usually adopts porous ceramics to achieve heat insulation effect. The common ceramic composition is the zirconia 


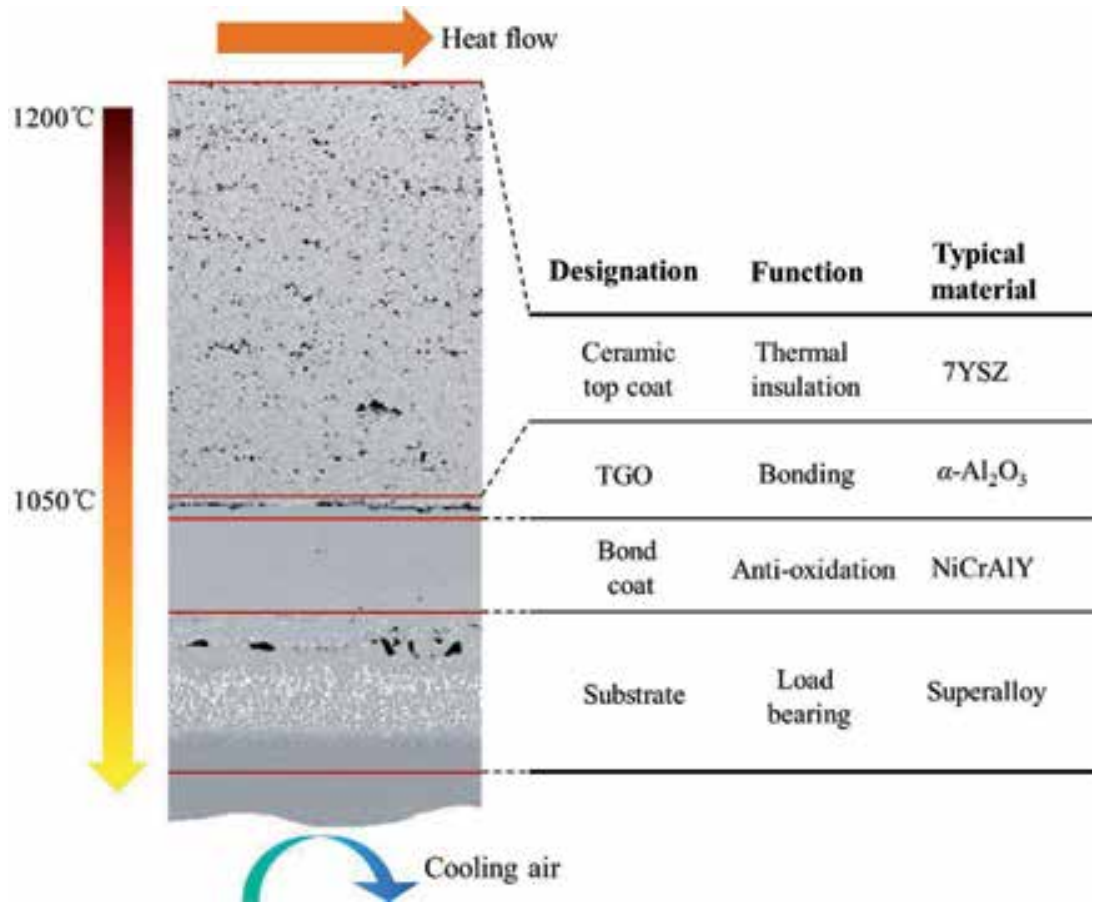

Figure 1.

The schematic of typical TBCs.

'partially stabilized' with about 6-8 wt.\% yttria (7YSZ), which has the good heatinsulating property and long thermal cycle life. TGO, whose composition is $\alpha-\mathrm{Al}_{2} \mathrm{O}_{3}$, is formed by the reaction between aluminum diffusing from the bond coat and exterior oxygen. TGO can provide good bonding of TBC to bond coat. The bond coat contains the source of elements to create TGO in oxidizing environment and provides oxidation protection, primarily of NiCoCrAlY- or NiAlPt-based compositions. The superalloy substrate, which has high strength at high temperatures, can experience complicated mechanical loads during service $[1,2,4]$.

Recently, many methods have been developed to prepare the ceramic top coat, such as air plasma spray (APS) and electron beam physical vapor deposition (EB-PVD) process [5, 6]. In APS process, the ceramic feedstock are injected into the high temperature plasma plume, heated to the molten or high-plasticity condition, impinge onto the surface of specimen with a certain momentum, and rapidly solidify. Then the lamellar microstructures, which consist of a large number of overlapped splats, are formed, as shown in Figure 2(a). In EB-PVD process, ingots of a ceramic composition are vaporized in a vacuum chamber using a focused electron beam. The ceramic vapor gradually deposit on the specimen and form columnar microstructure, which are perpendicular to the surface of specimen, as shown in Figure 2(b).

TBCs prepared by APS process, which has lower cost, has been widely used in the larger stationary components. However, the failure behavior such as premature spallation of TBCs during preparation and operation process is still an overriding concern. The premature spallation of TBCs may expose the superalloy substrate to hot gases, resulting in the oxidization of superalloy. This may influence the service performance, lifetime and safety of aircraft, even lead to catastrophic damage [7]. The premature spallation of TBCs mainly results from intralayer and interlayer fractures [8]. The fracture behavior of materials is closely related to stress state. When the stress in a material is tensile, and is larger than strength, the fracture behavior may happen. The change of stress state is considered as the driving force 

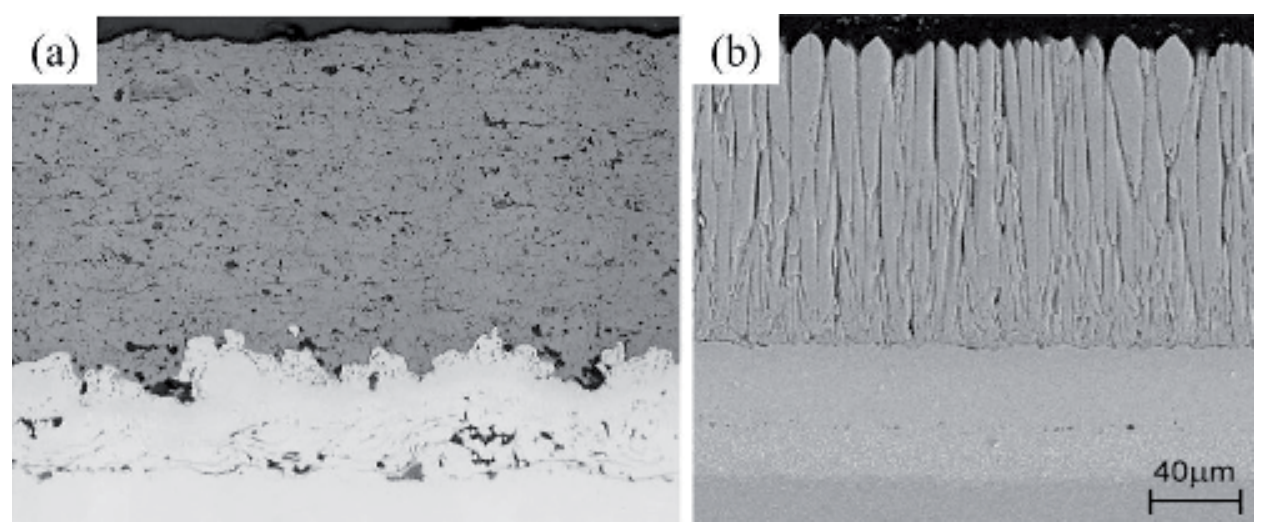

Figure 2.

The microstructures of TBCs prepared by: (a) APS and (b) EB-PVD.

for the initiation, propagation of cracks [9]. Besides, the stress state may influence the macroscopic properties of TBCs [10]. Specially, the microstructures of TBCS prepared by APS process are typical lamellar microstructures. The lamellar microstructures may not totally melt and bond each other. There are a large number of defects such as pores and microcracks between lamellar microstructures [11]. As the defects are sensitive to stress state, the material near the defects tends to fracture under stress, leading to the spallation of coatings. Therefore, the analysis and characterization of stress in TBCs prepared by APS process is necessary for the study of failure mechanism and service reliability.

This chapter reviews the research progress on the analysis and characterization of stress among the APS-prepared TBCs in recent years. The origin, category, measurement technology and characterization method for stress are focused. It is believed this will be helpful for the investigation on failure mechanism, and promote the application and development of TBCs.

\section{The origin and category of stress among the APS-prepared TBCs}

TBCs experiences complicated loads during the preparation process and service. Then, stress state in TBCs dynamically changes and influences the service properties and behaviors of TBCs.

\subsection{The origin and category of stress during preparation process}

In APS process, the molten ceramic feedstock impinge onto the surface of metal specimen, stack and form TBCs [12]. The coatings may experience violent temperature change in the process. The mismatch of thermal expansion coefficients between ceramics layer and superalloy may produce stress [13]. According to the mechanism of stress generation, the stress generating in preparation process mainly includes quenching stress and thermal mismatch stress, as shown in Figure 3.

The quenching stress is generated in the interaction process between molten ceramic feedstock and metal specimen. In this process, the feedstock after impact may form a lamellar structure and rapidly cool from the molten temperature to the specimen temperature in a short time. The lamellar structure shrinks sharply due to rapid cooling. The shrinkage of the newly formed lamellar structure is constrained by the specimen and the previous lamellar structure, resulting in stress in the coating [14]. The constraint of the specimen and the previous lamellar structure depends 


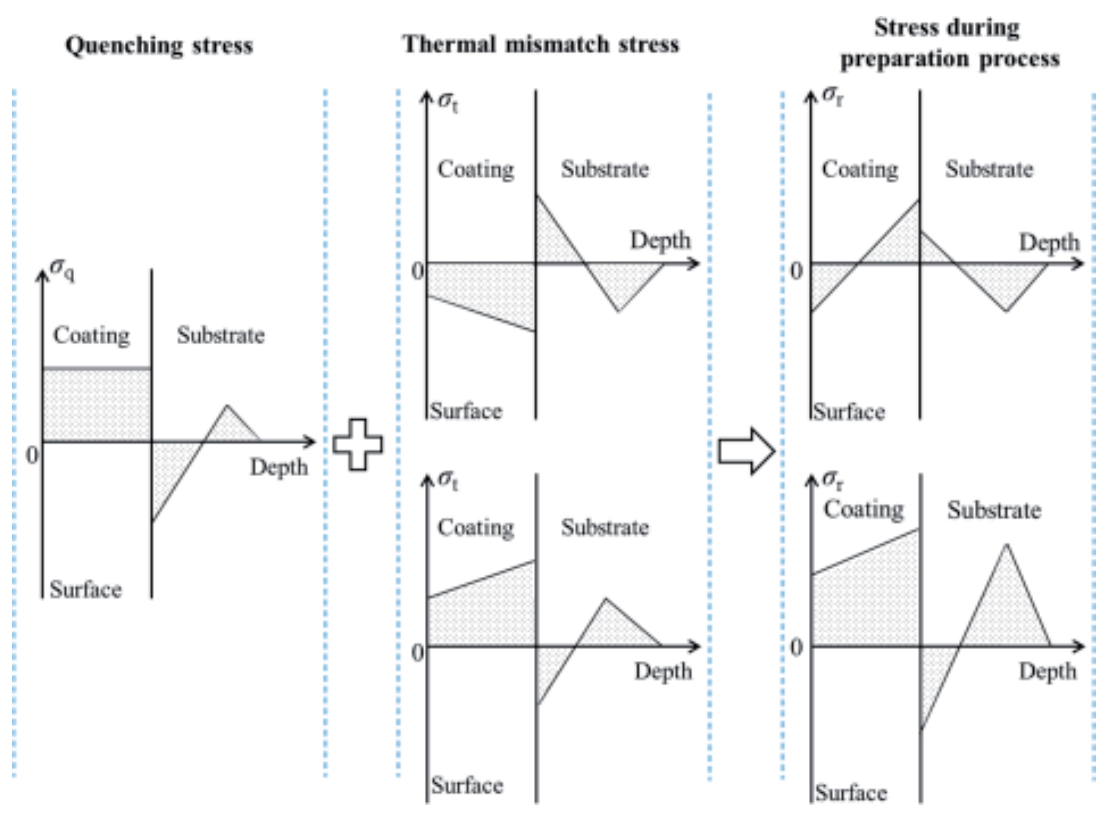

Figure 3.

The stresses during preparation process of APS-prepared TBCs.

mainly on the material of the lamellar structure, the temperature of the specimen, and the boundary shapes between the lamellar structures [15]. The existence of quenching stress has been proven by McPherson, and the value has been measured by Kuroda et al. It is found that the quenching stress is always tensile stress [16, 17]. Assuming that the shrinkage deformation of the lamellar structure is fully constrained, the resulting stress will be large, and much higher than the yield strength or fracture strength of the material. The maximum value of quenching stress given by the elastic mechanics analysis is about $1 \mathrm{GPa}$, while the values obtained from the experiments are mostly below $100 \mathrm{MPa}$. This is mainly due to the existence of many stress release mechanisms during the preparation of the coating. For example, a large number of microcracks are generated inside and at the boundary of the lamellar structure during the preparation process. These microcracks can act as important means of stress release, reducing stress below the fracture strength $[13,18]$.

The thermal mismatch stress generates during the cooling process after spraying. The thermal mismatch stress results from the mismatch of thermal expansion coefficients between the ceramic coating and the metal specimen $[9,19]$. In the elastic range, the thermal mismatch stress can be estimated by:

$$
\begin{gathered}
\Delta \varepsilon_{t h}=\int_{T_{2}}^{T_{1}}\left(\alpha_{1}(T)-\alpha_{2}(T)\right) d T \\
\sigma_{t h}(T)=\Delta \varepsilon_{t h} E(T)
\end{gathered}
$$

where, $\Delta \alpha(T)$ is the difference in thermal expansion coefficients between ceramic coating and metal material, and changes with temperature. $T_{1}$ is the spray temperature. $T_{2}$ is the certain temperature during the cooling process. $\sigma_{\mathrm{th}}(T)$ is the thermal mismatch stress of coatings. $E(T)$ is the elastic modulus of coating material. According to Eqs. (1) and (2), the thermal mismatch stress is related to the difference in thermal expansion coefficients, the spray temperature, and the elastic modulus of the coating material. The thermal mismatch stress increases with 
increasing the difference between spray and room temperature, the difference in the thermal expansion coefficients and the elastic modulus of the coating material [20]. Besides, the thermal mismatch stress may be tensile or compressive stress [21].

\subsection{The origin and category of stress during service}

TBCs usually operate in harsh environments such as high temperatures, high pressures, and extreme mechanical loads. TBCs may undergo chemical changes such as oxidation and sintering, and withstand external loads such as particle erosion and $\mathrm{CaO}-\mathrm{MgO}-\mathrm{Al}_{2} \mathrm{O}_{3}-\mathrm{SiO}_{2}$ (CMAS) corrosion, as shown in Figure 4. The composition, microstructure and properties may change dynamically. The stress state may also evolve, and the internal crack may appear and propagate, leading to the failure behaviors such as fracture, delamination and even spalling [2, 22].

During service, the aluminum element in the bond coat may continuously diffuse to the interface between the bond coat and the TGO, and react with oxygen entering from the external environment to generate $\alpha-\mathrm{Al}_{2} \mathrm{O}_{3}$. In this process, TGO gradually grows thicker. Due to the constraint of the upper ceramic top coat and the lower bond coat, the volume expansion caused by the thickening of TGO is limited. A large compressive growth stress in TGO thereby generates [23]. Besides, the thermal expansion coefficient mismatch of the various layers may also produce high residual compressive stresses in TGO during cooling from the service to room temperature. It is found that the compressive stress in TGO can reach 3-6GPa at room temperature [24]. TGO is subjected to large in-plane compression, and tends to undergo elongation or bending deformation in order to release stress. At high temperatures, the plasticity of the bond coat will increase, and creep even may occur. In addition, there are usually many defects at the interface between the ceramic top coat and TGO. During service, TGO may have an out-of-plane displacement into the bond coat at these defects. The compressive stress in TGO may release, resulting in redistribution of stress. The out-of-plane displacement may cause out-of-plane stress in TBCs, leading to crack initiation, crack propagation, and eventual delamination damage [2, 4, 25]. The stress evolution in TGO plays a crucial role in the TBCs failure, and is one of the most important incentives for delamination failure [26].

When TBCs operate in high temperature environments, the ceramic top coat material may sinter. The sintering may cause the voids between the sheet structures and the cracks in the sheet structures to heal, resulting in a significant increase in the stiffness of the ceramic top coat. The changes in the mechanical properties may

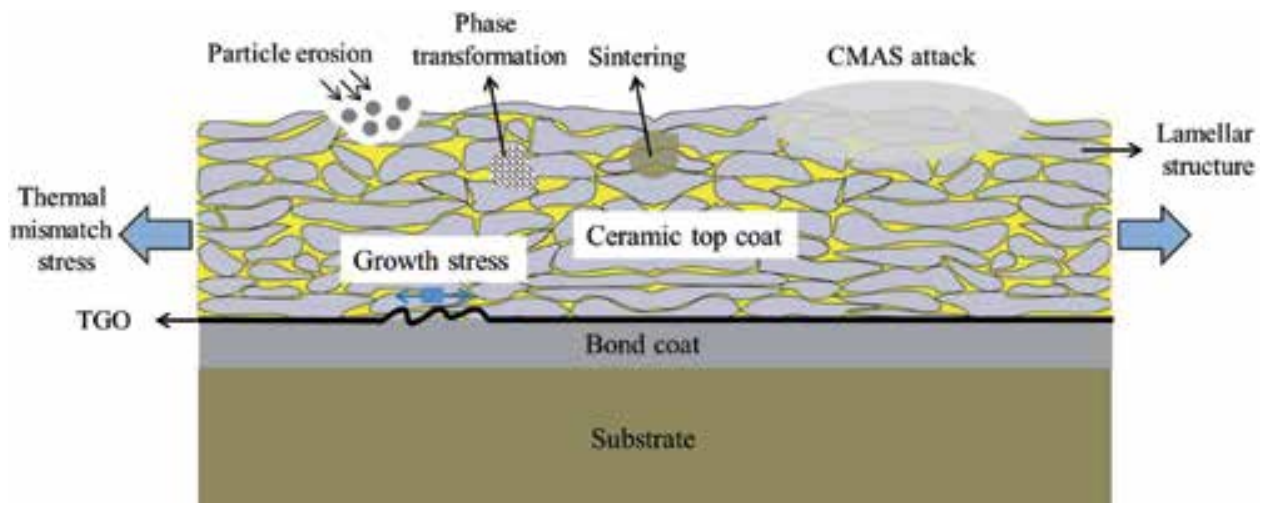

Figure 4.

The factors affecting the stress among APS-prepared TBCs during service. 
lead to the change in residual stress. Particularly, the thermal mismatch stress may increase with increasing the modulus, thereby promoting the occurrence of failure [27]. When the temperature is higher than $1200^{\circ} \mathrm{C}$, the non-equilibrium metastable phase of 7YSZ may transform into tetragonal phase and monoclinic phase. Large volume deformation may occur in the process of transforming into monoclinic phase, leading to the change in the stress state of TBCs [2].

In some service areas, such as Middle East, silicon-containing debris may enter the engine and melt on the concave (hot side) of the blade. The main component of the melt is $\mathrm{CaO}-\mathrm{MgO}-\mathrm{Al}_{2} \mathrm{O}_{3}-\mathrm{SiO}_{2}$, which is called CMAS $[2,28]$. When the surface temperature of TBCs exceeds the melting point of CMAS $\left(1240^{\circ} \mathrm{C}\right), \mathrm{CMAS}$ will infiltrate into the microcracks and voids in TBCs and chemically react with the ceramic top coat material. During the shutdown process of the engine, the ceramic top coat after CMAS infiltration will quickly solidify into a dense layer. The strain tolerance of the top coat will decrease, and the stiffness will increase, increasing the thermal mismatch stress in TBCs $[28,29]$.

Besides, solid particles in air may also enter the engine, impacting TBCs at high speed during service. The erosion of high speed particles may change the stress state in TBCs [30]. The erosion of the particles produces tensile stress in certain regions of TBCs. Defects such as sheet-like structural interfaces and microcracks in these regions may develop into macroscopic cracks under tensile stress. And macroscopic crack propagation will eventually lead to the spalling of TBCs [31].

\section{The measurement technology and characterization method for stress among the APS-prepared TBCs}

The stress plays an important role in the failure of the APS-prepared TBCs. It is important to test and characterize the stress. Up to now, various testing techniques and characterization methods for stress among the APS-prepared TBCs have been developed. According to the working principles, the methods can be divided into physical and mechanical testing methods.

\subsection{Physical testing methods}

In the physical testing methods, the information obtained from the interaction (including diffraction, scattering, etc.) between electromagnetic or particle radiation and the material is used to evaluate the stress distribution in the material. The common physical testing methods mainly include X-ray diffraction, neutron diffraction, Raman spectroscopy, photoluminescence piezospectroscopy and so on.

\subsubsection{X-ray diffraction (XRD)}

The stress in the coating may cause the crystal plane spacing to change. When $\mathrm{X}$-ray are incident on the coating at different angles, the diffraction angle changes with the incidence angle, which results from the change in the crystal plane spacing. And the change value is related to the stress [32]. In XRD method, X-rays are incident on the surface of the coating at different angles several times, and the changes in the diffraction angle value $2 \theta$ are measured, as shown in Figure 5 [18]. The stress $\sigma$ can be obtained by calculating the slope of $2 \theta$ versus $\sin 2 \psi$, as follows:

$$
\sigma=K \frac{d(2 \theta)}{d\left(\sin ^{2} \psi\right)}
$$



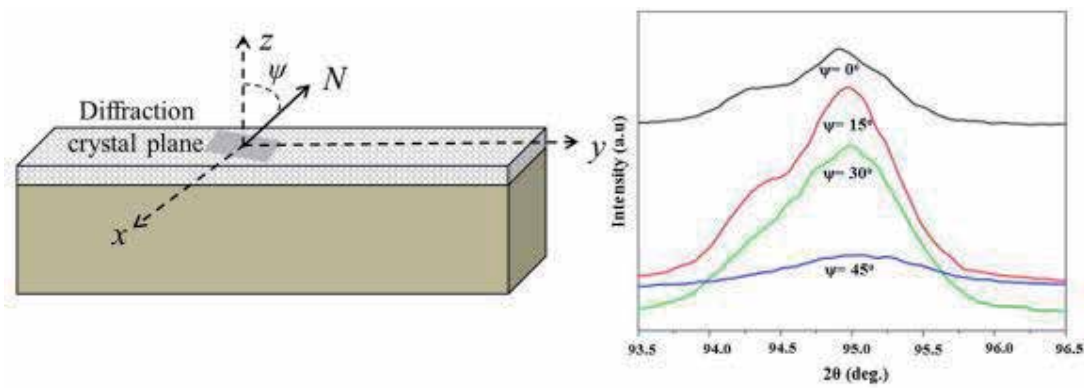

Figure 5.

The schematic diagram for measuring stress by XRD.

where, $\psi$ is the angle between the normal direction of the diffraction crystal plane and coating surface. $K$ are elastic constants.

$\mathrm{XRD}$, as a fast and reliable non-destructive testing technology, has no specific requirements on sample size and shape and is suitable for micro-area stress measurement. It has been widely used in the testing and characterization of stress among TBCs. XRD has been used to study the stress evolution in the ceramic top coat and bond coat after operating at different conditions [33-35]. Meanwhile, Xiao et al. studied the stress evolution of the bond coat during oxidation at $1150^{\circ} \mathrm{C}$ for different time based on XRD. It was found that the stress in the bond coat mainly generated during the process of cooling from 1150 to $600^{\circ} \mathrm{C}$. This may be due to that the $\beta$ phase deposition during cooling changes the volume of the bond coat $[34,35]$.

Although XRD has been widely used to test stress among TBCs, the penetration depth of X-ray generated by laboratory sources is limited to only a few tens of microns. And the thickness of the coating ranges from 300 to $500 \mu \mathrm{m}$. Thus, XRD can only measure the stress state of the near surface zone and not characterize the stress state deep inside TBCs [36].

In order to overcome the problem for small penetration depth of X-ray generated by laboratory sources, synchrotron radiation XRD has been developed. The X-ray generated by synchrotron radiation source is used to test the stress deep inside the material. Comparing with the X-ray generated by the laboratory source, the penetration ability is greatly enhanced [19]. The composition of the local phase and the stress deep inside the thermal spray coating were determined by synchrotron radiation XRD [36]. However, the synchrotron radiation device with the large size, high cost, limited machine time is difficult to promote in the laboratory. The application of synchrotron radiation XRD is limited.

\subsubsection{Neutron diffraction}

Neutrons with a strong penetrating ability (up to a few tens of millimeters), can penetrate through most materials. Neutron diffraction can be used to measure stress deep inside TBCs, whose principle is basically similar to XRD. The stress distribution in the depth direction of the coating was studied by neutron diffraction. The influence of various operation conditions on the stress distribution was discussed [37,38]. Neutron diffraction is also suitable for measuring the stress in a large specimen and obtaining the average stress inside the specimen. However, during neutron diffraction testing, the position of the surface with respect to the neutron beam must be accurately known. The 'center of gravity' of a near-surface gauge measurement volume must be calculated. A correction may be required to allow for any pseudostrain effects. Besides, sufficient data are difficult to obtain in a limited time using a weak neutron source, and a special strong neutron source is generally required [38]. 


\subsubsection{Raman spectroscopy}

When the laser with a certain frequency is incident on the material, the molecules in the material absorb part of the energy, vibrate in different ways and degrees, and scatter light with a lower frequency. This phenomenon is called Raman scattering. After the incident photons collide with the molecules, the vibrational energy or the rotational energy of the molecules and the photon energy superimpose each other to form a Raman spectrum. When there is stress in the material, some stress-sensitive bands may move and deform relative to the stress-free state, and the position of the spectral peak also may move, as shown in Figure 6 [39]. It is found that there is a linear relationship between Raman frequency shift and the stress. The frequency shift of the spectral peak can be expressed as:

$$
\Delta \omega=\Pi_{i j} \sigma_{i j}
$$

where, $\prod_{i j}$ is the piezospectroscopic tensor, which represents the stress sensitivity of Raman band. $\sigma_{i j}$ refers to the stress tensor. $\Delta \omega=\omega_{s}-\omega_{o}$, with $\omega_{o}$ being the peak position of the stress-free state and $\omega_{s}$ being the peak position of the stressed state. Then, the stress value can be obtained by measuring the positions of the Raman spectrum peak when the material is stressed or not.

Raman spectroscopy has been widely used to test and characterize stress among APS-prepared TBCs [40]. It is well known that stress in TBCs is inevitably generated during the preparation process. Therefore, it is difficult to obtain a TBCs specimen coated on the substrate in a stress-free state. Generally, a TBCs specimen without the substrate is chosen as a test piece for stress-free conditions. First, the laser with a certain frequency is incident on the TBCs specimen without the substrate to obtain a Raman spectrum (labeled as spectrum 1) corresponding to a stress-free state. Then, a known external stress is applied on the TBCs specimen without the substrate, and the measured Raman spectrum is labeled as spectrum 2. By comparing the spectrum 1 and 2, the piezospectroscopic tensor of TBCs can be obtained according to Eq. (4). Finally, the laser with the same frequency is incident on the TBCs specimen with the substrate, and Raman spectrum, which is labeled as spectrum 3, is obtained. By comparing the spectrum 1 and 3, the stress state in TBCs with the substrate can be evaluated combining the piezospectroscopic tensor obtained above [39, 40].

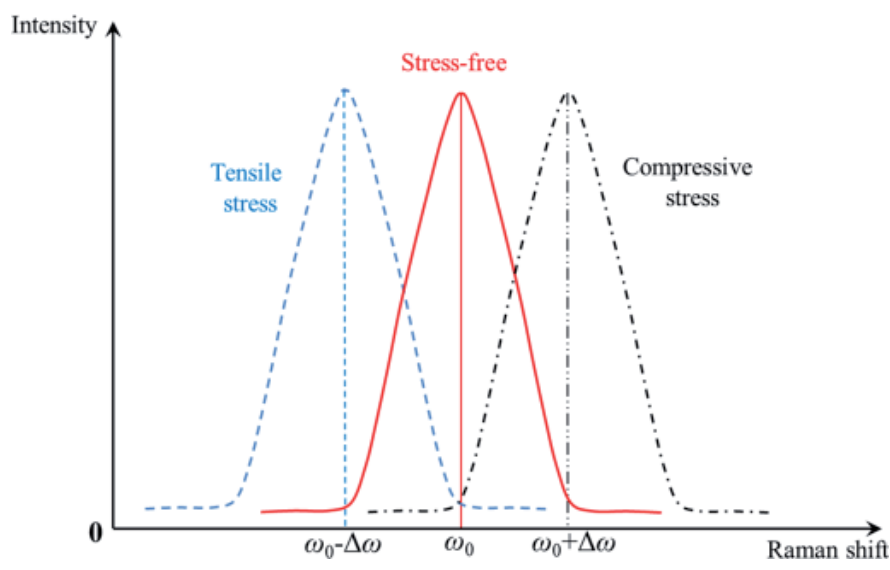

Figure 6.

The schematic diagram for measuring stress by Raman spectroscopy. 
TBCs is generally constructed of porous structures for thermal insulation. When the laser is incident on the porous region, the signal intensity will decrease rapidly due to the optical focus limitation of the instrument. In order to reduce the occurrence of the above phenomenon, the incident position of the laser is set in the dense region to obtain the maximum signal intensity, thereby reducing the influence of voids and cracks [40]. Raman spectroscopy, as a non-destructive, non-contact stress testing method, has many advantages such as high spatial resolution, large spectral range, and so on. Besides, it can measure the stress in the depth direction by adjusting the focusing parameters. However, Raman spectral peak shift is susceptible to external factors such as focus depth, laser heating effect, temperature stability, and so on. And high precision is difficult to achieve without effective calibrations. Besides, as the spot of the laser is generally small to obtain high intensity, it is impossible to measure the stress in a large area. Only local stress information can be obtained.

\subsubsection{Photoluminescence piezospectroscopy}

Since the TGO (mainly composed of $\alpha-\mathrm{Al}_{2} \mathrm{O}_{3}$ ) usually contains a trace amount of $\mathrm{Cr}^{3+}$, the ion may generate fluorescence under laser excitation, and its characteristic fluorescence spectrum is bimodal $R_{1}$ and $R_{2}$. Similar to the Raman spectroscopy, stress can also lead to changes in the peak frequencies of $R_{1}$ and $R_{2}$ spectrum. The stress value in the TGO can be obtained by measuring the change in the peak frequency of the fluorescence spectrum under stress. The above method is called as photoluminescence piezospectroscopy [41, 42].

Up to now, photoluminescence piezospectroscopy is mainly applied to the EB-PVD prepared TBCs. The laser easily penetrates the columnar crystal structure, and the reflected signals are strong. However, the scattering of pores and grain boundaries in the APS-prepared TBCs may weaken reflection signals and make it difficult to perform spectral analysis.

\subsection{Mechanical testing methods}

In the mechanical testing methods, the mechanical information such as displacement and strain of the coating system under certain operating or external excitation conditions is measured. Based on the theoretical model, the stress distribution in the coating can be evaluated. The common mechanical testing methods include curvature measurement, material removal, indentation and so on.

\subsubsection{Curvature measurement method}

During the preparation process or service, the deformation of the coating is limited by the substrate, and an interaction force is generated between the substrate and the coating. Meanwhile, a bending moment appears to bend the overall structure, and curvature occurs to balance the stress in TBCs. The curvature of the substrate is measured by optical or mechanical methods. By analyzing the change in the curvature of the substrate, the stress evolution of TBCs can be derived. The curvature measurement method was first proposed by Stoney [43] and later applied to APS-prepared coatings. Kuroda et al. [44] developed an in-situ curvature monitoring method. In this method, the stress evolution of TBCs during preheating, spraying and cooling process were monitored. The quenching stress during the spraying process and thermal mismatch stress during the cooling process were obtained, as shown in Figure 7. In the spraying process, the thickness of the coating gradually increases, and the curvature of the substrate also changes continuously. According to the equilibrium conditions, the quenching stress can be calculated. 


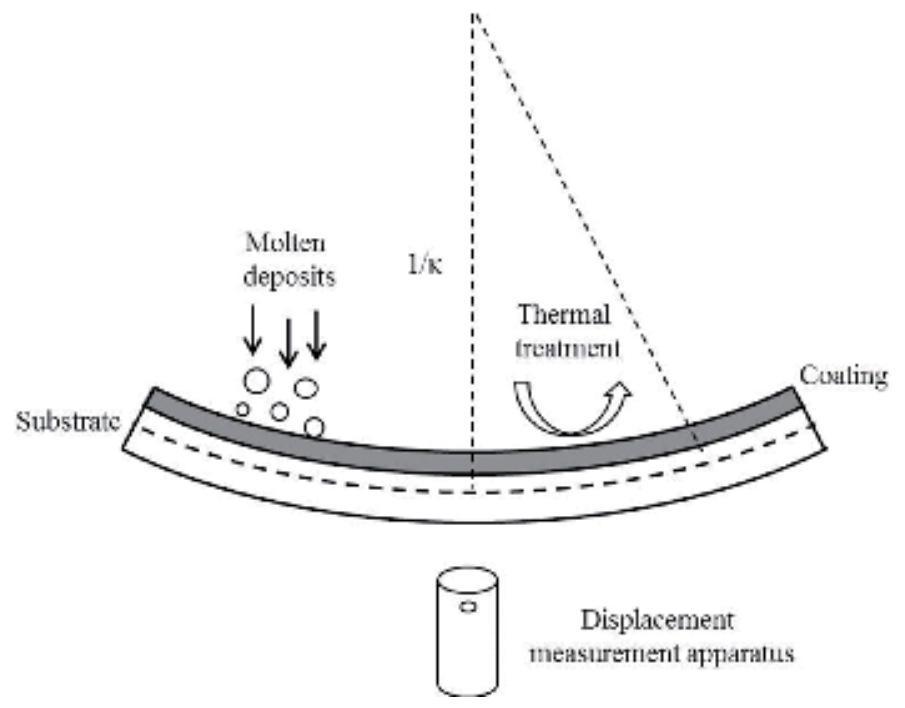

Figure 7.

The schematic diagram for measuring stress by curvature measurement method.

In the cooling process, the thermal mismatch strain between the coating and substrate changes the curvature of the substrate. Then, the thermal mismatch stress can be estimated. Besides, the complicated service loads also lead to the change in the curvature of the substrate. The stress evolution in service can also be obtained by the curvature measurement method [20, 39, 45].

In the curvature measurement method, the substrate deformation of the single point or multiple points is measured by the displacement measurement method. According to the geometric relationship, the curvature is calculated. The stress value can also be obtained based on the equilibrium equations. There are two key problems in the curvature measurement method: one is the accurate measurement of deformation, and the other is the accurate calculation of stress.

Many methods have been developed to measure the deformation, mainly including contact measurement and non-contact measurement method. In the contact measurement method, the deformation at specific point is measured by the highprecision contact displacement sensors, such as extensometers, linear variable differential transformer and so on $[46,47]$. In the non-contact measurement method, the deformation of the substrate is measured by a non-contact displacement measuring device, such as laser displacement sensor, optical microscope, CCD camera, and so on $[48,49]$. For example, during the measurement of deformation by a laser displacement sensor. The laser was incident on the surface of the curved substrate. And deformations at regular intervals were measured. Since the deformation (a few microns) was much smaller than the length of the specimen (a few centimeters), the contour of the substrate was approximated as a parabola or arc. The deformation values were fitted to a parabolic or circular equation according to the least squares method. The curvature of the specimen was calculated based on the above equations. This method has higher accuracy compared to simply measuring the deformation of the middle or end position of the specimen [48].

Once the curvature of the substrate is determined, the stress distribution in the coating can be determined according to the equilibrium equation. The relationship between the curvature and stress of film established by Stoney has been widely used in the stress measurement of film system [43]. However, for thicker coating and multilayer film system, the application of the above relationship is controversial. Clyne 
et al. proposed a two-layer beam (or plate) bending model [14]. The relationship between the curvature change $\Delta \kappa$ and the coating average stress $\sigma_{r}$ can be given by:

$$
\sigma_{r}=\Delta \kappa \frac{E_{c}^{2} h_{c}^{4}+4 E_{c} E_{s} h_{c}^{3} h_{s}+6 E_{c} E_{s} h_{c}^{2} h_{s}^{2}+4 E_{c} E_{s} h_{c} h_{s}^{3}+E_{s}^{2} h_{s}^{4}}{6 h_{s}(1-v) E_{s} h_{s}\left(h_{c}+h_{s}\right)}
$$

where, $E_{c}$ and $E_{s}$ are the modulus of the coating and substrate, respectively. $h_{c}$ and $h_{s}$ are the thickness of the coating and substrate, respectively. $v$ is the Poisson's ratio of the coating. During the preparation process and service, the material properties change with temperature. Clyne et al. considered the influence of temperature on the material properties and obtained more accurate stress values. In order to measure the curvature accurately, test specimens with regular shape such as beam shape and plate shape are chosen in the curvature measurement method. The stress measurement of the test specimens with irregular shape was limited. Besides, the average stress of the coating is obtained from curvature measurement results. More stress information inside the coating is difficult to get.

\subsubsection{Material removal method}

In the material removal method, the stress state is obtained by monitoring the strain change at a specific position before and after removing the material. The common measurement methods for APS-prepared TBCs include hole-drilling and layer-removal method.

\subsubsection{Hole-drilling method}

In the hole-drilling method, some of the stress-bearing material is removed by drilling holes in the surface of the material. The stress in the remaining material will be redistributed, resulting in a change in the shape of the circular hole. The deformation of the remaining material near the circular hole is measured by strain gauge rosette. The strain distribution can be calculated according to analytical models, and stress distribution can also be estimated [50]. In order to accurately measure the strain change caused by drilling, a specially designed strain gauge rosette is arranged around the drilling point, and the center of the strain gauge rosette should coincide with the drilling point. By analyzing the stress state at the circular hole, the strain measured by different strain gauges can be expressed as:

$$
\varepsilon_{i}=A\left(\sigma_{\max }+\sigma_{\min }\right)+B\left(\sigma_{\max }-\sigma_{\min }\right) \cos \left(2 \alpha_{i}\right)
$$

where, $A$ and $B$ are calibration coefficients, which are related to parameters such as elastic modulus, Poisson's ratio, and radius of the hole. $\sigma_{\max }$ and $\sigma_{\min }$ are maximum principal and minimum principal stress, respectively. $\alpha_{i}$ is the angle between the axis of strain gauge and the principal stress axis. By measuring the strains in different directions around the circular hole, the maximum principal and the minimum principal stress at the circular hole can be calculated by Eq. (6). Then the stress state at the circular hole can be estimated. It is worth noting that only when the hole is a through hole and the stress distribution is uniform, $A$ and $B$ have analytical solutions. There are only numerical solutions in the case where the hole is a blind hole or the stress distribution is non-uniform.

As the stress distribution among the APS-prepared TBCs is not uniform, it is recommended to gradually measure the stress distribution in the thickness direction with the incremental hole drilling depth. Then, the drilling method can be developed to the incremental hole drilling method. In this method, the drilling process 
is performed in the form of a small step at a time, and the strain changes caused by each step can be recorded by the strain gauges. It is found that after the first drilling step the measured strain changes were affected by both the current and previous small drilling steps $[17,51,52]$. Meanwhile, the calibration coefficients A and B are also related to the drilling depth increment.

Many theoretical studies have been conducted on the incremental hole drilling method. Among them, the integral method can accurately obtain the stress distribution at each drilling step, accounting for the influence of the current and previous small drilling steps. Thus, the integration method is particularly effective for non-uniform stress distribution, especially when the stress changes abruptly with thickness. The stress gradient in the thickness direction can be calculated $[53,54]$. However, it is not easy to analyze strain data by the integral method. Numerical methods are usually required. A general method for calculating calibration coefficients based on the finite element method was developed, and the calibration coefficients were obtained accurately [55].

It is worth noting that the above theories are mostly based on the linear elastic model. But the coating may undergo plastic deformation or cracking damage during the drilling process. The stress value calculated by the above theories may deviate from the true value.

\subsubsection{Layer-removal method}

Similar to the hole-drilling method, the layer-removal method also measures the strain change caused by the material reduction to analyze the stress state of the material. But the layer-removal method mainly removes the coating material of a specific thickness by mechanical methods such as grinding and polishing or chemical methods such as corrosion. The physical or mechanical testing methods are used to measure the strain change at a specific position of the remaining material. Then the stress state in the coating can be evaluated $[56,57]$.

Similarly, if plastic deformation or damage occurs during the removal of the coating material, the linear elastic assumption in the theoretical analysis will no longer be suitable. Besides, it is difficult to remove the same thickness of material each time, especially when the specimen has deformed before the removal of material.

\subsubsection{Indentation method}

The indentation method, as a common micro-scale mechanical testing method, has been widely used to study the stress in the material. The indentation method mainly includes the nanoindentation and indentation fracture method.

\subsubsection{Nanoindentation method}

It is found that the stress in the materials may lead to the change in the loaddisplacement curve obtained from the nanoindentation tests. In the indentation method, the tensile stress in the material increases the indentation depth (when the indentation load is chosen) or decreases the indentation load (when the indentation depth is chosen). The compressive stress in the material decreases the indentation depth (when the indentation load is chosen) or increases the indentation load (when the indentation depth is chosen), as shown in Figure 8. Then, an indentation method was proposed by Suresh et al. to measure the stress in the materials [58].

Assuming that the stress in the material is an equal-biaxial state, the relationship between the contact area $A_{0}$ in a stress-free state and the contact area $A$ under the stress $\sigma_{R}$ can be obtained based on the superposition principle, as follows: 


$$
\frac{A}{A_{0}}=\left(1-\frac{\sigma^{R} \sin \alpha}{H}\right)^{-1}
$$

where, $H$ is the indentation hardness. $\alpha$ is the angle between the cone surface of the equivalent conical indenter and the surface of the material (for the Vickers indenter, $\alpha=22^{\circ}$; for the Berkovich indenter, $\alpha=24.7^{\circ}$ ).

In the nanoindentation method, indentation tests are conducted on the coating material in the stress-free and stress state, respectively. After indentation load is chosen, the contact areas in the loading stage under the stress-free and stress conditions can be obtained from the load-displacement curves. Then the stress in the material can be evaluated according to Eq. (7) $[9,59,60]$.

Two kinds of coating materials corresponding to a stress-free and stress state are required in this method. As mentioned earlier, it is difficult to obtain a TBCs specimen coated on the substrate in a stress-free state. Besides, the nanoindentation method usually has high requirements on the surface quality of the material. But the APS-prepared TBCs is mostly porous, which limits the application of the nanoindentation method.

\subsubsection{Indentation fracture method}

In addition to the elastic-plastic behavior of materials, the indentation method can also be used to study the fracture behavior. When the indentation load is large enough, the stress intensity factor will be larger than the fracture toughness of the material, and the fracture will occur, as shown in Figure 9. The fracture toughness of the material can be calculated based on the critical conditions. The stress intensity factor $K_{s}$ in the stress-free state can be expressed as:

$$
K_{s}=\delta\left(\frac{E}{H}\right)^{1 / 2} \frac{P}{c^{3 / 2}}
$$

where, $\delta$ is a geometric parameter, which is related with the shape of the indenter. $E$ and $H$ are the modulus and hardness of the material, respectively. $P$ is the indentation load. $c$ is the average length of the cracks induced by indentation.

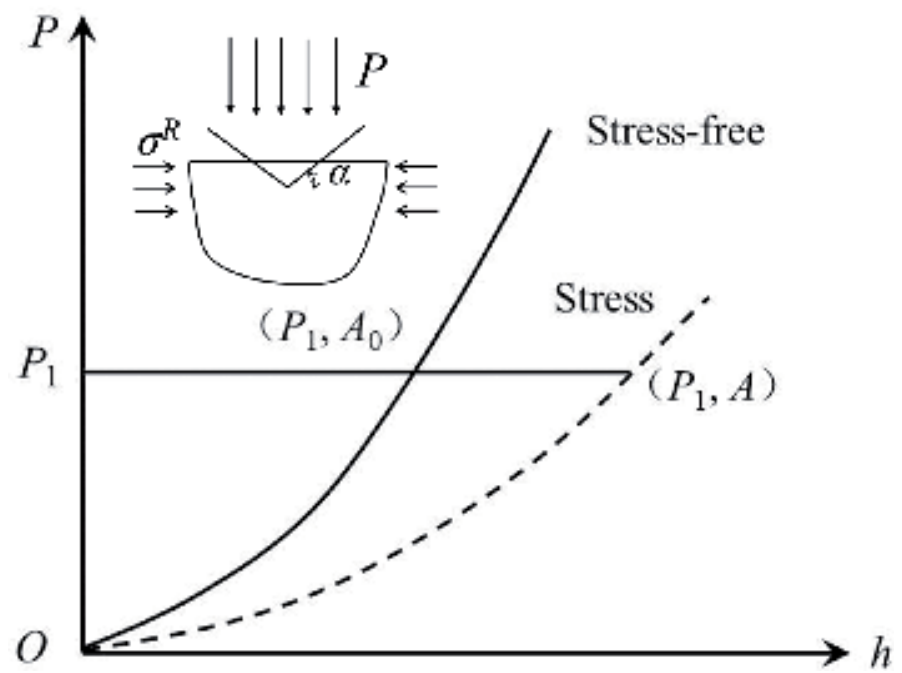

Figure 8.

The schematic diagram for measuring stress by nanoindentation method. 

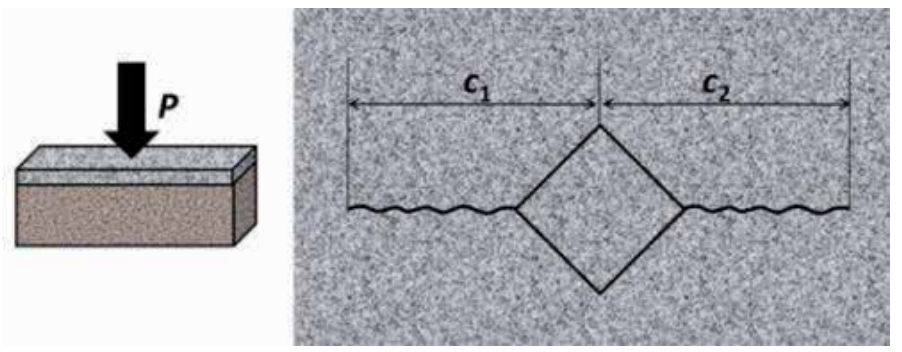

Figure 9.

The schematic of indentation fracture.

The stress in the material may influence the critical load corresponding to the occurrence of facture. Tensile stress promotes the initiation and propagation of cracks. When the stress in the material is tensile, the critical load decreases. Compressive stress inhibits the initiation and propagation of cracks. When the stress in the material is compressive, the critical load increases. Assuming that the stress $\sigma_{r}$ in the coating is uniform, the contribution of stress to the stress intensity factor $K_{r}$ can be expressed as:

$$
K_{r}=\psi \sigma_{r} \sqrt{t}(2-\sqrt{t / c})
$$

where, $t$ is the thickness of the coating. $\psi=2 / \sqrt{ } \pi$ is crack geometric parameter. Based on the superposition principle, combing Eq. (8) and (9), the total stress intensity factor $K$ can be expressed as:

$$
K=\delta\left(\frac{E}{H}\right)^{1 / 2} \frac{P}{c^{3 / 2}}+2 \psi \sigma_{r} t^{1 / 2}-\psi \sigma_{r} t / c^{1 / 2}
$$

When the stress intensity factor is larger than the fracture toughness $K_{I C}$ of the material, the fracture will occur. According to the critical conditions, Eq. (10) can be rewritten as:

$$
\frac{P}{c^{3 / 2}}=\frac{K_{I C}-2 \psi \sigma_{r} t^{1 / 2}}{\chi}+\left(\psi \sigma_{\mathrm{r}} \mathrm{t}\right) c^{-1 / 2}
$$

where $\chi=\delta(\mathrm{E} / \mathrm{H})^{1 / 2}$.

According to Eq. (11), there is linear relationship between $P / c^{3 / 2}$ and $c^{-1 / 2} \cdot \psi \sigma \sigma_{r} t$ and $K_{I C}-2 \psi \sigma_{r} t^{1 / 2}$ represent the slope and intercept, respectively. Therefore, the indentation fracture tests under different indentation loads need to be conducted. The crack lengths under different indentation loads are measured. By linear fitting, the slope and intercept values can be obtained. Then the residual stress and fracture toughness of the material can be evaluated [61]. The indentation fracture method has been successfully used to measure and analyze the stress in ceramic top coat and at the interface between the ceramic top and the bond coat. [33, 62]. Besides, the indentation fracture method has also been extended to the high temperature environments. The stress evolution behavior at different service temperatures was studied [63].

As TBCs is a porous non-uniform structure, the process of inducing cracks by indentation is random. The cracks are susceptible to microstructures such as voids, and the data are discrete, which provides difficulties for subsequent data analysis. Generally, a large of experiential results is required. 


\section{Conclusions and future directions}

Up to now, many testing techniques and characterization methods for stress among APS-prepared TBCs have been developed. The stress in the ceramic top coat, TGO and bond coat under various operating conditions were obtained. However, some topics, such as the measurement of the stress deep inside TBCs, the in-situ evaluation of the stress among TBCs applied on the profiled blade, and the real-time monitoring of the stress among TBCs under the complicated service environments have yet to be further studied. Thus, for the testing of stress among APS-prepared TBCs, the following aspects should be considered in the future:

1. The APS-prepared TBCs has complicated microstructure, and internal stress distribution is non-uniform. Existing laboratory testing techniques only non-destructively measure the stress state of the near surface zone. In order to non-destructively measure the stress deep inside the coating, large scientific equipment is required, which has a lot of limitations. It is necessary to further develop the non-destructive testing technology and characterization method of the stress deep inside the TBCs to realize the analysis of the stress in all zones.

2. The existing testing specimens for the measurement of stress among TBCs are mostly custom-made regular shape specimens and generally cut from the actual profiled blade. The cutting process may affect the stress inside the coating. Besides, the change in the shape of the substrate may also affect the stress in the coating, resulting in the measured stress deviating from the actual stress. Thus, it is necessary to develop testing techniques for the stress among the TBCs coated on profiled substrate. Special attention should be given to a portable testing instrument for in situ non-destructive stress measurement.

3. The existing testings on stress among the TBCs are mostly conducted at room temperature. The residual stress states in the TBCs were obtained. However, TBCs usually operates under high temperature oxidation environments, and the stress state is different from that at room temperature. The testing and characterization of stress under high temperature oxidation environment are also of great significance for the failure mechanism analysis of TBCs. It is necessary to develop testing techniques and characterization methods for the stress among TBCs under high temperature oxidation environments. The study on real-time monitoring of stress among TBCs during service should be conducted.

\section{Acknowledgements}

This work was supported by the Program for Postdoctoral Innovative Talents (No. BX201700031), the National Natural Science Foundation of China (No. 11802021), the China Postdoctoral Science Foundation (No. 2018 M630078), and the Beijing Natural Science Foundation (No. 1194026).

\section{Conflict of interest}

The authors declared that they have no conflicts of interest to this work. 


\section{Author details}

Zhaoliang Qu*, Rujie He and Daining Fang

Beijing Institute of Technology, Beijing, China

*Address all correspondence to: quzl@bit.edu.cn

\section{IntechOpen}

(C) 2019 The Author(s). Licensee IntechOpen. This chapter is distributed under the terms of the Creative Commons Attribution License (http://creativecommons.org/licenses/ by/3.0), which permits unrestricted use, distribution, and reproduction in any medium, provided the original work is properly cited. (cc) BY 


\section{References}

[1] Padture N, Gell M, Jordan E. Thermal barrier coatings for gasturbine engine applications. Science. 2002;296(5566):280-284. DOI: 10.1126/ science.1068609

[2] Darolia R. Thermal barrier coatings technology: Critical review, progress update, remaining challenges and prospects. International Materials Reviews. 2013;58(6):315-348. DOI: 10.1179/1743280413Y.0000000019

[3] Levi C. Emerging materials and processes for thermal barrier systems. Current Opinion in Solid State and Materials Science. 2004;8(1):77-91. DOI: 10.1016/j.cossms.2004.03.009

[4] Evans A, He M, Hutchinson J. Mechanics-based scaling laws for the durability of thermal barrier coatings. Progress in Materials Science. 2001;46(3-4):249-271. DOI: $10.1016 /$ S0079-6425(00)00007-4

[5] Vaßen R, Jarligo M, Steinke T, Mack D, Stöver D. Overview on advanced thermal barrier coatings. Surface and Coatings Technology. 2010;205(4):938-942. DOI: 10.1016/j.surfcoat.2010.08.151

[6] Kumar V, Kandasubramanian B. Processing and design methodologies for advanced and novel thermal barrier coatings for engineering applications. Particuology. 2016;27:1-28. DOI: 10.1016/j.partic.2016.01.007

[7] Hardwicke C, Lau Y. Advances in thermal spray coatings for gas turbines and energy generation: A review. Journal of Thermal Spray Technology. 2013;22(5):564-576. DOI: 10.1007/ s11666-013-9904-0

[8] Kumar V, Balasubramanian K. Progress update on failure mechanisms of advanced thermal barrier coatings: A review. Progress in Organic Coatings. 2016;90:54-82. DOI: 10.1016/j. porgcoat.2015.09.019
[9] Zhu J, Xie H, Hu Z, Chen P, Zhang Q. Cross-sectional residual stresses in thermal spray coatings measured by moiré interferometry and nanoindentation technique. Journal of Thermal Spray Technology. 2012;21(5):810-817. DOI: 10.1007/ s11666-012-9732-7

[10] He M, Hutchinson J, Evans A. Simulation of stresses and delamination in a plasma-sprayed thermal barrier system upon thermal cycling. Materials Science and Engineering A. 2003;345(1-2):172-178. DOI: $10.1016 /$ S0921-5093(02)00458-6

[11] Qu Z, Cheng X, Wu J, He R, Pei Y, Fang D. An investigation on erosion behavior of nanostructured 7YSZ coatings at elevated temperature. Surface and Coatings Technology. 2016;299:129-134. DOI: 10.1016/j. surfcoat.2016.05.003

[12] Golosnoy I, Cipitria A, Clyne T. Heat transfer through plasma-sprayed thermal barrier coatings in gas turbines: A review of recent work. Journal of Thermal Spray Technology. 2009;18(5-6):809-821. DOI: $10.1007 /$ s11666-009-9337-y

[13] Clyne T, Gill S. Residual stresses in thermal spray coatings and their effect on interfacial adhesion: A review of recent work. Journal of Thermal Spray Technology. 1996;5(4):401

[14] Tsui Y, Clyne T. An analytical model for predicting residual stresses in progressively deposited coatings. Part 1: Planar geometry. Thin Solid Films. 1997;306(1):23-33. DOI: 10.1016/ S0040-6090(97) 00199-5

[15] Valente T, Bartuli C, Sebastiani M, Loreto A. Implementation and development of the incremental hole drilling method for the measurement of residual stress in thermal spray 
coatings. Journal of Thermal Spray

Technology. 2005;14(4):462-470. DOI: $10.1361 / 105996305 \times 76432$

[16] McPherson R. The relationship between the mechanism of formation, microstructure and properties of plasma-sprayed coatings. Thin Solid Films. 1981;83(3):297-310. DOI: 10.1016/0040-6090(81)90633-7

[17] Kuroda S, Fukushima T, Kitahara S. Significance of quenching stress in the cohesion and adhesion of thermally sprayed coatings. Journal of Thermal Spray Technology. 1992;1(4):325-332

[18] Matejicek J, Sampath S, Dubsky J. $\mathrm{X}$-ray residual stress measurement in metallic and ceramic plasma sprayed coatings. Journal of Thermal Spray Technology. 1998;7(4):489-496

[19] Ang A, Berndt C. A review of testing methods for thermal spray coatings. International Materials Reviews. 2014;59(4):179-223. DOI: 10.1179/1743280414Y.0000000029

[20] Matejicek J, Sampath S. In situ measurement of residual stresses and elastic moduli in thermal sprayed coatings. Part 1: Apparatus and analysis. Acta Materialia. 2003;51(3):863-872. DOI: 10.1016/S1359-6454(02)00478-0

[21] Matejicek J, Sampath S. Intrinsic residual stresses in single splats produced by thermal spray processes. Acta Materialia. 2001;49(11):1993-1999. DOI: 10.1016/S1359-6454(01)00099-4

[22] Chen X, He M, Spitsberg I, Fleck N, Hutchinson J, Evans A. Mechanisms governing the high temperature erosion of thermal barrier coatings. Wear. 2004;256(7-8):735-746. DOI: $10.1016 /$ S0043-1648(03)00446-0

[23] Rabiei A, Evans A. Failure mechanisms associated with the thermally grown oxide in plasmasprayed thermal barrier coatings. Acta
Materialia. 2000;48(15):3963-3976.

DOI: 10.1016/S1359-6454(00)00171-3

[24] Lipkin D, Clarke D. Measurement of the stress in oxide scales formed by oxidation of alumina-forming alloys. Oxidation of Metals. 1996;45(3-4): 267-280. DOI: 10.1007/BF01046985

[25] Hutchinson J, He M, Evans A. The influence of imperfections on the nucleation and propagation of buckling driven delaminations. Journal of the Mechanics and Physics of Solids. 2000;48(4):709-734. DOI: $10.1016 /$ S0022-5096(99)00050-2

[26] Cheruvu N, Chan K, Viswanathan R. Evaluation, degradation and life assessment of coatings for land based combustion turbines. Energy Materials. 2006;1(1):33-47. DOI: 10.1179/174892306X99705

[27] Cipitria A, Golosnoy I, Clyne T. A sintering model for plasma-sprayed zirconia thermal barrier coatings. Part II: Coatings bonded to a rigid substrate. Acta Materialia. 2009;57(4):993-1003. DOI: $10.1016 /$ j.actamat.2008.10.058

[28] Krämer S, Faulhaber S, Chambers M, Clarke D, Levi C, Hutchinson J, et al. Mechanisms of cracking and delamination within thick thermal barrier systems in aero-engines subject to calcium-magnesium-alumino-silicate (CMAS) penetration. Materials Science and Engineering A. 2008;490(1-2): 26-35. DOI: 10.1016/j.msea.2008.01.006

[29] Krause A, Garces H, Dwivedi G, Ortiz A, Sampath S, Padture N. Calciamagnesia-alumino-silicate (CMAS)induced degradation and failure of air plasma sprayed yttria-stabilized zirconia thermal barrier coatings. Acta Materialia. 2016;105:355-366. DOI: 10.1016/j.actamat.2015.12.044

[30] Janos B, Lugscheider E, Remer P. Effect of thermal aging on the erosion resistance of air plasma sprayed 
zirconia thermal barrier coating. Surface and Coatings Technology. 1999;113(3):278-285. DOI: 10.1016/ S0257-8972(99)00002-X

[31] Ramachandran C, Balasubramanian V, Ananthapadmanabhan P. Erosion of atmospheric plasma sprayed rare earth oxide coatings under air suspended corundum particles. Ceramics International. 2013;39(1):649-672. DOI: 10.1016/j.ceramint.2012.06.077

[32] Noyan I, Huang T, York B. Residual stress/strain analysis in thin films by X-ray diffraction. Critical Reviews in Solid State and Materials Sciences. 1995;20(2):125-177. DOI: 10.1080/10408439508243733

[33] Chen Q, Mao W, Zhou Y, Lu C. Effect of Young's modulus evolution on residual stress measurement of thermal barrier coatings by X-ray diffraction. Applied Surface Science. 2010;256(23):7311-7315. DOI: 10.1016/j. apsusc.2010.05.071

\section{[34] Chen Y, Zhao X, Dang Y, Xiao P,} Curry N, Markocsan N, et al. Characterization and understanding of residual stresses in a NiCoCrAlY bond coat for thermal barrier coating application. Acta Materialia. 2015;94: 1-14. DOI: 10.1016/j.actamat.2015.04.053

[35] Yang L, Zou Z, Kou Z, Chen Y, Zhao G, Zhao X, et al. High temperature stress and its influence on surface rumpling in NiCoCrAlY bond coat. Acta Materialia. 2017;139:122-137. DOI: 10.1016/j.actamat.2017.08.001

[36] Weyant C, Almer J, Faber K. Through-thickness determination of phase composition and residual stresses in thermal barrier coatings using high-energy X-rays. Acta Materialia. 2010;58(3):943-951. DOI: 10.1016/j. actamat.2009.10.010

[37] Scardi P, Leoni M, Bertini L, Bertamini L, Cernuschid F. Strain gradients in plasma-sprayed zirconia thermal barrier coatings. Surface and Coating Technology. 1998;108:93-98. DOI: 10.1016/S0257-8972(98)00616-1

[38] Ahmed R, Yu H, Stoica V, Edwards L, Santisteban J. Neutron diffraction residual strain measurements in posttreated thermal spray cermet coatings. Materials Science and Engineering A. 2008;498(1-2):191-202. DOI: 10.1016/j. msea.2008.08.023

[39] Yang L, Yang F, Long Y, Zhao Y, Xiong X, Zhao X, et al. Evolution of residual stress in air plasma sprayed yttria stabilised zirconia thermal barrier coatings after isothermal treatment. Surface and Coatings Technology. 2014;251:98-105. DOI: 10.1016/j. surfcoat.2014.04.009

[40] Tanaka M, Hasegawa M, Dericioglu A, Kagawa Y. Measurement of residual stress in air plasma-sprayed $\mathrm{Y}_{2} \mathrm{O}_{3}-$ $\mathrm{ZrO}_{2}$ thermal barrier coating system using micro-Raman spectroscopy. Materials Science and Engineering A. 2006;419(1-2):262-268. DOI: 10.1016/j. msea.2005.12.034

[41] Schlichting K, Vaidyanathan K, Sohn Y, Jordan E, Gell M, Padture N. Application of $\mathrm{Cr}^{3+}$ photoluminescence piezospectroscopy to plasma-sprayed thermal barrier coatings for residual stress measurement. Materials Science and Engineering A. 2000;291(1-2):68-77. DOI: $10.1016 /$ S0921-5093(00)00973-4

[42] Majewski M, Kelley C, Lake J, Renfro M, Hassan W, Brindley W, et al. Stress measurements via photoluminescence piezospectroscopy on engine run thermal barrier coatings. Surface and Coatings Technology. 2012;206(11-12):2751-2758. DOI: 10.1016/j.surfcoat.2011.11.026

[43] Stoney G. The tension of metallic films deposited by electrolysis. 
Proceedings of the Royal Society A. 1909;82(553):172-175

[44] Kuroda S, Fukushima T, Kitahara S. Generation mechanisms of residual stresses in plasma-sprayed coatings. Vacuum. 1990;41(4-6):1297-1299. DOI: 10.1016/0042-207X(90)93938-F

[45] Gill S, Clyne T. Investigation of residual stress generation during thermal spraying by continuous curvature measurement. Thin Solid Films. 1994;250(1-2):172-180. DOI: 10.1016/0040-6090(94)90182-1

[46] Zhang X, Watanabe M, Kuroda S. Effects of residual stress on the mechanical properties of plasmasprayed thermal barrier coatings. Engineering Fracture Mechanics. 2013;110:314-327. DOI: 10.1016/j. engfracmech.2013.08.016

[47] Dwivedi G, Nakamura T, Sampath S. Determination of thermal spray coating property with curvature measurements. Journal of Thermal Spray Technology. 2013;22(8):1337-1347. DOI: 10.1007/ s11666-013-9981-0

[48] Teixeira V, Andritschky M, Fischer W, Buchkremer P, Stöver D. Analysis of residual stresses in thermal barrier coatings. Journal of Materials Processing Technology. 1999;92:209-216. DOI: 10.1016/S0924-0136(99)00157-0

[49] Zhu J, Xie H, Hu Z, Chen P, Zhang Q. Residual stress in thermal spray coatings measured by curvature based on 3D digital image correlation technique. Surface and Coatings Technology. 2011;206(6):1396-1402. DOI: 10.1016/j.surfcoat.2011.08.062

[50] Schajer G, Yang L. Residualstress measurement in orthotropic materials using the hole-drilling method. Experimental Mechanics. 1994;34(4):324-333

[51] Wu L, Zhu J, Xie H. Numerical and experimental investigation of residual stress in thermal barrier coatings during APS process. Journal of Thermal Spray Technology. 2014;23(4):653-665. DOI: 10.1007/s11666-014-0063-8

[52] Santana Y, La Barbera-Sosa J, Staia M, Lesage J, Puchi-Cabrera E, Chicot D, et al. Measurement of residual stress in thermal spray coatings by the incremental hole drilling method. Surface and Coatings Technology. 2006;201(5):2092-2098. DOI: 10.1016/j. surfcoat.2006.04.056

[53] Schajer G. Measurement of nonuniform residual stresses using the hole-drilling method. Part I-Stress calculation procedures. Journal of Engineering Materials and Technology. 1988;110(4):338-343

[54] Huang X, Liu Z, Xie H. Recent progress in residual stress measurement techniques. Acta Mechanica Solida Sinica. 2013;26(6):570-583. DOI: 10.1016/S0894-9166(14)60002-1

[55] Schajer G. Application of finite element calculations to residual stress measurements. Journal of Engineering Materials and Technology. 1981;103(2):157-163

[56] Greving D, Rybicki E, Shadley J. Through-thickness residual stress evaluations for several industrial thermal spray coatings using a modified layer-removal method. Journal of Thermal Spray Technology. 1994;3(4):379

[57] Lima C, Nin J, Guilemany J. Evaluation of residual stresses of thermal barrier coatings with HVOF thermally sprayed bond coats using the modified layer removal method (MLRM). Surface and Coatings Technology. 2006;200 (20-21):5963-5972. DOI: $10.1016 / \mathrm{j}$. surfcoat.2005.09.016

[58] Suresh S, Giannakopoulos A. A new method for estimating residual stresses 
by instrumented sharp indentation.

Acta Materialia. 1998;46(16):5755-5767.

DOI: 10.1016/S1359-6454(98)00226-2

[59] Xiao L, Ye D, Chen C. A further study on representative models for calculating the residual stress based on the instrumented indentation technique. Computational Materials Science. 2014;82:476-482. DOI: 10.1016/j.commatsci.2013.10.014

[60] Atar E, Sarioglu C, Demirler U, Kayali E, Cimenoglu H. Residual stress estimation of ceramic thin films by $\mathrm{X}$-ray diffraction and indentation techniques. Scripta Materialia. 2003;48(9):1331-1336. DOI: $10.1016 /$ S1359-6462(03)00019-8

[61] Lawn B, Fuller E. Measurement of thin-layer surface stresses by indentation fracture. Journal of Materials Science. 1984;19(12):4061-4067

[62] Mao W, Wan J, Dai C, Ding J, Zhang Y, Zhou Y, et al. Evaluation of microhardness, fracture toughness and residual stress in a thermal barrier coating system: A modified Vickers indentation technique. Surface and Coatings Technology. 2012;206(21):4455-4461. DOI: 10.1016/j.surfcoat.2012.02.060

[63] Qu Z, Wei K, He Q, He R, Pei Y, Wang $S$, et al. High temperature fracture toughness and residual stress in thermal barrier coatings evaluated by an in-situ indentation method. Ceramics International. 2018;44(7):7926-7929. DOI: $10.1016 /$ j.ceramint.2018.01.230 


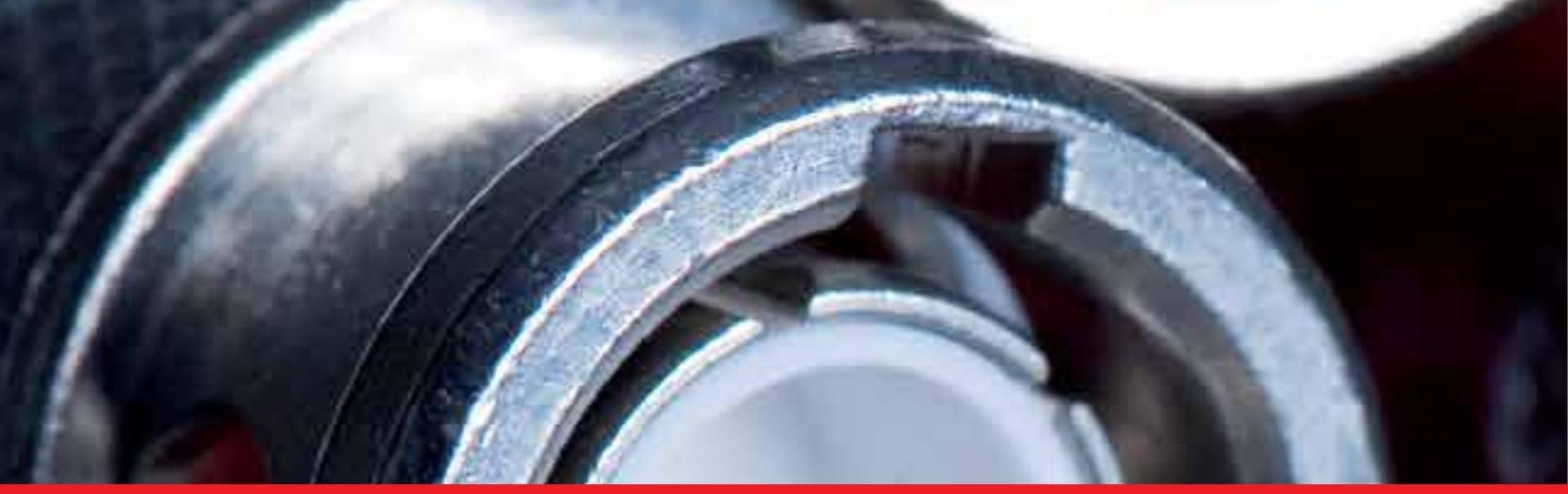

\section{Edited by László Nánai, Aneeya Samantara, László Fábián and Satyajit Ratha}

In recent years, thin layer technologies, including fabrication of different micro- and nano-structures, have undergone tremendous progress. Such layers are made for a variety of industrial and scientific applications. Due to the extreme physico-chemical properties of the available structures, there are many promising applications (eg, due to biocompatibility, biological and medical applications between living tissues and materials). Pre-tailored special surface layers/structures could be realized for implants in dental, neurological and orthopedic applications.

There are also different methods that have been applied to produce special mono and multilayers with extreme electrical end magnetic properties. Also some methods have been developed to produce surface structure applications eg, for environmental applications with necessary resistivity and anti-corrosion properties.Some theoretical/ mathematical simulation methods have also been developed for better compatibility of theory with experiments.This book consists of 10 chapters describing the physicochemical base of deposition and coating microfabrication, thus providing some overview on how to measure the physical and chemical parameters of fabricated structures and how to solve compatibility and fitting problems, etc.

\section{IntechOpen}
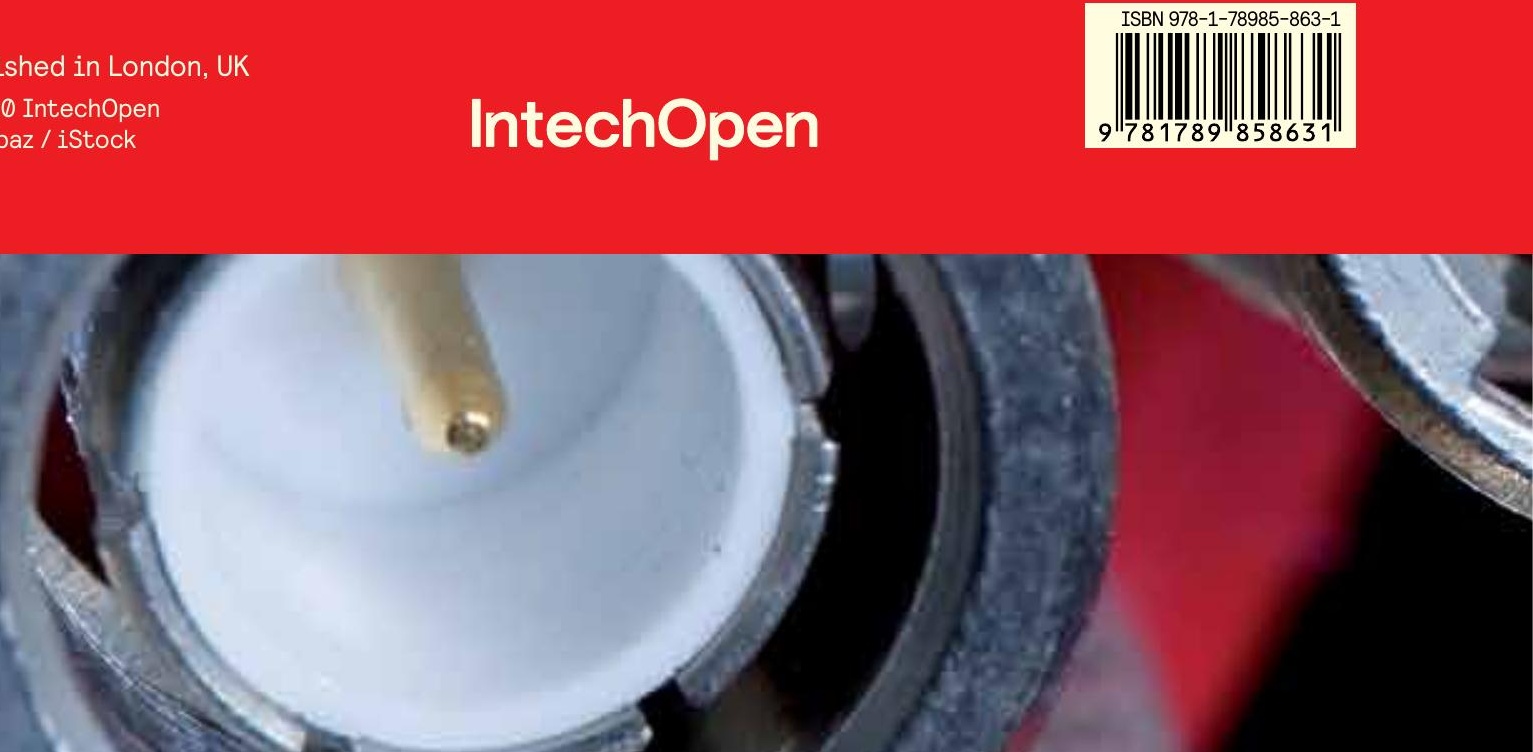